\title{
GCU
}

Glasgow Caledonian

University

University for the Common Good

\section{Interventions for improving oral health in people after stroke}

Campbell, Pauline; Bain, Brenda; Furlanetto, Denise L.C.; Brady, Marian C.

\section{Published in:}

Cochrane Database of Systematic Reviews

DOI:

10.1002/14651858.CD003864.pub3

Publication date:

2020

Document Version

Publisher's PDF, also known as Version of record

Link to publication in ResearchOnline

Citation for published version (Harvard):

Campbell, P, Bain, B, Furlanetto, DLC \& Brady, MC 2020, 'Interventions for improving oral health in people after stroke', Cochrane Database of Systematic Reviews, vol. 2020, no. 12, CD003864.

https://doi.org/10.1002/14651858.CD003864.pub3

\section{General rights}

Copyright and moral rights for the publications made accessible in the public portal are retained by the authors and/or other copyright owners and it is a condition of accessing publications that users recognise and abide by the legal requirements associated with these rights.

Take down policy

If you believe that this document breaches copyright please view our takedown policy at https://edshare.gcu.ac.uk/id/eprint/5179 for details of how to contact us. 
Cochrane Database of Systematic Reviews

\section{Interventions for improving oral health in people after stroke} (Review)

Campbell P, Bain B, Furlanetto DLC, Brady MC

Campbell P, Bain B, Furlanetto DLC, Brady MC.

Interventions for improving oral health in people after stroke.

Cochrane Database of Systematic Reviews 2020, Issue 12. Art. No.: CD003864.

DOI: 10.1002/14651858.CD003864.pub3.

www.cochranelibrary.com 
TABLE OF CONTENTS

HEADER

ABSTRACT

PLAIN LANGUAGE SUMMARY

SUMMARY OF FINDINGS

2

BACKGROUND

OBJECTIVES

METHODS

RESULTS

Figure 1.

Figure 2.

Figure 3.

DISCUSSION

AUTHORS' CONCLUSIONS

ACKNOWLEDGEMENTS

REFERENCES

CHARACTERISTICS OF STUDIES

DATA AND ANALYSES

Analysis 1.1. Comparison 1: Oral health care $(\mathrm{OHC})$ interventions versus usual care, Outcome 1: Dental plaque (up to $1 \mathrm{month}$ ) .

Analysis 1.2. Comparison 1: Oral health care $(\mathrm{OHC})$ interventions versus usual care, Outcome 2: Dental plaque (6 months) .....

Analysis 1.3. Comparison 1: Oral health care $(\mathrm{OHC})$ interventions versus usual care, Outcome 3: Denture plaque

Analysis 1.4. Comparison 1: Oral health care $(\mathrm{OHC})$ interventions versus usual care, Outcome 4: Presence of oral disease: gingivitis (up to 1 month)

Analysis 1.5. Comparison 1: Oral health care $(\mathrm{OHC})$ interventions versus usual care, Outcome 5: Presence of oral disease: gingivitis (6 months)

Analysis 1.6. Comparison 1: Oral health care $(\mathrm{OHC})$ interventions versus usual care, Outcome 6: Denture-induced stomatitis ... Analysis 1.7. Comparison 1: Oral health care $(\mathrm{OHC})$ interventions versus usual care, Outcome 7: Pneumonia ........................... Analysis 1.8. Comparison 1: Oral health care $(\mathrm{OHC})$ interventions versus usual care, Outcome 8: OHC knowledge (1 month) .... Analysis 1.9. Comparison 1: Oral health care $(\mathrm{OHC})$ interventions versus usual care, Outcome 9: OHC knowledge (2 months) ... Analysis 1.10. Comparison 1: Oral health care (OHC) interventions versus usual care, Outcome 10: OHC knowledge (6 months) . Analysis 1.11. Comparison 1: Oral health care $(\mathrm{OHC})$ interventions versus usual care, Outcome 11: Attitudes to oral care (1 month)

Analysis 1.12. Comparison 1: Oral health care $(\mathrm{OHC})$ interventions versus usual care, Outcome 12: Attitudes to oral care (2 months)

Analysis 1.13. Comparison 1: Oral health care $(\mathrm{OHC})$ interventions versus usual care, Outcome 13: Attitudes to oral care (6 months)

Analysis 2.1. Comparison 2: Oral health care $(\mathrm{OHC})$ interventions versus placebo, Outcome 1: Presence of oral disease: pneumonia

Analysis 2.2. Comparison 2: Oral health care $(\mathrm{OHC})$ interventions versus placebo, Outcome 2: Presence of oral disease: acquired Aerobic Gram-negative bacilli (AGNB)

Analysis 2.3. Comparison 2: Oral health care $(\mathrm{OHC})$ interventions versus placebo, Outcome 3: Presence of oral disease: carriage of AGNB

Analysis 2.4. Comparison 2: Oral health care $(\mathrm{OHC})$ interventions versus placebo, Outcome 4: Self-reported oral dryness ........ Analysis 3.1. Comparison 3: Oral health care $(\mathrm{OHC})$ interventions versus another $\mathrm{OHC}$ intervention, Outcome 1: Dental plaque (3 months)

Analysis 3.2. Comparison 3: Oral health care $(\mathrm{OHC})$ interventions versus another $\mathrm{OHC}$ intervention, Outcome 2: Dental plaque (6 months)

Analysis 3.3. Comparison 3: Oral health care $(\mathrm{OHC})$ interventions versus another $\mathrm{OHC}$ intervention, Outcome 3: Presence of oral disease: aerobic Gram-negative bacilli (AGNB) (3 months)

Analysis 3.4. Comparison 3: Oral health care $(\mathrm{OHC})$ interventions versus another $\mathrm{OHC}$ intervention, Outcome 4: Presence of oral disease: AGNB (6 months)

Analysis 3.5. Comparison 3: Oral health care $(\mathrm{OHC})$ interventions versus another $\mathrm{OHC}$ intervention, Outcome 5: Candida (3 months) 
Analysis 3.6. Comparison 3: Oral health care $(\mathrm{OHC})$ interventions versus another $\mathrm{OHC}$ intervention, Outcome 6: Candida (6 months)

Analysis 3.7. Comparison 3: Oral health care $(\mathrm{OHC})$ interventions versus another OHC intervention, Outcome 7: Staphylococcus aureus

ADDITIONAL TABLES

APPENDICES

WHAT'S NEW

HISTORY 163

CONTRIBUTIONS OF AUTHORS

164

DECLARATIONS OF INTEREST

164

SOURCES OF SUPPORT 
[Intervention Review]

\section{Interventions for improving oral health in people after stroke}

Pauline Campbell 1 , Brenda Bain 1 , Denise LC Furlanetto 2 , Marian C Brady 1

${ }^{1}$ Nursing, Midwifery and Allied Health Professions Research Unit, Glasgow Caledonian University, Glasgow, UK. ${ }^{2}$ Public Health

Department, Health Sciences Faculty, University of Brasilia, Brasilia, Brazil

Contact address: Marian C Brady, m.brady@gcu.ac.uk.

Editorial group: Cochrane Stroke Group.

Publication status and date: New search for studies and content updated (no change to conclusions), published in Issue 12, 2020.

Citation: Campbell P, Bain B, Furlanetto DLC, Brady MC. Interventions for improving oral health in people after stroke. Cochrane Database of Systematic Reviews 2020, Issue 12. Art. No.: CD003864. DOI: 10.1002/14651858.CD003864.pub3.

Copyright (c) 2020 The Cochrane Collaboration. Published by John Wiley \& Sons, Ltd.

\section{A B S T R A C T}

\section{Background}

For people with physical, sensory and cognitive limitations due to stroke, the routine practice of oral health care (OHC) may become a challenge. Evidence-based supported oral care intervention is essential for this patient group.

\section{Objectives}

To compare the effectiveness of $\mathrm{OHC}$ interventions with usual care or other treatment options for ensuring oral health in people after a stroke.

\section{Search methods}

We searched the Cochrane Stroke Group and Cochrane Oral Health Group trials registers, CENTRAL, MEDLINE, Embase, and six other databases in February 2019. We scanned reference lists from relevant papers and contacted authors and researchers in the field. We handsearched the reference lists of relevant articles and contacted other researchers. There were no language restrictions.

\section{Selection criteria}

We included randomised controlled trials (RCTs) that evaluated one or more interventions designed to improve the cleanliness and health of the mouth, tongue and teeth in people with a stroke who received assisted OHC led by healthcare staff. We included trials with a mixed population provided we could extract the stroke-specific data. The primary outcomes were dental plaque or denture plaque. Secondary outcomes included presence of oral disease, presence of related infection and oral opportunistic pathogens related to $\mathrm{OHC}$ and pneumonia, stroke survivor and providers' knowledge and attitudes to $\mathrm{OHC}$, and patient satisfaction and quality of life.

\section{Data collection and analysis}

Two review authors independently screened abstracts and full-text articles according to prespecified selection criteria, extracted data and assessed the methodological quality using the Cochrane 'Risk of bias' tool. We sought clarification from investigators when required. Where suitable statistical data were available, we combined the selected outcome data in pooled meta-analyses. We used GRADE to assess the quality of evidence for each outcome.

\section{Main results}

Fifteen RCTs (22 randomised comparisons) involving 3631 participants with data for 1546 people with stroke met the selection criteria.

\section{OHC interventions compared with usual care}

Seven trials (2865 participants, with data for 903 participants with stroke, 1028 healthcare providers, 94 informal carers) investigated OHC interventions compared with usual care. 
Multi-component $\mathrm{OHC}$ interventions showed no evidence of a difference in the mean score (DMS) of dental plaque one month after the intervention was delivered (DMS $-0.66,95 \% \mathrm{Cl}-1.40$ to $0.09 ; 2$ trials, 83 participants; $\mathrm{I}^{2}=83 \% ; \mathrm{P}=0.08$; very low-quality evidence).

Stroke survivors had less plaque on their dentures when staff had access to the multi-component OHC intervention (DMS -1.31, 95\% $\mathrm{Cl}-$ 1.96 to $-0.66 ; 1$ trial, 38 participants; $P<0.0001$; low-quality evidence).

There was no evidence of a difference in gingivitis (DMS $-0.60,95 \% \mathrm{Cl}-1.66$ to $0.45 ; 2$ trials, 83 participants; $\mathrm{I}^{2}=93 \% ; \mathrm{P}=0.26$ : very lowquality evidence) or denture-induced stomatitis (DMS $-0.33,95 \% \mathrm{Cl}-0.92$ to $0.26 ; 1$ trial, 38 participants; $\mathrm{P}=0.69$; low-quality evidence) among participants receiving the multi-component $\mathrm{OHC}$ protocol compared with usual care one month after the intervention. There was no difference in the incidence of pneumonia in participants receiving a multi-component OHC intervention (99 participants; 5 incidents of pneumonia) compared with those receiving usual care (105 participants; 1 incident of pneumonia) (OR 4.17, Cl 95\% 0.82 to 21.11; 1 trial, 204 participants; $\mathrm{P}=0.08$; low-quality evidence).

$\mathrm{OHC}$ training for stroke survivors and healthcare providers significantly improved their OHC knowledge at one month after training (SMD $0.70,95 \% \mathrm{Cl} 0.06$ to $1.35 ; 3$ trials, 728 participants; $1^{2}=94 \% ; \mathrm{P}=0.03$; very low-quality evidence). Pooled data one month after training also showed evidence of a difference between stroke survivor and providers' oral health attitudes (SMD $0.28,95 \% \mathrm{Cl} 0.01$ to $0.54 ; 3$ trials, 728 participants; $\left.\right|^{2}=65 \% ; P=0.06$; very low-quality evidence).

\section{OHC interventions compared with placebo}

Three trials (394 participants, with data for 271 participants with stroke) compared an OHC intervention with placebo. There were no data for primary outcomes. There was no evidence of a difference in the incidence of pneumonia in participants receiving an $\mathrm{OHC}$ intervention compared with placebo (OR 0.39, CI 95\% 0.14 to $1.09 ; 2$ trials, 242 participants; $1^{2}=42 \%$; $\mathrm{P}=0.07$; low-quality evidence). However, decontamination gel reduced the incidence of pneumonia among the intervention group compared with placebo gel group (OR $0.20,95 \%$ $\mathrm{Cl} 0.05$ to $0.84 ; 1$ trial, 203 participants; $\mathrm{P}=0.028$ ). There was no difference in the incidence of pneumonia in participants treated with povidone-iodine compared with a placebo (OR $0.81,95 \% \mathrm{Cl} 0.18$ to $3.51 ; 1$ trial, 39 participants; $\mathrm{P}=0.77$ ).

\section{One OHC intervention compared with another OHC intervention}

Twelve trials (372 participants with stroke) compared one OHC intervention with another OHC intervention. There was no difference in dental plaque scores between those participants that received an enhanced multi-component OHC intervention compared with conventional $\mathrm{OHC}$ interventions at three months (MD $-0.04,95 \% \mathrm{Cl}-0.33$ to $0.25 ; 1$ trial, 61 participants; $\mathrm{P}=0.78$; low-quality evidence). There were no data for denture plaque.

\section{Authors' conclusions}

We found low- to very low-quality evidence suggesting that $\mathrm{OHC}$ interventions can improve the cleanliness of patient's dentures and stroke survivor and providers' knowledge and attitudes. There is limited low-quality evidence that selective decontamination gel may be more beneficial than placebo at reducing the incidence of pneumonia. Improvements in the cleanliness of a patient's own teeth was limited. We judged the quality of the evidence included within meta-analyses to be low or very low quality, and this limits our confidence in the results. We still lack high-quality evidence of the optimal approach to providing $\mathrm{OHC}$ to people after stroke.

\section{PLAIN LANGUAGE SUMMARY}

\section{Interventions for improving oral health in people after stroke}

\section{Review question}

We wanted to know whether oral healthcare $(\mathrm{OHC})$ interventions improve the oral health of people who have had a stroke, and if any one $\mathrm{OHC}$ intervention provided more benefit than another approach.

\section{Background}

Three quarters of people who have had a stroke experience physical problems, and the weakness, lack of co-ordination and cognitive (attention, memory, language and orientation) problems that may accompany a stroke can make it difficult for a person to maintain the health and cleanliness of their mouth, tongue and teeth on their own. A clean mouth feels good and the practice of OHC (removing dental plaque (a soft, sticky film that builds up on your teeth) and traces of food) is a crucial factor in maintaining the health of the mouth, teeth and gums. A clean and healthy mouth also prevents pain or discomfort and allows people to eat a range of nutritious foods. Maintaining good oral care may be difficult after a stroke and healthcare staff may have to assist in providing such care.

We wanted to see whether $\mathrm{OHC}$ interventions could improve the cleanliness of stroke survivors' teeth by reducing dental plaque or denture plaque (our primary outcomes). We were also interested in whether OHC interventions would improve other (secondary) outcomes including patient satisfaction and quality of life, presence of oral disease, presence of related infection, and stroke survivor and providers' knowledge and attitudes to $\mathrm{OHC}$. 


\section{Search date}

The evidence is current to February 2019.

\section{Study characteristics}

We included 15 studies (22 comparisons) involving 1546 people with stroke, 1028 staff and 94 carers in this updated review. Seven trials compared $\mathrm{OHC}$ with usual care; three trials compared $\mathrm{OHC}$ with placebo (pretend treatment or usual care), and 12 trials compared two different types of $\mathrm{OHC}$.

\section{Key results}

We found little evidence to inform how $\mathrm{OHC}$ is best delivered. There was low-quality evidence from trials that compared $\mathrm{OHC}$ with standard care showing that $\mathrm{OHC}$ reduced denture plaque. There was no difference for studies that measured dental plaque. We found very lowquality evidence to show that training nursing staff and family carers improved their knowledge and attitudes to OHC. There was lowquality evidence that demonstrated the beneficial impact of a decontamination gel (to reduce the number of bacteria in the mouth) on the incidence of pneumonia compared with placebo gel among patients in a stroke ward. However, there was no other information on how best to provide $\mathrm{OHC}$ and more studies are urgently needed.

\section{Quality of the evidence}

Despite the inclusion of several new trials of $\mathrm{OHC}$ for people after stroke since our last review update there remains a lack of high-quality evidence to inform $\mathrm{OHC}$ in stroke care settings.

\section{Conclusion}

We judged the quality of the current evidence in this review to be low to very low. We lack high-quality evidence of the optimal approach to providing $\mathrm{OHC}$ to people after stroke. Additional well-conducted clinical trials are needed. 


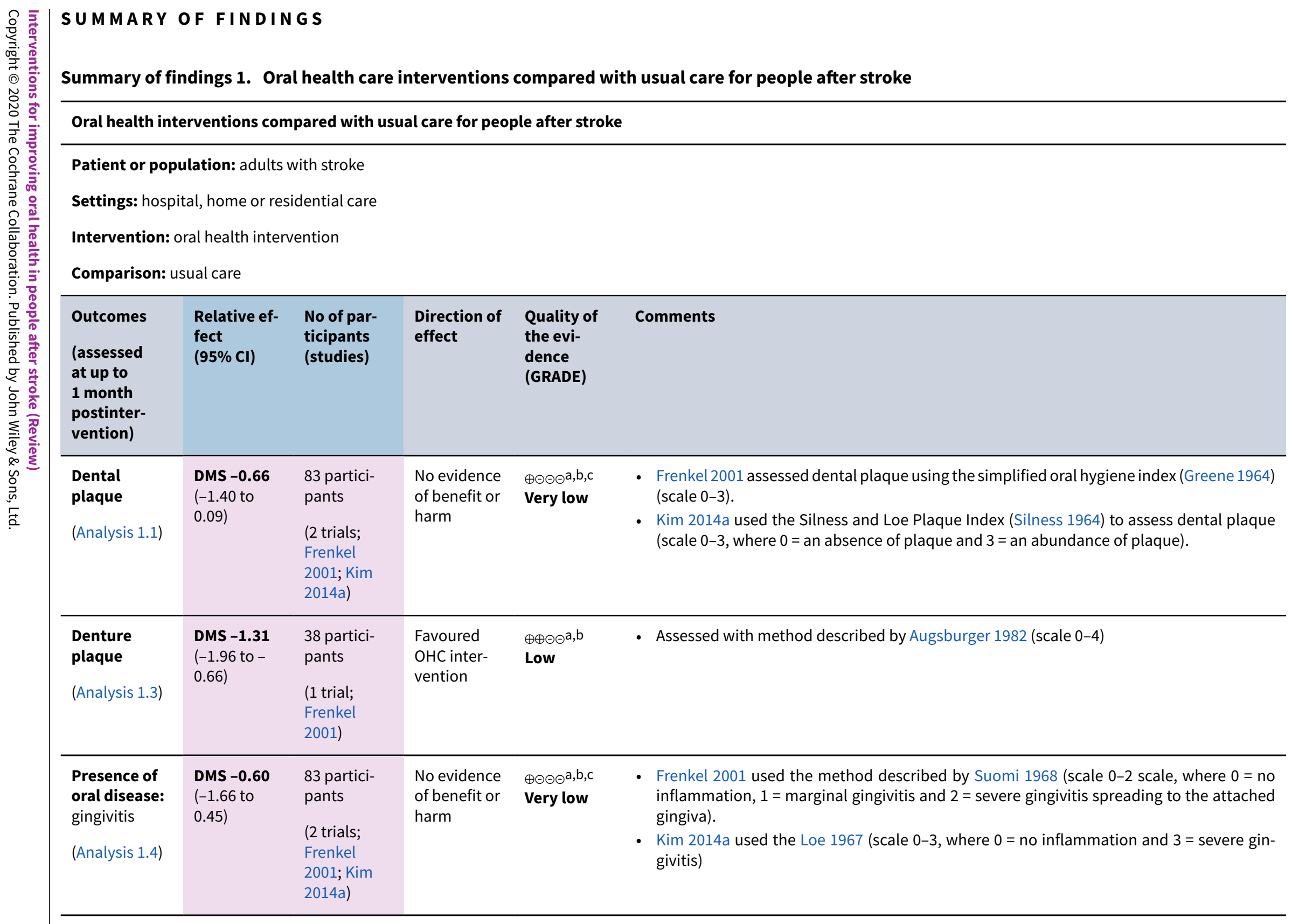




\begin{tabular}{|c|c|c|c|c|c|c|c|}
\hline 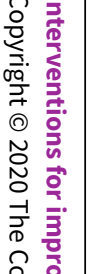 & $\begin{array}{l}\text { Presence of } \\
\text { oral disease: } \\
\text { denture-in- } \\
\text { duced stom- } \\
\text { atitis } \\
\text { (Analysis 1.6) }\end{array}$ & $\begin{array}{l}\text { DMS }-0.33 \\
(-0.92 \text { to } \\
0.26)\end{array}$ & $\begin{array}{l}38 \text { partici- } \\
\text { pants } \\
(1 \text { trial; } \\
\text { Frenkel } \\
\text { 2001) }\end{array}$ & $\begin{array}{l}\text { No evidence } \\
\text { of benefit or } \\
\text { harm }\end{array}$ & $\begin{array}{l}\oplus \oplus \Theta \Theta^{a, b} \\
\text { Low }\end{array}$ & - Assessed according to Budtz-Jorgensen 1978 classification (scale 0-3) & 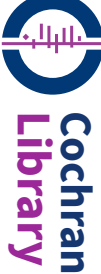 \\
\hline 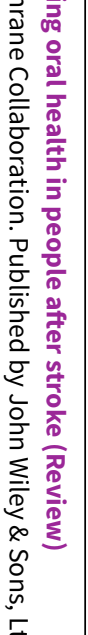 & $\begin{array}{l}\text { Presence of } \\
\text { related infec- } \\
\text { tion: pneu- } \\
\text { monia } \\
\text { (Analysis 1.7) }\end{array}$ & $\begin{array}{l}\text { OR 4.17 } \\
\text { (0.82 to } \\
21.11) \\
\text { (interven- } \\
\text { tion group: } \\
5 \text { incidents } \\
\text { of pneumo- } \\
\text { nia (99 par- } \\
\text { ticipants); } \\
\text { usual care } \\
\text { group: } 1 \text { in- } \\
\text { cident of } \\
\text { pneumonia } \\
\text { (105 partici- } \\
\text { pants) }\end{array}$ & $\begin{array}{l}204 \text { partici- } \\
\text { pants } \\
\text { (1 trial; SO- } \\
\text { CLE II) }\end{array}$ & $\begin{array}{l}\text { No evidence } \\
\text { of benefit or } \\
\text { harm }\end{array}$ & $\begin{array}{l}\oplus \oplus \Theta \Theta^{a, b} \\
\text { Low }\end{array}$ & - Assessed using Mann criteria (Mann 1999) & 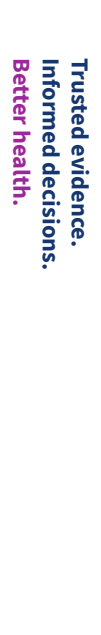 \\
\hline & $\begin{array}{l}\text { Stroke sur- } \\
\text { vivor and } \\
\text { providers' } \\
\text { knowledge to } \\
\text { OHC: knowl- } \\
\text { edge } \\
\text { (Analysis 1.8) }\end{array}$ & $\begin{array}{l}\text { SMD } \mathbf{0 . 7 0} \\
(0.06 \text { to } \\
1.35)\end{array}$ & $\begin{array}{l}728 \text { partici- } \\
\text { pants } \\
\text { (3 trials; Ab } \\
\text { Malik 2017; } \\
\text { Frenkel } \\
\text { 2001; Kuo } \\
\text { 2016) }\end{array}$ & $\begin{array}{l}\text { Favours } \\
\text { OHC inter- } \\
\text { vention }\end{array}$ & $\begin{array}{l}\oplus \ominus \ominus \ominus^{a, b}, \mathrm{c}, \mathrm{d} \\
\text { Very low }\end{array}$ & $\begin{array}{l}\text { Knowledge assessed with non-validated self-administered questionnaires. } \\
\text { - Ab Malik } 2017 \text { assessed knowledge of OHC using } 5 \text { items (dental plaque, gum bleeding, } \\
\text { consequences of dental plaque, how to prevent gingivitis and how oral health affects gen- } \\
\text { eral health) based on a questionnaire from Al-Omiri 2006. Scores were 0-5, with higher } \\
\text { scores indicating greater OHC knowledge. } \\
\text { - Frenkel } 2001 \text { measured knowledge using a true/false response to } 26 \text { statements, with each } \\
\text { correct answer scoring one. The outcome was presented as a composite outcome score. } \\
\text { - Kuo } 2016 \text { developed and measured OHC knowledge using a } 44 \text {-item Knowledge of Oral } \\
\text { Care questionnaire; } 26 / 44 \text { items were based on Frenkel } 2001 \text { carers questionnaire. Items } \\
\text { were scored using a true/false response, with each correct answer scoring } 1 \text {. The outcome } \\
\text { was presented as composite outcome score. }\end{array}$ & 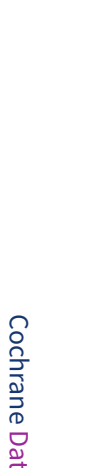 \\
\hline G & $\begin{array}{l}\text { Stroke sur- } \\
\text { vivor and } \\
\text { providers' } \\
\text { attitudes to } \\
\text { OHC: attitude } \\
\text { (Analysis } 1.11 \text { ) }\end{array}$ & $\begin{array}{l}\text { SMD } 0.28 \\
(0.01 \text { to } \\
0.54)\end{array}$ & $\begin{array}{l}728 \text { partici- } \\
\text { pants } \\
\text { (3 trials; Ab } \\
\text { Malik 2017; } \\
\text { Frenkel } \\
2001 ; \text { Kuo } \\
2016 \text { ) }\end{array}$ & $\begin{array}{l}\text { Favours } \\
\text { OHC inter- } \\
\text { vention }\end{array}$ & $\begin{array}{l}\oplus \ominus \ominus \ominus \mathrm{a}, \mathrm{b}, \mathrm{c}, \mathrm{d} \\
\text { Very low }\end{array}$ & $\begin{array}{l}\text { Attitude assessed with non-validated self-administered questionnaires. } \\
\text { - Ab Malik } 2017 \text { assessed attitude using items derived from the manual of "Constructing } \\
\text { Questionnaires Based on the Theory of Planned Behavior" (Francis 2004) and modified to } \\
\text { the oral health context. Higher scores reflect a more positive attitude to OHC. }\end{array}$ &  \\
\hline
\end{tabular}


- Frenkel 2001 assessed attitude to oral health using a 5-point Likert scale to 25 statements on $\mathrm{OHC}$ (including 12 on carers' own oral health) tested attitudes. The outcome was presented as a composite outcome score.

- Kuo 2016 developed and measured a 19-item Attitude to Oral Care questionnaire; 13/19 were based on Frenkel 2001 carers questionnaire and scored using a 5-point Likert scale.

\section{GRADE Working Group grades of evidence}

High quality: further research is very unlikely to change our confidence in the estimate of effect.

Moderate quality: further research is likely to have an important impact on our confidence in the estimate of effect and may change the estimate.

Low quality: further research is very likely to have an important impact on our confidence in the estimate of effect and is likely to change the estimate.

Very low quality: we are very uncertain about the estimate.

CI: confidence interval; DMS: difference in mean score; OHC: oral health care; OR: odds ratio; SMD: standard mean difference.

aDowngraded one level as there were serious limitations identified in the risk of bias.

bDowngraded one level because of imprecision.

cDowngraded one level because of inconsistency of results.

dDowngraded one level because of indirectness of the evidence based on variations in outcome measures.

\section{Summary of findings 2. Oral health care intervention compared with placebo for people after stroke}

\section{Oral health care intervention compared with placebo for stroke}

Patient or population: adults with stroke

Settings: hospital based

Intervention: oral care intervention

Comparison: placebo

\begin{tabular}{llllll}
\hline Outcomes & $\begin{array}{l}\text { Relative ef- } \\
\text { fect } \\
(95 \% \mathrm{CI})\end{array}$ & $\begin{array}{l}\text { No of par- } \\
\text { ticipants } \\
\text { (trials) }\end{array}$ & $\begin{array}{l}\text { Direction of } \\
\text { effect }\end{array}$ & $\begin{array}{l}\text { Quality of } \\
\text { the evi- } \\
\text { dence } \\
\text { (GRADE) }\end{array}$ & Comments \\
\hline Dental plaque & - & - & - & - & We found no studies. \\
\hline Denture plaque & - & - & - & - & We found no studies. \\
\hline Presence of oral disease & - & - & - & We found no studies. \\
\hline $\begin{array}{l}\text { Presence of related in- } \\
\text { fection: pneumonia }\end{array}$ & $\begin{array}{l}\text { OR 0.39 } \\
(0.14 \text { to } \\
1.09)\end{array}$ & $\begin{array}{l}242 \text { partici- } \\
\text { pants }\end{array}$ & $\begin{array}{l}\text { No evidence } \\
\text { of benefit or } \\
\text { harm }\end{array}$ & $\begin{array}{l}\oplus \oplus \ominus \ominus \text { a,b } \\
\text { Low }\end{array}$ & - Gosney 2006 - intervention was selective decontamination gel; evidence of \\
benefit as compared to placebo (OR 0.20, 95\% Cl 0.05 to 0.84). Assessed im-
\end{tabular}




$\begin{array}{lll} & \text { ney 2006; } & \text { Seguin 2014 - intervention was povidine-iodine; no evidence of benefit or } \\ \text { Seguin } & \text { harm (OR 0.81, 95\% CI 0.18 to 3.51). Assessed immediately postintervention } \\ \text { 2014) } & \text { (30 days) using criteria outlined in American Thoracic Society 2005. }\end{array}$

\section{Stroke survivor and}

(30 days) using criteria outlined in American Thoracic Society 2005

\section{providers' knowledge \\ and attitudes to oral}

health care

\section{GRADE Working Group grades of evidence}

High quality: further research is very unlikely to change our confidence in the estimate of effect.

Moderate quality: further research is likely to have an important impact on our confidence in the estimate of effect and may change the estimate.

Low quality: further research is very likely to have an important impact on our confidence in the estimate of effect and is likely to change the estimate.

Very low quality: we are very uncertain about the estimate.

Cl: confidence interval; OR: odds ratio; RR: risk ratio.

aDowngraded one level as there were serious limitations identified in the risk of bias.

bDowngraded one level because of indirectness.

Summary of findings 3. One oral healthcare intervention compared with another oral healthcare intervention for people after stroke

\section{Oral health care intervention compared with another oral health care intervention for stroke}

Patient or population: adults with stroke

Settings: hospital based

Intervention: oral care intervention

Comparison: another oral health care intervention

\begin{tabular}{|c|c|c|c|c|c|}
\hline Outcomes & $\begin{array}{l}\text { Relative ef- } \\
\text { fect } \\
(95 \% \mathrm{Cl})\end{array}$ & $\begin{array}{l}\text { No of par- } \\
\text { ticipants } \\
\text { (trials) }\end{array}$ & $\begin{array}{l}\text { Direction of } \\
\text { effect }\end{array}$ & $\begin{array}{l}\text { Quality of } \\
\text { the evi- } \\
\text { dence } \\
\text { (GRADE) }\end{array}$ & Comments \\
\hline $\begin{array}{l}\text { Dental plaque } \\
\text { (Analysis 3.1) }\end{array}$ & $\begin{array}{l}\text { MD - }-0.04(- \\
0.33 \text { to } 0.25)\end{array}$ & $\begin{array}{l}61 \text { partici- } \\
\text { pants } \\
\text { (1 trial; } A b \\
\text { Malik 2018) }\end{array}$ & $\begin{array}{l}\text { No evidence } \\
\text { of benefit or } \\
\text { harm }\end{array}$ & $\begin{array}{l}\oplus \oplus \Theta \Theta^{a, b} \\
\text { Low }\end{array}$ & $\begin{array}{l}\text { - Assessed immediately postintervention ( } 3 \text { months). } \\
\text { Measured using the Silness and Loe Plaque Index (Silness } \\
\text { 1964) (scale } 0-3 \text {, where } 0=\text { absence of plaque and } 3=\text { abun- } \\
\text { dant presence of plaque). }\end{array}$ \\
\hline
\end{tabular}




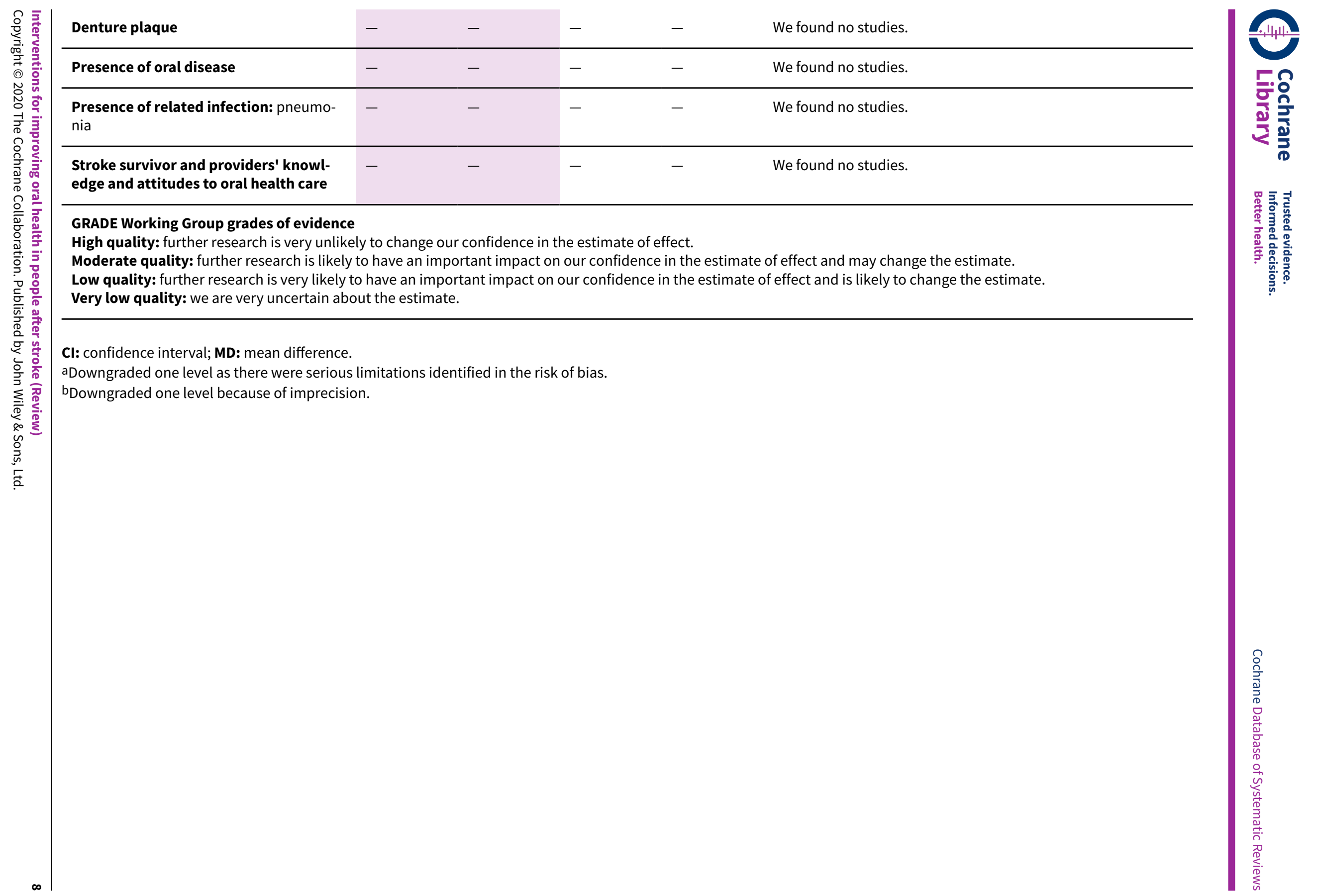




\section{B A C K G R O U N D}

Three quarters of stroke survivors experience physical deficits (Adamson 2004), and the weakness, lack of co-ordination and cognitive problems that may accompany a stroke can make it difficult for a person to maintain the health and cleanliness of their mouth, tongue and teeth on their own (RCP 2016). Facial muscle strength and tone and oral sensation may alter after stroke, resulting in poorly controlled dentures and altered chewing and oral clearance patterns. Together with swallowing impairment, all these factors impact on an individual's nutritional intake, which also has a negative impact on rehabilitation and other functional outcomes (Geeganage 2012; Nakazora 2017; RCP 2016).

\section{Description of the condition}

Dry mouth, oral ulcers and stomatitis are common side effects of medication (RCP 2016; Yuan 2015). Dysphagia and poor oral clearance of food and fluid residue further contribute to dental decay and microbial load observed among stroke survivors (Dai 2015; Kishore 2018; Zhu 2008). Some patients have pre-existing oral health problems - for example gum disease has been linked to the incidence of cardiovascular disease, diabetes and stroke (Michishige 1999). The more severe a stroke, the more dependent the stroke survivors are on others to support or facilitate their oral health care $(\mathrm{OHC})$.

Pneumonia is a common complication after stroke and is associated with high mortality, long stays in hospital and a lower potential for function recovery (Hilker 2003; Katzan 2003; Langhorne 2000). While reports of the numbers affected vary, stroke-associated pneumonia has been reported to affect between $2 \%$ and $63 \%$ of stroke survivors (Hannawi 2013; Kishore 2018). The onset of stroke-associated pneumonia is thought to be related to the severity of patients' stroke, their functional impairment (both pre- and poststroke onset) and level of consciousness (Chumbler 2010). People with stroke who have swallowing problems (dysphagia) are more likely to develop pneumonia than people with stroke with normal swallowing function, but aspiration of food and fluid into the lungs alone does not fully account for the incidence of pneumonia (Chumbler 2010). The possibility of a relationship between stroke-associated pneumonia and patients' oral health has received increasing attention.

\section{Description of the intervention}

Providing $\mathrm{OHC}$ to people with different stroke and dental profiles (those with natural teeth, dentures, both or neither) within stroke care settings is a challenge (Brady 2011). OHC practice varies across wards, often delegated to junior nursing staff. Staff are inadequately supported to provide this care (Horne 2015; Talbot 2005). Current descriptions of $\mathrm{OHC}$ interventions incorporate staff knowledge, assessment, equipment, agents, planned intervention, monitored nutritional intake and specialist referral components (Brady 2011; Wagner 2016) (see Types of interventions).

\section{How the intervention might work}

If the mouth is not kept clean then the increasing buildup of debris contributes to plaque, tartar, dental decay and gum disease. If left untreated and in a state of continuing poor oral health this can develop into calcified plaque (tartar), tooth loss, stomatitis, gingivitis and periodontitis (Peres 2019; Watt 2019). The health benefits of high-quality care after stroke (Ingeman 2011), and the complementary role that various members of the multidisciplinary stroke team could play in the provision of $\mathrm{OHC}$ has been outlined, including dental health, dietetic and occupational therapy professionals (Bailey 2004; Bellomo 2005). As in other aspects of stroke care, rehabilitation goals that aim to maintain or regain independent $\mathrm{OHC}$ skills would be appropriate in the stroke care setting (Bellomo 2005).

\section{Why it is important to do this review}

Systematic review evidence indicates that enhanced $\mathrm{OHC}$ has a preventive effect on the incidence of pneumonia among nursing home residents (absolute risk reductions between $6.6 \%$ and $11.7 \%$; numbers needed to treat for an additional beneficial outcome 9 to 15) (Sjögren 2008), and ventilated populations (Chan 2007). More recently one non-randomised study in a stroke care setting suggested benefits in the use of a coproduced $\mathrm{OHC}$ programme involving nursing staff education, access to $\mathrm{OHC}$ assessments, protocols and $\mathrm{OHC}$ equipment (odds ratio (OR) for pneumonia in the $\mathrm{OHC}$ group was $0.71,95 \%$ confidence interval $(\mathrm{Cl}) 0.51$ to $0.98 ; P=0.041$ ) (Wagner 2016). The dearth of evidence underpinning staff-led oral care practice in healthcare settings has been highlighted (Lyons 2018; RCP 2016). It is crucial to undertake a rigorous systematic review and meta-analyses of the available evidence relating to the effectiveness of oral care interventions for people after stroke in order to inform evidence-based care and rehabilitation of people after stroke.

\section{OB JECTIVES}

To compare the effectiveness of $\mathrm{OHC}$ interventions with usual care, or other treatment options for ensuring oral health in people after a stroke.

\section{METHODS}

\section{Criteria for considering studies for this review}

\section{Types of studies}

We identified randomised controlled trials (RCTs) that evaluated one or more interventions designed to improve oral health. We included trials that recruited from a healthcare setting with a mixed population provided it was possible to extract the data specific to the individuals poststroke.

\section{Types of participants}

We included adults (aged 18 years or greater) with a diagnosis of stroke who received assisted $\mathrm{OHC}$ led by healthcare staff.

\section{Types of interventions}

We included trials that evaluated an intervention designed to improve routine-assisted $\mathrm{OHC}$ in a stroke care setting.

The interventions fell into the following broad categories:

- assessment tool;

- equipment (e.g. toothbrush);

- agent (e.g. mouthwash);

- staff, volunteer or family carer training;

- OHC promotion. 


\section{Types of outcome measures}

A comprehensive, valid and reliable measurement tool for assessing oral health and cleanliness is currently lacking. We recorded a range of outcomes that correspond to different aspects of oral health and cleanliness and OHC delivery.

\section{Primary outcomes}

- Dental plaque.

- Denture plaque.

\section{Secondary outcomes}

- Presence of oral disease: gingivitis, denture-induced stomatitis, periodontal disease.

- Presence of related infection and primary oral opportunistic pathogens related to $\mathrm{OHC}$ and pneumonia: pneumonia, anaerobic Gram-negative bacillus (AGNB), Candida and Staphylococcus aureus.

- Oral health knowledge and attitudes.

- Patient satisfaction and quality of life: care received, oral comfort and appearance, quality of life.

We recorded outcome measurements taken up to 12 months postintervention. We took dental data of included studies at the patient level.

\section{Search methods for identification of studies}

See the 'Specialized register' section at the Cochrane Stroke Group website (www.dcn.ed.ac.uk/csrg/entity/searchmethods.pdf). We searched for trials in all languages and planned to arrange translation of relevant papers published in languages other than English.

\section{Electronic searches}

We searched the trials registers of the Cochrane Stroke Group (last searched 18 February 2019) and the Cochrane Oral Health Group (last searched 20 February 2018) (Appendix 1).

In addition, we searched the following databases:

- Cochrane Central Register of Controlled Trials (CENTRAL; 2019, Issue 2) in the Cochrane Library (searched 18 February 2019) (Appendix 2);

- MEDLINE Ovid (1946 to 15 February 2019) (Appendix 3);

- Embase Ovid (1974 to 18 February 2019) (Appendix 4); and

- CINAHL EBSCO (Cumulative Index to Nursing and Allied Health Literature; 1982 to 18 February 2019) (Appendix 5).

We also searched the following resources for ongoing trials:

- US National Institutes of Health Ongoing Trials Register ClinicalTrials.gov (http://www.clinical trials.gov; searched 18 February 2019) (Appendix 6);

- World Health Organization International Clinical Trials Registry Platform (apps.who.int/trialsearch; searched 18 February 2019) (Appendix 6).

For the previous version of this review, we searched the Research Findings Electronic Register (to February 2006), and the National Research Register (Issue 1, 2006). These sources are no longer available and so our search update did not include them. The earlier search strategies are shown in Appendix 7.

\section{Searching other resources}

In an effort to identify further published, unpublished and ongoing studies, we searched Web of Science Conference Proceedings Citation Index-Science (last searched 25 February 2019), Zetoc (last search 25 February 2019) and Proquest Dissertations and Theses (last search 25 February 2019) using key terms shown in Appendix 8.

We scanned reference lists from relevant papers and contacted authors and researchers in the field. We did not handsearch any journals or conference proceedings in addition to those already searched on behalf of Cochrane UK and the Cochrane Stroke Group.

\section{Data collection and analysis}

\section{Selection of studies}

We considered RCTs that addressed $\mathrm{OHC}$ interventions for inclusion on the basis of study design, interventions and outcome measures used. All RCTs that examined OHC interventions for older populations (which had the potential to have included individuals post stroke) were eligible for inclusion. One review author (MB, $\mathrm{BB}$ or $\mathrm{PC}$ ) screened titles of the records identified through the electronic searches described above and excluded any obviously irrelevant studies. Two members of the review team (MB, and $\mathrm{BB}, \mathrm{PC}$ or $\mathrm{DF}$ ) independently reviewed the abstracts of potentially relevant studies to determine if they met the selection criteria.

We obtained full-text papers of the remaining studies that fulfilled the listed inclusion criteria and these were independently assessed by two members of the review team (MB, BB, PC, DF). In some cases, we contacted the trial authors to retrieve additional information before we could make a final decision. We resolved conflicting decisions through discussion. Studies judged as ineligible for inclusion, together with reasons for their exclusion, are listed in the Characteristics of excluded studies table.

\section{Data extraction and management}

Two members of the review team (MB, BB, PC, DF) independently performed data extraction, and we contacted study authors to request missing data (or data in a suitable format) for inclusion in the review. For trials based on a mixed population, we contacted the study authors to establish whether the details relating to stroke survivors were available. All data provided were at participant level, rather than tooth level.

We developed and piloted a standardised data extraction sheet. We extracted the following information: study design, recruitment and setting, participants' demographics, inclusion and exclusion criteria, outcome measures used and time points, duration of follow-up and summary outcome data.

We profiled specific intervention details using the template for intervention description and replication (TIDieR) checklist (Hoffmann 2014). This included details of the intervention (intervention rationale, materials, procedures, provider, delivery mode, dose, tailoring, modification, adherence and related aspects of fidelity).

We also used the TIDieR checklist to extract relevant data for each control group to document what intervention was delivered 
(i.e. we made every effort to profile all interventions, including those in the comparison role of 'usual care.' by their constituent components). Where trialists used the term 'usual care' in the absence of any additional details such profiling was not possible. Usual care is highly variable (e.g. Talbot 2005), and thus we profiled the intervention by that general term only.

\section{Assessment of risk of bias in included studies}

Two review authors (MB, BB PC, DF) independently documented the methodological quality of the included studies using items specified by the Cochrane Handbook for Systematic Reviews of Interventions (Higgins 2019). They judged each study as potentially 'high risk', 'low risk' or 'unclear' risk of bias, against the following nine quality criteria.

- Random sequence generation (selection bias).

- Allocation concealment (selection bias).

- Blinding of participants and personnel (performance bias).

- Blinding of outcome assessment (detection bias).

- Incomplete outcome data (attrition bias).

- Selective reporting (reporting bias).

- Baseline comparability of groups.

- Whether an a priori power calculation had been conducted.

- Other potential confounders.

We sought clarification from study authors if details were unavailable from the text. We resolved disagreements by consensus between the review authors.

\section{Measures of treatment effect}

We grouped studies together in terms of their interventions and outcomes. Where suitable statistical summary data were available, we combined the selected outcome data in pooled meta-analyses. For dichotomous outcomes, we calculated the effect measure as the risk ratio (RR) with $95 \%$ confidence intervals $(\mathrm{Cl})$. For dichotomous outcomes with rare events (i.e. an event rate of less than $10 \%$ ), we calculated Peto odds ratios (OR) with $95 \% \mathrm{Cl}$.

For ordinal scales (10 or more categories) and for continuous data, and where the same measurement tool was used across trials, we calculated the treatment effect using mean differences (MD) and $95 \% \mathrm{Cl}$. If different scales were used in different trials, we planned to use standardised mean differences (SMD) and 95\% Cl. For nonnormal data and ordinal scales with fewer than 10 categories, we planned to use a defined cut-off and to treat the data as a dichotomous outcome.

An earlier version of the review, Brady 2006, used Proc Mixed in the statistical package SAS (www.sas.com/) to analyse the individual patient data for poststroke participants to take account of the clustering in the Frenkel 2001 study, and used the generic inverse variance section of Review Manager 5 for presentation purposes (Review Manager 2014). Consequently, we calculated the estimates and standard errors of the same effect measure for all the other studies in the same meta-analysis using the methods outlined in the Cochrane Handbook for Systematic Reviews of Interventions (Higgins 2019).

\section{Unit of analysis issues}

The unit of analysis was per participant randomised, rather than tooth level. Where a trial included three or more arms, we split the number of participants in the control group across the two interventions. In the case of continuous data, the means and standard deviations (SD) remained the same. In the case of dichotomous data, both the number of events and total number of participants were split across the relevant number of arms. Where we identified a cluster RCT, we planned to identify the unit of randomisation, the unit of analysis and, wherever possible, the intraclass correlation coefficient to adjust results to account for cluster effect.

\section{Dealing with missing data}

In cases where only partial summary data were reported, for example mean final value scores were available but SDs were unavailable, we calculated these values from available information using methods described in the Cochrane Handbook for Systematic Reviews of Interventions (Higgins 2019). In cases where data needed to be transformed (e.g. from median and interquartile range (IQR) scores to mean and SD), we used methods described in Weir 2018. We also contacted trialists to request missing data.

\section{Assessment of heterogeneity}

We assessed statistical heterogeneity between trials using the 12 statistic available in the Review Manager 5 (Review Manager 2014). If statistical heterogeneity existed (in the absence of co-existing clinical or methodological heterogeneity), we planned to use a random-effects model to pool the trials. We used a fixed-effect model if there was no evidence of clinical, methodological or statistical heterogeneity.

We interpreted the results using the $1^{2}$ statistic thresholds recommended by the Cochrane Handbook for Systematic Reviews of Interventions (Higgins 2019):

- 0 to $40 \%$ - potentially unimportant;

- $30 \%$ to $60 \%$ - may represent moderate heterogeneity;

- $50 \%$ to $90 \%$ - may represent substantial heterogeneity;

- $75 \%$ to $100 \%$ - considerable heterogeneity.

\section{Data synthesis}

We analysed data using Review Manager 5 (Review Manager 2014). We combined data from individual trials for meta-analysis if the interventions and outcomes were sufficiently similar (determined by consensus).

We created 'Summary of findings' tables for the three comparisons identified. We presented the key findings of the review, including a summary of the quantity of data, the magnitude of effect size, and the overall quality of evidence. We summarised the shortterm findings for our primary outcomes including dental plaque and denture plaque. We also presented data for the presence of oral disease (i.e. gingivitis, denture-induced stomatitis), presence of related infection (i.e. for pneumonia only), and stroke survivor and providers' oral health knowledge and attitude.

We used the GRADE approach (Guyatt 2008; Guyatt 2011a), as described in the Cochrane Handbook for Systematic Reviews of 
Interventions, to present the evidence quality for each combination of intervention and outcome (Higgins 2019).

The quality of a body of evidence for a specific outcome was graded against the following factors:

- limitations of study (e.g. risk of bias due to poor study design or conduct (Guyatt 2011b);

- publication bias (Guyatt 2011c);

- imprecision of results (e.g. wide Cls for treatment effect) (Guyatt 2011d);

- inconsistency of results (e.g. large 12 statistic) (Guyatt 2011e);

- indirectness of evidence (e.g. variations in participants, interventions, comparisons and outcomes) (Guyatt 2011f).

The GRADE approach specifies four levels of quality, that is, high-, moderate-, low- and very low-quality evidence, based on the following definitions:

- high quality: it is unlikely that further research will change our confidence in the estimate of effect;

- moderate quality: further research is likely to have an impact and may change our confidence in the estimates of effect;

- low quality: further research is very likely to have an important impact on our confidence in the estimate of effect;

- very low quality: any estimate of effect is very uncertain.

\section{Sensitivity analysis}

We planned to conduct sensitivity analyses for primary outcomes to explore the effect of the following methodological features:
- method of randomisation (high risk of bias, low risk of bias and unclear risk of bias);

- extent of allocation concealment at randomisation (high risk of bias, low risk of bias and unclear risk of bias);

- presence of assessor blinding (high risk of bias, low risk of bias and unclear risk of bias).

We planned to carry out these planned sensitivity analyses when there were six or more studies included in a single analysis.

\section{RE S U L T S}

\section{Description of studies}

\section{Results of the search}

Our updated search strategy identified 19,525 records from electronic databases (Appendix 1; Appendix 2; Appendix 3; Appendix 4; Appendix 5; Appendix 6). The flow of literature through the searching and screening is shown in the PRISMA flow diagram (Figure 1). Following the updated search, we identified 12 new studies (19 randomised comparisons for inclusion in this 2019 update) (Ab Malik 2017; Ab Malik 2018; Chipps 2014; Dai 2017; Juthani-Mehta 2015; Kim 2014a; Kobayashi 2017i/Kobayashi 2017ii/Kobayashi 2017iii/Kobayashi 2017iv/Kobayashi 2017v/Kobayashi 2017vi; Kuo 2016; Lam 2013i/Lam 2013ii/Lam 2013iii; Lee 2011; Seguin 2014; SOCLE II). These new trials were synthesised with the three trials (Fields 2008; Frenkel 2001; Gosney 2006) included in earlier versions of this review (Brady 2006). 
Figure 1. Study flow diagram. RCT: randomised controlled trial.

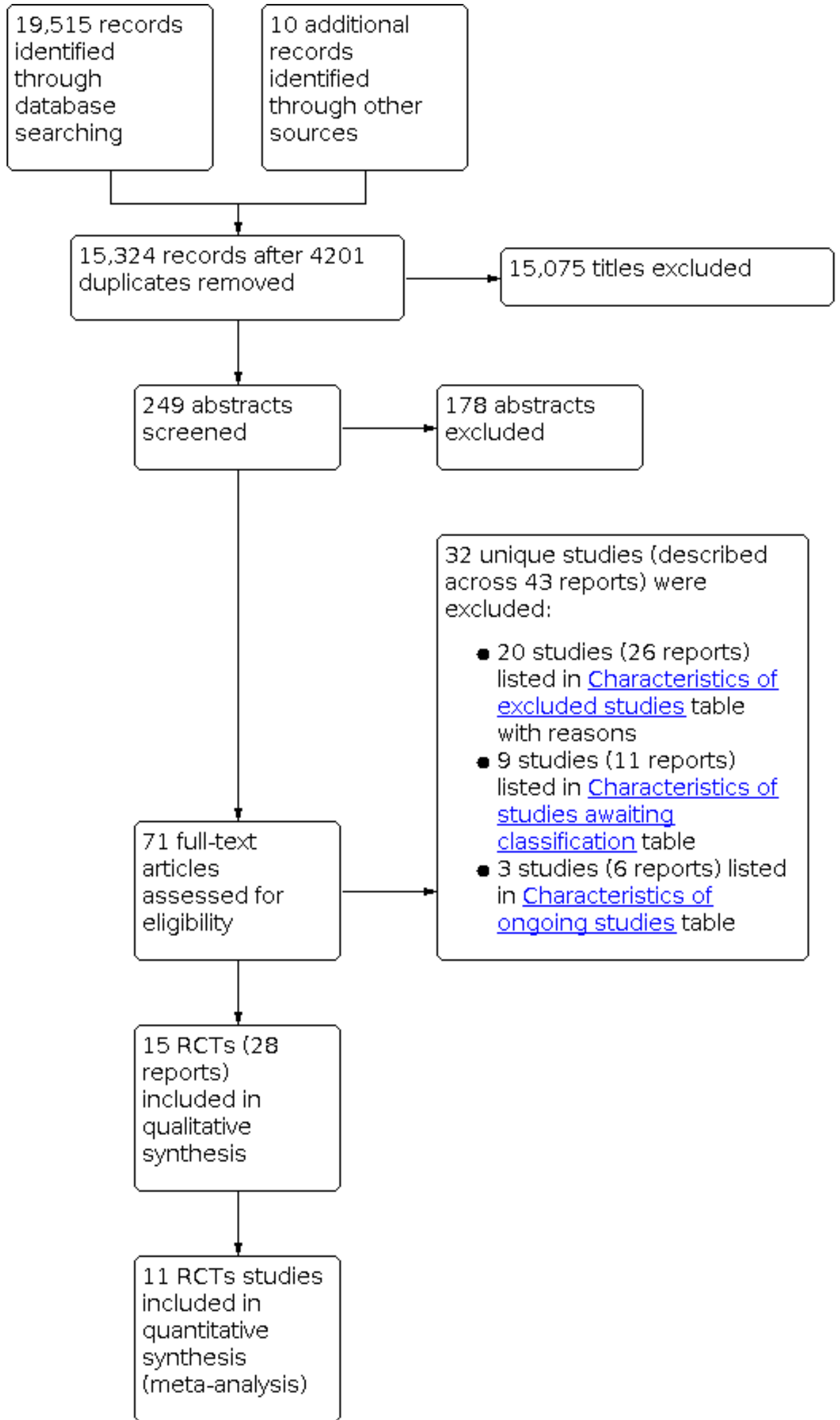


We also identified three ongoing trials (ChiCTR-IPR-17013403; Hollaar 2015; MAPS-2) (see Characteristics of ongoing studies table). Our searches identified nine trials which may be eligible for inclusion, but we were unable to retrieve stroke-specific data from them for the purposes of this review (Cabov 2010; IRCT2017012232101N1; IRCT2017091636194N1; Jin 2018; Marchini 2018; Mori 2012; NCT00610324; NCT03219346; Yakiwchuk 2013). These studies are detailed in the Characteristics of studies awaiting classification table.

\section{Included studies}

In this update of our review, we included 15 trials (22 randomised controlled comparisons) (Ab Malik 2017; Ab Malik 2018; Chipps 2014; Dai 2017; Fields 2008; Frenkel 2001; Gosney 2006, Juthani-Mehta 2015; Kim 2014; Kobayashi 2017i/Kobayashi 2017ii/Kobayashi 2017iii/Kobayashi 2017iv/Kobayashi 2017v/Kobayashi 2017vi; Kuo 2016; Lam 2013i/Lam 2013ii/Lam 2013iii; Lee 2011; Seguin 2014; SOCLE II).

Seven trials were registered on clinical trials databases (Ab Malik 2017; Ab Malik 2018; Dai 2017; Juthani-Mehta 2015; Lam 2013i/Lam 2013ii;/Lam 2013iii; Seguin 2014; SOCLE II); the remaining eight trials were not registered (Chipps 2014; Fields 2008; Frenkel 2001; Gosney 2006; Kim 2014; Kobayashi 2017i/Kobayashi 2017ii/Kobayashi 2017iii/Kobayashi 2017iv/Kobayashi 2017v/Kobayashi 2017vi; Kuo 2016; Lee 2011) (Table 1).

Nine studies employed a parallel RCT design (Ab Malik 2018; Chipps 2014; Dai 2017; Fields 2008; Gosney 2006; Kim 2014; Kuo 2016; Lee 2011; Seguin 2014); three conducted a cluster RCT design (Ab Malik 2017; Frenkel 2001; Juthani-Mehta 2015); and one used a stepped-wedge cluster RCT design (SOCLE II). Two trials randomised participants across three or more trial arms (Kobayashi 2017i/Kobayashi 2017ii/Kobayashi 2017iii/Kobayashi 2017iv/Kobayashi 2017v/Kobayashi 2017vi; Lam 2013i/Lam 2013ii/Lam 2013iii). For the purposes of this review, we have presented these data separately within randomised paired comparisons (indicated using roman numerals i, ii, iii, etc. as appropriate) and these paired comparisons will be referred to as 'trials,' from this point onwards.

Four trials recruited a mixed participant population (Frenkel 2001; Juthani-Mehta 2015; Seguin 2014; SOCLE II), but some of the trialists shared the stroke-specific dataset with the authors for the purposes of this review (Frenkel 2001; Seguin 2014; SOCLE II).

We present a summary of the key features of the studies in the following sections, and have provided a more indepth description in the Characteristics of included studies table.

\section{Location and recruitment setting}

Most trials recruited from single sites (14/22) (Chipps 2014; Dai 2017; Fields 2008; Kim 2014a; Kobayashi 2017i; Kobayashi 2017ii; Kobayashi 2017iii; Kobayashi 2017iv; Kobayashi 2017v; Kobayashi 2017vi; Lam 2013i; Lam 2013ii; Lam 2013iii; Lee 2011); the remaining trials recruited participants from multiple centres, ranging from three sites (Gosney 2006; Kuo 2016) to 36 sites (Juthani-Mehta 2015).

Studies were carried out in France (Seguin 2014), Hong Kong, People's Republic of China (Dai 2017; Lam 2013i; Lam 2013ii;
Lam 2013iii), Japan (Kobayashi 2017i; Kobayashi 2017ii; Kobayashi 2017iii; Kobayashi 2017iv; Kobayashi 2017v; Kobayashi 2017vi), Malaysia (Ab Malik 2017; Ab Malik 2018), South Korea (Kim 2014a; Lee 2011), Taiwan (Kuo 2016), the UK (Frenkel 2001; Gosney 2006; SOCLE II), and the USA (Chipps 2014; Fields 2008; Juthani-Mehta 2015).

The setting varied across trials, including intensive care units (Fields 2008; Kim 2014a; Seguin 2014), acute rehabilitation unit (Chipps 2014), stroke rehabilitation units (Gosney 2006; Lam 2013i; Lam 2013ii; Lam 2013iii; SOCLE II), hospital (no details) (Ab Malik 2017; Ab Malik 2018; Kobayashi 2017i; Kobayashi 2017ii; Kobayashi 2017iii; Kobayashi 2017iv; Kobayashi 2017v; Kobayashi 2017vi), outpatient (Dai 2017), nursing homes (Frenkel 2001; Juthani-Mehta 2015), and hospital-outreach home care (Kuo 2016). Setting details were unavailable for one trial (Lee 2011).

Details of recruitment strategies, settings, geographical location and trial registration details are summarised in Table 1.

\section{Type of participants}

Of the 3631 participants involved in the 22 trials, 1028 were staff (registered nurses, care assistants and nursing home carers) (Ab Malik 2017; Frenkel 2001; SOCLE II); 94 family carers (Kuo 2016), and 1546 people with stroke (Ab Malik 2018; Chipps 2014; Dai 2017; Fields 2008; Frenkel 2001; Gosney 2006; Juthani-Mehta 2015; Kim 2014a; Kobayashi 2017i; Kobayashi 2017ii; Kobayashi 2017iii; Kobayashi 2017iv; Kobayashi 2017v; Kobayashi 2017vi; Lam 2013i; Lam 2013ii; Lam 2013iii; Lee 2011; Seguin 2014; SOCLE II) (see Table 2).

The number of participants randomised ranged from 24 (Lee 2011), to 834 (Juthani-Mehta 2015), with six trials randomising more than 100 participants (Ab Malik 2017; Frenkel 2001; Gosney 2006; Juthani-Mehta 2015; Seguin 2014; SOCLE II). The age of participants ranged from 20 to 96 years, but was not reported in three trials ( $A b$ Malik 2017; Fields 2008; Lee 2011).

Most trials included stroke-only populations (Ab Malik 2017; Ab Malik 2018; Chipps 2014; Dai 2017; Fields 2008; Gosney 2006; Kim 2014a; Kobayashi 2017i; Kobayashi 2017ii; Kobayashi 2017iii; Kobayashi 2017iv; Kobayashi 2017v; Kobayashi 2017vi; Kuo 2016; Lam 2013i; Lam 2013ii; Lam 2013iii; Lee 2011); four trials recruited participants from mixed populations (Frenkel 2001; Juthani-Mehta 2015; Seguin 2014; SOCLE II). Further details of the type of stroke and onset and other details of the participants included are summarised in Table 2.

Participants were randomised at the hospital level in two trials (Ab Malik 2017; SOCLE II), nursing home in two trials (Frenkel 2001; Juthani-Mehta 2015), or at the individual level in 18 trials (Ab Malik 2018; Chipps 2014; Dai 2017; Fields 2008; Gosney 2006; Kim 2014a; Kobayashi 2017i; Kobayashi 2017ii; Kobayashi 2017iii; Kobayashi 2017iv; Kobayashi 2017v; Kobayashi 2017vi; Kuo 2016; Lam 2013i; Lam 2013ii; Lam 2013iii; Lee 2011; Seguin 2014).

\section{Type of interventions}

In the following section, we present a narrative synthesis of the different interventions that were delivered within the three comparisons groups: $\mathrm{OHC}$ versus no treatment/usual care, $\mathrm{OHC}$ versus placebo and one $\mathrm{OHC}$ intervention versus another $\mathrm{OHC}$ 
intervention. Details of the different intervention components are summarised in Table 3.

\section{Oral healthcare interventions versus no treatment or usual care}

In this comparison we considered the benefits of $\mathrm{OHC}$ interventions compared to no treatment or usual care, where usual care lacked description of the nature and content of that intervention.

Of the 22 randomised trials, seven investigated $\mathrm{OHC}$ interventions compared with usual care. Three of these trials were educational interventions (Ab Malik 2017; Frenkel 2001; Kuo 2016), and the remaining four trials delivered a multi-component $\mathrm{OHC}$ protocol (Fields 2008; Juthani-Mehta 2015; Kim 2014a; SOCLE II).

Four trials involved the delivery of multi-component $\mathrm{OHC}$ protocol compared to usual care, involving the provision of various combinations of education and training, materials (e.g. toothbrush, toothpaste, mouth gel, mouthwash, tongue cleaners, lip balm, care protocols) and assessment tools (Table 3; Fields 2008; JuthaniMehta 2015; Kim 2014a; SOCLE II). The intervention was delivered once a day (Kim 2014a), twice a day (Juthani-Mehta 2015; SOCLE II), or three times a day (Fields 2008), by a dentist (Kim 2014a), nursing aides (Juthani-Mehta 2015), or nursing staff (registered nurses, nursing assistants, nursing students) (Fields 2008; SOCLE II).

Trials which delivered specific educational training interventions were diverse, and aimed at registered nurses (Ab Malik 2017), care assistants (Frenkel 2001), or informal carers (Kuo 2016). Educational interventions for staff included an online continuing professional development programme for registered nurses (Ab Malik 2017), while Frenkel 2001 described face-to-face standardised $\mathrm{OHC}$ education training in combination with practical demonstrations for care assistants working in nursing homes. Kuo 2016 delivered home-based $\mathrm{OHC}$ training using multiple teaching strategies

The control group was offered general stroke care training (Ab Malik 2017), delayed OHC training (Frenkel 2001; Kuo 2016), usual oral care provided by nursing staff (Fields 2008; SOCLE II), or standard care (Juthani-Mehta 2015). It was not clear what the control group received in Kim 2014a (Table 3).

\section{Oral healthcare interventions versus placebo}

Three trials compared an $\mathrm{OHC}$ intervention with placebo (Gosney 2006; Lee 2011; Seguin 2014) (Table 3). The interventions included selective decontamination of the digestive tract using an Orabase gel (Gosney 2006), a povidone-iodine rinse (Seguin 2014), and Saengmaeg-san extract (Lee 2011). The interventions in this comparison were delivered by a nurse or the patient (or both) in the Gosney 2006 trial. The regimens for each intervention varied: interventions were delivered three times a day (Lee 2011), four times a day (Gosney 2006), or six times per day (Seguin 2014). The duration of the intervention also varied across these trials from seven days (Lee 2011), three weeks (Gosney 2006), and up to 30 days (Gosney 2006).

\section{One oral healthcare interventions versus another oral healthcare intervention}

Twelve trials compared one $\mathrm{OHC}$ intervention with another $\mathrm{OHC}$ intervention (Ab Malik 2018; Chipps 2014; Dai 2017; Kobayashi 2017i; Kobayashi 2017ii; Kobayashi 2017iii; Kobayashi 2017iv;
Kobayashi 2017v; Kobayashi 2017vi; Lam 2013i; Lam 2013ii; Lam 2013iii).

Multi-component $\mathrm{OHC}$ interventions involved the provision of various combinations (see Table 3):

- training: tooth models (Ab Malik 2018; Dai 2017), provision of educational leaflets (Ab Malik 2018; Dai 2017), manufacturers' instructions (Dai 2017);

- toothbrush: powered toothbrush (Ab Malik 2018; Chipps 2014; Dai 2017; Lam 2013i; Lam 2013ii; Lam 2013iii), or manual toothbrush (Ab Malik 2018; Chipps 2014; Dai 2017; Kobayashi 2017i; Kobayashi 2017ii; Kobayashi 2017iii; Kobayashi 2017iv; Kobayashi 2017v; Kobayashi 2017vi);

- toothpaste: commercial and generic brands (Ab Malik 2018; Chipps 2014, Dai 2017);

- mouth gel (Ab Malik 2018; Kobayashi 2017i; Kobayashi 2017ii; Kobayashi 2017iii; Kobayashi 2017iv; Kobayashi 2017vi);

- mouthwash: various commercial and generic brands (Chipps 2014; Dai 2017; Kobayashi 2017i; Kobayashi 2017ii; Kobayashi 2017iii; Kobayashi 2017iv; Kobayashi 2017v; Lam 2013i; Lam 2013ii; Lam 2013iii);

- tongue cleaners (Chipps 2014; Kobayashi 2017i; Kobayashi 2017ii; Kobayashi 2017iii; Kobayashi 2017iv; Kobayashi 2017v; Kobayashi 2017vi);

- lip balm (Chipps 2014);

- care protocols: for example assisted brushing (Lam 2013i; Lam 2013ii; Lam 2013iii);

- other: for example floss picks (Chipps 2014); mouthpaste (Chipps 2014); water (Kobayashi 2017ii; Kobayashi 2017iii; Kobayashi 2017iv; Kobayashi 2017v; Kobayashi 2017vi).

The intervention was delivered by dental assistants (Ab Malik 2018; Dai 2017; Lam 2013i; Lam 2013ii; Lam 2013iii), registered nurses (Chipps 2014; Kobayashi 2017i; Kobayashi 2017ii; Kobayashi 2017iii; Kobayashi 2017iv; Kobayashi 2017v; Kobayashi 2017vi), nurse aides (Lam 2013i; Lam 2013ii; Lam 2013iii), and dentists Kobayashi 2017i; Kobayashi 2017ii; Kobayashi 2017iii; Kobayashi 2017iv; Kobayashi 2017v; Kobayashi 2017vi; Lam 2013i; Lam 2013ii; Lam 2013iii).

The mode of delivery was typically individual and face-to-face, but the regimen varied across trials in this comparison including $\mathrm{OHC}$ 'daily' (Ab Malik 2018), once a day (Kobayashi 2017i; Kobayashi 2017ii; Kobayashi 2017iii; Kobayashi 2017iv; Kobayashi 2017v; Kobayashi 2017vi), or twice daily (Chipps 2014; Dai 2017; Lam 2013i; Lam 2013ii; Lam 2013iii).

\section{Outcomes}

In the absence of any core outcome measurement set, we collected a broad range of outcome data reflecting data from patient, staff and service levels of care. Table 4 summarises the outcome measures reported across the included trials.

\section{Primary outcomes}

- Dental plaque: eight trials measured dental plaque. Six used the Silness and Loe Plaque Index described by Silness 1964 (Ab Malik 2018; Dai 2017; Kim 2014a; Lam 2013i; Lam 2013ii; Lam 2013iii), and two used the simplified Oral Hygiene Method described by Greene 1964 (Frenkel 2001; SOCLE II). 
- Denture plaque: two trials measured denture plaque using a method described by Augsburger 1982 (Frenkel 2001; SOCLE II).

Registered dentists assessed plaque (dental and denture) in Lam 2013i; Lam 2013ii; Lam 2013iii, and dentist and dental hygienist assessed plaque in Kim 2014a. In SOCLE II, the SOCLE research assistant and one research nurse measured plaque. Both were trained in the procedure. A dental specialist trained the research assistant over two half-day sessions, and performed inter-rater reliability checks. The research assistant then trained the nurse and performed checks to ensure consistency in scoring. Assessor details were unclear in two trials (Ab Malik 2018; Dai 2017); however, Ab Malik 2018 reported that the assessor was trained by the head of the research team.

\section{Secondary outcomes}

- Presence of oral disease. Six trials measured gingival bleeding using the Gingival Bleeding Index (Dai 2017; Frenkel 2001; Kim 2014a; Lam 2013i; Lam 2013ii; Lam 2013iii). Other measures at patient level included denture-induced stomatitis (Frenkel 2001), Tooth Mobility Index (Frenkel 2001; Kim 2014a), Decayed, Missing and Filled Teeth Index (Dai 2017; Kim 2014a), Clinical Attachment Loss (Kim 2014a), calculus (buccal and lingual surfaces) (Frenkel 2001), and root caries (Frenkel 2001).

- Presence of related infection and oral opportunistic pathogens related to $\mathrm{OHC}$ and pneumonia. Eight trials collected information on pneumonia events (Fields 2008; Gosney 2006; Juthani-Mehta 2015; Lam 2013i; Lam 2013ii; Lam 2013iii; Seguin 2014; SOCLE II), although diagnostic criteria varied across studies (see Table 5). Fourteen trials measured the prevalence of different opportunistic pathogens (Ab Malik 2018; Chipps 2014; Dai 2017; Gosney 2006; Kobayashi 2017i; Kobayashi 2017ii; Kobayashi 2017iii; Kobayashi 2017iv; Kobayashi 2017v; Kobayashi 2017vi; Lam 2013i; Lam 2013ii; Lam 2013iii; Seguin 2014) (Table 4).

- Oral health knowledge and attitudes. Four trials used selfadministered questionnaires to capture attitudes towards and knowledge of OHC provision (Ab Malik 2017; Frenkel 2001; Kuo 2016; SOCLE II).

- Patient satisfaction and quality of life. Six trials included a measure of patient satisfaction or quality of life. SOCLE II reported the Oral Health Impact Profile (O-HIP), Seguin 2014 reported the tolerance of the oral procedure and Lee 2011 used a visual analogue scale to evaluate oral dryness. Patient satisfaction with the intervention and the condition of their mouth was assessed using a 5-point rating scale (Lam 2013i; Lam 2013ii; Lam 2013iii).

\section{Adverse events}

One trial reported data relating to any intervention adverse event (e.g. broken or missing dentures) (SOCLE II).

\section{other}

We noted measures of length of hospital stay (Seguin 2014; SOCLE II), death (Seguin 2014; SOCLE II), use of antibiotics (Gosney 2006; SOCLE II), nutritional intake (Chipps 2014), swallowing assessments (Chipps 2014), and stroke severity (Ab Malik 2018; Gosney 2006; Lam 2013i; Lam 2013ii; Lam 2013iii), but these were not extracted for the purposes of this review (see Table 4).
Most trials collected short-term data (less than one month). Follow-up data collection ranged from day five (Chipps 2014), day 10 (Chipps 2014; Fields 2008); one week (Kobayashi 2017i; Kobayashi 2017ii; Kobayashi 2017iii; Kobayashi 2017iv; Kobayashi 2017v; Kobayashi 2017vi; Lee 2011), two weeks (Kobayashi 2017i; Kobayashi 2017ii; Kobayashi 2017iii; Kobayashi 2017iv; Kobayashi 2017v; Kobayashi 2017vi), 2.2 weeks (ranged from one to five weeks) (Kim 2014a), three weeks (Gosney 2006; Lam 2013i; Lam 2013ii; Lam 2013iii), to one month (Ab Malik 2017; Frenkel 2001; Kuo 2016; Seguin 2014).

Longer-term follow-up ranged from two months (Kuo 2016), three months (Ab Malik 2018; Dai 2017), six months (Ab Malik 2017; Ab Malik 2018; Dai 2017; Frenkel 2001), to 2.5 years (Juthani-Mehta 2015). One trial captured participant data throughout the duration of their hospital ward stay and used national health record linkage to follow-up participants three months after discharge (SOCLE II).

\section{Funding sources}

Funding details are summarised in the Characteristics of included studies table. Twenty trials provided funding statements (Ab Malik 2017; Ab Malik 2018; Chipps 2014; Dai 2017; Frenkel 2001; Gosney 2006; Juthani-Mehta 2015; Kim 2014a; Kobayashi 2017i; Kobayashi 2017ii; Kobayashi 2017iii; Kobayashi 2017iv; Kobayashi 2017v; Kobayashi 2017vi; Kuo 2016; Lam 2013i; Lam 2013ii; Lam 2013iii; Seguin 2014; SOCLE II); one trials provided no funding details (Fields 2008).

Sixteen trials reported no conflict of interest (Ab Malik 2017; Ab Malik 2018; Dai 2017; Juthani-Mehta 2015; Kim 2014a; Kobayashi 2017i; Kobayashi 2017ii; Kobayashi 2017iii; Kobayashi 2017iv; Kobayashi 2017v; Kobayashi 2017vi; Kuo 2016; Lam 2013i; Lam 2013ii; Lam 2013iii; SOCLE II); three trials did not report a conflict of interest statement (Chipps 2014; Fields 2008; Frenkel 2001); and two trials reported a potential conflict of interest (Gosney 2006; Seguin 2014) (see Characteristics of included studies table).

We were unable to determine whether Lee 2011 had published a funding statement or reported a conflict of interest because of a lack of translation.

\section{Excluded studies}

We excluded 20 trials. We were unable to obtain information specific to participants who had experienced a stroke from eight potentially eligible trials (Brailsford 2002; Hajizamani 2006; Mojon 1998; Quagliarello 2009; Redwood 2001; Schou 1989; Simons 1997; Simons 2002). We excluded one trial as it did not target $\mathrm{OHC}$ in people after stroke (Kim 2014b). We excluded four trials as they were not OHC interventions (Duck-Won 2013; Forster 2013; Hägglund 2017; NCT01777672). We excluded three trials evaluating specialist dental interventions (e.g. periodontal therapy), which were not 'routine assisted OHC' (Jones 2007; Kikutani 2006; NCT02541032). Two trials had an OHC components but one did not report relevant outcome measures (Murray 2016), and the other provided matched $\mathrm{OHC}$ interventions across both participant groups (NCT02379182). We excluded the remaining trials because they reported no patient involvement (Lee 2017), or targeted secondary stroke prevention (Boden-Albala 2016). Details for exclusion can be found in the Characteristics of excluded studies table. 


\section{Risk of bias in included studies}

Details of the methodological quality can be found in the 'Risk of bias' tables for each of the included trials within the Characteristics of included studies table (see Figure 2 and Figure 3).

Figure 2. Risk of bias graph: review authors' judgements about each risk of bias item presented as percentages across all included studies.

Random sequence generation (selection bias)

Allocation concealment (selection bias)

Blinding of participants and personnel (performance bias): All outcomes

Blinding of outcome assessment (detection bias): All outcomes

Incomplete outcome data (attrition bias): All outcomes

Selective reporting (reporting bias)

Baseline data comparable?

A priori power calculation

Other bias

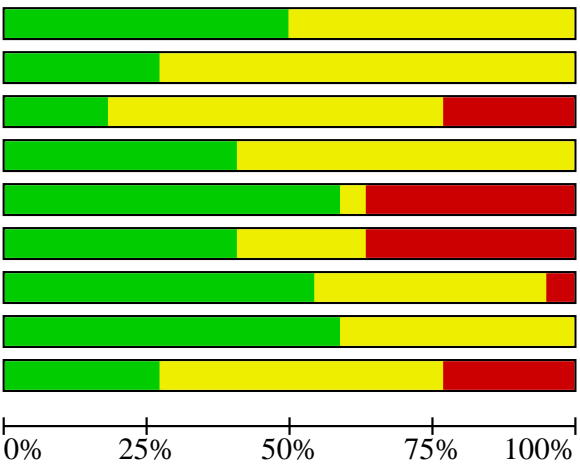


Figure 3. Risk of bias summary: review authors' judgements about each risk of bias item for each included study.

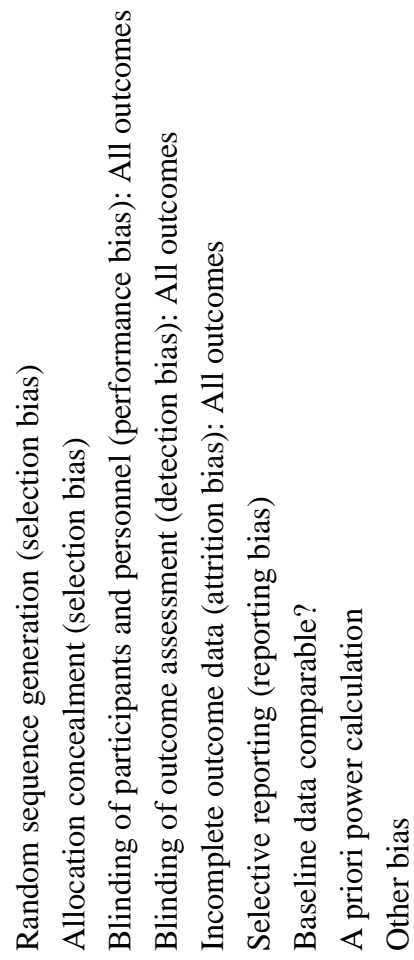

Ab Malik 2017

Ab Malik 2018

Chipps 2014

Dai 2017

Fields 2008

Frenkel 2001

Gosney 2006 Juthani-Mehta 2015

Kim 2014a

Kobayashi 2017i

Kobayashi 2017ii

Kobayashi 2017iii

Kobayashi 2017iv

Kobayashi 2017v

Kobayashi 2017vi

Kuo 2016

Lam 2013i

Lam 2013ii

Lam 2013iii

Lee 2011

Seguin 2014

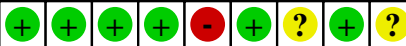

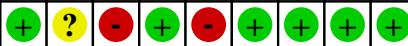
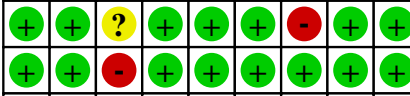
Figure 3. (Continued)

\section{SOCLE II $\lfloor+|+|-|+|+|+|+|+|+\mid$}

Half of the randomised trials (11/22) explicitly reported both inclusion and exclusion criteria (Chipps 2014; Fields 2008; Frenkel 2001; Gosney 2006; Juthani-Mehta 2015; Kuo 2016; Lam 2013i; Lam 2013ii; Lam 2013iii; Seguin 2014; SOCLE II). Four trials did not provide details of the exclusion criteria (Ab Malik 2017; Ab Malik 2018; Dai 2017; Kim 2014a). Six trials reported the exclusion criteria only (Kobayashi 2017i; Kobayashi 2017ii; Kobayashi 2017iii; Kobayashi 2017iv; Kobayashi 2017v; Kobayashi 2017vi), and we were unable to extract inclusion and exclusion criteria details in Lee 2011.

Nine trials provided statistical data for the meta-analyses (Ab Malik 2017; Ab Malik 2018; Frenkel 2001; Gosney 2006; Kim 2014a; Kuo 2016; Lee 2011; Seguin 2014; SOCLE II). Suitable statistical summary data were unavailable or could not be extracted for inclusion within the meta-analysis in 13 trials (Chipps 2014; Dai 2017; Fields 2008; Juthani-Mehta 2015; Kobayashi 2017i; Kobayashi 2017ii; Kobayashi 2017iii; Kobayashi 2017iv; Kobayashi 2017v; Kobayashi 2017vi; Lam 2013i; Lam 2013ii; Lam 2013iii).

\section{Allocation}

Eleven trials reported the randomisation sequence. Methods to generate the sequence included block randomisation (Dai 2017; Lam 2013i; Lam 2013ii; Lam 2013iii), computer generated (Ab Malik 2017; Ab Malik 2018; Chipps 2014; Gosney 2006; Seguin 2014; SOCLE II), and a random number table (Frenkel 2001). We judged the remaining trials as having an unclear risk of bias because the method of randomisation sequence generation was not reported (Fields 2008; Juthani-Mehta 2015; Kim 2014a; Kobayashi 2017i; Kobayashi 2017ii; Kobayashi 2017iii; Kobayashi 2017iv; Kobayashi 2017v; Kobayashi 2017vi; Kuo 2016), or we were unable to translate the full text (Lee 2011).

We judged allocation concealment as adequate in six trials ( $\mathrm{Ab}$ Malik 2017; Chipps 2014; Dai 2017; Frenkel 2001; Gosney 2006; SOCLE II); we judged the remaining 16 trials as unclear risk of bias as they did not report allocation concealment in sufficient detail (Ab Malik 2018; Fields 2008; Juthani-Mehta 2015; Kim 2014a; Kobayashi 2017i; Kobayashi 2017ii; Kobayashi 2017iii; Kobayashi 2017iv; Kobayashi 2017v; Kobayashi 2017vi; Kuo 2016; Lam 2013i; Lam 2013ii; Lam 2013iii; Lee 2011; Seguin 2014).

\section{Blinding}

Four trials reported blinding participants who were involved in the trial (Ab Malik 2017; Gosney 2006; Lee 2011; Seguin 2014); of these, three trials compared $\mathrm{OHC}$ intervention with a placebo (Gosney 2006; Lee 2011; Seguin 2014). We judged five trials as potentially high risk for blinding participants and personnel (Ab Malik 2018; Dai 2017; Fields 2008; Frenkel 2001; SOCLE II). There was insufficient information available to judge risk of bias in the remaining 13 trials (Chipps 2014; Juthani-Mehta 2015; Kim 2014a; Kobayashi 2017i; Kobayashi 2017ii; Kobayashi 2017iii; Kobayashi 2017iv; Kobayashi 2017v; Kobayashi 2017vi; Kuo 2016; Lam 2013i; Lam 2013ii; Lam 2013iii).

Interventions for improving oral health in people after stroke (Review)

Copyright (c) 2020 The Cochrane Collaboration. Published by John Wiley \& Sons, Ltd.
While it is frequently challenging to blind participants or clinicians because of the nature of the intervention, it is possible to blind the outcome assessor. However, only nine trials reported blinding the outcome assessors to group allocation (Ab Malik 2017; Ab Malik 2018; Chipps 2014; Dai 2017; Gosney 2006; Juthani-Mehta 2015; Lee 2011; Seguin 2014; SOCLE II). Blinding to outcome measures was unclear in 13 trials (Fields 2008; Frenkel 2001; Kim 2014a; Kobayashi 2017i; Kobayashi 2017ii; Kobayashi 2017iii; Kobayashi 2017iv; Kobayashi 2017v; Kobayashi 2017vi; Kuo 2016; Lam 2013i; Lam 2013ii; Lam 2013iii).

\section{Incomplete outcome data}

Thirteen trials reported dropout and withdrawals adequately (Chipps 2014; Dai 2017; Frenkel 2001; Juthani-Mehta 2015; Kobayashi 2017i; Kobayashi 2017ii; Kobayashi 2017iii; Kobayashi 2017iv; Kobayashi 2017v; Kobayashi 2017vi; Kuo 2016; Seguin 2014; SOCLE II). We judged eight trials at high risk of bias because of high attrition rates and a lack of explanation for dropouts (Ab Malik 2017; Ab Malik 2018; Fields 2008; Gosney 2006; Kim 2014a; Lam 2013i; Lam 2013ii; Lam 2013iii). We were unable to judge attrition bias in one trial because we were unable to obtain a translation (Lee 2011). Where available, we present details of dropouts in Table 6 .

Three trials used an intention-to-treat (ITT) analysis (Chipps 2014; Juthani-Mehta 2015; SOCLE II), and one trial conducted a partial ITT analysis (Frenkel 2001). One trial reported that they employed ITT analysis although not all participants were included in the final analysis (Ab Malik 2017). Sixteen trials did not use an ITT analysis (Ab Malik 2018; Dai 2017; Fields 2008; Gosney 2006; Kim 2014a; Kobayashi 2017i; Kobayashi 2017ii; Kobayashi 2017iii; Kobayashi 2017iv; Kobayashi 2017v; Kobayashi 2017vi; Kuo 2016; Lam 2013i; Lam 2013ii; Lam 2013iii; Seguin 2014). We were unable to judge whether ITT was employed in Lee 2011 because of a lack of translation.

\section{Selective reporting}

We considered nine trials at low risk of reporting bias (Ab Malik 2017; Ab Malik 2018; Chipps 2014; Dai 2017; Juthani-Mehta 2015; Kim 2014a; Kuo 2016; Seguin 2014; SOCLE II) (Figure 2; Figure 3). We judged eight trials at high risk (Fields 2008; Gosney 2006; Kobayashi 2017i; Kobayashi 2017ii; Kobayashi 2017iii; Kobayashi 2017iv; Kobayashi 2017v; Kobayashi 2017vi). We judged five trials as unclear because of insufficient detail (Frenkel 2001), due to a lack of translation (Lee 2011), or statistical information was presented in such a way that further clarification was required from the authors (Lam 2013i; Lam 2013ii; Lam 2013iii).

\section{Other potential sources of bias}

Baseline demographics were comparable and judged at low risk in 12 trials (Ab Malik 2018; Dai 2017; Frenkel 2001; Gosney 2006; Juthani-Mehta 2015; Kim 2014a; Kuo 2016; Lam 2013i; Lam 2013ii; Lam 2013iii; Seguin 2014; SOCLE II). We judged one trial at high risk as the intervention group had a higher baseline incidence of positive $S$ aureus cultures (Chipps 2014). The remaining trials did not present participants' baseline demographic details so we were unable to draw any conclusions about comparability in these trials 
(Ab Malik 2017; Fields 2008; Kobayashi 2017i; Kobayashi 2017ii; Kobayashi 2017iii; Kobayashi 2017iv; Kobayashi 2017v; Kobayashi $2017 v i)$. We were unable to obtain baseline demographics in Lee 2011 because of a lack of translation.

Sample size calculations were conducted a priori in 13 trials ( $A b$ Malik 2017; Ab Malik 2018; Chipps 2014; Dai 2017; Fields 2008; Frenkel 2001; Juthani-Mehta 2015; Kuo 2016; Lam 2013i; Lam 2013ii; Lam 2013iii; Seguin 2014; SOCLE II). As a pilot trial, SOCLE II described plans for sample size calculations based on the trial findings but described an a priori sample target for the patient and healthcare staff participant population within the pilot. Sample size calculations were not reported in the remaining nine comparisons (Gosney 2006; Kim 2014a; Kobayashi 2017i; Kobayashi 2017ii; Kobayashi 2017iii; Kobayashi 2017iv; Kobayashi 2017v; Kobayashi 2017vi; Lee 2011).

We judged several trials to have an unclear risk of bias due to limited data (Kobayashi 2017i; Kobayashi 2017ii; Kobayashi 2017iii; Kobayashi 2017iv; Kobayashi 2017v; Kobayashi 2017vi), or partial reporting of trial methodology (Ab Malik 2017; Kim 2014a; Seguin 2014). For example, Kim 2014a reported that complete randomisation was not performed through the entire process of the trial, but there is little information about what issues may have led to incomplete randomisation. We were unable to obtain a complete translation of one paper and were unable to judge whether there were other bias reported (Lee 2011).

Two trials were terminated early for futility (Fields 2008; JuthaniMehta 2015). The quality of the Fields 2008 trial was difficult to judge because there were very little information or summary data in the published report. In contrast, Juthani-Mehta 2015 was stopped as the conditional power under observed treatment difference was nearly zero.

\section{Effects of interventions}

See: Summary of findings 1 Oral health care interventions compared with usual care for people after stroke; Summary of findings 2 Oral health care intervention compared with placebo for people after stroke; Summary of findings 3 One oral healthcare intervention compared with another oral healthcare intervention for people after stroke

The results of this review are presented below within the three comparisons: $\mathrm{OHC}$ versus usual care or no treatment, $\mathrm{OHC}$ versus placebo, and $\mathrm{OHC}$ intervention versus another $\mathrm{OHC}$ intervention.

\section{Comparison 1: oral health care versus usual care}

See Summary of findings 1 .

Seven trials investigated the effectiveness of an $\mathrm{OHC}$ intervention compared with usual care (Ab Malik 2017; Fields 2008; Frenkel 2001; Juthani-Mehta 2015; Kim 2014a; Kuo 2016; SOCLE II).

\section{Primary outcomes}

\subsection{Dental plaque}

We present the data from two trials that reported dental plaque (Frenkel 2001; Kim 2014a). Multi-component OHC interventions showed no evidence of a difference in the mean score (DMS) for dental plaque at one month post-intervention (DMS $-0.66,95 \% \mathrm{Cl}$
-1.40 to $0.09 ; 2$ trials, 83 participants; $I^{2}=83 \% ; P=0.08$ : very lowquality evidence; Analysis 1.1).

Six months after the multi-component $\mathrm{OHC}$ intervention, dental plaque scores in Frenkel 2001 were similar for the residents in both groups of residential homes (DMS $-0.43,95 \% \mathrm{Cl}-0.98$ to 0.13 ; $\mathrm{P}=$ 0.13) (Analysis 1.2).

\subsection{Denture plaque}

Residents in the homes where staff had access to the multicomponent $\mathrm{OHC}$ intervention had less plaque on their dentures than those residents in homes that continued to provide usual care (DMS $-1.31,95 \% \mathrm{Cl}-1.96$ to $-0.66 ; 1$ trial, 38 participants; $\mathrm{P}$ $<0.0001$; low-quality evidence) (Frenkel 2001). This difference was still observed six months after the training intervention (DMS -1.57 , $95 \% \mathrm{Cl}-2.23$ to $-0.92 ; \mathrm{P}<0.00001$ ) (Frenkel 2001) (Analysis 1.3).

\section{Secondary outcomes}

\subsection{Presence of oral disease}

\subsubsection{Gingivitis}

There was no evidence of a difference in gingivitis among participants receiving the multi-component $\mathrm{OHC}$ protocol compared with usual care one month after the intervention (DMS $0.60,95 \% \mathrm{Cl}-1.66$ to $0.45 ; 2$ trials, 83 participants; $\mathrm{I}^{2}=93 \% ; \mathrm{P}=0.26$; very low-quality evidence) (Frenkel 2001; Kim 2014a) (Analysis 1.4).

Six months after training, there was no evidence of a significant difference in gingivitis between the intervention and usual care groups in the Frenkel 2001 trial (DMS $-0.25,95 \% \mathrm{Cl}-0.61$ to 0.10 ) (Analysis 1.5).

\subsubsection{Denture-induced stomatitis}

Residents' denture-induced stomatitis showed no evidence of a difference between the groups one or six months after the multicomponent OHC intervention (1 month: DMS $-0.33,95 \% \mathrm{Cl}-0.92$ to 0.26 ; 38 participants; 1 trial; $P=0.28$; low-quality evidence; 6 months: DMS $-0.10,95 \% \mathrm{Cl}-0.61$ to $0.40 ; 1$ trial; $\mathrm{P}=0.69$ ) (Frenkel 2001) (Analysis 1.6).

\subsection{Presence of related infection or oral opportunistic pathogens}

\subsubsection{Pneumonia}

There was no evidence of a difference in the incidence of pneumonia among participants in wards with access to a multicomponent $\mathrm{OHC}$ intervention (99 participants; 5 incidents of pneumonia) compared with those receiving usual care (105 participants; 1 incident of pneumonia) (OR 4.17, Cl 95\% 0.82 to 21.11; 1 trial; $P=0.08$; low-quality evidence) (SOCLE II) (Analysis $1.7)$.

\subsection{Stroke survivor and providers' knowledge of and attitudes to oral health care}

\subsubsection{Knowledge}

We pooled the data from three trials that targeted change in $\mathrm{OHC}$ knowledge among stroke survivors and OHC providers' including registered nurses (Ab Malik 2017), nursing home care assistants (Frenkel 2001), and family carers (Kuo 2016). One month after training, stroke survivors and $\mathrm{OHC}$ providers demonstrated higher knowledge scores than providers who had no access to training 
(SMD 0.70, 95\% Cl 0.06 to 1.35; 3 trials, 728 participants; 12 = 94\%; $P$ = 0.03; very low-quality evidence) (Analysis 1.8).

Trained family carers continued to demonstrate higher knowledge two months after training (MD 11.30, Cl 95\% 8.78 to 13.82; 1 trial, 94 participants; $\mathrm{P}<0.00001$ ) (Analysis 1.9), as did trained staff six months after training compared with usual care (SMD 0.34, 95\% Cl 0.18 to $0.50 ; 2$ trials, 596 participants; $12=7 \% ; \mathrm{P}<0.0001$ ) (Analysis 1.10).

\subsubsection{Attitude}

We pooled the data from three trials which targeted change in stroke survivor and providers' oral health attitudes. Trials rated staff attitudes (Ab Malik 2017; Frenkel 2001), and family carers attitudes (Kuo 2016), to OHC using a Likert scale. Pooled data one month after training showed evidence of a difference between stroke survivor and $\mathrm{OHC}$ providers who had received $\mathrm{OHC}$-specific training compared to those who received generic Internet-based professional development training (Ab Malik 2017), or delayed training (Frenkel 2001; Kuo 2016) (SMD 0.28, 95\% Cl 0.01 to $0.54 ; 3$ trials, 728 participants; $12=65 \% ; P=0.04$; very low-quality evidence) (Analysis 1.11).

Family carers' improved attitudes was not sustained two months after training (MD 2.00, Cl 95\% -0.12 to 4.12; 1 trial, 94 participants; $\mathrm{P}=0.06$ ) (Analysis 1.12). Similarly, there was no evidence of a difference six months after training in staff attitude (SMD 0.36, 95\% $\mathrm{Cl}-0.01$ to $0.74 ; 2$ trials, 596 participants; $\mathrm{L}=80 \%, \mathrm{P}=0.06$ ) (Ab Malik 2017; Frenkel 2001) (Analysis 1.13).

\section{Comparison 2: oral healthcare intervention versus placebo}

See Summary of findings 2 .

\section{Primary outcomes}

\subsection{Dental plaque}

None of the trials in this comparison group reported dental plaque.

\subsection{Denture plaque}

None of the trials in this comparison group reported denture plaque.

\section{Secondary outcomes}

\subsection{Presence of related infection or oral opportunistic pathogens}

\subsubsection{Pneumonia}

Two trials reported the incidence of pneumonia (Gosney 2006; Seguin 2014). Data from all 203 randomised participants were available from the Gosney 2006 trial, although full follow-up data were only available for 164 individuals. The trialists provided stroke-specific data (39 participants) from Seguin 2014 for the purposes of this review.

Decontamination gel reduced the incidence of pneumonia among the intervention group compared with participants receiving placebo gel (OR $0.20,95 \% \mathrm{Cl} 0.05$ to $0.84 ; 203$ participants; 1 trial; $P$ $=0.028$ ) (Gosney 2006). There was no difference in the incidence of pneumonia in participants treated with povidone-iodine compared with a placebo (OR $0.81,95 \% \mathrm{Cl} 0.18$ to $3.51 ; 39$ participants; 1 trial; $P=0.77$ ) (Seguin 2014). Pooling these data found no evidence of a difference in the incidence of pneumonia in participants receiving an $\mathrm{OHC}$ intervention compared with placebo (OR 0.39, $\mathrm{Cl} 95 \% 0.14$ to 1.09 ; 2 trials, 242 participants; $I^{2}=42 \% ; \mathrm{P}=0.07$; low-quality evidence) (Analysis 2.1).

\subsubsection{Aerobic Gram-negative bacilli}

\section{- 2.3.2.1 Acquired AGNB}

Two trials reported the incidence of acquired AGNB following admission with stroke (Gosney 2006; Seguin 2014). There was no evidence of a difference between participants who were using the $\mathrm{OHC}$ intervention and those in the placebo group (RR $0.56,95 \% \mathrm{Cl}$ 0.32 to $1.01 ; 2$ trials, 242 participants; $\left.\right|^{2}=0 \% ; P=0.05$ ) (Analysis 2.2 ).

\section{- 2.3.2.2 Carriage of AGNB}

There was no evidence of a difference between the groups in relation to carriage of AGNB (RR 0.91, CI 95\% 0.48 to 1.74) (Gosney 2006) (Analysis 2.3).

\subsection{Patient satisfaction}

\subsubsection{Patient-reported oral dryness}

One trial examined the effectiveness of Saengmaeg-san extract (11 participants) compared with placebo (10 participants) on xerostomia using a patient-reported questionnaire (Lee 2011). There was no evidence of a difference between groups after one week of treatment for: oral dryness (day and night) (MD $-0.13, \mathrm{Cl}$ $95 \%-1.81$ to $1.55 ; \mathrm{P}=0.88$ ); oral dryness (daytime only) (MD -0.64 , $\mathrm{Cl} 95 \%-2.43$ to $1.15 ; \mathrm{P}=0.48$ ); oral dryness while eating a meal (MD $0.66, \mathrm{Cl} 95 \%-1.61$ to $2.93 ; \mathrm{P}=0.57$ ) or while swallowing food (MD 0.62 , Cl 95\% -2.53 to 1.29; $\mathrm{P}=0.53$ ); lack of saliva (MD 1.12, Cl 95\% -0.28 to $2.52 ; \mathrm{P}=0.12$ ) or general discomfort (MD 0.45, $\mathrm{Cl} 95 \%-0.91$ to $1.81 ; \mathrm{P}=0.52$ ) (Analysis 2.4).

\section{Comparison 3: oral health care versus another oral health care intervention}

Twelve trials investigated the effectiveness of one enhanced multi-component $\mathrm{OHC}$ intervention compared with another $\mathrm{OHC}$ intervention (Ab Malik 2018; Chipps 2014; Dai 2017; Kobayashi 2017i; Kobayashi 2017ii; Kobayashi 2017iii; Kobayashi 2017iv; Kobayashi 2017v; Kobayashi 2017vi; Lam 2013i; Lam 2013ii; Lam 2013iii).

\section{See Summary of findings 3.}

\section{Primary outcomes}

\subsection{Dental plaque}

Five RCTs reported dental plaque index scores (Ab Malik 2018; Dai 2017; Lam 2013i; Lam 2013ii; Lam 2013iii); however, we were only able to extract dental plaque scores from one trial for inclusion in this comparison (Ab Malik 2018). There was no evidence of a difference in dental plaque between those participants who received an enhanced multi-component $\mathrm{OHC}$ intervention compared with conventional $\mathrm{OHC}$ group at three or six months (3 months: $\mathrm{MD}-0.04, \mathrm{Cl} 95 \%-0.33$ to $0.25 ; 1$ trial, 61 participants; $\mathrm{P}=$ 0.78 ; Analysis $3.1 ; 6$ months: MD -0.15 , Cl $95 \%-0.46$ to 0.16 ; 1 trial, 54 participants; $\mathrm{P}=0.34$; Analysis 3.2).

\subsection{Denture plaque}

None of the trials in this comparison group reported denture plaque. 


\section{Secondary outcomes}

\subsection{Presence of related infection or oral opportunistic pathogens}

\subsubsection{Aerobic Gram-negative bacilli}

Two trials reported the prevalence of AGNB at three months (Ab Malik 2018; Dai 2017). There was no evidence of a difference between participants who received the enhanced $\mathrm{OHC}$ intervention and those who received routine OHC (RR 1.00, Cl 95\% 0.71 to 1.42 ; 126 participants; $\mathrm{P}=1.00$ ) (Analysis 3.3).

Similarly, there was no evidence of a difference in the prevalence of AGNB at six months in one trial (RR 0.80, CI 95\% 0.47 to 1.38; 52 participants; $\mathrm{P}=0.42$ ) (Analysis 3.4).

\subsubsection{Candida}

One trial reported the prevalence of oral candida (Ab Malik 2018). There was no evidence of a difference in the total number of participants with oral candida among participants who received

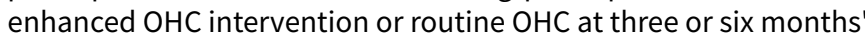
follow-up (3 months: RR 1.08, CI 95\% 0.61 to 1.89; 52 participants; $\mathrm{P}=0.80$; Analysis $3.5 ; 6$ months: RR $1.17, \mathrm{Cl} 95 \% 0.62$ to $2.20 ; 52$ participants; $\mathrm{P}=0.63$; Analysis 3.6).

\subsubsection{Staphylococcus aureus}

Two trials reported the prevalence of $S$ aureus in stroke survivors measured at day 10 (Chipps 2014), and at three months (Dai 2017). There was no evidence of a difference between the groups receiving enhanced $\mathrm{OHC}$ or routine $\mathrm{OHC}$ interventions (OR 1.29, $\mathrm{Cl}$ 95\% 0.57 to $2.91 ; 119$ participants; $\mathrm{P}=0.55$ ) (Analysis 3.7 ).

\section{Sensitivity analysis}

As such disparate trials were included in the review, we had no opportunity to conduct the sensitivity analyses planned at the protocol stage.

\section{DISCUSSION}

\section{Summary of main results}

In this third update of this review we included 15 trials (22 randomised comparisons, which we referred to as 22 trials) involving 3631 participants with data for 1546 people with stroke, 1028 healthcare providers and 94 informal carers that compared the effects of $\mathrm{OHC}$ interventions with usual care, placebo or another $\mathrm{OHC}$ intervention (see Summary of findings 1 ; Summary of findings 2; Summary of findings 3).

\section{Comparison 1: oral healthcare interventions versus usual care}

See Summary of findings 1 .

- No moderate or high-quality evidence for improving oral health in people after stroke.

- Low and very low-quality evidence showed that:

* OHC interventions could improve denture plaque one month after training which was maintained six months after the intervention was delivered;

* OHC interventions could improve stroke survivor and providers' knowledge one month after training. The

Interventions for improving oral health in people after stroke (Review)

Copyright (c) 2020 The Cochrane Collaboration. Published by John Wiley \& Sons, Ltd. improvement in knowledge was sustained six months after the intervention was delivered;

* OHC interventions could improve stroke survivor and providers' attitudes to $\mathrm{OHC}$ one month after training, but this improvement was not sustained longer term (greater than one month).

\section{Comparison 2: oral healthcare intervention versus placebo}

See Summary of findings 2 .

- No moderate- or high-grade evidence for improving oral health in people after stroke.

- Low-quality evidence showed showed no benefit or harm for $\mathrm{OHC}$ interventions compared with placebo on the incidence of pneumonia; however, people with stroke treated with gel for selective decontamination of the digestive tract had a lower incidence of pneumonia compared with placebo gel.

Comparison 3: one oral healthcare intervention versus another oral healthcare intervention

See Summary of findings 3.

- No moderate- or high-quality evidence for improving oral health in people after stroke.

- Low-quality evidence showed no benefit or harm for enhanced multi-component $\mathrm{OHC}$ interventions compared with other $\mathrm{OHC}$ interventions for dental plaque.

\section{Overall completeness and applicability of evidence}

Despite the inclusion of several new trials of $\mathrm{OHC}$ for people after stroke since our last review update (Brady 2006), there remains a lack of high-quality evidence to inform $\mathrm{OHC}$ in stroke care settings. Trials have evaluated three broad groups of $\mathrm{OHC}$ interventions: specialist $\mathrm{OHC}$ training compared to usual care (which was often no training), a specific $\mathrm{OHC}$ product compared to a placebo or enhanced multi-component $\mathrm{OHC}$ intervention compared to usual $\mathrm{OHC}$ interventions.

OHC interventions were shown to have a positive benefit on denture plaque at one month (Frenkel 2001), which was still evident at six months (Frenkel 2001). OHC interventions provided to healthcare staff had a positive impact on staff knowledge in two trials (Ab Malik 2017; Frenkel 2001), as did training for informal carers (i.e. family carers) who were caring for stroke survivors at home in a third trial (Kuo 2016). These benefits persisted two months (Kuo 2016), and six months in a residential care setting after the training (Frenkel 2001). Staff attitudes towards OHC showed no evidence of training benefit, but improved attitudes were evident among family carers attitudes after OHC training (Kuo 2016).

Our review identified one trial that evaluated the effectiveness of a highly specific OHC intervention across a wide stroke population, including participants who were unable to provide informed consent (but proxy consent was provided instead). There was evidence of a beneficial effect of the decontamination gel compared with placebo gel (Gosney 2006).

This was a highly complex review which incorporated many multicomponent interventions. Additional description of the specific participants included within each of the trials would be relevant, but we did not plan to profile participants based on their level 
of dependency for personal self-care, presence of dysphagia, cognitive status or the chronicity of the stroke.

A wide range of complex, multi-component $\mathrm{OHC}$ interventions were developed, delivered and evaluated compared to usual care or another OHC treatment, involving the provision of various combinations of training, toothbrush, toothpaste, mouth gel, mouthwash, tongue cleaners, lip balm, care protocols and assessment tools. Comparisons also involved differences in the quality of the equipment such as powered toothbrushes versus manual, or different types of lip balm.

However, there was limited overlap in the outcomes captured across these trials which included dental plaque, denture plaque, stomatitis, oral pharyngeal cultures, gingival bleeding, pneumonia, antibiotic use, dryness and quality of life. Carers' OHC knowledge and attitudes were measured as was the documentation of $\mathrm{OHC}$ assessments and care plans, specialist dental referrals and economic outcomes. Similarly, many trialists used questionnaires to capture outcome data that were not validated (Ab Malik 2017; Frenkel 2001; Kuo 2016; Lee 2011), or captured using different diagnostic criteria which for pneumonia was reported using clinical signs and symptoms (Gosney 2006), Mann chest criteria (SOCLE II), or reported as a radiographically documented event (JuthaniMehta 2015).

\section{Quality of the evidence}

It was often difficult to judge the quality of the evidence as a result of incomplete reporting. Randomisation was adequately reported in half of the trials, but allocation concealment was only clearly reported in six trials, and the remainder were judged as unclear. Blinding to avoid performance bias was possible and adequately reported in four trials with the majority of trials being judged as unclear or at high risk of bias. While it is not always possible to blind the participants or clinicians because of the nature of the intervention, it should be possible to blind the outcome assessor. While blinding outcome assessors is always desirable, it is not possible when it is a self-report measure, and the patients are not blinded. However, whether blinding outcome assessors to outcome measures was attempted was judged as low risk of bias in eight randomised trials.

Finally, we noted that over a third of the included trials were also judged as having a high risk of attrition bias and selective reporting. These judgments contributed to the downgrading of the quality of the evidence from high to moderate for all outcomes. We also downgraded the quality of evidence for all outcomes, other than staff knowledge, for imprecision as the results were often derived from a single trial. There were too few trials to assess inconsistency of results or publication bias. In summary, we judged the quality of the evidence synthesised within the meta-analyses to be low to very low quality, and this limits our confidence in the results.

\section{Potential biases in the review process}

We conducted a comprehensive search for high-quality trials that evaluated the effectiveness of $\mathrm{OHC}$ in people after stroke. We are confident we have identified most published trials of relevance to the review, but it is possible that despite our efforts, we may be unaware of additional unpublished work. Our search strategy and study selection criteria were agreed in advance and applied to all identified trials.
Our data extraction processes were completed independently and then compared. Whenever possible, we extracted all relevant data and sought missing data directly from the trialists for inclusion within the review. However, there remains a number of other relevant trials that could not be fully included. Of the trials eligible for inclusion in this review, eight were unable to provide stroke-specific data. Of these, five investigated $\mathrm{OHC}$ programme interventions (Hajizamani 2006; Mojon 1998; Quagliarello 2009; Redwood 2001; Schou 1989), two examined the use of medicated gum (Simons 1997; Simons 2002), and one a varnish (Brailsford 2002). Our searches also identified a further nine trials which may be eligible for inclusion in updates of this review, but it is unclear at this time whether stroke-specific data are available (Cabov 2010; IRCT2017012232101N1; IRCT2017091636194N1; Jin 2018; Marchini 2018; Mori 2012; NCT00610324; NCT03219346; Yakiwchuk 2013).

\section{Agreements and disagreements with other studies or reviews}

The maintenance of oral health after stroke should be a priority (in research and clinical settings) given the wide-reaching implications of poor oral health. One recent systematic review found that periodontal problems, dental caries and tooth loss were greater among stroke survivors than controls (Dai 2017). They were also less likely to seek specialist dental support after their stroke than non-stroke peers. We also have national-based audit data to support the premise that poor oral health may be closely linked to stroke survivors' ability to care for their own mouth and teeth, seek specialist support when required, and their stroke-related functional abilities and mobility (Kim 2018). Efforts continue to be made to improve the quality of $\mathrm{OHC}$ in stroke care settings and a range of possible approaches to enhance the provision of $\mathrm{OHC}$ after stroke were considered in this review. We continue to lack moderate- or high-quality evidence of whether high-quality $\mathrm{OHC}$ interventions reduce the number of people experiencing pneumonia after stroke (Lyons 2018).

\section{AUTHORS' CONCLUSIONS}

\section{Implications for practice}

There is a paucity of moderate- or high-quality evidence relating to oral care interventions for people after a stroke. What little evidence is available suggests that a specialist training session can improve healthcare staff's and family carers' knowledge of oral health care $(\mathrm{OHC})$, and this is maintained over time. It may also have a positive impact on family carers' attitudes towards OHC. Our review also found limited low-quality evidence to show a beneficial effect of training and multi-component $\mathrm{OHC}$ intervention on patient's oral health.

Good oral health is vital to an individual's ability to speak, eat, stay healthy and recover well after their stroke. Although we lack clear evidence of the optimal approach to providing $\mathrm{OHC}$ to people after stroke, it appears important that staff are supported (training in particular) to deliver such care. Our findings support the recommendations within several international clinical guidelines that oral care intervention of some type is better than nothing. Further clarity about the specific type, frequency and regimen of oral care that results in superior outcomes for people after stroke is still required. 


\section{Implications for research}

The evidence presented within this review indicates the potential benefits of specialist $\mathrm{OHC}$ on nursing staff and family members' knowledge and attitudes, and the benefits of decontamination gel on the incidence of pneumonia. Further trials are needed to identify the optimal approach to OHC after stroke. Some efforts need to be made to increase the co-ordination of research on this topic given the wide range of outcome measures and even wider range of measurement tools seen in this review. Consistent use of the recent consensus terminology and diagnostic criteria for pneumonia after stroke (Smith 2015), and consensus on core outcome set for trials of $\mathrm{OHC}$ interventions after stroke would greatly improve the strength of future meta-analyses on this topic. We welcome the recently funded work on a core outcome set relevant to this review (COMET Initiative; www.comet-initiative.org/studies/details/1081? result=true).

Inclusion of a clinically representative stroke population is important for the clinical relevance of future research. Of the trials included in this review, only four reported including people with incapacity or severe stroke impairments. We know that severity of stroke is linked to pneumonia incidence and that people who are most severely impaired are those who are also most reliant on others to support their OHC (Kim 2018). While recruitment of these subgroups of stroke survivors may be a challenge, it is important to capture a clinically relevant trial population so that we can develop and evaluate effective interventions that will benefit these subgroups in practice.

\section{ACK N O WLEDGEMENTS}

We thank the following people.

The trial authors for the time they took to respond to our queries and the provision of additional details whenever possible, particularly Frenkel and Seguin.

Hazel Fraser, Joshua Cheyne and colleagues from the Cochrane Stroke Group Editorial Team, and Anne Littlewood, Emma Tavender and Sylvia Bickley from the Cochrane Oral Care Group for their most valued assistance.

Cochrane Stroke Group editors and external reviewers, Peter Langhorne, Joanne Murray, Sandra Paget and Odie Geiger, for their comments on an earlier draft of this review.

Romana Hunter, Steff Lewis, and Vikki Milne for their invaluable input into earlier versions of this review.

The views expressed here are those of the review authors and not necessarily those of the Chief Scientist Office or the Scottish Government. 


\section{R E F E R E N C E S}

\section{References to studies included in this review}

\section{Ab Malik 2017 \{published data only\}}

Ab Malik N, Mohamad Yatim S, Abdul Razak F, Lam OL, Jin L, Li LS, et al. Effectiveness of a web-based health education program to promote oral hygiene care among stroke survivors: randomized controlled trial. Journal of Medical Internet Research 2017;19(3):e87.

\section{Ab Malik 2018 \{published data only\}}

Ab Malik N, Abdul Razak F, Jin L, Li LS, Mohamad Yatim S, McGrath C. Opportunistic oral pathogen among stroke survivors. Neurorehabilitation and Neural Repair 2018;32:317.

* Ab Malik N, Mohamad Yatim S, Abdul Razak F, Lam OL, Jin L, Li LS, et al. A multi-centre randomised clinical trial of oral hygiene interventions following stroke - a 6-month trial. Journal of Oral Rehabilitation 2018;45(2):132-9.

Ab Malik N, Mohamad Yatim S, Lam OL, Jin L, Li LS, McGrath C. Oral health interventions using chlorhexidine-effects on the prevalence of oral opportunistic pathogens in stroke survivors: a randomized clinical trial. Journal of Evidence Based Dental Practice 2018;18:99-109.

\section{Chipps 2014 \{published data only\}}

Chipps E, Gatens C, Genter L, Musto M, Dubis-Bohn A, Gliemmo M, et al. Pilot study of an oral care protocol on poststroke survivors. Rehabilitation Nursing 2014;39:294-304.

\section{Dai 2017 \{published data only\}}

* Dai R, Lam OL, Lo EC, Li LS, McGrath C. A randomised clinical trial of oral hygiene care programmes during stroke rehabilitation. Journal of Dentistry 2017;61:48-54.

Dai R, Lam OLT, Lo EC, Li LS, MCGrath C. Oral health-related quality of life in patients with stroke: a randomized clinical trial of oral hygiene care during outpatient rehabilitation. Scientific Reports 2017;7(1):7632.

Dai RL, Lam OL, Lo EC, Li LS, McGrath C. Effect of oral hygiene programmes on oral opportunistic pathogens during stroke rehabilitation. Oral Diseases 2019;25:617-33.

Fields 2008 \{published data only (unpublished sought but not used)\}

Fields LB. Oral care intervention to reduce incidence of ventilation-associated pneumonia in the neurologic intensive care unit. Journal of Neuroscience Nursing 2008;40(5):291-8.

\section{Frenkel 2001 \{published and unpublished data\}}

Frenkel H, Harvey I, Needs K. Oral health care education and its effect on caregivers' knowledge and attitudes: a randomised controlled trial. Community Dentistry and Oral Epidemiology 2002;30(2):91-100.

* Frenkel HF, Harvey I, Newcombe RG. Improving oral health of institutionalised elderly people by educating caregivers: a randomised controlled trial. Community Dentistry and Oral Epidemiology 2001;29:289-97.
Gosney 2006 \{published and unpublished data\}

Gosney M, Martin MV, Wright AE. The role of selective decontamination of the digestive tract in acute stroke. Age and Ageing 2006;35:42-7.

\section{Juthani-Mehta 2015 \{published data only\}}

Juthani-Mehta M, Van Ness PH, McGloin J, Argraves S, Chen S, Charpentier $\mathrm{P}$, et al. A cluster-randomized controlled trial of a multicomponent intervention protocol for pneumonia prevention among nursing home elders. Clinical Infectious Diseases 2015;60(6):849-57.

\section{Kim 2014a \{published data only\}}

* Kim E-K, Jang S-H, Choi Y-H, Lee K-S, Kim Y-J, Kim S-H, et al. Effect of an oral hygienic care program for stroke patients in the intensive care unit. Yonsei Medical Journal 2014;55(1):240-6.

Kim EK, Park EY, Sa Gong JW, Jang SH, Choi YH, Lee HK. Lasting effect of an oral hygiene care program for patients with stroke during in-hospital rehabilitation: a randomized single-center clinical trial. Disability and Rehabilitation 2017;39(22):2324-9.

\section{Kobayashi 2017i \{published data only\}}

Kobayashi K, Ryu M, Izumi S, Ueda T, Sakurai K. Effect of oral cleaning using mouthwash and a mouth moisturizing gel on bacterial number and moisture level of the tongue surface of older adults requiring nursing care. Geriatrics Gerontology International 2017;17(1):116-21.

\section{Kobayashi 2017ii \{published data only\}}

Kobayashi K, Ryu M, Izumi S, Ueda T, Sakurai K. Effect of oral cleaning using mouthwash and a mouth moisturizing gel on bacterial number and moisture level of the tongue surface of older adults requiring nursing care. Geriatrics Gerontology International 2017;17(1):116-21.

\section{Kobayashi 2017iii \{published data only\}}

Kobayashi K, Ryu M, Izumi S, Ueda T, Sakurai K. Effect of oral cleaning using mouthwash and a mouth moisturizing gel on bacterial number and moisture level of the tongue surface of older adults requiring nursing care. Geriatrics Gerontology International 2017;17(1):116-21.

\section{Kobayashi 2017iv \{published data only\}}

Kobayashi K, Ryu M, Izumi S, Ueda T, Sakurai K. Effect of oral cleaning using mouthwash and a mouth moisturizing gel on bacterial number and moisture level of the tongue surface of older adults requiring nursing care. Geriatrics Gerontology International 2017;17(1):116-21.

\section{Kobayashi 2017v \{published data only\}}

Kobayashi K, Ryu M, Izumi S, Ueda T, Sakurai K. Effect of oral cleaning using mouthwash and a mouth moisturizing gel on bacterial number and moisture level of the tongue surface of older adults requiring nursing care. Geriatrics Gerontology International 2017;17(1):116-21. 
Kobayashi 2017vi \{published data only\}

Kobayashi K, Ryu M, Izumi S, Ueda T, Sakurai K. Effect of oral cleaning using mouthwash and a mouth moisturizing gel on bacterial number and moisture level of the tongue surface of older adults requiring nursing care. Geriatrics Gerontology International 2017;17(1):116-21.

\section{Kuo 2016 \{published data only\}}

Kuo T-W, Yen M, Fetzer S, Chiang L-C, Shyu Y-IL, Lee T-H, et al. A home-based training programme improves family caregivers' oral care practices with stroke survivors: a randomized controlled trial. International Journal of Dental Hygiene 2016;14:82-91.

\section{Lam 2013i \{published data only\}}

Lam OL, McGrath C, Samaranyake L, Li LS. Evaluation of oral hygiene interventions in patients following acute stroke. 89th General Session of the International Association for Dental Research; 2011 Mar 16-19; San Diego (CA).

Lam OL, McMillan AS, Samaranayake LP, Li LS, McGrath C. Effect of oral hygiene interventions on opportunistic pathogens in patients after stroke. American Journal of Infection Control 2013;41:149-54.

* Lam OL, McMillan AS, Samaranayake LP, Li LS, McGrath C. Randomized clinical trial of oral health promotion interventions among patients following stroke. Archives of Physical Medicine and Rehabilitation 2013;94:435-43.

NCT01265043. A clinical trial on the effect of chlorhexidine mouth rinse and assisted tooth brushing on the health condition and quality of life of elderly stroke patients. clinicaltrials.gov/ct2/show/NCT01265043 (first received 22 December 2010).

\section{Lam 2013ii \{published data only\}}

Lam OL, McGrath C, Samaranyake L, Li LS. Evaluation of oral hygiene interventions in patients following acute stroke. 89th General Session of the International Association for Dental Research; 2011 Mar 16-19; San Diego (CA).

Lam OL, McMillan AS, Samaranayake LP, Li LS, McGrath C. Effect of oral hygiene interventions on opportunistic pathogens in patients after stroke. American Journal of Infection Control 2013;41:149-54.

* Lam OL, McMillan AS, Samaranayake LP, Li LS, McGrath C. Randomized clinical trial of oral health promotion interventions among patients following stroke. Archives of Physical Medicine and Rehabilitation 2013;94:435-43.

NCT01265043. A clinical trial on the effect of chlorhexidine mouth rinse and assisted tooth brushing on the health condition and quality of life of elderly stroke patients. clinicaltrials.gov/ct2/show/NCT01265043 (first received 22 December 2010).

\section{Lam 2013iii \{published data only\}}

Lam OL, McGrath C, Samaranyake L, Li LS. Evaluation of oral hygiene interventions in patients following acute stroke. 89th
General Session of the International Association for Dental Research; 2011 Mar 16-19; San Diego (CA).

Lam OL, McMillan AS, Samaranayake LP, Li LS, McGrath C. Effect of oral hygiene interventions on opportunistic pathogens in patients after stroke. American Journal of Infection Control 2013;41:149-54.

* Lam OL, McMillan AS, Samaranayake LP, Li LS, McGrath C. Randomized clinical trial of oral health promotion interventions among patients following stroke. Archives of Physical Medicine and Rehabilitation 2013;94:435-43.

NCT01265043. A clinical trial on the effect of chlorhexidine mouth rinse and assisted tooth brushing on the health condition and quality of life of elderly stroke patients. clinicaltrials.gov/ct2/show/NCT01265043 (first received 22 December 2010).

\section{Lee 2011 \{published data only\}}

Lee DH, Kang SY, Han HJ, Kim RH, Jang IS. Effect of Saengmaegsan extract on xerostomia in stroke patients: a double-blind randomised controlled study. Journal of Korean Oriental Internal Medicine 2011;32(4):542-9.

\section{Seguin 2014 \{published data only\}}

Laviolle B, Seguin P, Malledant Y, Bellissant E. Effect of orophayngeal povidone-iodine preventive oral care on ventilatorassociated pneumonia in severe brain injury or cerebral haemorrhage patients: a multicentre randomized controlled trial for the SPIRIT-ICU study and AtlanRea groups. Fundamental and Clinical Pharmacology 2013;27 Suppl 1:2.

* Seguin P, Laviolle B, Dahyot-Fizelier C, Dumont R, Veber B, Gergaud S, for the Study of Povidone lodine to Reduce Pulmonary Infection in HeadTrauma and Cerebral Hemorrhage Patients (SPIRIT) ICU Study and AtlanRéa Groups. Effect of oropharyngeal povidon-iodine preventive oral care on ventilator-associated pneumonia in severely brain-injured or cerebral hemorrhage patients: a multicenter, randomized controlled trial. Critical Care Medicine 2014;42(1):1-8.

\section{SOCLE II \{published data only\}}

Brady MC, Stott D, Chalmers C, Sweeney P, Weir CJ, Donaldson C, et al. A pilot stepped wedge, cluster randomised controlled trial (RCT) the effectiveness of an oral healthcare intervention compared to standard care in stroke wards (SOCLE II). European Stroke Journal 2018;3:3-586: AS13-024.

Brady MC, Stott D, Weir CJ, Chalmers C, Sweeney P, Donaldson C, et al. Clinical and cost effectiveness of enhanced oral healthcare in stroke care settings (SOCLE II): a pilot, stepped wedge, cluster randomized, controlled trial protocol. International Journal of Stroke 2015;10(6):979-84.

* Brady MC, Stott D, Weir CJ, Chalmers C, Sweeney P, Donaldson C. A pragmatic, multi-centred, stepped wedge, cluster randomised controlled trial pilot of the clinical and cost effectiveness of a complex Stroke Oral health Care intervention pLan compared to usual oral health care in stroke wards (SOCLE II). International Journal of Stroke 2020;15(3):318-23. 
Brady MC, Stott DJ, Norrie J, Chalmers C, St George B, Sweeney PM, et al. Developing and evaluating the implementation of a complex intervention: using mixed methods to inform the design of a randomised controlled trial of an oral healthcare intervention after stroke. Trials 2011;12:168.

\section{References to studies excluded from this review}

Boden-Albala 2016 \{published data only\}

Boden-Albala BR, Parikh N, Goldmann E, Southwick L, Carman H. Family/caregiver member opportunity for intervention. International Journal of Stroke 2016;11 Suppl 3:256-7.

\section{Brailsford 2002 \{published and unpublished data\}}

Brailsford SR, Fiske J, Gilbert S, Clark D, Beighton D. The effects of the combination of chlorhexidine/thymol- and fluoridecontaining varnishes on the severity of root caries lesions in frail institutionalised elderly people. Journal of Dentistry 2002;30:319-24.

\section{Duck-Won 2013 \{published data only\}}

Duck-Won OT, Sun-Ju K. Effect of stomatognathic alignment exercise on temporomandibular joint function and swallowing function of stroke patients with limited mouth opening. Journal of Physical Therapy Science 2013;25:1325-9.

Forster 2013 \{published data only\}

Forster AY, Patel A, Nixon J, Chapman K, Knapp M, Mellish K, et al. Cluster randomised trial evaluation of a patient and carer centred system of longer-term stroke care (the LoTS care trial). Cerebrovascular Diseases 2013;35:586.

Hägglund 2017 \{published data only\}

Hägglund P, Olai L, Ståhlnacke K, Persenius M, Hägg M, Andersson M, et al. Study protocol for the SOFIA project: Swallowing function, Oral health, and Food Intake in old Age: a descriptive study with a cluster randomized trial. BMC Geriatrics 2017:17:1-8.

\section{Hajizamani 2006 \{unpublished data only\}}

Craven R. Facilitating best practice in oral care for older adults in residential homes. National Research Register (accessed on 3 October 2005).

* Hajizamani A. Facilitating Best Practice in Oral Care for Older Adults in Residential Homes. Manchester, UK: University of Manchester, 2006.

Jones 2007 \{published data only (unpublished sought but not used)\}

* Jones JA, Miller DR, Wehler CJ, Rich S, Krall E, Christiansen CL, et al. Study design, recruitment and baseline characteristics: the Department of Veterans Affairs Dental Diabetes Study. Journal of Clinical Periodontology 2007;34:40-5.

Jones JA, Miller DR, Wehler CJ, Rich SE, Krall-Kay R, McCoy LC, et al. Does periodontal care improve glycemic control? The Department of Veterans Affairs Dental Diabetes Study. Journal of Clinical Periodontology 2007;34:46-52.
Kikutani 2006 \{published data only\}

Kikutani T, Enomoto ER, Tamura F, Oyaizu K, Suzuki A, Inaba S. Effects of oral functional training for nutritional improvement in Japanese older people requiring long-term care. Gerodontology 2006;23:93-8.

\section{Kim 2014b \{published data only\}}

Kim JH, Ahn HJ, Choi JH, Jung DW, Kwon JS. Effect of $0.1 \%$ pilocarpine mouthwash on xerostomia: double-blind, randomised controlled trial. Journal of Oral Rehabilitation 2014;41(3):226-35

\section{Lee 2017 \{published data only\}}

Lee YS, Yap XY, Chia AA, Wong SM. Oral health screening by speech and language pathologists (SLPS) using the oral health assessment tool (OHAT). Dysphagia 2017;32:799.

\section{Mojon 1998 \{published data only\}}

Budtz-Jørgensen E, Mojon P, Rentsch A, Deslauriers N. Effects of an oral health program on the occurrence of oral candidosis in a long-term care facility. Community Dentistry and Oral Epidemiology 2000;28:141-9.

* Mojon P, Rentsch A, Butz-Jørgensen E, Baehni PC. Effects of an oral health program on selected clinical parameters and salivary bacteria in a long-term care facility. European Journal of Oral Sciences 1998;106(4):827-34.

\section{Murray 2016 \{unpublished data only\}}

ACTRN12610000752066. Managing swallowing in stroke patients - free water versus thickened fluids. www.anzctr.org.au/Trial/Registration/TrialReview.aspx? ACTRN=12610000752066 (first received 9 August 2010).

* Murray J, Doeltgen S, Miller M, Scholten I. Does a water protocol improve the hydration and health status of individuals with thin liquid aspiration following stroke? A randomizedcontrolled trial. Dysphagia 2016;31(3):424-33.

Murray J, Scholten I. An oral hygiene protocol improves oral health for patients in inpatient stroke rehabilitation. Gerodontology 2018;35:18-24.

\section{NCT01777672 \{unpublished data only\}}

NCT01777672. Effect of afferent oropharyngeal pharmacological and electrical stimulation on swallow response and on activation of human cortex in stroke patients with oropharyngeal dysphagia. clinicaltrials.gov/show/NCT01777672 (first recieived 29 January 2013).

NCT02379182 \{unpublished data only\}

NCT02379182. Effect of Vitalstim in patients with chronic poststroke oropharyngeal dysphagia (VITAL). clinicaltrials.gov/ show/NCT02379182 (first received 4 March 2015).

\section{NCT02541032 \{unpublished data only\}}

NCT02541032. Periodontal treatment to eliminate minority inequality and rural disparities in stroke (PREMIERS). clinicaltrials.gov/show/NCT02541032 (first received 4 September 2015). 
Quagliarello 2009 \{published data only\}

Quagliarello V, Juthani-Mehta M, Ginter S, Towle V, Allore H, Tinetti M. Pilot testing of interventions protocols to prevent pneumonia in nursing home residents. Journal of the American Geriatrics Society 2009;57:1226-31.

\section{Redwood 2001 \{published data only\}}

Redwood S. Pilot study to explore the effect of daily oral hygiene procedures in nursing home residents. National Research Register Issue 32001.

\section{Schou 1989 \{published data only\}}

Schou L, Wight C, Clemson N, Douglas S, Clark C. Oral health promotion for institutionalised elderly. Community Dentistry and Oral Epidemiology 1989;17:2-6.

\section{Simons 1997 \{published data only\}}

Simons D, Kidd EA, Beighton D, Jones B. The effect of chlorhexidine/xylitol chewing gum on cariogenic salivary microflora: a clinical trial in elderly patients. Caries Research 1997;31:91-6.

\section{Simons 2002 \{published data only\}}

* Simons D, Brailsford SR, Kidd EA, Beighton D. The effect of medicated chewing gums on oral health in frail older people: a one-year clinical trial. Journal of the American Geriatrics Society 2002;50(8):1348-53.

Simons D, Kidd EA, Beighton D. Oral health of elderly occupants in residential homes. Lancet 1999;353:1761.

\section{References to studies awaiting assessment}

\section{Cabov 2010 \{published data only\}}

Cabov T, Macan D, Husedzinovic I, Skrlin-Subic J, Bosnjak D, Sestan-Crnek S, et al. The impact of oral health and $0.2 \%$ chlorhexidine oral gel on the prevalence of nosocomial infections in surgical intensive-care patients: a randomized placebo-controlled study. Wiener Klinische Wochenschrift 2010;122(13-14):397-404

\section{IRCT2017012232101N1 \{published data only\}}

IRCT2017012232101N1. Comparing the effect of Ortodentol and chlorhexidine mouthwashes $10 \%$ and $/ 12$ percent on oral hygiene intubated patients in intensive care units. en.irct.ir/ trial/25092 (first received 2 April 2017).

\section{IRCT2017091636194N1 \{published data only\}}

IRCT2017091636194N1. The comparison of the impact of Nanosil and Chlorhexidine mouthwashes in an oral decontamination plan on the occurrence of ventilator associated pneumonia in hospitalised patients in the intensive care unit. en.irct.ir/trial/27125 (first received 7 October 2017).

\section{Jin 2018 \{published data only\}}

Jin J, Bao Y, Jiang Y. Application of ageratum-liquid combined with gynecologic long cotton swab in oral nursing of stroke patients with halitosis. Chinese Nursing Research 2018;6:955-7.

\section{Marchini 2018 \{published data only\}}

Marchini L, Recker E, Hartshorn J, Coewn H, Lynch D, Drake D, et al. lowa nursing facility oral hygiene (INFOH) intervention: a clinical and microbiological pilot randomized trial. IADR GORG, ECG, JSG Satellite Symposium; 2018 Jul 24; London (UK).

* Marchini L, Recker E, Hartshorn J, Cowen H, Lynch D, Drake D, et al. lowa nursing facility oral hygiene (INFOH) intervention: a clinical and microbiological pilot randomized trial. Special Care in Dentistry 2018;38(6):345-55.

NCT02668809. Oral hygiene intervention pilot study. clinicaltrials.gov/ct2/show/NCT02668809 (first received 29 January 2016).

\section{Mori 2012 \{published data only\}}

Mori C, Hakuta C, Endo K, Nariaia T, Ueno M, Shinada K, et al. The effects of professional oral health care on patients in the subacute stage of emergent neurosurgical disorders. Special Care in Dentistry 2012;32(6):259-64.

\section{NCT00610324 \{published data only\}}

NCT00610324. Effect of oral decontamination using chlorhexidine or potassium permanganate in ICU patients. clinicaltrials.gov/ct2/show/record/NCT00610324 (first received 7 February 2008)

\section{NCT03219346 \{unpublished data only\}}

NCT03219346. The effectiveness of oral health in improving dysphagia of patients after stroke of swallowing function and oral health quality of life. clinicaltrials.gov/show/NCT03219346 (first received 17 July 2017).

\section{Yakiwchuk 2013 \{published data only\}}

Yakiwchuk C-A, Bertone M, Ghlabi E, Brown S, Llarakos M, Brothwell DJ. Suction toothbrush use for dependent adults with dysphagia: a pilot examiner blind randomized clinical trial. Canadian Journal of Dental Hygiene 2013;47(1):15-23.

\section{References to ongoing studies}

ChiCTR-IPR-17013403 \{published and unpublished data\}

ChiCTR-IPR-17013403. Effect of oral care on the incidence of pneumonia in acute stroke patients with different degrees of dysphagia. www.chictr.org.cn/showproj.aspx?proj=22474 (first received 15 November 2017)

\section{Hollaar 2015 \{published data only\}}

* Hollaar V, van der Maarel-Wierink C, van der Putten GJ, de Swart B, de Baat C. Effect of daily application of a $0.05 \%$ chlorhexidine solution on the incidence of (aspiration) pneumonia in care home residents: design of a multicentre cluster randomised controlled clinical trial. BMJ 2015;5(12):e007889.

NL3367. The effect of chlorhexidine on the incidence of aspiration pneumonia in care home residents: design of a double-blind cluster randomized placebo-controlled trial. www.trialregister.nl/trial/3367 (first received 9 July 2012). 
MAPS-2 \{published data only\}

ISRCTN14124645. Metoclopramide and selective oral decontamination for avoiding pneumonia after stroke. www.isrctn.com/ISRCTN14124645 (first received 10 October 2016).

* Roffe C, Warusevitane A, Smith C, Gosney M, Knox E, Buttery A, et al. The Metoclopramide and selective oral decontamination for Avoiding Pneumonia after Stroke (MAPS-2) trial: a $2 \times 2$ double-blind, randomized controlled trial of metoclopramide and selective oral decontamination for the prevention of pneumonia in patients with dysphagia after an acute stroke. 12th UK Stroke Forum Conference; 2017 Nov 28-30; Liverpool (UK).

Roffe C. The Metoclopramide and selective oral decontamination for Avoiding Pneumonia after Stroke trial: a $2 \times 2$ double-blind, randomized controlled trial of metoclopramide and selective oral decontamination for the prevention of pneumonia in patients with dysphagia after an acute stroke. www.keele.ac.uk/maps2/ (accessed prior to 30 September 2020).

\section{Additional references}

\section{Adamson 2004}

Adamson J, Beswick A, Ebrahim S. Is stroke the most common cause of disability? Journal of Stroke and Cerebrovascular Diseases 2004;13:171-7.

\section{Ainamo 1975}

Ainamo J, Bay I. Problems and proposals for recording gingivitis and plaque. International Dental Journal 1975;25(4):229-35.

\section{Al-Omiri 2006}

Al-Omiri MK, Al-Wahadni AM, Saeed KN. Oral health attitudes, knowledge and behaviour among school children in North Jordan. Journal of Dental Education 2006;70(2):179-87.

\section{American Thoracic Society 2005}

American Thoracic Society. Infectious Diseases Society of America: guidelines for the management of adults with hospital-acquired, ventilator-associated, and healthcareassociated pneumonia. American Journal of Respiratory and Critical Care Medicine 2005;171:388-416.

\section{Augsburger 1982}

Augsburger RH, Elahi JM. Evaluation of seven proprietary denture cleansers. Journal of Prosthetic Dentistry 1982;47:356-9.

\section{Bailey 2004}

Bailey RL, Ledikwe JH, Smiciklas-Wright $\mathrm{H}$, Mitchell DC, Jensen GL. Persistent oral health problems associated with comorbidity and impaired diet quality in older adults. Journal of the American Dietetic Association 2004;104:1273-6.

\section{Bellomo 2005}

Bellomo F, De Preux F, Chung J-P, Julien N, Budtz-Jørgensen E, Müller $F$. The advantages of occupational therapy in oral hygiene measures for institutionalised elderly adults. Gerodontology 2005;22(1):24-31.

\section{Brady 2011}

Brady MC, Stott DJ, Norrie J, Chalmers C, St George B, Sweeney PM, et al. Developing and evaluating the implementation of a complex intervention: using mixed methods to inform the design of a randomised controlled trial of an oral healthcare intervention after stroke. Trials 2011;12:168.

\section{Budtz-Jorgensen 1978}

Budtz-Jorgensen E. Clinical aspects of Candida infection in denture wearers. Journal of American Dental Association 1978;96:474-9.

\section{Chan 2007}

Chan EY, Ruest A, Meade MO, Cook DJ. Oral decontamination for prevention of pneumonia in mechanically ventilated adults: systematic review and meta-analysis. BMJ 2007;334:889.

\section{Chumbler 2010}

Chumbler NR, Williams LS, Wells CK, Lo AC, Nadeau S, Peixoto AJ, et al. Derivation and validation of a clinical system for predicting pneumonia in acute stroke. Neuroepidemiology 2010;34(4):193-9.

\section{Dai 2015}

Dai R, Lam OL, Lo RE, Li LS, Wen Y, McGrath C. A systematic review and meta-analysis of clinical, microbiological, and behavioural aspects of oral health among patients with stroke. Journal of Dentistry 2015;43(2):171-80.

\section{Francis 2004}

Francis JJ, Eccles MP, Johnston M, Walker A, Grimshaw J, Foy R, et al. Constructing questionnaires based on the theory of planned behaviour: a manual for health services researchers. openaccess.city.ac.uk/id/eprint/17352004.

\section{Geeganage 2012}

Geeganage C, Beavan J, Ellender S, Bath PM. Interventions for dysphagia and nutritional support in acute and subacute stroke. Cochrane Database of Systematic Reviews 2012, Issue 10. Art. No: CD000323. [DOI: 10.1002/14651858.CD000323.pub2]

\section{Greene 1964}

Greene JC, Vermillion JR. The simplified oral hygiene index. Journal of the American Dental Association 1964;68:25-31.

\section{Guyatt 2008}

Guyatt GH, Oxman AD, Vist G, Kunz R, Falck-Ytter Y, AlonsoCoello $P$, et al. GRADE Working Group. Rating quality of evidence and strength of recommendations GRADE: an emerging consensus on rating quality of evidence and strength of recommendations. BMJ 2008;336(7650):924-6.

\section{Guyatt 2011a}

Guyatt GH, Oxman AD, Schünemann HJ, Tugwell P, Knotterus A. GRADE guidelines: a new series of articles in the Journal of Clinical Epidemiology. Journal of Clinical Epidemiology 2011;64(4):380-2. 


\section{Guyatt 2011b}

Guyatt GH, Oxman AD, Vist G, Kunz R, Brozek J, Alonso-Coello P, et al. GRADE guidelines: 4. rating the quality of evidence - risk of bias. Journal of Clinical Epidemiology 2011;64(4):407-15.

\section{Guyatt 2011c}

Guyatt GH, Oxman AD, Montori V, Vist G, Kunz R, Brozek J, et al. GRADE guidelines: 5 . rating the quality of evidence - publication bias. Journal of Clinical Epidemiology 2011;64(12):1277-82.

\section{Guyatt 2011d}

Guyatt G, Oxman AD, Kunz R, Brozek J, Alonso-Coello P, Rind D, et al. GRADE guidelines: 6 . Rating the quality of evidence imprecision. Journal of Clinical Epidemiology 2011;12:1283-93.

\section{Guyatt 2011e}

Guyatt GH, Oxman AD, Kunz R, Woodcock J, Brozek J, Helfand M, et al. The GRADE Working Group. GRADE guidelines: 7. Rating the quality of evidence - inconsistency. Journal of Clinical Epidemiology 2011;64(12):1294-302.

\section{Guyatt $2011 f$}

Guyatt GH, Oxman AD, Kunz R, Woodcock J, Brozek J, Helfand $M$, et al. The GRADE Working Group. GRADE guidelines: 8. Rating the quality of evidence - indirectness. Journal of Clinical Epidemiology 2011;64(12):1294-302.

\section{Hannawi 2013}

Hannawi Y, Hannawi B, Rao CP, Suarez JI, Bershad EM. Strokeassociated pneumonia: major advances and obstacles. Cerebrovascular Diseases 2013;35(5):430-43.

\section{Higgins 2019}

Higgins JP, Thomas J, Chandler J, Cumpston M, Li T, Page MJ, Welch VA, editor(s). Cochrane Handbook for Systematic Reviews of Interventions version 6.0 (updated July 2019). Cochrane, 2019. Available from www.training.cochrane.org/handbook.

\section{Hilker 2003}

Hilker R, Poetter C, Findeisen N, Sobesky J, Jacobs A, Neveling M, et al. Nosocomial pneumonia after acute stroke implications for neurological intensive care medicine. Stroke 2003;34:975-81.

\section{Hoffmann 2014}

Hoffmann TC, Glasziou PP, Boutron I, Milne R, Perera R, Moher D, et al. Better reporting of interventions: template for intervention description and replication (TIDieR) checklist and guide. BMJ 2014;348:1-12.

\section{Horne 2015}

Horne M, McCracken G, Walls A, Tyrrell PJ, Smith CJ. Organisation, practice and experiences of mouth hygiene in stroke unit care: a mixed methods study. Journal of Clinical Nursing 2015;24(5-6):728-38.

\section{Ingeman 2011}

Ingeman A, Andersen G, Hundborg HH, Svendsenand ML, Johnsen SP. Processes of care and medical complications in patients with stroke. Stroke 2011;42:167-72.

\section{Katzan 2003}

Katzan IL, Cebul RD, Husak SH, Dawson NV, Baker DW. The effect of pneumonia on mortality among patients hospitalized for acute stroke. Neurology 2003;60(4):620-5.

\section{Kim 2018}

Kim HT, Park JB, Lee WC, Kim YJ, Lee Y. Differences in the oral health status and oral hygiene practices according to the extent of post-stroke sequelae. Journal of Oral Rehabilitation 2018;45:476-84.

\section{Kishore 2018}

Kishore AK, Vail A, Jeans AR, Chamorro A, Napoli MD, Kalra L, Pneumonia in Stroke Consensus (PISCES) Group. Microbiological etiologies of pneumonia complicating stroke. Stroke 2018;49(6):1-10.

\section{Langhorne 2000}

Langhorne P, Stott DJ, Robertson L, MacDonald J, Jones L, McAlpine C, et al. Medical complications after stroke: a multicentre study. Stroke 2000;31:1223-9.

\section{Lefebvre 2011}

Lefebvre C, Manheimer E, Glanville J. Chapter 6: Searching for studies. In: Higgins JP, Green S, editor(s). Cochrane Handbook for Systematic Reviews of Interventions Version 5.1.0 (updated March 2011). The Cochrane Collaboration, 2011. Available from handbook.cochrane.org.

\section{Loe 1967}

Loe H. The Gingival Index, the Plaque Index and the Retention Index systems. Journal of Periodontal Research 1967;38:610-6.

\section{Lyons 2018}

Lyons M, Smith C, Boaden E, Brady MC, Brocklehurst P, Dickinson $\mathrm{H}$, et al. Oral care after stroke: where are we now? European Journal of Stroke 2018;0(0):1-8.

\section{Mann 1999}

Mann G, Hankey GJ, Cameron D. Swallowing function after stroke: prognosis and prognostic factors at 6 months. Stroke 1999;30:744-8.

\section{Michishige 1999}

Michishige F, Yoshinaga S, Harada E, Hirota K, Mlyake Y, Matsuo T, et al. Relationships between activity of daily living, and oral cavity care and the number of oral cavity microorganisms in patients with cerebrovascular diseases. Journal of Medical Investigation 1999;46:79-85.

\section{Nakazora 2017}

Nakazora T, Maeda J, Iwamoto K, Hanashiro S, Nakamura Y, Kiyozuka T, et al. Intervention by speech therapists to promote oral intake of patients with acute stroke: a retrospective cohort study. Journal of Stroke and Cerebrovascular Diseases 2017;26(3):480-7.

\section{Peres 2019}

Peres MA, Macpherson LM, Weyant RJ, Daly B, Venturelli R, Mathur MR, et al. Oral diseases: a global public health challenge. Lancet 2019;394(10194):249-60. 


\section{RCP 2016}

RCP. Royal college of Physicians (RCP) stroke guidelines: national clinical guidelines for stroke. www.rcplondon.ac.uk/ guidelines-policy/stroke-guidelines (accessed prior to 30 September 2020).

\section{Review Manager 2014 [Computer program]}

Nordic Cochrane Centre, The Cochrane Collaboration Review Manager 5 (RevMan 5). Version 5.3. Copenhagen: Nordic Cochrane Centre, The Cochrane Collaboration, 2014.

\section{Silness 1964}

Silness J, Loe H. Periodontal disease in pregnancy II. Correlation between oral hygiene and periodontal condition. Acta Odontologica Scandinavica 1964;22:131-5.

\section{Sjögren 2008}

Sjögren P, Nilsson E, Forsell M, Johansson O, Hoogstraate J. A systematic review of the preventive effect of oral hygiene on pneumonia and respiratory tract infection in elderly people in hospitals and nursing homes: effect estimates and methodological quality of randomized controlled trials. Journal of the American Geriatrics Society 2008;56:2124-30.

\section{Smith 2015}

Smith CJ, Kishore AK, Vail A, Chamorro A, Garau J, Hopkins SJ, et al. Diagnosis of stroke-associated pneumonia: recommendations from the Pneumonia in Stroke Consensus Group. Stroke 2015;46(8):2335-40.

\section{Suomi 1968}

Suomi JD, Barbano JP. Patterns of gingivitis. Journal of Periodontology 1968;39:71-4.

\section{Talbot 2005}

Talbot A, Brady M, Furlanetto DL, Frenkel H, Williams BO. The challenge of providing oral care in stroke care settings across Scotland. Gerodontology 2005;22(2):77-83.

\section{CHARACTERISTICS OF STUDIES}

Characteristics of included studies [ordered by study ID]

\section{Wagner 2016}

Wagner C, Marchina S, Deveau JA, Frayne C, Sulmonte K, Kumar S. Risk of stroke-associated pneumonia and oral hygiene. Cerebrovascular Diseases 2016;41:35-9.

\section{Watt 2019}

Watt RG, Daly B, Allison A, Macpherson LM, Venturelli R, Listl S, et al. Ending the neglect of global oral health: time for radical action. Lancet 2019;394(10194):261-72.

\section{Weir 2018}

Weir CJ, Butcher I, Assi V, Lewis SC, Murray GD, Langhorne P, et al. Dealing with missing standard deviation and mean values in meta-analysis of continuous outcomes: a systematic review. BMC Medical Research Methodology 2018;18(25):1-14.

\section{Yuan 2015}

Yuan A, Woo SB. Adverse drug events in the oral cavity. Oral Surgery, Oral Medicine, Oral Pathology and Oral Radiology 2015;119(1):35-47.

\section{Zhu 2008}

Zhu HW, McMillan AS, McGrath C, Li LS, Samaranayake LP. Oral carriage of yeasts and coliforms in stroke sufferers: a prospective longitudinal study. Oral Diseases 2008;14:60-6.

\section{References to other published versions of this review Brady 2006}

Brady M, Furlanetto D, Hunter R, Lewis SC, Milne V. Staff-led interventions for improving oral hygiene in patients following stroke. Cochrane Database of Systematic Reviews 2006, Issue 4. Art. No: CD003864. [DOI: 10.1002/14651858.CD003864.pub2]

* Indicates the major publication for the study

Ab Malik 2017

\section{Study characteristics}

Methods Cluster RCT randomised at hospital level, Malaysia

Study recruitment and setting details: see Table 1

Participants

Inclusion criteria: all registered nurses caring for people with stroke were invited to take part; informed written consent

Exclusion criteria: not reported

OHC training group: 277 registered nurses

General stroke care training group: 270 registered nurses

Details of participants are shown in Table 2 
Ab Malik 2017 (Continued)

Interventions

\section{OHC training}

- Intervention: Internet-based continuing professional development programme

- Materials: secure internet portal, computer

- Agent: none

- Procedures: online training programme was specific to provision of oral hygiene care in stroke patients. Programme covered oral health knowledge, attitudes, subjective norms, means of behavioural control and intention. Contents included information on good oral condition and importance of having good oral health, consequences of poor oral hygiene and importance of nurses' roles and care of people with stroke. Provided by: stroke physicians (rehabilitation medicine) and dentists, and followed good practices of computer-aided learning for oral health. Development of contents was guided by the definition of the theory of planned behaviour domains and scope of the study.

- Training: as described above

- Delivery: online; 1-to-1

- Location: unclear

- Regimen: participants were reminded and encouraged to complete the Internet-based continuing professional development programme every 6 weeks; no details about length of programme

- Tailoring: not reported

- Modification: not reported

- Adherence: not reported

\section{General stroke care training}

- Intervention: Internet-based generic continuing professional development programme not specific to $\mathrm{OHC}$

- Materials: secure internet portal, computer

- Procedures: programme related to 'bundles of care' for people with stroke that included some details on oral hygiene care but not specific to theory of planned behaviour.

- Provided by: stroke physicians and physicians

- Training: as described above

- Delivery: online; 1-to-1

- Location: unclear

- Regimen: participants were reminded and encouraged to complete the Internet-based continuing professional development programme every 6 weeks; no details about length of programme

- Tailoring: not reported

- Modification: not reported

- Adherence: not reported

Outcomes

Outcomes: questionnaire on practice of providing oral hygiene care to people with stroke (contained 12 items specific to attitudes, subjective norm, perceived behaviour control and general intention to providing oral hygiene care related to Theory of Planned Behaviour), knowledge of $\mathrm{OHC}$ (assessed using 5 items related to dental plaque, gum bleeding, consequences of dental plaque, how to prevent gingivitis and how oral health affects general health)

Data collection: baseline, 1 and 6 months postintervention

Funding Authors declared no conflicts of interest. Study funded by The University of Hong Kong

Notes Dropouts are detailed in Table 6

Statistical data included within the review meta-analyses

\section{Risk of bias}


Ab Malik 2017 (Continued)

Random sequence genera- Low risk tion (selection bias)
Quote: "Hospitals were first stratified by size into either large, medium, or small in terms of number of health care providers. From each stratified group, hospitals were block-randomized in groups of 4 ('ABBA') by a computer-generated randomization method."

\begin{tabular}{ll}
\hline $\begin{array}{l}\text { Allocation concealment } \\
\text { (selection bias) }\end{array}$ & Quote: "5 hospitals were assigned to the test group (277 registered nurses) and \\
& 5 hospitals were assigned to the control group ( 270 registered nurses). The al- \\
& $\begin{array}{l}\text { location sequence was concealed from the investigator coordinating the trial } \\
\text { (who had contact with the centers)." }\end{array}$
\end{tabular}

$\begin{array}{ll}\begin{array}{l}\text { Blinding of participants } \\ \text { and personnel (perfor- }\end{array} & \text { Low risk }\end{array} \quad \begin{aligned} & \text { Quote: "Participants were also blind as to what groups they were assigned to, } \\ & \text { as both received a form of Web-based CPD." }\end{aligned}$
as both received a form of Web-based CPD."

mance bias)

All outcomes

\begin{tabular}{|c|c|c|}
\hline $\begin{array}{l}\text { Blinding of outcome as- } \\
\text { sessment (detection bias) } \\
\text { All outcomes }\end{array}$ & Low risk & $\begin{array}{l}\text { Quote: "the assessor was 'blind' as to what group participants had been as- } \\
\text { signed." }\end{array}$ \\
\hline
\end{tabular}

Incomplete outcome data High risk
(attrition bias)

All outcomes

Comment; high attrition rate (82/277 in $\mathrm{OHC}$ training group and $92 / 270$ in general stroke care training group). Total dropouts accounted for (quote: "loss to follow-up was because nurses were transferred to other wards or hospitals"). However, dropouts were only reported in CONSORT diagram as loss to follow-up, so unclear when participants dropped out (month 1 or 6). Study authors reported that ITT analysis employed but not all participants appeared to be included in the final analyses.

Selective reporting (re- Low risk $\quad$ Comment: all prespecified outcomes reported.
porting bias)
porting bias)

Baseline data compara- Unclear risk
ble?

Comment: insufficient information. Unable to compare baseline demographics for healthcare provider and environmental characteristics as data were combined.

Quote: "no significant difference between the response rate among those in the test and control groups."

\begin{tabular}{ll}
\hline A priori power calculation Low risk & Comment: yes \\
& Quote: "With the assumption that this practice is at $50 \%$ and that it will not \\
change without education intervention, whereas there will be a $25 \%$ improve- & ment in practices following CAL intervention (i.e. $63 \%$ of nurses will practice \\
oral care in rehabilitation). Then a proposed sample size of 247 in each group \\
is required with sample power at $80 \%$. Allowing for nonparticipation and a \\
dropout rate of $~ 20 \%$, thus it was prudent to attempt to recruit over 600 nurses \\
(300 per group) in total to test the hypothesis."
\end{tabular}

Other bias Unclear risk

Comment: limited information supplied about how long each group were exposed to the intervention (i.e. how frequently they used the programme and total duration).

\section{Ab Malik 2018}

\section{Study characteristics}

Methods Parallel RCT randomised at individual level, Malaysia


Ab Malik 2018 (Continued)

Study recruitment and setting details: see Table 1

Participants

Inclusion criteria: hospitalised people with stroke managed by a stroke rehabilitation team $(\mathrm{mBI}<70)$, able to follow instructions, medically stable, not receiving antibiotics or antimicrobial agents and were not edentulous

Exclusion criteria: not reported

Intense method group: 38 participants

Conventional method group: 48 participants

Details of participants are shown in Table 2

\section{Multi-component OHC intervention}

- Intervention: intense method for plaque control

- Materials: powered tooth-brush (Oral B Pro-Health DB4010), gel (Hexigel chlorhexidine gluconate gel)

- Agent: $1 \%$ chlorhexidine gel (Hexigel chlorhexidine gluconate gel)

- Procedures: daily tooth brushing with powered toothbrush and gel. Individual oral hygiene instruction given by dental assistant, using a plastic tooth model and a pamphlet on tooth brushing techniques

- Provided by: dental assistant

- Training: not reported

- Delivery: face-to-face, 1:1, ward

- Regimen: "daily"; no other details reported

- Tailoring: not reported

- Modification: not reported

- Adherence: not reported

\section{Multi-component OHC intervention}

- Intervention: conventional method for plaque control

- Materials: manual Oral-B-super thin and extra soft bristles toothbrush, standard commercial toothpaste (Colgate Maximum Cavity Protection)

- Procedures: daily manual tooth brushing. Individual oral hygiene instruction given by dental assistant, using a plastic tooth model and a pamphlet on tooth brushing techniques

- Provided by: dental assistant

- Training: not reported

- Delivery: face-to-face, 1:1, ward

- Regimen: "daily"; no other details reported

- Tailoring: not reported

- Modification: not reported

- Adherence: not reported
Primary outcomes: Dental Plaque Index assessed using Silness and Loe Plaque Index (Silness 1964)

Secondary outcomes: presence and type of dental prosthesis, $\mathrm{mBI}$

Data collection: baseline, 3 and 6 months postintervention

Funding Study authors declared no conflicts of interest. Study funded by The University of Hong Kong

Notes $\quad$ Dropouts are detailed in Table 6

Statistical data included within the review meta-analyses

\section{Risk of bias}


Ab Malik 2018 (Continued)

\section{Bias Authors' judgement Support for judgement}

Random sequence genera- Low risk tion (selection bias)

Comment: participants were block randomised into 2 groups, in a group size of 2 (ABBA)

Quote: "Computer-generated randomisation sequences were used for the random allocation of the patients, and this was performed by the head of the research team."

Allocation concealment $\quad$ Unclear risk $\quad$ Comment: insufficient information
(selection bias)

\begin{tabular}{|c|c|c|}
\hline $\begin{array}{l}\text { Blinding of participants } \\
\text { and personnel (perfor- } \\
\text { mance bias) } \\
\text { All outcomes }\end{array}$ & High risk & $\begin{array}{l}\text { Comment: reported as a "single-blinded study." Oral hygiene kits were pre- } \\
\text { pared by a dental assistant who was not involved in oral health assessments } \\
\text { and sample collections. Each oral hygiene kit was placed in the same type of } \\
\text { packaging, colour coded and was not transparent. However, participants must } \\
\text { have been aware of difference in toothbrushes (manual vs powered), and the } \\
\text { application of gel (or not). }\end{array}$ \\
\hline
\end{tabular}

\begin{tabular}{lll}
\hline $\begin{array}{l}\text { Blinding of outcome as- } \\
\text { sessment (detection bias) }\end{array}$ & Low risk & $\begin{array}{l}\text { Quote: "Patient's allocation was kept anonymous from the examiner." "One } \\
\text { examiner was involved in the assessment of all patients at the three-time } \\
\text { All outcomes }\end{array}$ \\
$\begin{array}{l}\text { points. The examiner was trained on the oral assessment by the head of the re- } \\
\text { search team and functional assessments (mBI) by a rehabilitation physician } \\
\text { before commencing with the study." }\end{array}$
\end{tabular}

\begin{tabular}{lll}
\hline Incomplete outcome data & High risk & Comment: dropouts accounted for but high attrition rate (37\%) across the tri- \\
(attrition bias) & & al (13/38 in intensive group; 19/48 in conventional group) at 6 months. ITT not \\
All outcomes & employed.
\end{tabular}

\begin{tabular}{l}
$\begin{array}{l}\text { Selective reporting (re- } \\
\text { porting bias) }\end{array}$ \\
\hline
\end{tabular}

Baseline data compara- Low risk Quote: "No significant differences between test and control groups."
ble?

A priori power calculation Low risk Yes.

Quote: "The primary outcome was the changes in the dental plaque score [PI scores]. A sample size of 23 subjects per group was calculated based on the detection of a clinically meaningful PI change score of 0.55 an anticipated SD of 0.642 and $80 \%$ power. To allow for potential dropout rates of $40 \%$; at least 38 patients per group were required."

Other bias Low risk None identified.

Ab Malik 2018

\section{Study characteristics}

\begin{tabular}{ll}
\hline Methods & Parallel RCT randomised at individual level, Malaysia \\
& Study recruitment and setting details: see Table 1 \\
\hline Participants & $\begin{array}{l}\text { Inclusion criteria: hospitalised people with stroke managed by a stroke rehabilitation team (mBI }<70), \\
\text { able to follow instructions, medically stable, not receiving antibiotics or antimicrobial agents and were } \\
\text { not edentulous }\end{array}$
\end{tabular}


Ab Malik 2018 (Continued)

\author{
Exclusion criteria: not reported \\ Intense method group: 38 participants \\ Conventional method group: 48 participants \\ Details of participants are shown in Table 2
}

\begin{tabular}{|c|c|}
\hline Interventions & $\begin{array}{l}\text { Multi-component OHC intervention } \\
\text { - Intervention: intense method for plaque control } \\
\text { - Materials: powered tooth-brush (Oral B Pro-Health DB4010), gel (Hexigel chlorhexidine gluconate gel) } \\
\text { - Agent: } 1 \% \text { chlorhexidine gel (Hexigel chlorhexidine gluconate gel) } \\
\text { - Procedures: daily tooth brushing with powered toothbrush and gel. Individual oral hygiene instruction } \\
\text { given by dental assistant, using a plastic tooth model and a pamphlet on tooth brushing techniques } \\
\text { - Provided by: dental assistant } \\
\text { - Training: not reported } \\
\text { - Delivery: face-to-face, } 1: 1 \text {, ward } \\
\text { - Regimen: "daily"; no other details reported } \\
\text { - Tailoring: not reported } \\
\text { - Modification: not reported } \\
\text { - Adherence: not reported } \\
\text { Multi-component OHC intervention } \\
\text { - Intervention: conventional method for plaque control } \\
\text { - Materials: manual Oral-B-super thin and extra soft bristles toothbrush, standard commercial tooth- } \\
\text { - paste (Colgate Maximum Cavity Protection) } \\
\text { - using a plastic tooth model and a pamphlet on tooth brushing techniques } \\
\text { - Provided by: dental assistant } \\
\text { - Training: not reported } \\
\text { - Delivery: face-to-face, } 1: 1 \text {, ward } \\
\text { - Tailoring: not reported }\end{array}$ \\
\hline
\end{tabular}

Outcomes Primary outcomes: Dental Plaque Index assessed using Silness and Loe Plaque Index (Silness 1964)

Secondary outcomes: presence and type of dental prosthesis, $\mathrm{mBI}$

Data collection: baseline, 3 and 6 months postintervention

\begin{tabular}{ll}
\hline Funding & Study authors declared no conflicts of interest. Study funded by The University of Hong Kong \\
\hline Notes & Dropouts are detailed in Table 6 \\
& Statistical data included within the review meta-analyses \\
\hline
\end{tabular}

\title{
Risk of bias
}

\begin{tabular}{lll}
\hline Bias & Authors' judgement & Support for judgement \\
\hline $\begin{array}{ll}\text { Random sequence genera- } \\
\text { tion (selection bias) }\end{array}$ & Low risk & $\begin{array}{l}\text { Comment: participants were block randomised into 2 groups, in a group size of } \\
2 \text { (ABBA) }\end{array}$
\end{tabular}


Ab Malik 2018 (Continued)

Quote: "Computer-generated randomisation sequences were used for the random allocation of the patients, and this was performed by the head of the research team."

Allocation concealment $\quad$ Unclear risk $\quad$ Comment: insufficient information
(selection bias)

Blinding of participants High risk
and personnel (perfor-
and personnel (perforComment: reported as a "single-blinded study." Oral hygiene kits were prepared by a dental assistant who was not involved in oral health assessments mance bias) and sample collections. Each oral hygiene kit was placed in the same type of All outcomes packaging, colour coded and was not transparent. However, participants must have been aware of difference in toothbrushes (manual vs powered), and the application of gel (or not).

\begin{tabular}{lll}
$\begin{array}{l}\text { Blinding of outcome as- } \\
\begin{array}{l}\text { sessment (detection bias) } \\
\text { All outcomes }\end{array}\end{array}$ & Low risk & $\begin{array}{l}\text { Quote: "Patient's allocation was kept anonymous from the examiner." "One } \\
\text { examiner was involved in the assessment of all patients at the three-time } \\
\text { points. The examiner was trained on the oral assessment by the head of the re- } \\
\text { search team and functional assessments (mBI) by a rehabilitation physician } \\
\text { before commencing with the study." }\end{array}$ \\
\hline $\begin{array}{l}\text { Incomplete outcome data } \\
\text { (attrition bias) } \\
\text { All outcomes }\end{array}$ & High risk & $\begin{array}{l}\text { Comment: dropouts accounted for but high attrition rate }(37 \%) \text { across the tri- } \\
\text { al (13/38 in intensive group; } 19 / 48 \text { in conventional group) at } 6 \text { months. ITT not } \\
\text { employed. }\end{array}$
\end{tabular}

Selective reporting (re- Low risk Comment: all prespecified outcomes reported.
porting bias)

Baseline data compara- Low risk Quote: "No significant differences between test and control groups."
ble?

A priori power calculation Low risk Yes.

Quote: "The primary outcome was the changes in the dental plaque score [PI scores]. A sample size of 23 subjects per group was calculated based on the detection of a clinically meaningful PI change score of 0.55 an anticipated SD of 0.642 and $80 \%$ power. To allow for potential dropout rates of $40 \%$; at least 38 patients per group were required."

Other bias Low risk None identified.

Chipps 2014

\section{Study characteristics}

\begin{tabular}{ll} 
Methods & RCT randomised at individual level, USA \\
& Study recruitment and setting details: see Table 1 \\
\hline Participants & $\begin{array}{l}\text { Inclusion criteria: aged } \geq 18 \text { years, able to communicate in English and give informed consent, prima- } \\
\text { ry diagnosis of a stroke within } 30 \text { days of admission to the rehabilitation unit, admitted directly from an } \\
\text { acute care facility, oral or pharyngeal dysphasia identified by a bedside swallow examination by speech } \\
\text { and language therapist, modified barium swallow or fibreoptic endoscopic evaluation of swallowing } \\
\text { Exclusion criteria: current comorbid diagnoses of pneumonia, known infection of oral cavity or receiv- } \\
\text { ing therapy for infection of oral cavity (or both), documented history of a haematological disorder, } \\
\text { medically restricted fluid intake, allergy to Listerine or other study products, currently wearing den- } \\
\text { tures, pregnant or nursing mothers, history of MRSA infection or colonisation }\end{array}$
\end{tabular}


Chipps 2014 (Continued)

Enhanced oral care group: 29 participants

Routine oral care group: 22 participants

Details of participants are shown in Table 2

- Intervention: enhanced oral care

- Materials: oral care box which contained supplies (battery-operated toothbrush, toothpaste, Listerine, floss picks, tongue cleaner, lip balm)

- Agent: Braun Oral B with timer, Crest-Pro-Health Toothpaste, Listerine, Glide disposable Floss Picks, Sunstar Dual Action tongue Cleaner, Carmex Lip Balm

- Procedures: twice daily $\mathrm{OHC}, 5$ elements - timed toothbrushing with battery powered toothbrush twice a day for 30 seconds in each quadrant, tongue brushing, flossing, mouthrinse and lip care provided by trained registered nurse interventionists

- Provided by: registered nurses

- Training: all staff - in-service training which included details of study, and importance of blinded assessments. Subgroup of Royal College of Nurses selected as study interventionists had training sessions on the new protocol. Dentist and dental hygienist provided training in use of equipment and approach

- Delivery: face-to-face, 1:1, ward

- Regimen: twice daily at predetermined time points for 10 days, mouthrinse once per day. Timed toothbrushing 30 seconds in each quadrant for 10 days

- Tailoring: none

- Modification: none

- Adherence: not reported

\section{Multi-component OHC intervention}

- Intervention: routine oral care

- Materials: standard stock hospital care products

- Agent: hospital toothbrush (Sage), Oral Care Sodium Bicarbonate Mouthpaste (Sage), Careline alcohol-free mouthwash, Regular Chaplet lip balm

- Procedures: OHC as per hospital policy

- Training: inservice describing the study protocol, included details of study and importance of blinded oral assessments

- Provided by: all nursing staff and patient care assistants

- Delivery: face-to-face, 1:1, ward

- Regimen: OHC as per hospital policy which includes toothbrushing, mouthrinse and lip balm with standard stock hospital $\mathrm{OHC}$ products. Once or twice daily as clinically appropriate

- Tailoring: none

- Modification: none

- Adherence: not reported

Outcomes Outcomes: nasal and oropharyngeal cultures; R-THROAT assessment; MASA; FOIS

Data collection: baseline (time 1), study day 5 (time 2), and following completion of 10-day protocol (time 3). FOIS assessed on days 2 and 10

Funding Conflicts of interest: not reported. Study funded by Sigma Theta Tau International and the Rehabilitation Nurses Foundation

Notes Dropouts are detailed in Table 6

Suitable statistical data permitting inclusion within the review meta-analyses unavailable 
Chipps 2014 (Continued)

Risk of bias

\begin{tabular}{lll}
\hline Bias & Authors' judgement & Support for judgement \\
\hline $\begin{array}{l}\text { Random sequence genera- } \\
\text { tion (selection bias) }\end{array}$ & Low risk & Comment: computer-generated randomised table. \\
\hline $\begin{array}{l}\text { Allocation concealment } \\
\text { (selection bias) }\end{array}$ & Low risk & Comment: sealed envelope determining study group. \\
\hline $\begin{array}{l}\text { Blinding of participants } \\
\text { and personnel (perfor- } \\
\text { mance bias) }\end{array}$ & Unclear risk & $\begin{array}{l}\text { Quote: "subjects in the intervention group received an 'oral care box' which } \\
\text { contained supplies required for the intervention oral care intervention. This } \\
\text { box was placed out of view of the speech and language therapists. All staff } \\
\text { members were made aware of the patient's inclusion in the study with a sign } \\
\text { over the bed." }\end{array}$ \\
& $\begin{array}{l}\text { Comment: the initial training provided to all nursing staff and patient care as- } \\
\text { sistants who worked on the unit provided details of the study and included the } \\
\text { importance of the blinded oral assessments done by the speech and language } \\
\text { therapists }\end{array}$
\end{tabular}

$\begin{array}{lll}\begin{array}{l}\text { Blinding of outcome as- } \\ \text { sessment (detection bias) }\end{array} & \text { Low risk } & \begin{array}{l}\text { Comment: oral cavity assessments (R-THROAT) and MASA were obtained by } 2 \\ \text { blinded speech and language therapists }\end{array} \\ \text { All outcomes } & \end{array}$

\begin{tabular}{ll}
\hline $\begin{array}{l}\text { Incomplete outcome data } \\
\text { (attrition bias) }\end{array}$ & Low risk \\
All outcomes & $\begin{array}{l}\text { Comment: dropouts accounted for. High attrition rate for the enhanced group } \\
\text { (8 participants) compared with routine group (1 participant). ITT analysis em- } \\
\text { ployed. }\end{array}$ \\
\hline
\end{tabular}

Selective reporting (re- Low risk Comment; all prespecified outcomes reported. porting bias)

\begin{tabular}{|c|c|c|}
\hline $\begin{array}{l}\text { Baseline data compara- } \\
\text { ble? }\end{array}$ & High risk & $\begin{array}{l}\text { Quote: "No significant in patient characteristics (age, gender and race) or swal- } \\
\text { lowing ability. However the control group had a significantly higher baseline R- } \\
\text { THROAT score and the intervention group had a higher baseline incidence of } \\
\text { positive S. aureus cultures." }\end{array}$ \\
\hline
\end{tabular}

A priori power calculation Low risk Yes.

Quote: "Sample size based on a 22 point difference in MASA test. To obtain $70 \%$ power for a 2 -sample t-test, 21 subjects were needed for each group."

\begin{tabular}{ll}
\hline Other bias Low risk Comment: none identified. \\
\hline
\end{tabular}

\section{Chipps 2014}

\section{Study characteristics}

\begin{tabular}{ll}
\hline Methods & RCT randomised at individual level, USA \\
& Study recruitment and setting details: see Table 1 \\
\hline Participants & $\begin{array}{l}\text { Inclusion criteria: aged } \geq 18 \text { years, able to communicate in English and give informed consent, prima- } \\
\text { ry diagnosis of a stroke within } 30 \text { days of admission to the rehabilitation unit, admitted directly from an } \\
\text { acute care facility, oral or pharyngeal dysphasia identified by a bedside swallow examination by speech } \\
\text { and language therapist, modified barium swallow or fibreoptic endoscopic evaluation of swallowing }\end{array}$
\end{tabular}


Exclusion criteria: current comorbid diagnoses of pneumonia, known infection of oral cavity or receiving therapy for infection of oral cavity (or both), documented history of a haematological disorder, medically restricted fluid intake, allergy to Listerine or other study products, currently wearing dentures, pregnant or nursing mothers, history of MRSA infection or colonisation

Enhanced oral care group: 29 participants

Routine oral care group: 22 participants

Details of participants are shown in Table 2

\section{Multi-component OHC intervention}

- Intervention: enhanced oral care

- Materials: oral care box which contained supplies (battery-operated toothbrush, toothpaste, Listerine, floss picks, tongue cleaner, lip balm)

- Agent: Braun Oral B with timer, Crest-Pro-Health Toothpaste, Listerine, Glide disposable Floss Picks, Sunstar Dual Action tongue Cleaner, Carmex Lip Balm

- Procedures: twice daily OHC, 5 elements - timed toothbrushing with battery powered toothbrush twice a day for 30 seconds in each quadrant, tongue brushing, flossing, mouthrinse and lip care provided by trained registered nurse interventionists

- Provided by: registered nurses

- Training: all staff - in-service training which included details of study, and importance of blinded assessments. Subgroup of Royal College of Nurses selected as study interventionists had training sessions on the new protocol. Dentist and dental hygienist provided training in use of equipment and approach

- Delivery: face-to-face, 1:1, ward

- Regimen: twice daily at predetermined time points for 10 days, mouthrinse once per day. Timed toothbrushing 30 seconds in each quadrant for 10 days

- Tailoring: none

- Modification: none

- Adherence: not reported

\section{Multi-component OHC intervention}

- Intervention: routine oral care

- Materials: standard stock hospital care products

- Agent: hospital toothbrush (Sage), Oral Care Sodium Bicarbonate Mouthpaste (Sage), Careline alcohol-free mouthwash, Regular Chaplet lip balm

- Procedures: OHC as per hospital policy

- Training: inservice describing the study protocol, included details of study and importance of blinded oral assessments

- Provided by: all nursing staff and patient care assistants

- Delivery: face-to-face, 1:1, ward

- Regimen: $\mathrm{OHC}$ as per hospital policy which includes toothbrushing, mouthrinse and lip balm with standard stock hospital OHC products. Once or twice daily as clinically appropriate

- Tailoring: none

- Modification: none

- Adherence: not reported
Outcomes: nasal and oropharyngeal cultures; R-THROAT assessment; MASA; FOIS

Data collection: baseline (time 1), study day 5 (time 2), and following completion of 10-day protocol (time 3). FOIS assessed on days 2 and 10 
Chipps 2014 (Continued)
Notes
Dropouts are detailed in Table 6
Suitable statistical data permitting inclusion within the review meta-analyses unavailable

\title{
Risk of bias
}

\begin{tabular}{lll}
\hline Bias & Authors' judgement & Support for judgement \\
\hline $\begin{array}{l}\text { Random sequence genera- } \\
\text { tion (selection bias) }\end{array}$ & Low risk & Comment: computer-generated randomised table. \\
\hline $\begin{array}{l}\text { Allocation concealment } \\
\text { (selection bias) }\end{array}$ & Low risk & Comment: sealed envelope determining study group. \\
\hline $\begin{array}{l}\text { Blinding of participants } \\
\text { and personnel (perfor- } \\
\text { mance bias) }\end{array}$ & Unclear risk & $\begin{array}{l}\text { Quote: "subjects in the intervention group received an 'oral care box' which } \\
\text { contained supplies required for the intervention oral care intervention. This } \\
\text { box was placed out of view of the speech and language therapists. All staff } \\
\text { members were made aware of the patient's inclusion in the study with a sign } \\
\text { over the bed." }\end{array}$ \\
& $\begin{array}{l}\text { Comment: the initial training provided to all nursing staff and patient care as- } \\
\text { sistants who worked on the unit provided details of the study and included the } \\
\text { importance of the blinded oral assessments done by the speech and language } \\
\text { therapists }\end{array}$
\end{tabular}

\begin{tabular}{|c|c|c|}
\hline $\begin{array}{l}\text { Blinding of outcome as- } \\
\text { sessment (detection bias) }\end{array}$ & Low risk & $\begin{array}{l}\text { Comment: oral cavity assessments (R-THROAT) and MASA were obtained by } 2 \\
\text { blinded speech and language therapists }\end{array}$ \\
\hline
\end{tabular}

All outcomes

\begin{tabular}{|c|c|c|}
\hline $\begin{array}{l}\text { Incomplete outcome data } \\
\text { (attrition bias) } \\
\text { All outcomes }\end{array}$ & Low risk & $\begin{array}{l}\text { Comment: dropouts accounted for. High attrition rate for the enhanced group } \\
\text { ( } 8 \text { participants) compared with routine group ( } 1 \text { participant). ITT analysis em- } \\
\text { ployed. }\end{array}$ \\
\hline
\end{tabular}

\begin{tabular}{|c|c|c|}
\hline $\begin{array}{l}\text { Selective reporting (re- } \\
\text { porting bias) }\end{array}$ & Low risk & Comment; all prespecified outcomes reported. \\
\hline $\begin{array}{l}\text { Baseline data compara- } \\
\text { ble? }\end{array}$ & High risk & $\begin{array}{l}\text { Quote: "No significant in patient characteristics (age, gender and race) or swal- } \\
\text { lowing ability. However the control group had a significantly higher baseline R- } \\
\text { THROAT score and the intervention group had a higher baseline incidence of } \\
\text { positive S. aureus cultures." }\end{array}$ \\
\hline
\end{tabular}

A priori power calculation Low risk Yes.

Quote: "Sample size based on a 22 point difference in MASA test. To obtain $70 \%$ power for a 2 -sample t-test, 21 subjects were needed for each group."

Other bias Low risk Comment: none identified.

Dai 2017

\section{Study characteristics}

Methods

\author{
RCT randomised at individual level, Hong Kong Special Administrative Region of the People's Republic \\ of China \\ Study recruitment and setting details: see Table 1
}


Dai 2017 (Continued)

Participants
Inclusion criteria: admitted to outpatient rehabilitation programme within 6 months; had moderate-tosevere functional disability - BI scores < 70; not edentulous; no more than mild cognitive impairment (i.e.) Mini Mental Status Examination > 18; able to follow a 1-step command (as an assessment of communication); no indwelling nasogastric feeding tubes

Exclusion criteria: none reported

Advanced oral hygiene care group: 47 participants

Conventional oral hygiene care group: 47 participants

Details of participants are shown in Table 2
Interventions

\section{Multi-component OHC intervention}

- Intervention: advanced oral hygiene care programme

- Materials: powered toothbrush (Oral-B AdvancePowerTM 400 series), $0.2 \%$ chlorhexidine gluconate mouthrinse (Corsodyl), a standard toothpaste (Colgate Maximum Cavity Protection), oral hygiene pamphlet

- Agent: $0.2 \%$ chlorhexidine gluconate mouthrinse (Corsodyl), standardised toothpaste (Colgate Maximum Cavity Protection)

- Procedures: supply of a powered toothbrush, mouthrinse, toothpaste and oral hygiene training. All participants attended a 1-to-1 oral hygiene training conducted by a dental surgery assistant. Participants were provided with specific manufacturer's instructions regarding the use of powered toothbrush. In addition, they were provided with a 3 months' supply of mouthrinse and were instructed to rinse twice daily with $10 \mathrm{~mL}$ of the mouthrinse (at least 30 minutes after brushing)

- Provided by: dental surgery assistant

- Training: all participants were given a standardised $\mathrm{OHC}$ pamphlet. OHC practice was demonstrated on tooth block models. Participants were asked to adhere to $\mathrm{OHC}$ protocol and brush their teeth in a systematic way. Training sessions lasted approximately 30 minutes

- Delivery: face-to-face, 1:1

- Location: non-clinical room

- Regimen: toothbrushing and mouthrinse twice daily for 6 months

- Tailoring: none

- Modification: none

- Adherence: none

\section{Multi-component OHC Intervention}

- Intervention: conventional oral hygiene care programme

- Materials: standard stock hospital care products

- Agent: manual toothbrush (Oral-B Pro-Health All-In-One), standard toothpaste (Colgate Maximum Cavity Protection)

- Procedures: supplied manual toothbrush and toothpaste plus oral hygiene training

- Provided by: dental surgery assistant

- Training: all participants attended a 1-to-1 OHC training conducted by a dental surgery assistant. All participants were given a standardised $\mathrm{OHC}$ pamphlet. $\mathrm{OHC}$ practice was demonstrated on tooth block models. Participants were asked to adhere to $\mathrm{OHC}$ protocol and brush their teeth in a systematic way. Training sessions lasted approximately 30 minutes

- Delivery: face-to-face, 1:1

- Location: non-clinical room

- Regimen: twice daily for 6 months

- Tailoring: none

- Modification: none

- Adherence: none 
Dai 2017 (Continued)

Outcomes
Primary outcomes: oral hygiene status as assessed by Dental Plaque Index (Silness 1964), and Gingival Bleeding Index (Ainamo 1975)

Secondary outcomes: oral hygiene status and gingival bleeding at 6 months, dental caries experience, periodontal health, oral mucosa conditions, dental prosthesis status, adverse effects of chlorhexidine

Data collection: baseline, 3- and 6-month follow-up

Study authors declared no conflicts of interest. Study funded by General Research Fund, Hong Kong (Project no. 774012)

Funding

Dropouts are detailed in Table 6

Suitable statistical data permitting inclusion within the review meta-analyses were not available

\section{Risk of bias}

\begin{tabular}{lll}
\hline Bias & Authors' judgement & Support for judgement \\
\hline $\begin{array}{l}\text { Random sequence genera- } \\
\text { tion (selection bias) }\end{array}$ & Low risk & Quote: computer generated "block randomized with a group size of 4 (ABBA)." \\
\hline $\begin{array}{l}\text { Allocation concealment } \\
\text { (selection bias) }\end{array}$ & Low risk & $\begin{array}{l}\text { Quote: "The randomized sequence was computer generated by the project su- } \\
\text { pervisor. The allocation sequence number of each subject was concealed in an } \\
\text { opaque envelope and provided to a nurse at the rehabilitation centre who was } \\
\text { independent of the research team." }\end{array}$ \\
\hline
\end{tabular}

Blinding of participants High risk Comment: single-blind study. Participants were aware of their treatment and personnel (perfor-

mance bias)

All outcomes

Blinding of outcome as- Low risk

Quote: "Assessors were blind to which group subjects were assigned to."

sessment (detection bias)

All outcomes

Incomplete outcome data Low risk

(attrition bias)

All outcomes

Comment: dropouts accounted for. High attrition rate for the conventional care group.

Quote: "no significant difference in the profile and oral health status of participants with respect to participation and drop-out at 3-month assessment were apparent (Table A and B in Appendix II [of the publication]). No significant difference in the profile and oral health status of participants with respect to participation and drop-out at 6-month assessment were apparent except reported dental attendance pattern and brushing habits $(p<0.01)$ (Table $C$ and $D$ in Appendix II [of the publication]). ITT not employed but it was reported that when conducting regression analysis, the method Last Observation Carried Forward (LOCF) was employed to deal with missing outcomes at follow-up reviews."
Selective reporting (re-
Low risk
Comment: all prespecified outcomes reported. porting bias)

Baseline data compara- Low risk ble?

Quote: "At baseline there was no significant difference in the profile of subject$s$ " [between the enhanced and conventional care groups (Table E in Appendix II in the publication)]

A priori power calculation Low risk Yes. 
Dai 2017 (Continued)

Quote: "Sample size was calculated based on intended ability to detect a significant difference in the primary outcome variable - the level of dental plaque between two groups at three-month review ... the number of study subjects would require 38 per group, based on $80 \%$ power and the statistical significance level set at 0.05 . Anticipating a $20 \%$ dropout rate over the course of the clinical trial, the initial sample size for each treatment group was proposed as 47 patients per group (94 subjects in total)."

\begin{tabular}{ll}
\hline Other bias $\quad$ Low risk $\quad$ None identified. \\
\hline
\end{tabular}

\section{Dai 2017}

\section{Study characteristics}

Methods $\quad$ RCT randomised at individual level, Hong Kong Special Administrative Region of the People's Republic of China

Study recruitment and setting details: see Table 1

Participants

Inclusion criteria: admitted to outpatient rehabilitation programme within 6 months; had moderate-tosevere functional disability - BI scores < 70; not edentulous; no more than mild cognitive impairment (i.e.) Mini Mental Status Examination > 18; able to follow a 1-step command (as an assessment of communication); no indwelling nasogastric feeding tubes

Exclusion criteria: none reported

Advanced oral hygiene care group: 47 participants

Conventional oral hygiene care group: 47 participants

Details of participants are shown in Table 2

Interventions

\section{Multi-component OHC intervention}

- Intervention: advanced oral hygiene care programme

- Materials: powered toothbrush (Oral-B AdvancePowerTM 400 series), $0.2 \%$ chlorhexidine gluconate mouthrinse (Corsodyl), a standard toothpaste (Colgate Maximum Cavity Protection), oral hygiene pamphlet

- Agent: $0.2 \%$ chlorhexidine gluconate mouthrinse (Corsodyl), standardised toothpaste (Colgate Maximum Cavity Protection)

- Procedures: supply of a powered toothbrush, mouthrinse, toothpaste and oral hygiene training. All participants attended a 1-to-1 oral hygiene training conducted by a dental surgery assistant. Participants were provided with specific manufacturer's instructions regarding the use of powered toothbrush. In addition, they were provided with a 3 months' supply of mouthrinse and were instructed to rinse twice daily with $10 \mathrm{~mL}$ of the mouthrinse (at least 30 minutes after brushing)

- Provided by: dental surgery assistant

- Training: all participants were given a standardised $\mathrm{OHC}$ pamphlet. $\mathrm{OHC}$ practice was demonstrated on tooth block models. Participants were asked to adhere to $\mathrm{OHC}$ protocol and brush their teeth in a systematic way. Training sessions lasted approximately 30 minutes

- Delivery: face-to-face, 1:1

- Location: non-clinical room

- Regimen: toothbrushing and mouthrinse twice daily for 6 months

- Tailoring: none

- Modification: none

- Adherence: none

\section{Multi-component OHC Intervention}


Dai 2017 (Continued)

- Intervention: conventional oral hygiene care programme

- Materials: standard stock hospital care products

- Agent: manual toothbrush (Oral-B Pro-Health All-In-One), standard toothpaste (Colgate Maximum Cavity Protection)

- Procedures: supplied manual toothbrush and toothpaste plus oral hygiene training

- Provided by: dental surgery assistant

- Training: all participants attended a 1-to-1 OHC training conducted by a dental surgery assistant. All participants were given a standardised $\mathrm{OHC}$ pamphlet. $\mathrm{OHC}$ practice was demonstrated on tooth block models. Participants were asked to adhere to $\mathrm{OHC}$ protocol and brush their teeth in a systematic way. Training sessions lasted approximately 30 minutes

- Delivery: face-to-face, 1:1

- Location: non-clinical room

- Regimen: twice daily for 6 months

- Tailoring: none

- Modification: none

- Adherence: none

Outcomes Primary outcomes: oral hygiene status as assessed by Dental Plaque Index (Silness 1964), and Gingival Bleeding Index (Ainamo 1975)

Secondary outcomes: oral hygiene status and gingival bleeding at 6 months, dental caries experience, periodontal health, oral mucosa conditions, dental prosthesis status, adverse effects of chlorhexidine

Data collection: baseline, 3- and 6-month follow-up

Notes Dropouts are detailed in Table 6

Suitable statistical data permitting inclusion within the review meta-analyses were not available

\section{Risk of bias}

\begin{tabular}{lll}
\hline Bias & Authors' judgement & Support for judgement \\
\hline $\begin{array}{l}\text { Random sequence genera- } \\
\text { tion (selection bias) }\end{array}$ & Low risk & Quote: computer generated "block randomized with a group size of 4 (ABBA)." \\
\hline $\begin{array}{l}\text { Allocation concealment } \\
\text { (selection bias) }\end{array}$ & Low risk & $\begin{array}{l}\text { Quote: "The randomized sequence was computer generated by the project su- } \\
\text { pervisor. The allocation sequence number of each subject was concealed in an } \\
\text { opaque envelope and provided to a nurse at the rehabilitation centre who was } \\
\text { independent of the research team." }\end{array}$
\end{tabular}

Blinding of participants High risk Comment: single-blind study. Participants were aware of their treatment
and personnel (performance bias)

All outcomes

\begin{tabular}{lll}
\hline $\begin{array}{l}\text { Blinding of outcome as- } \\
\text { sessment (detection bias) } \\
\text { All outcomes }\end{array}$ & Low risk & Quote: "Assessors were blind to which group subjects were assigned to." \\
\hline $\begin{array}{l}\text { Incomplete outcome data } \\
\text { (attrition bias) }\end{array}$ & Low risk & $\begin{array}{l}\text { Comment: dropouts accounted for. High attrition rate for the conventional } \\
\text { care group. }\end{array}$ \\
Qutcomes & $\begin{array}{l}\text { Quote: "no significant difference in the profile and oral health status of partici- } \\
\text { pants with respect to participation and drop-out at 3-month assessment were }\end{array}$
\end{tabular}


Dai 2017 (Continued)

apparent (Table A and B in Appendix II [of the publication]). No significant difference in the profile and oral health status of participants with respect to participation and drop-out at 6-month assessment were apparent except reported dental attendance pattern and brushing habits $(p<0.01)$ (Table $C$ and $D$ in Appendix II [of the publication]). ITT not employed but it was reported that when conducting regression analysis, the method Last Observation Carried Forward (LOCF) was employed to deal with missing outcomes at follow-up reviews."

Selective reporting (re- Low risk Comment: all prespecified outcomes reported.
porting bias)

\begin{tabular}{ll}
$\begin{array}{l}\text { Baseline data compara- } \\
\text { ble? }\end{array}$ & Low risk \\
& $\begin{array}{l}\text { Quote: "At baseline there was no significant difference in the profile of subject- } \\
\text { II in the publication)] }\end{array}$ \\
\hline
\end{tabular}

A priori power calculation Low risk Yes.

Quote: "Sample size was calculated based on intended ability to detect a significant difference in the primary outcome variable - the level of dental plaque between two groups at three-month review ... the number of study subjects would require 38 per group, based on $80 \%$ power and the statistical significance level set at 0.05 . Anticipating a $20 \%$ dropout rate over the course of the clinical trial, the initial sample size for each treatment group was proposed as 47 patients per group (94 subjects in total)."

\begin{tabular}{lll}
\hline Other bias Low risk None identified. & L
\end{tabular}

\section{Fields 2008}

\section{Study characteristics}

\begin{tabular}{ll}
\hline Methods & RCT randomised at individual level, USA \\
& Study recruitment and setting details: see Table 1 \\
\hline Participants & 345 (but completed data only available on 200) \\
& Inclusion criteria: admissions to intensive care unit, mechanically ventilated, intubated in hospital for < \\
& 24 hours, no previous diagnosis of pneumonia \\
& Exclusion criteria: people with prior tracheostomies, aged < 18 years, people with AIDS secondary to \\
immunocompromised systems, people who were edentulous & \\
& OHC group: number of participants not reported \\
& Usual care group: number of participants not reported \\
& Details of participants are shown in Table 2
\end{tabular}

\section{Multi-component OHC Intervention}

- Intervention: $\mathrm{OHC}$ and timed toothbrushing in care bundle (nurse education; protocol; $\mathrm{OHC}$ assessment every 12 hours; OHC kit)

- Materials: OHC kit containing - new toothbrush for every OHC session; toothpaste; Toothette (foam swab), lip moisturiser

- Procedures: teeth were brushed with a suction toothbrush every 8 hours; suction as required

- Provided by: nursing staff 
Fields 2008 (Continued)

- Training: nursing staff instruction on OHC. Laminated care with basic instructions

- Delivery: face-to-face, 1:1

- Location: 24-bed intensive care unit

- Regimen: protocol: brushing of teeth, tongue and hard palate every 8 hours ( 3 times daily) for $\geq 1$ minute, Toothette on teeth, tongue and hard palate for $\geq 1$ minute; application of moisturiser as required; oral/pharyngeal suction as required. OHC assessment every 12 hours

- Tailoring: none

- Modification: none

- Adherence: not reported

\section{Control}

- Intervention: usual oral care

- Materials: toothbrush (kit had 2 toothbrushes); Toothette (foam swab), lip moisturiser

- Procedures: received "usual care" which could include daily toothbrushing along with Toothette mouth care as needed

- Provided by: nursing staff

- Training: none

- Delivery: face-to-face, 1:1

- Location: 24-bed intensive care unit

- Regimen: "as required"

- Tailoring: none

- Modification: none

- Adherence: not reported

Primary outcome: VAP (Table 5 for diagnostic criteria)

Secondary outcome: nurse-completed patient worksheets

Data collection: worksheets documented after each oral care session

\begin{tabular}{|c|c|}
\hline Funding & Conflicts of interest: not reported. Funding: not reported \\
\hline Notes & $\begin{array}{l}\text { Unable to obtain additional unpublished information from authors. RCT terminated early when the } \\
\text { OHC group had a VAP rate of } 0 \% \text { over } 1000 \text { ventilator days, which was sustained for } 6 \text {-months (while } \\
\text { there were } 4 \text { VAPs over } 6 \text { months in usual care group) }\end{array}$ \\
\hline & Outcome measures reported prevent inclusion within a meta-analysis \\
\hline
\end{tabular}

\section{Risk of bias}

\begin{tabular}{lll}
\hline Bias & Authors' judgement & Support for judgement \\
\hline $\begin{array}{l}\text { Random sequence genera- } \\
\text { tion (selection bias) }\end{array}$ & Unclear risk & $\begin{array}{l}\text { Comment: randomisation assisted by the clinical nursing research programme } \\
\text { of Summa Health Systems and the Biostatistics Department of North Eastern } \\
\text { Ohio Universities Colleges of Medicine and Pharmacy. }\end{array}$ \\
\hline $\begin{array}{l}\text { Allocation concealment } \\
\text { (selection bias) }\end{array}$ & Unclear risk & $\begin{array}{l}\text { Comment: sequentially numbered envelopes (unclear whether they were } \\
\text { opaque) containing the randomised worksheets. Envelopes were taken in se- } \\
\text { quence. }\end{array}$ \\
\hline
\end{tabular}

Blinding of participants High risk Comment: nurses carrying out the OHC interventions were not blinded.
and personnel (perfor-
mance bias)
All outcomes

Blinding of outcome assessment (detection bias)
Unclear risk Comment: VAP was collected by infection control nurse who may have been blinded. 
Fields 2008 (Continued)

All outcomes

\begin{tabular}{|c|c|c|}
\hline $\begin{array}{l}\text { Incomplete outcome data } \\
\text { (attrition bias) }\end{array}$ & High risk & $\begin{array}{l}\text { Comment: } 345 \text { participants but completed data only available for } 200 \text {. ITT } \\
\text { analysis not performed. }\end{array}$ \\
\hline
\end{tabular}

All outcomes

Selective reporting (re- High risk
porting bias)

Comment: $>4000$ ventilator days but authors reported only adequate documentation for 1850 days. Few details reported in publication (e.g. information on baseline groups, numbers randomised to each intervention, other outcome measures collected were unreported).

Baseline data compara- Unclear risk Comment: no information given to judge comparability of groups.
?
ble?

$\begin{array}{ll}\text { A priori power calculation } \quad \text { Low risk } & \text { Comment: yes, sample size calculation was performed requiring a sample of } \\ 200 \text { ventilator-dependent participants or } 2000 \text { ventilator days. }\end{array}$

Other bias High risk Comment: trial terminated early.

Fields 2008

\section{Study characteristics}

\begin{tabular}{ll}
\hline Methods & RCT randomised at individual level, USA \\
& Study recruitment and setting details: see Table 1 \\
\hline Participants & 345 (but completed data only available on 200) \\
& Inclusion criteria: admissions to intensive care unit, mechanically ventilated, intubated in hospital for < \\
& 24 hours, no previous diagnosis of pneumonia \\
& Exclusion criteria: people with prior tracheostomies, aged < 18 years, people with AIDS secondary to \\
immunocompromised systems, people who were edentulous & \\
& OHC group: number of participants not reported \\
& Usual care group: number of participants not reported \\
& Details of participants are shown in Table 2
\end{tabular}

Interventions

\section{Multi-component OHC Intervention}

- Intervention: $\mathrm{OHC}$ and timed toothbrushing in care bundle (nurse education; protocol; $\mathrm{OHC}$ assessment every 12 hours; OHC kit)

- Materials: OHC kit containing - new toothbrush for every OHC session; toothpaste; Toothette (foam swab), lip moisturiser

- Procedures: teeth were brushed with a suction toothbrush every 8 hours; suction as required

- Provided by: nursing staff

- Training: nursing staff instruction on OHC. Laminated care with basic instructions

- Delivery: face-to-face, 1:1

- Location: 24-bed intensive care unit

- Regimen: protocol: brushing of teeth, tongue and hard palate every 8 hours ( 3 times daily) for $\geq 1$ minute, Toothette on teeth, tongue and hard palate for $\geq 1$ minute; application of moisturiser as required; oral/pharyngeal suction as required. OHC assessment every 12 hours

- Tailoring: none

- Modification: none 
Fields 2008 (Continued)

- Adherence: not reported

\section{Control}

- Intervention: usual oral care

- Materials: toothbrush (kit had 2 toothbrushes); Toothette (foam swab), lip moisturiser

- Procedures: received "usual care" which could include daily toothbrushing along with Toothette mouth care as needed

- Provided by: nursing staff

- Training: none

- Delivery: face-to-face, 1:1

- Location: 24-bed intensive care unit

- Regimen: "as required"

- Tailoring: none

- Modification: none

- Adherence: not reported

\begin{tabular}{ll}
\hline Outcomes & Primary outcome: VAP (Table 5 for diagnostic criteria) \\
& Secondary outcome: nurse-completed patient worksheets \\
& Data collection: worksheets documented after each oral care session \\
\hline Funding & Conflicts of interest: not reported. Funding: not reported \\
\hline Notes & $\begin{array}{l}\text { Unable to obtain additional unpublished information from authors. RCT terminated early when the } \\
\text { OHC group had a VAP rate of } 0 \% \text { over } 1000 \text { ventilator days, which was sustained for } 6 \text {-months (while } \\
\text { there were } 4 \text { VAPs over } 6 \text { months in usual care group) } \\
\text { Outcome measures reported prevent inclusion within a meta-analysis }\end{array}$
\end{tabular}

\section{Risk of bias}

\begin{tabular}{lll}
\hline Bias & Authors' judgement & Support for judgement \\
\hline $\begin{array}{l}\text { Random sequence genera- } \\
\text { tion (selection bias) }\end{array}$ & Unclear risk & $\begin{array}{l}\text { Comment: randomisation assisted by the clinical nursing research programme } \\
\text { of Summa Health Systems and the Biostatistics Department of North Eastern } \\
\text { Ohio Universities Colleges of Medicine and Pharmacy. }\end{array}$ \\
\hline $\begin{array}{l}\text { Allocation concealment } \\
\text { (selection bias) }\end{array}$ & Unclear risk & $\begin{array}{l}\text { Comment: sequentially numbered envelopes (unclear whether they were } \\
\text { opaque) containing the randomised worksheets. Envelopes were taken in se- } \\
\text { quence. }\end{array}$
\end{tabular}

Blinding of participants High risk Comment: nurses carrying out the OHC interventions were not blinded.
and personnel (perfor-
mance bias)
All outcomes

\begin{tabular}{lll}
\hline $\begin{array}{l}\text { Blinding of outcome as- } \\
\text { sessment (detection bias) }\end{array}$ & Unclear risk & $\begin{array}{l}\text { Comment: VAP was collected by infection control nurse who may have been } \\
\text { blinded. }\end{array}$
\end{tabular}
All outcomes

\begin{tabular}{lll}
\hline $\begin{array}{l}\text { Incomplete outcome data } \\
\text { (attrition bias) } \\
\text { All outcomes }\end{array}$ & High risk & $\begin{array}{l}\text { Comment: } 345 \text { participants but completed data only available for 200. ITT } \\
\text { analysis not performed. }\end{array}$ \\
\hline $\begin{array}{l}\text { Selective reporting (re- } \\
\text { porting bias) }\end{array}$ & High risk & $\begin{array}{l}\text { Comment: > } 4000 \text { ventilator days but authors reported only adequate docu- } \\
\text { mentation for } 1850 \text { days. Few details reported in publication (e.g. information }\end{array}$
\end{tabular}


Fields 2008 (Continued)

on baseline groups, numbers randomised to each intervention, other outcome measures collected were unreported).

\begin{tabular}{lll}
\hline $\begin{array}{l}\text { Baseline data compara- } \\
\text { ble? }\end{array}$ & Unclear risk & Comment: no information given to judge comparability of groups. \\
\hline A priori power calculation & Low risk & $\begin{array}{l}\text { Comment: yes, sample size calculation was performed requiring a sample of } \\
200 \text { ventilator-dependent participants or 2000 ventilator days. }\end{array}$ \\
\hline Other bias & High risk & Comment: trial terminated early. \\
\hline
\end{tabular}

Frenkel 2001

\section{Study characteristics}

Methods Cluster RCT randomised at nursing home level, UK

Study recruitment and setting details: see Table 1

Participants

22 nursing homes (with 20-40 beds), 369 carers employed in the nursing homes

Inclusion criteria: residents who wore dentures or had $\geq 1$ natural teeth or both, and whose general health permitted oral examination

Exclusion criteria: significant cognitive impairment

Workplace OHC training session group: 9 nursing homes; 72 residents (from 151 non-stroke specific residents)

Usual care group: 11 nursing homes; 40 residents (from 144 non-stroke specific residents)

Details of participants are shown in Table 2

- Intervention: workplace OHC training session

- Materials: booklet, teaching aids and models (including a dentate manikin head), toothbrushes

- Agent: none

- Procedures: educational session involved opportunity for carers to discuss feelings about oral health, role of plaque in oral disease, demonstrations of brushing techniques for dentures and natural teeth; practice on teaching aids and models (e.g. dentate manikin head). Participants given booklet on oral health and course attendance certificate. Toothbrushes were distributed to all participants to encourage oral hygiene activity

- Provided by: health promotor - dental hygienist who had a Further Adult Education certificate, a certificate in Health Education, Diploma in Dental health Delivery, 20 years' teaching experience

- Training: as described above

- Delivery: face-to-face; group; nursing homes

- Regimen: 60-minute session delivered 2 months postbaseline

- Tailoring: none

- Modification: none

- Adherence: not reported

\section{Usual care}

- Intervention: usual care

- Materials: none

- Agent: none 
Frenkel 2001 (Continued)

- Procedures: none reported (quote: "health education programme was delivered to control homes after all data collection was complete")

- Provided by: none

- Delivery: none

- Regimen: none

- Tailoring: none

- Modification: none

- Adherence: not reported

Outcomes

Primary outcomes: dental plaque (Simplified Oral Hygiene Index), denture plaque (0-4 scale), denture-induced stomatitis ( $0-3$ scale), dental plaque ( $0-3$ scale), gingivitis ( $0-2$ scale), carers' oral health knowledge ( 26 questions), carers' attitudes ( 25 statements rated on 0 - to 5-point scale)

Secondary outcomes: calculus on buccal and lingual surfaces (present/absent), root caries (present/ absent), tooth mobility (present/absent)

Data collection: questionnaires were administered at baseline, 1 and 6 months

Funding Conflicts of interest: not reported. Study funded by the NHS Executive South West, Research and Development Directorate

Notes Dropouts are detailed in Table 6

Note: availability of residents varied over the duration of the trial (baseline: 55 residents; 1 month after training: 57 residents; 6 months after training: 53 residents)

Data included in the review reflected the knowledge and attitude of all care assistants employed within the nursing homes at the data collection points including those that started their employment after the training intervention. Thus, the impact of a training intervention delivered in a care setting with a characteristically high rate of staff turnover was reflected in the results. Not all available care assistants chose to participate in the training or to return a completed questionnaire (baseline $=80.5 \%$; 1 month after training $=81.1 \% ; 6$ months after training $=77.2 \%)$. The number of care assistants employed varied (baseline: 369 assistants; 1 month after training: 322 assistants; 6 months after training: 289 assistants)

Statistical data included within the review meta-analyses

\section{Risk of bias}

Bias Authors' judgement Support for judgement

Random sequence genera- Low risk tion (selection bias)

Comment: 1 researcher was not involved in the intervention or data collection allocated the 22 nursing homes using block randomisation (block size 4) to either a workplace OHC training session group or a usual care group using a table of random numbers.

\begin{tabular}{|c|c|c|}
\hline $\begin{array}{l}\text { Allocation concealment } \\
\text { (selection bias) }\end{array}$ & Low risk & $\begin{array}{l}\text { Comment: allocation codes were passed directly to the health promoter deliv- } \\
\text { ering the training programme and the participating homes were asked to con- } \\
\text { ceal their allocation from the data collector. }\end{array}$ \\
\hline
\end{tabular}

\begin{tabular}{lll}
\hline $\begin{array}{l}\text { Blinding of participants } \\
\text { and personnel (perfor- } \\
\text { mance bias) }\end{array}$ & High risk & $\begin{array}{l}\text { Comment: self-administered questionnaires so carers were aware of alloca- } \\
\text { tion. }\end{array}$ \\
$\begin{array}{ll}\text { All outcomes } \\
\text { Blinding of outcome as- } \\
\text { sessment (detection bias) }\end{array}$ & Unclear risk & $\begin{array}{l}\text { Quote: "Health promoter visited control and intervention group homes at the } \\
\text { outset of the trial to explain when the training sessions would take place, and } \\
\text { to ask staff to conceal their group allocation from the investigator conducting } \\
\text { follow-up assessments." }\end{array}$
\end{tabular}


Frenkel 2001 (Continued)

Incomplete outcome data Low risk Comment: partial, ITT analysis - analysis of carer measures was repeated on (attrition bias) data from all carers working at each measurement time point. This allowed asAll outcomes sessment of whether including carers that had not been present at the time of the initial intervention impacted upon the findings. Analysis of patient data was based only on individuals who were resident within the nursing homes at both baseline and follow-up time point.

$\begin{aligned} & \text { Selective reporting (re- Unclear risk } \\ & \text { porting bias) }\end{aligned} \quad \begin{aligned} & \text { Comment: some indication of completeness of follow-up except for the dental } \\ & \text { plaque measure where some teeth could not be scored. }\end{aligned}$

\begin{tabular}{lll}
\hline $\begin{array}{l}\text { Baseline data compara- } \\
\text { ble? }\end{array}$ & Low risk & $\begin{array}{l}\text { Comment: baseline groups comparable (age, dental status, oral health status); } \\
\text { some differences (gender, mobility, last seen by dentist). }\end{array}$ \\
\hline $\begin{array}{l}\text { A priori power calculation } \\
\text { Other bias }\end{array}$ & Low risk & $\begin{array}{l}\text { Comment: yes; sample size calculations were conducted a priori for both car- } \\
\text { ers and patients. }\end{array}$ \\
\hline
\end{tabular}

Frenkel 2001

\section{Study characteristics}

\begin{tabular}{ll}
\hline Methods & Cluster RCT randomised at nursing home level, UK \\
& Study recruitment and setting details: see Table 1 \\
\hline Participants & 22 nursing homes (with 20-40 beds), 369 carers employed in the nursing homes \\
& $\begin{array}{l}\text { Inclusion criteria: residents who wore dentures or had } \geq 1 \text { natural teeth or both, and whose general } \\
\text { health permitted oral examination }\end{array}$ \\
& Exclusion criteria: significant cognitive impairment \\
& $\begin{array}{l}\text { Workplace OHC training session group: } 9 \text { nursing homes; } 72 \text { residents (from } 151 \text { non-stroke specific res- } \\
\text { idents) } \\
\text { Usual care group: } 11 \text { nursing homes; } 40 \text { residents (from } 144 \text { non-stroke specific residents) } \\
\text { Details of participants are shown in Table } 2\end{array}$ \\
\hline
\end{tabular}

Interventions

\section{Multi-component OHC Intervention}

- Intervention: workplace OHC training session

- Materials: booklet, teaching aids and models (including a dentate manikin head), toothbrushes

- Agent: none

- Procedures: educational session involved opportunity for carers to discuss feelings about oral health, role of plaque in oral disease, demonstrations of brushing techniques for dentures and natural teeth; practice on teaching aids and models (e.g. dentate manikin head). Participants given booklet on oral health and course attendance certificate. Toothbrushes were distributed to all participants to encourage oral hygiene activity

- Provided by: health promotor - dental hygienist who had a Further Adult Education certificate, a certificate in Health Education, Diploma in Dental health Delivery, 20 years' teaching experience

- Training: as described above

- Delivery: face-to-face; group; nursing homes

- Regimen: 60-minute session delivered 2 months postbaseline

- Tailoring: none

- Modification: none 
Frenkel 2001 (Continued)

- Adherence: not reported

\section{Usual care}

- Intervention: usual care

- Materials: none

- Agent: none

- Procedures: none reported (quote: "health education programme was delivered to control homes after all data collection was complete")

- Provided by: none

- Delivery: none

- Regimen: none

- Tailoring: none

- Modification: none

- Adherence: not reported

Outcomes Primary outcomes: dental plaque (Simplified Oral Hygiene Index), denture plaque (0-4 scale), denture-induced stomatitis ( $0-3$ scale), dental plaque ( $0-3$ scale), gingivitis $(0-2$ scale), carers' oral health knowledge ( 26 questions), carers' attitudes ( 25 statements rated on 0 - to 5 -point scale)

Secondary outcomes: calculus on buccal and lingual surfaces (present/absent), root caries (present/ absent), tooth mobility (present/absent)

Data collection: questionnaires were administered at baseline, 1 and 6 months

Funding

Conflicts of interest: not reported. Study funded by the NHS Executive South West, Research and Development Directorate

Notes

Dropouts are detailed in Table 6

Note: availability of residents varied over the duration of the trial (baseline: 55 residents; 1 month after training: 57 residents; 6 months after training: 53 residents)

Data included in the review reflected the knowledge and attitude of all care assistants employed within the nursing homes at the data collection points including those that started their employment after the training intervention. Thus, the impact of a training intervention delivered in a care setting with a characteristically high rate of staff turnover was reflected in the results. Not all available care assistants chose to participate in the training or to return a completed questionnaire (baseline $=80.5 \%$; 1 month after training $=81.1 \% ; 6$ months after training $=77.2 \%$ ). The number of care assistants employed varied (baseline: 369 assistants; 1 month after training: 322 assistants; 6 months after training: 289 assistants)

Statistical data included within the review meta-analyses

\section{Risk of bias}

\begin{tabular}{lll}
\hline Bias & Authors' judgement & Support for judgement \\
\hline $\begin{array}{l}\text { Random sequence genera- } \\
\text { tion (selection bias) }\end{array}$ & Low risk & $\begin{array}{l}\text { Comment: } 1 \text { researcher was not involved in the intervention or data collection } \\
\text { allocated the } 22 \text { nursing homes using block randomisation (block size } 4) \text { to ei- } \\
\text { ther a workplace OHC training session group or a usual care group using a ta- } \\
\text { ble of random numbers. }\end{array}$ \\
\hline $\begin{array}{l}\text { Allocation concealment } \\
\text { (selection bias) }\end{array}$ & Low risk & $\begin{array}{l}\text { Comment: allocation codes were passed directly to the health promoter deliv- } \\
\text { ering the training programme and the participating homes were asked to con- } \\
\text { ceal their allocation from the data collector. }\end{array}$ \\
\hline $\begin{array}{l}\text { Blinding of participants } \\
\text { and personnel (perfor- } \\
\text { mance bias) }\end{array}$ & High risk & $\begin{array}{l}\text { Comment: self-administered questionnaires so carers were aware of alloca- } \\
\text { tion. }\end{array}$
\end{tabular}


Frenkel 2001 (Continued)

All outcomes

$\begin{array}{lll}\begin{array}{l}\text { Blinding of outcome as- } \\ \text { sessment (detection bias) }\end{array} & \text { Unclear risk } & \begin{array}{l}\text { Quote: "Health promoter visited control and intervention group homes at the } \\ \text { outset of the trial to explain when the training sessions would take place, and } \\ \text { to ask staff to conceal their group allocation from the investigator conducting } \\ \text { follow-up assessments." }\end{array}\end{array}$

$\begin{array}{ll}\begin{array}{l}\text { Incomplete outcome data } \\ \text { (attrition bias) }\end{array} & \begin{array}{l}\text { Comment: partial, ITT analysis - analysis of carer measures was repeated on } \\ \text { datl outcomes }\end{array} \\ \begin{array}{l}\text { sessment of whether including carers that had not been present at the time } \\ \text { of the initial intervention impacted upon the findings. Analysis of patient data } \\ \text { was based only on individuals who were resident within the nursing homes at } \\ \text { both baseline and follow-up time point. }\end{array}\end{array}$

\begin{tabular}{|c|c|c|}
\hline $\begin{array}{l}\text { Selective reporting (re- } \\
\text { porting bias) }\end{array}$ & Unclear risk & $\begin{array}{l}\text { Comment: some indication of completeness of follow-up except for the dental } \\
\text { plaque measure where some teeth could not be scored. }\end{array}$ \\
\hline
\end{tabular}

\begin{tabular}{|c|c|c|}
\hline $\begin{array}{l}\text { Baseline data compara- } \\
\text { ble? }\end{array}$ & Low risk & $\begin{array}{l}\text { Comment: baseline groups comparable (age, dental status, oral health status); } \\
\text { some differences (gender, mobility, last seen by dentist). }\end{array}$ \\
\hline A priori power calculation & Low risk & $\begin{array}{l}\text { Comment: yes; sample size calculations were conducted a priori for both car- } \\
\text { ers and patients. }\end{array}$ \\
\hline Other bias & Unclear risk & Comment: details of inter- or intrarater reliability were not reported. \\
\hline
\end{tabular}

Gosney 2006

\section{Study characteristics}

\begin{tabular}{ll}
\hline Methods & RCT randomised at individual level, UK \\
& Study recruitment and setting details: see Table 1 \\
\hline Participants & Inclusions: within 24 hours of admission, first acute stroke \\
& Exclusions: receiving antibiotic or steroid medication (including inhaled steroids), prior stroke \\
& OHC gel group: 103 participants \\
& Placebo gel group: 100 participants \\
& Details of participants are shown in Table 2 \\
\hline
\end{tabular}

Interventions

\section{OHC gel (colistin, polymyxin, amphotericin B)}

- Intervention: selective decontamination of digestive tract oral gel

- Materials: Orabase gel, gloves, spatula

- Agent: Orabase $500 \mathrm{mg}$ gel (containing $2 \%(\mathrm{w} / \mathrm{v})$ colistin, $2 \%(\mathrm{w} / \mathrm{v})$ polymyxin E, $2 \%(\mathrm{w} / \mathrm{v})$ amphotericin B)

- Training: not reported

- Procedures: gel was applied by a nurse (gloved finger or spatula) or by the patient (clean finger) to the mucous membranes of the mouth

- Provided by: nurse or patient

- Delivery: face-to-face; $1: 1$; acute stroke assessment units, hospital

- Regimen: 4 times daily. Treatment duration for participants with 'unsafe swallow' was 3 weeks; for participants with a 'safe swallow' was 2 weeks

- Tailoring: none 
Gosney 2006 (Continued)

- Modification: none

- Adherence: not reported

\section{Placebo gel}

- Intervention: placebo

- Materials: placebo gel $500 \mathrm{mg}$

- Procedures: gel was applied by a nurse (gloved finger or spatula) or by the patient (clean finger) to the mucous membranes of the mouth

- Provided by: nurse or patient

- Delivery: face-to-face; $1: 1$; acute stroke assessment units, hospital

- Regimen: 4 times daily. Treatment duration for participants with 'unsafe swallow' was 3 weeks; for participants with a 'safe swallow' was 2 weeks

- Tailoring: none

- Modification: none

- Adherence: not reported

\section{Outcomes}

Outcomes: colonisation by AGNB; carriage of AGNB on $\geq 2$ consecutive samples; septicaemia or respiratory tract infections (or both) during hospital stay; pneumonia; BI; Scandinavian Stroke Scale; administration of antibiotics

Data collection: oral swabs obtained at baseline, and 3 days/week for 3 weeks; BI and Scandinavian Stroke Scale measured at baseline, days 8 and 15 of hospital stay; clinical signs and symptoms of pneumonia and antibiotics prescribed were obtained from case notes

\begin{tabular}{ll}
\hline Funding & $\begin{array}{l}1 \text { study author (AEW) was employed as a research nurse by the funding body. Authors declared that } \\
\text { they had no conflicts of interest. Study funded by Northwest Zonal Research and Development }\end{array}$ \\
\hline Notes & Dropouts are detailed in Table 6 \\
& Statistical data included within the review meta-analyses \\
\hline
\end{tabular}

\section{Risk of bias}

\begin{tabular}{|c|c|c|}
\hline Bias & Authors' judgement & Support for judgement \\
\hline $\begin{array}{l}\text { Random sequence genera- } \\
\text { tion (selection bias) }\end{array}$ & Low risk & Comment: computer-generated random numbers. \\
\hline $\begin{array}{l}\text { Allocation concealment } \\
\text { (selection bias) }\end{array}$ & Low risk & Comment: research pharmacist conducted randomisation remotely. \\
\hline $\begin{array}{l}\text { Blinding of participants } \\
\text { and personnel (perfor- } \\
\text { mance bias) } \\
\text { All outcomes }\end{array}$ & Low risk & Comment: double-blind study. \\
\hline $\begin{array}{l}\text { Blinding of outcome as- } \\
\text { sessment (detection bias) } \\
\text { All outcomes }\end{array}$ & Low risk & Comment: double-blind study. \\
\hline $\begin{array}{l}\text { Incomplete outcome data } \\
\text { (attrition bias) } \\
\text { All outcomes }\end{array}$ & High risk & $\begin{array}{l}\text { Comment: dropouts not fully accounted for. } 20 \text { participants died, but } 19 \text { par- } \\
\text { ticipants withdrew. No explanation for the } 19 \text { withdrawals. ITT analysis not } \\
\text { employed. }\end{array}$ \\
\hline $\begin{array}{l}\text { Selective reporting (re- } \\
\text { porting bias) }\end{array}$ & High risk & $\begin{array}{l}\text { Comment: of } 203 \text { participants included at baseline, data only on } 164 \text { remain- } \\
\text { ing in study at follow-up. BI (on days } 8 \text { and } 15 \text { of hospital stay) and Scandina- } \\
\text { vian Stroke Scale (on days } 8 \text { and } 15 \text { of hospital stay) unreported. }\end{array}$ \\
\hline
\end{tabular}


Gosney 2006 (Continued)

Baseline data compara- Low risk Comment: groups comparable (gender, age, discharge destination). ble?

\begin{tabular}{lll}
\hline A priori power calculation & Unclear risk & Comment: not reported. \\
\hline Other bias & Low risk & Comment: none identified.
\end{tabular}

\section{Study characteristics}

\begin{tabular}{ll}
\hline Methods & RCT randomised at individual level, UK \\
& Study recruitment and setting details: see Table 1 \\
\hline Participants & Inclusions: within 24 hours of admission, first acute stroke \\
& Exclusions: receiving antibiotic or steroid medication (including inhaled steroids), prior stroke \\
& OHC gel group: 103 participants \\
& Placebo gel group: 100 participants \\
& Details of participants are shown in Table 2
\end{tabular}

\section{OHC gel (colistin, polymyxin, amphotericin B)}

- Intervention: selective decontamination of digestive tract oral gel

- Materials: Orabase gel, gloves, spatula

- Agent: Orabase $500 \mathrm{mg}$ gel (containing 2\% (w/v) colistin, 2\% (w/v) polymyxin E, 2\% (w/v) amphotericin B)

- Training: not reported

- Procedures: gel was applied by a nurse (gloved finger or spatula) or by the patient (clean finger) to the mucous membranes of the mouth

- Provided by: nurse or patient

- Delivery: face-to-face; 1:1; acute stroke assessment units, hospital

- Regimen: 4 times daily. Treatment duration for participants with 'unsafe swallow' was 3 weeks; for participants with a 'safe swallow' was 2 weeks

- Tailoring: none

- Modification: none

- Adherence: not reported

\section{Placebo gel}

- Intervention: placebo

- Materials: placebo gel $500 \mathrm{mg}$

- Procedures: gel was applied by a nurse (gloved finger or spatula) or by the patient (clean finger) to the mucous membranes of the mouth

- Provided by: nurse or patient

- Delivery: face-to-face; 1:1; acute stroke assessment units, hospital

- Regimen: 4 times daily. Treatment duration for participants with 'unsafe swallow' was 3 weeks; for participants with a 'safe swallow' was 2 weeks

- Tailoring: none

- Modification: none

- Adherence: not reported 
Gosney 2006 (Continued)

Outcomes

Outcomes: colonisation by AGNB; carriage of AGNB on $\geq 2$ consecutive samples; septicaemia or respiratory tract infections (or both) during hospital stay; pneumonia; BI; Scandinavian Stroke Scale; administration of antibiotics

Data collection: oral swabs obtained at baseline, and 3 days/week for 3 weeks; BI and Scandinavian Stroke Scale measured at baseline, days 8 and 15 of hospital stay; clinical signs and symptoms of pneumonia and antibiotics prescribed were obtained from case notes

Funding $\begin{aligned} & 1 \text { study author (AEW) was employed as a research nurse by the funding body. Authors declared that } \\ & \text { they had no conflicts of interest. Study funded by Northwest Zonal Research and Development }\end{aligned}$

Notes Dropouts are detailed in Table 6

Statistical data included within the review meta-analyses

\section{Risk of bias}

\begin{tabular}{|c|c|c|}
\hline Bias & Authors' judgement & Support for judgement \\
\hline $\begin{array}{l}\text { Random sequence genera- } \\
\text { tion (selection bias) }\end{array}$ & Low risk & Comment: computer-generated random numbers. \\
\hline $\begin{array}{l}\text { Allocation concealment } \\
\text { (selection bias) }\end{array}$ & Low risk & Comment: research pharmacist conducted randomisation remotely. \\
\hline $\begin{array}{l}\text { Blinding of participants } \\
\text { and personnel (perfor- } \\
\text { mance bias) } \\
\text { All outcomes }\end{array}$ & Low risk & Comment: double-blind study. \\
\hline $\begin{array}{l}\text { Blinding of outcome as- } \\
\text { sessment (detection bias) } \\
\text { All outcomes }\end{array}$ & Low risk & Comment: double-blind study. \\
\hline $\begin{array}{l}\text { Incomplete outcome data } \\
\text { (attrition bias) } \\
\text { All outcomes }\end{array}$ & High risk & $\begin{array}{l}\text { Comment: dropouts not fully accounted for. } 20 \text { participants died, but } 19 \text { par- } \\
\text { ticipants withdrew. No explanation for the } 19 \text { withdrawals. ITT analysis not } \\
\text { employed. }\end{array}$ \\
\hline $\begin{array}{l}\text { Selective reporting (re- } \\
\text { porting bias) }\end{array}$ & High risk & $\begin{array}{l}\text { Comment: of } 203 \text { participants included at baseline, data only on } 164 \text { remain- } \\
\text { ing in study at follow-up. BI (on days } 8 \text { and } 15 \text { of hospital stay) and Scandina- } \\
\text { vian Stroke Scale (on days } 8 \text { and } 15 \text { of hospital stay) unreported. }\end{array}$ \\
\hline $\begin{array}{l}\text { Baseline data compara- } \\
\text { ble? }\end{array}$ & Low risk & Comment: groups comparable (gender, age, discharge destination). \\
\hline A priori power calculation & Unclear risk & Comment: not reported. \\
\hline Other bias & Low risk & Comment: none identified. \\
\hline
\end{tabular}

Juthani-Mehta 2015

\section{Study characteristics}

\begin{tabular}{ll}
\hline Methods & Cluster-RCT randomised at nursing home level, USA \\
& Study recruitment and setting details: see Table 1
\end{tabular}


Juthani-Mehta 2015 (Continued)

Participants

Inclusion criteria: long-term care residents aged $>65$ years, resided at the nursing home for $\geq 1$ month, at least 1 of 2 modifiable risk factors for pneumonia (impaired oral hygiene, swallowing difficulty)

Exclusion criteria: housing for short-term rehabilitation, presence of a gastric or jejunostomy tube, presence of a tracheostomy, life expectancy $<3$ months, current use of chlorhexidene, pneumonia within the previous 6 weeks, previous enrolment in the study, unwillingness to give informed consent, non-English speaking, inappropriateness for the study in opinion of nursing home administration

Multi-component OHC group: 18 homes allocated (434 participants; of whom 100 had a stroke)

Usual care group: 18 homes allocated (400 participants; of whom 92 had a stroke)

Details of participants are shown in Table 2

Multi-component OHC intervention
- Interventions
- Materials: oral chlorhexidene
- Agent: $0.12 \%$ chlorhexidene oral rinse
- Training: study personnel trained nursing home staff about intervention procedures
- Procedures: manual tooth and gum brushing plus chlorhexidene oral rinse, plus upright positioning
- during feeding. Tailored to participants who could either perform self-care or required assistance
- Provided by: nursing aides
- Training provider: not reported
- Reginery: face-to-face; $1: 1 ;$ nursing home
- Duration: unclear but study participants were followed up for 2.5 years
- Tailoring: intervention protocol was tailored to participants who could either perform self-care or re-
- quired assistance (detailed in Supplementary Appendix of paper)
- Modification: none
Adherence: adherence to chlorhexidene and toothpaste usage were measured by comparing expect-
ed val volumes (Table 4). No dropouts reported

\section{Usual care}

- Intervention: standard care

- Materials: not reported

- Procedures: not reported

- Provided by: not reported

- Delivery: not reported

- Regimen: not reported

- Tailoring: not reported

- Modification: none

- Adherence: no dropouts reported

Outcomes Primary outcomes: radiographically documented pneumonia (Table 5)

Secondary outcomes: development of a first lower respiratory tract infection; adherence to chlorhexidine (compared expected vs actual chlorhexidine volume expenditure), oral brushing adherence (compared expected vs actual residual toothpaste tube weight), upright feeding positioning adherence was evaluated qualitatively once per month

Data collection: baseline and participants were followed for up to 2.5 years for development of primary outcome National Institute on Aging (NIA) (K23AG028691, R01AG030093 and P30AG021342) 
Juthani-Mehta 2015 (Continued)
Notes
Dropouts are detailed in Table 6
Statistical data not included within the review meta-analyses
Note: the number of stroke participants were reported but we were unable to access the outcome data specific to participants who had a stroke and so they were not included in the meta-analyses

\section{Risk of bias}

\begin{tabular}{lll}
\hline Bias & Authors' judgement & Support for judgement \\
\hline $\begin{array}{l}\text { Random sequence genera- } \\
\text { tion (selection bias) }\end{array}$ & Unclear risk & $\begin{array}{l}\text { Comment: nursing homes were stratified into } 2 \text { groups by number of minutes } \\
\text { that nursing aides spent with residents per day, }>140 \text { aide minutes were high } \\
\text { stratum, }<140 \text { minutes per day were low stratum. Homes were randomised } \\
\text { within stratum using a permuted block design. }\end{array}$ \\
\end{tabular}

\begin{tabular}{lll}
\hline $\begin{array}{l}\text { Allocation concealment } \\
\text { (selection bias) }\end{array}$ & Unclear risk & Comment: insufficient information. \\
\hline $\begin{array}{l}\text { Blinding of participants } \\
\text { and personnel (perfor- }\end{array}$ & Unclear risk & Comment: insufficient information. \\
mance bias) & & \\
All outcomes & &
\end{tabular}

\begin{tabular}{|c|c|c|}
\hline $\begin{array}{l}\text { Blinding of outcome as- } \\
\text { sessment (detection bias) } \\
\text { All outcomes }\end{array}$ & Low risk & $\begin{array}{l}\text { Comment: } 2 \text { investigators adjudicated all the outcomes, blinded to the ran- } \\
\text { domisation status of the participants and the cumulative incidence during the } \\
\text { trial. }\end{array}$ \\
\hline
\end{tabular}

\begin{tabular}{|c|c|c|}
\hline $\begin{array}{l}\text { Incomplete outcome data } \\
\text { (attrition bias) } \\
\text { All outcomes }\end{array}$ & Low risk & $\begin{array}{l}\text { Comment: dropouts accounted for. Missing outcome data balanced, with no } \\
\text { significance differences for either outcome between the } 2 \text { groups. ITT em- } \\
\text { ployed. }\end{array}$ \\
\hline $\begin{array}{l}\text { Selective reporting (re- } \\
\text { porting bias) }\end{array}$ & Low risk & Comment: all prespecified outcomes were reported. \\
\hline $\begin{array}{l}\text { Baseline data compara- } \\
\text { ble? }\end{array}$ & Low risk & $\begin{array}{l}\text { Comment: no difference in age, sex, race or ethnicity, comorbidities, mental } \\
\text { status, functional status except for } 1 \text { measure of behaviour (resists care). }\end{array}$ \\
\hline A priori power calculation & Low risk & $\begin{array}{l}\text { Comment: yes; target of } 828 \text { participants to detect a } 25 \% \text { reduction in pneu- } \\
\text { monia rate. }\end{array}$ \\
\hline Other bias & Unclear risk & $\begin{array}{l}\text { Comment; the study was terminated for futility as the conditional power under } \\
\text { observed treatment difference was nearly } 0 \text {. }\end{array}$ \\
\hline
\end{tabular}

Juthani-Mehta 2015

\section{Study characteristics}

\begin{tabular}{ll} 
Methods & Cluster-RCT randomised at nursing home level, USA \\
& Study recruitment and setting details: see Table 1 \\
\hline Participants & $\begin{array}{l}\text { Inclusion criteria: long-term care residents aged }>65 \text { years, resided at the nursing home for } \geq 1 \text { month, } \\
\text { at least } 1 \text { of } 2 \text { modifiable risk factors for pneumonia (impaired oral hygiene, swallowing difficulty) }\end{array}$ \\
Exclusion criteria: housing for short-term rehabilitation, presence of a gastric or jejunostomy tube, \\
presence of a tracheostomy, life expectancy $<3$ months, current use of chlorhexidene, pneumonia
\end{tabular}


Juthani-Mehta 2015 (Continued)

within the previous 6 weeks, previous enrolment in the study, unwillingness to give informed consent, non-English speaking, inappropriateness for the study in opinion of nursing home administration

Multi-component OHC group: 18 homes allocated (434 participants; of whom 100 had a stroke)

Usual care group: 18 homes allocated (400 participants; of whom 92 had a stroke)

Details of participants are shown in Table 2

Interventions

\section{Multi-component OHC intervention}

- Intervention: multi-component $\mathrm{OHC}$ intervention

- Materials: oral chlorhexidene

- Agent: $0.12 \%$ chlorhexidene oral rinse

- Training: study personnel trained nursing home staff about intervention procedures

- Procedures: manual tooth and gum brushing plus chlorhexidene oral rinse, plus upright positioning during feeding. Tailored to participants who could either perform self-care or required assistance

- Provided by: nursing aides

- Training provider: not reported

- Delivery: face-to-face; 1:1; nursing home

- Regimen: twice per day

- Duration: unclear but study participants were followed up for 2.5 years

- Tailoring: intervention protocol was tailored to participants who could either perform self-care or required assistance (detailed in Supplementary Appendix of paper)

- Modification: none

- Adherence: adherence to chlorhexidene and toothpaste usage were measured by comparing expected vs actual volumes (Table 4). No dropouts reported

\section{Usual care}

- Intervention: standard care

- Materials: not reported

- Procedures: not reported

- Provided by: not reported

- Delivery: not reported

- Regimen: not reported

- Tailoring: not reported

- Modification: none

- Adherence: no dropouts reported

Outcomes

Primary outcomes: radiographically documented pneumonia (Table 5)

Secondary outcomes: development of a first lower respiratory tract infection; adherence to chlorhexidine (compared expected vs actual chlorhexidine volume expenditure), oral brushing adherence (compared expected vs actual residual toothpaste tube weight), upright feeding positioning adherence was evaluated qualitatively once per month

Data collection: baseline and participants were followed for up to 2.5 years for development of primary outcome National Institute on Aging (NIA) (K23AG028691, R01AG030093 and P30AG021342)

\section{Notes}

Dropouts are detailed in Table 6

Statistical data not included within the review meta-analyses 
Juthani-Mehta 2015 (Continued)

Note: the number of stroke participants were reported but we were unable to access the outcome data specific to participants who had a stroke and so they were not included in the meta-analyses

\section{Risk of bias}

\begin{tabular}{|c|c|c|}
\hline Bias & Authors' judgement & Support for judgement \\
\hline $\begin{array}{l}\text { Random sequence genera- } \\
\text { tion (selection bias) }\end{array}$ & Unclear risk & $\begin{array}{l}\text { Comment: nursing homes were stratified into } 2 \text { groups by number of minutes } \\
\text { that nursing aides spent with residents per day, }>140 \text { aide minutes were high } \\
\text { stratum, }<140 \text { minutes per day were low stratum. Homes were randomised } \\
\text { within stratum using a permuted block design. }\end{array}$ \\
\hline $\begin{array}{l}\text { Allocation concealment } \\
\text { (selection bias) }\end{array}$ & Unclear risk & Comment: insufficient information. \\
\hline $\begin{array}{l}\text { Blinding of participants } \\
\text { and personnel (perfor- } \\
\text { mance bias) } \\
\text { All outcomes }\end{array}$ & Unclear risk & Comment: insufficient information. \\
\hline $\begin{array}{l}\text { Blinding of outcome as- } \\
\text { sessment (detection bias) } \\
\text { All outcomes }\end{array}$ & Low risk & $\begin{array}{l}\text { Comment: } 2 \text { investigators adjudicated all the outcomes, blinded to the ran- } \\
\text { domisation status of the participants and the cumulative incidence during the } \\
\text { trial. }\end{array}$ \\
\hline $\begin{array}{l}\text { Incomplete outcome data } \\
\text { (attrition bias) } \\
\text { All outcomes }\end{array}$ & Low risk & $\begin{array}{l}\text { Comment: dropouts accounted for. Missing outcome data balanced, with no } \\
\text { significance differences for either outcome between the } 2 \text { groups. ITT em- } \\
\text { ployed. }\end{array}$ \\
\hline $\begin{array}{l}\text { Selective reporting (re- } \\
\text { porting bias) }\end{array}$ & Low risk & Comment: all prespecified outcomes were reported. \\
\hline $\begin{array}{l}\text { Baseline data compara- } \\
\text { ble? }\end{array}$ & Low risk & $\begin{array}{l}\text { Comment: no difference in age, sex, race or ethnicity, comorbidities, mental } \\
\text { status, functional status except for } 1 \text { measure of behaviour (resists care). }\end{array}$ \\
\hline A priori power calculation & Low risk & $\begin{array}{l}\text { Comment: yes; target of } 828 \text { participants to detect a } 25 \% \text { reduction in pneu- } \\
\text { monia rate. }\end{array}$ \\
\hline Other bias & Unclear risk & $\begin{array}{l}\text { Comment; the study was terminated for futility as the conditional power under } \\
\text { observed treatment difference was nearly } 0 \text {. }\end{array}$ \\
\hline
\end{tabular}

Kim 2014a

\section{Study characteristics}

\begin{tabular}{ll}
\hline Methods & RCT randomised at individual level, South Korea \\
& Study recruitment and setting details: see Table 1 \\
\hline Participants & Inclusion criteria: first-ever stroke, had $\geq 6$ teeth and no sign of infection with any contagious pathogen \\
& Exclusion criteria: not reported \\
& OHC group: 29 participants \\
& Usual care group: 27 participants \\
& Details of participants are shown in Table 2 \\
\hline
\end{tabular}


Kim 2014a (Continued)

Interventions

\section{Multi-component OHC intervention}

- Intervention: OHC programme

- Materials: childrens toothbrush, interdental toothbrush, mouth gag (for unconscious patients), vacuum suction

- Agent: chlorhexidine

- Procedures: toothbrushes were used to remove tooth plaque, and tongue cleaner to remove tongue plaque. Gauze soaked in $0.5 \%$ chlorhexidine used to clean oral mucosa and tooth surface, vacuum suction performed to clean mouth

- Provided by: dentist

- Training: not reported

- Delivery: face-to-face; 1 -to-1

- Location: intensive care unit

- Regimen: once a day delivered over a mean period of dental intervention: 15.69 (SD 10.02) days

- Tailoring: none

- Modification: none

- Adherence: not reported

\section{Usual care}

- Intervention: no details; just referred to as a control group

- Materials: not reported

- Procedures: not reported

- Provided by: not reported

- Delivery: face-to-face; 1 -to-1

- Location: intensive care unit

- Regimen: mean period of dental intervention: 18.15 (SD 8.07) days

- Tailoring: not reported

- Modification: none

- Adherence: not reported

Outcomes

Outcomes: decayed missing and filled teeth index; Tooth Mobility Index; Loe and Silness Dental Plaque Index (Loe 1967); Gingival Index; clinical attachment loss; colonisation degree of Candida (under artificial lighting)

Data collection: baseline (after stabilisation of vital signs following intensive care unit admission) and post-treatment (before discharge: mean 2.2 weeks; range 1-5 weeks)

\section{Funding}

Study authors declared no financial conflicts of interest. Study funded by research grants from Yeung-nam University (2010)

Notes Dropouts are detailed in Table 6

Statistical data included within the review meta-analyses

\section{Risk of bias}

\begin{tabular}{lll}
\hline Bias & Authors' judgement & Support for judgement \\
\hline $\begin{array}{l}\text { Random sequence genera- } \\
\text { tion (selection bias) }\end{array}$ & Unclear risk & $\begin{array}{l}\text { Quote: "Patients were assigned randomly to two groups (intervention or con- } \\
\text { trol) matched with sex and age by a nurse who managed the Intensive Care } \\
\text { Unit and was independently involved in this research." }\end{array}$ \\
\hline $\begin{array}{l}\text { Allocation concealment } \\
\text { (selection bias) }\end{array}$ & Unclear risk & Comment: not reported. \\
\hline
\end{tabular}


Kim 2014a (Continued)

Blinding of participants Unclear risk Comment: not reported.
and personnel (perfor-
mance bias)
All outcomes

$\begin{array}{ll}\text { Blinding of outcome as- } & \text { Unclear risk }\end{array}$ Comment: not reported.

All outcomes

\begin{tabular}{|c|c|c|}
\hline $\begin{array}{l}\text { Incomplete outcome data } \\
\text { (attrition bias) }\end{array}$ & High risk & $\begin{array}{l}\text { Comment: dropouts accounted for but high attrition rate for both groups ( } 34 \\
\text { participants) reported in the first week after first oral examination. }\end{array}$ \\
\hline
\end{tabular}

\begin{tabular}{|c|c|c|}
\hline $\begin{array}{l}\text { Selective reporting (re- } \\
\text { porting bias) }\end{array}$ & Low risk & Comment: all prespecified outcomes reported. \\
\hline $\begin{array}{l}\text { Baseline data compara- } \\
\text { ble? }\end{array}$ & Low risk & $\begin{array}{l}\text { Comment: groups were comparable for demographic and disease characteris- } \\
\text { tics. More participants in the multi-component } \mathrm{OHC} \text { intervention } 45 \text { - to 54-year } \\
\text { age group compared with usual care group. This was not significant across the } \\
\text { entire age range. }\end{array}$ \\
\hline A priori power calculation & Unclear risk & Comment: not reported. \\
\hline Other bias & High risk & $\begin{array}{l}\text { Quote: "Complete randomisation was not performed throughout the entire } \\
\text { process of the research." } \\
\text { Comment: no other details reported. }\end{array}$ \\
\hline
\end{tabular}

Kim 2014a

\section{Study characteristics}

\begin{tabular}{|c|c|}
\hline Methods & $\begin{array}{l}\text { RCT randomised at individual level, South Korea } \\
\text { Study recruitment and setting details: see Table } 1\end{array}$ \\
\hline Participants & $\begin{array}{l}\text { Inclusion criteria: first-ever stroke, had } \geq 6 \text { teeth and no sign of infection with any contagious pathogen } \\
\text { Exclusion criteria: not reported } \\
\text { OHC group: } 29 \text { participants } \\
\text { Usual care group: } 27 \text { participants } \\
\text { Details of participants are shown in Table } 2\end{array}$ \\
\hline Interventions & $\begin{array}{l}\text { Multi-component OHC intervention } \\
\text { - Intervention: OHC programme } \\
\text { - Materials: childrens toothbrush, interdental toothbrush, mouth gag (for unconscious patients), vacu- } \\
\text { um suction } \\
\text { - Agent: chlorhexidine } \\
\text { - Procedures: toothbrushes were used to remove tooth plaque, and tongue cleaner to remove tongue } \\
\text { plaque. Gauze soaked in } 0.5 \% \text { chlorhexidine used to clean oral mucosa and tooth surface, vacuum } \\
\text { suction performed to clean mouth } \\
\text { - Provided by: dentist } \\
\text { - Training: not reported }\end{array}$ \\
\hline
\end{tabular}


Kim 2014a (Continued)

- Delivery: face-to-face; 1 -to-1

- Location: intensive care unit

- Regimen: once a day delivered over a mean period of dental intervention: 15.69 (SD 10.02) days

- Tailoring: none

- Modification: none

- Adherence: not reported

\section{Usual care}

- Intervention: no details; just referred to as a control group

- Materials: not reported

- Procedures: not reported

- Provided by: not reported

- Delivery: face-to-face; 1-to-1

- Location: intensive care unit

- Regimen: mean period of dental intervention: 18.15 (SD 8.07) days

- Tailoring: not reported

- Modification: none

- Adherence: not reported

Outcomes

Outcomes: decayed missing and filled teeth index; Tooth Mobility Index; Loe and Silness Dental Plaque Index (Loe 1967); Gingival Index; clinical attachment loss; colonisation degree of Candida (under artificial lighting)

Data collection: baseline (after stabilisation of vital signs following intensive care unit admission) and post-treatment (before discharge: mean 2.2 weeks; range 1-5 weeks)

Funding

Study authors declared no financial conflicts of interest. Study funded by research grants from Yeung-nam University (2010)

Notes Dropouts are detailed in Table 6

Statistical data included within the review meta-analyses

\section{Risk of bias}

\begin{tabular}{lll}
\hline Bias & Authors' judgement & Support for judgement \\
\hline $\begin{array}{l}\text { Random sequence genera- } \\
\text { tion (selection bias) }\end{array}$ & Unclear risk & $\begin{array}{l}\text { Quote: "Patients were assigned randomly to two groups (intervention or con- } \\
\text { trol) matched with sex and age by a nurse who managed the Intensive Care } \\
\text { Unit and was independently involved in this research." }\end{array}$ \\
\hline $\begin{array}{l}\text { Allocation concealment } \\
\text { (selection bias) }\end{array}$ & Unclear risk & Comment: not reported. \\
\hline $\begin{array}{l}\text { Blinding of participants } \\
\begin{array}{l}\text { and personnel (perfor- } \\
\text { mance bias) } \\
\text { All outcomes }\end{array}\end{array}$ & Unclear risk & Comment: not reported. \\
\hline
\end{tabular}

Blinding of outcome as- $\quad$ Unclear risk Comment: not reported.
sessment (detection bias)
All outcomes

$\begin{array}{lll}\text { Incomplete outcome data } & \text { High risk } & \text { Comment: dropouts accounted for but high attrition rate for both groups (34 } \\ \text { (attrition bias) } & \text { participants) reported in the first week after first oral examination. } \\ \text { All outcomes } & \end{array}$

(attrition bias)
All outcomes

participants) reported in the first week after first oral examination. 
Kim 2014a (Continued)

Selective reporting (re- Low risk $\quad$ Comment: all prespecified outcomes reported.
porting bias)

Baseline data compara- Low risk ble?
Comment: groups were comparable for demographic and disease characteristics. More participants in the multi-component OHC intervention 45- to 54-year age group compared with usual care group. This was not significant across the entire age range.

\begin{tabular}{lll}
\hline A priori power calculation & Unclear risk & Comment: not reported. \\
\hline Other bias & High risk & $\begin{array}{l}\text { Quote: "Complete randomisation was not performed throughout the entire } \\
\text { process of the research." } \\
\end{array}$ \\
& Comment: no other details reported. \\
\hline
\end{tabular}

Kobayashi 2017i

\section{Study characteristics}

\begin{tabular}{ll}
\hline Methods & RCT randomised at individual level, Japan \\
& Study recruitment and setting details: see Table 1 \\
\hline Participants & Inclusion criteria: not reported \\
Exclusion criteria: receiving antibiotic or steroid therapy within 1 month before start of study & Sample size: quote: "60 participants randomly divided" \\
Details of participants are shown in Table 2
\end{tabular}

\section{Multi-component OHC intervention}

- Intervention: mouthwash and moisturising gel

- Materials: toothbrush (Dent EX; Lion Dental Products Company, Tokyo, Japan), mouthwash (ConCool Mouth Rinse; Weltec, Osaka, Japan), tongue brush (TongueMate Kamemizu Chem, Osaka, Japan), mouth gel (1 g containing glycerine, lactoferrin and whey protein; ConCool Mouth Gel; Weltec, Osaka, Japan), tongue scraper (Tongood; Molten, Hiroshima, Japan)

- Agent: mouthwash contained cetylpyridinium chloride (ConCool Mouth Rinse; Weltec, Osaka, Japan), mouth gel (1 g containing glycerine, lactoferrin and whey protein; ConCool Mouth Gel; Weltec, Osaka, Japan)

- Procedures: tooth and tongue cleaning once each day while participant was in a lying position. Teeth were cleaned for 3 minutes using a toothbrush immersed in mouthwash. Toothpaste was not applied. To clean the tongue, a tongue brush that was immersed in mouthwash was applied in 1 direction from the back to the tip of the tongue with a cleaning pressure of $100 \mathrm{gf}$ applied 5 times on each side. After wiping intraoral residues, the moisturising gel was applied to the surface of the tongue using an elastomeric tongue scraper

- Provided by: a dentist or 1 of 5 nurses

- Training: instructed on the method of $\mathrm{OHC}$ by the dentist

- Delivery: face-to-face; 1-to-1

- Location: hospital

- Regimen: specified oral cleaning (3 minutes) once each day for 2 weeks

- Tailoring: none

- Modification: none

- Adherence: not reported 
Kobayashi 2017i (Continued)

\section{Multi-component OHC intervention}

- Intervention: mouthwash

- Materials: toothbrush (Dent EX; Lion Dental Products Company, Tokyo, Japan), mouthwash (ConCool Mouth Rinse; Weltec, Osaka, Japan), tongue brush (TongueMate Kamemizu Chem, Osaka, Japan)

- Agent: mouthwash contained cetylpyridinium chloride (ConCool Mouth Rinse; Weltec, Osaka, Japan)

- Procedures: tooth and tongue cleaning once each day while participant was in a lying position. Teeth were cleaned for 3 minutes using a toothbrush immersed in mouthwash. Toothpaste was not applied. To clean the tongue, a tongue brush that was immersed in mouthwash was applied in 1 direction from the back to the tip of the tongue with a cleaning pressure of $100 \mathrm{gf}$ applied 5 times on each side

- Provided by: a dentist or 1 of 5 nurses

- Training: instructed on the method of $\mathrm{OHC}$ by the dentist

- Delivery: face-to-face; 1 -to-1

- Location: hospital

- Regimen: specified oral cleaning (3 minutes) once each day for 2 weeks

- Tailoring: none

- Modification: none

- Adherence: not reported

Outcomes

Outcomes: total number of anaerobic bacteria on the tongue surface, tongue coating index, moisture level of the tongue surface

Data collection: baseline, weeks 1 and 2

Funding Study authors declared no conflicts of interest. Study funded by Research Funding for Longesvity
Sciences (25-7) from the National Center for Geriatrics and Gerontology, Japan

Notes Dropouts are detailed in Table 6

Suitable statistical data permitting inclusion within the review meta-analyses unavailable

\section{Risk of bias}

\begin{tabular}{lll}
\hline Bias & Authors' judgement & Support for judgement \\
\hline $\begin{array}{l}\text { Random sequence genera- } \\
\text { tion (selection bias) }\end{array}$ & Unclear risk & $\begin{array}{l}\text { Quote: "... randomly divided into four groups according to the methods used } \\
\text { to clean the teeth and tongue." }\end{array}$ \\
\hline $\begin{array}{l}\text { Allocation concealment } \\
\text { (selection bias) }\end{array}$ & Unclear risk & Comment: not reported. \\
\hline $\begin{array}{l}\text { Blinding of participants } \\
\text { and personnel (perfor- } \\
\text { mance bias) } \\
\text { All outcomes }\end{array}$ & Unclear risk & Comment: not reported. \\
\hline
\end{tabular}

\begin{tabular}{lll}
\hline Blinding of outcome as- & Unclear risk & $\begin{array}{l}\text { Quote: "Measurements were carried out by one dentist who was excluded } \\
\text { sessment (detection bias) }\end{array}$
\end{tabular}
All outcomes

Comment: insufficient information.

\begin{tabular}{lll}
$\begin{array}{l}\text { Incomplete outcome data } \\
\text { (attrition bias) } \\
\text { All outcomes }\end{array}$ & Low risk & Comment: no CONSORT diagram, no dropouts reported. \\
\hline $\begin{array}{l}\text { Selective reporting (re- } \\
\text { porting bias) }\end{array}$ & High risk & $\begin{array}{l}\text { Comment: sample size for each group not reported and limited statistical in- } \\
\text { formation presented for each outcome measure. }\end{array}$
\end{tabular}


Kobayashi 2017i (Continued)

Baseline data compara- Unclear risk Comment: study authors reported no significant difference between groups on ble? outcome measures at baseline; however, no baseline demographics reported so unable to judge whether the groups were comparable.

\begin{tabular}{lll}
\hline A priori power calculation & Unclear risk & Comment: not reported. \\
\hline Other bias & Unclear risk & Comment: limited data reported in the study. \\
\hline
\end{tabular}

Kobayashi 2017i

\section{Study characteristics}

$\begin{array}{ll}\text { Methods } & \text { RCT randomised at individual level, Japan } \\ \text { Study recruitment and setting details: see Table } 1\end{array}$

Participants Inclusion criteria: not reported

Exclusion criteria: receiving antibiotic or steroid therapy within 1 month before start of study

Sample size: quote: "60 participants randomly divided"

Details of participants are shown in Table 2

\section{Multi-component OHC intervention}

- Intervention: mouthwash and moisturising gel

- Materials: toothbrush (Dent EX; Lion Dental Products Company, Tokyo, Japan), mouthwash (ConCool Mouth Rinse; Weltec, Osaka, Japan), tongue brush (TongueMate Kamemizu Chem, Osaka, Japan), mouth gel (1 g containing glycerine, lactoferrin and whey protein; ConCool Mouth Gel; Weltec, Osaka, Japan), tongue scraper (Tongood; Molten, Hiroshima, Japan)

- Agent: mouthwash contained cetylpyridinium chloride (ConCool Mouth Rinse; Weltec, Osaka, Japan), mouth gel (1 g containing glycerine, lactoferrin and whey protein; ConCool Mouth Gel; Weltec, Osaka, Japan)

- Procedures: tooth and tongue cleaning once each day while participant was in a lying position. Teeth were cleaned for 3 minutes using a toothbrush immersed in mouthwash. Toothpaste was not applied. To clean the tongue, a tongue brush that was immersed in mouthwash was applied in 1 direction from the back to the tip of the tongue with a cleaning pressure of $100 \mathrm{gf}$ applied 5 times on each side. After wiping intraoral residues, the moisturising gel was applied to the surface of the tongue using an elastomeric tongue scraper

- Provided by: a dentist or 1 of 5 nurses

- Training: instructed on the method of $\mathrm{OHC}$ by the dentist

- Delivery: face-to-face; 1-to-1

- Location: hospital

- Regimen: specified oral cleaning (3 minutes) once each day for 2 weeks

- Tailoring: none

- Modification: none

- Adherence: not reported

\section{Multi-component $\mathrm{OHC}$ intervention}

- Intervention: mouthwash

- Materials: toothbrush (Dent EX; Lion Dental Products Company, Tokyo, Japan), mouthwash (ConCool Mouth Rinse; Weltec, Osaka, Japan), tongue brush (TongueMate Kamemizu Chem, Osaka, Japan)

- Agent: mouthwash contained cetylpyridinium chloride (ConCool Mouth Rinse; Weltec, Osaka, Japan) 
- Procedures: tooth and tongue cleaning once each day while participant was in a lying position. Teeth were cleaned for 3 minutes using a toothbrush immersed in mouthwash. Toothpaste was not applied. To clean the tongue, a tongue brush that was immersed in mouthwash was applied in 1 direction from the back to the tip of the tongue with a cleaning pressure of 100 gf applied 5 times on each side

- Provided by: a dentist or 1 of 5 nurses

- Training: instructed on the method of $\mathrm{OHC}$ by the dentist

- Delivery: face-to-face; 1-to-1

- Location: hospital

- Regimen: specified oral cleaning (3 minutes) once each day for 2 weeks

- Tailoring: none

- Modification: none

- Adherence: not reported

Outcomes

Outcomes: total number of anaerobic bacteria on the tongue surface, tongue coating index, moisture level of the tongue surface

Data collection: baseline, weeks 1 and 2

Funding Study authors declared no conflicts of interest. Study funded by Research Funding for Longesvity Sciences (25-7) from the National Center for Geriatrics and Gerontology, Japan

Notes Dropouts are detailed in Table 6

Suitable statistical data permitting inclusion within the review meta-analyses unavailable

\section{Risk of bias}

\begin{tabular}{|c|c|c|}
\hline Bias & Authors' judgement & Support for judgement \\
\hline $\begin{array}{l}\text { Random sequence genera- } \\
\text { tion (selection bias) }\end{array}$ & Unclear risk & $\begin{array}{l}\text { Quote: "... randomly divided into four groups according to the methods used } \\
\text { to clean the teeth and tongue." }\end{array}$ \\
\hline $\begin{array}{l}\text { Allocation concealment } \\
\text { (selection bias) }\end{array}$ & Unclear risk & Comment: not reported. \\
\hline $\begin{array}{l}\text { Blinding of participants } \\
\text { and personnel (perfor- } \\
\text { mance bias) } \\
\text { All outcomes }\end{array}$ & Unclear risk & Comment: not reported. \\
\hline $\begin{array}{l}\text { Blinding of outcome as- } \\
\text { sessment (detection bias) } \\
\text { All outcomes }\end{array}$ & Unclear risk & $\begin{array}{l}\text { Quote: "Measurements were carried out by one dentist who was excluded } \\
\text { from carrying out the oral cleaning." } \\
\text { Comment: insufficient information. }\end{array}$ \\
\hline $\begin{array}{l}\text { Incomplete outcome data } \\
\text { (attrition bias) } \\
\text { All outcomes }\end{array}$ & Low risk & Comment: no CONSORT diagram, no dropouts reported. \\
\hline $\begin{array}{l}\text { Selective reporting (re- } \\
\text { porting bias) }\end{array}$ & High risk & $\begin{array}{l}\text { Comment: sample size for each group not reported and limited statistical in- } \\
\text { formation presented for each outcome measure. }\end{array}$ \\
\hline $\begin{array}{l}\text { Baseline data compara- } \\
\text { ble? }\end{array}$ & Unclear risk & $\begin{array}{l}\text { Comment: study authors reported no significant difference between groups on } \\
\text { outcome measures at baseline; however, no baseline demographics reported } \\
\text { so unable to judge whether the groups were comparable. }\end{array}$ \\
\hline
\end{tabular}

A priori power calculation Unclear risk Comment: not reported.


Kobayashi 2017i (Continued)

Other bias Unclear risk Comment: limited data reported in the study.

Kobayashi 2017ii

\section{Study characteristics}

Methods RCT randomised at individual level, Japan

Study recruitment and setting details: see Table 1

Participants Inclusion criteria: not reported

Exclusion criteria: receiving antibiotic or steroid therapy within 1 month before start of study

Sample size: quote: "60 participants randomly divided."

Details of participants are shown in Table 2

Interventions

Multi-component OHC intervention

- Intervention: mouthwash and gel

- Materials: toothbrush (Dent EX; Lion Dental Products Company, Tokyo, Japan), mouthwash (ConCool Mouth Rinse; Weltec, Osaka, Japan), tongue brush (TongueMate Kamemizu Chem, Osaka, Japan), mouth gel ( $1 \mathrm{~g}$ containing glycerine, lactoferrin and whey protein: ConCool Mouth Gel; Weltec, Osaka, Japan), tongue scraper (Tongood; Molten, Hiroshima, Japan)

- Agent: mouthwash contained cetylpyridinium chloride (ConCool Mouth Rinse; Weltec, Osaka, Japan), mouth gel (1 g containing glycerine, lactoferrin and whey protein: ConCool Mouth Gel; Weltec, Osaka, Japan)

- Procedures: tooth and tongue cleaning once each day while participant was in a lying position. Teeth were cleaned for 3 minutes using a toothbrush immersed in mouthwash. Toothpaste was not applied. To clean the tongue, a tongue brush that was immersed in mouthwash was applied in 1 direction from the back to the tip of the tongue with a cleaning pressure of $100 \mathrm{gf}$ applied 5 times on each side. After wiping intraoral residues, the moisturising gel was applied to the surface of the tongue using an elastomeric tongue scraper

- Provided by: a dentist or 1 of 5 nurses

- Training: instructed on the method of $\mathrm{OHC}$ by the dentist

- Delivery: face-to-face; 1 -to-1

- Location: hospital

- Regimen: specified oral cleaning (3 minutes) once each day for 2 weeks

- Tailoring: none

- Modification: none

- Adherence: no dropouts reported

\section{Multi-component OHC intervention}

- Intervention: water and moisturising gel

- Materials: toothbrush (Dent EX; Lion Dental Products Company, Tokyo, Japan), mouth gel (1 g containing glycerine, lactoferrin and whey protein: ConCool Mouth Gel; Weltec, Osaka, Japan), tongue scraper (Tongood; Molten, Hiroshima, Japan)

- Agent: mouth gel (1 g containing glycerine, lactoferrin and whey protein: ConCool Mouth Gel; Weltec, Osaka, Japan)

- Procedures: tooth and tongue cleaning once each day while participant was in a lying position. Teeth were cleaned for 3 minutes using a toothbrush immersed in water. Toothpaste was not applied. To clean the tongue, a tongue brush that was immersed in water was applied in applied in 1 direction from the back to the tip of the tongue with a cleaning pressure of $100 \mathrm{gf}$ applied 5 times on each side. 
Kobayashi 2017ii (Continued)

After wiping intraoral residues, the moisturising gel was applied to the surface of the tongue using an elastomeric tongue scraper

- Provided by: a dentist or 1 of 5 nurses

- Training: instructed on the method of oral cleaning by the dentist

- Delivery: face-to-face; 1-to-1

- Location: hospital

- Regimen: specified oral cleaning (3 minutes) once each day for 2 weeks

- Tailoring: none

- Modification: none

- Adherence: no dropouts reported

Outcomes Outcomes: total number of anaerobic bacteria on the tongue surface, tongue coating index, moisture level of the tongue surface

Data collection: baseline, week 1 and 2

$\begin{array}{ll}\text { Funding } & \text { Study authors declared no conflicts of interest. Study funded by Research Funding for Longesvity } \\ \text { Sciences (25-7) from the National Center for Geriatrics and Gerontology, Japan }\end{array}$
Sciences (25-7) from the National Center for Geriatrics and Gerontology, Japan

\begin{tabular}{ll}
\hline Notes & Dropouts are detailed in Table 6 \\
& Suitable statistical data permitting inclusion within the review meta-analyses unavailable
\end{tabular}

\section{Risk of bias}

\begin{tabular}{|c|c|c|}
\hline Bias & Authors' judgement & Support for judgement \\
\hline $\begin{array}{l}\text { Random sequence genera- } \\
\text { tion (selection bias) }\end{array}$ & Unclear risk & $\begin{array}{l}\text { Quote: "... randomly divided into four groups according to the methods used } \\
\text { to clean the teeth and tongue." }\end{array}$ \\
\hline $\begin{array}{l}\text { Allocation concealment } \\
\text { (selection bias) }\end{array}$ & Unclear risk & Comment: not reported. \\
\hline $\begin{array}{l}\text { Blinding of participants } \\
\text { and personnel (perfor- } \\
\text { mance bias) } \\
\text { All outcomes }\end{array}$ & Unclear risk & Comment: not reported. \\
\hline $\begin{array}{l}\text { Blinding of outcome as- } \\
\text { sessment (detection bias) } \\
\text { All outcomes }\end{array}$ & Unclear risk & $\begin{array}{l}\text { Quote: "measurements were carried out by one dentist who was excluded } \\
\text { from carrying out the oral cleaning." } \\
\text { Comment: insufficient information. }\end{array}$ \\
\hline $\begin{array}{l}\text { Incomplete outcome data } \\
\text { (attrition bias) } \\
\text { All outcomes }\end{array}$ & Low risk & Comment: no CONSORT diagram, no dropouts reported. \\
\hline $\begin{array}{l}\text { Selective reporting (re- } \\
\text { porting bias) }\end{array}$ & High risk & $\begin{array}{l}\text { Comment: sample size for each group not reported and limited statistical in- } \\
\text { formation presented for each outcome measure. }\end{array}$ \\
\hline $\begin{array}{l}\text { Baseline data compara- } \\
\text { ble? }\end{array}$ & Unclear risk & $\begin{array}{l}\text { Comment: study authors reported no significant difference between groups on } \\
\text { outcome measures at baseline; however, no baseline demographics reported } \\
\text { so unable to judge whether the groups were comparable. }\end{array}$ \\
\hline A priori power calculation & Unclear risk & Comment: not reported. \\
\hline Other bias & Unclear risk & Comment: limited data reported in the study. \\
\hline
\end{tabular}


Kobayashi 2017ii

\section{Study characteristics}

\begin{tabular}{ll} 
Methods & RCT randomised at individual level, Japan \\
& Study recruitment and setting details: see Table 1 \\
\hline Participants & Inclusion criteria: not reported \\
& Exclusion criteria: receiving antibiotic or steroid therapy within 1 month before start of study \\
& Sample size: quote: "60 participants randomly divided." \\
& Details of participants are shown in Table 2
\end{tabular}

Multi-component $\mathrm{OHC}$ intervention

- Intervention: mouthwash and gel

- Materials: toothbrush (Dent EX; Lion Dental Products Company, Tokyo, Japan), mouthwash (ConCool Mouth Rinse; Weltec, Osaka, Japan), tongue brush (TongueMate Kamemizu Chem, Osaka, Japan), mouth gel (1 g containing glycerine, lactoferrin and whey protein: ConCool Mouth Gel; Weltec, Osaka, Japan), tongue scraper (Tongood; Molten, Hiroshima, Japan)

- Agent: mouthwash contained cetylpyridinium chloride (ConCool Mouth Rinse; Weltec, Osaka, Japan), mouth gel (1 g containing glycerine, lactoferrin and whey protein: ConCool Mouth Gel; Weltec, Osaka, Japan)

- Procedures: tooth and tongue cleaning once each day while participant was in a lying position. Teeth were cleaned for 3 minutes using a toothbrush immersed in mouthwash. Toothpaste was not applied. To clean the tongue, a tongue brush that was immersed in mouthwash was applied in 1 direction from the back to the tip of the tongue with a cleaning pressure of $100 \mathrm{gf}$ applied 5 times on each side. After wiping intraoral residues, the moisturising gel was applied to the surface of the tongue using an elastomeric tongue scraper

- Provided by: a dentist or 1 of 5 nurses

- Training: instructed on the method of $\mathrm{OHC}$ by the dentist

- Delivery: face-to-face; 1 -to-1

- Location: hospital

- Regimen: specified oral cleaning (3 minutes) once each day for 2 weeks

- Tailoring: none

- Modification: none

- Adherence: no dropouts reported

\section{Multi-component OHC intervention}

- Intervention: water and moisturising gel

- Materials: toothbrush (Dent EX; Lion Dental Products Company, Tokyo, Japan), mouth gel (1 g containing glycerine, lactoferrin and whey protein: ConCool Mouth Gel; Weltec, Osaka, Japan), tongue scraper (Tongood; Molten, Hiroshima, Japan)

- Agent: mouth gel (1 g containing glycerine, lactoferrin and whey protein: ConCool Mouth Gel; Weltec, Osaka, Japan)

- Procedures: tooth and tongue cleaning once each day while participant was in a lying position. Teeth were cleaned for 3 minutes using a toothbrush immersed in water. Toothpaste was not applied. To clean the tongue, a tongue brush that was immersed in water was applied in applied in 1 direction from the back to the tip of the tongue with a cleaning pressure of $100 \mathrm{gf}$ applied 5 times on each side. After wiping intraoral residues, the moisturising gel was applied to the surface of the tongue using an elastomeric tongue scraper

- Provided by: a dentist or 1 of 5 nurses

- Training: instructed on the method of oral cleaning by the dentist

- Delivery: face-to-face; 1-to-1 
Kobayashi 2017ii (Continued)

- Location: hospital

- Regimen: specified oral cleaning (3 minutes) once each day for 2 weeks

- Tailoring: none

- Modification: none

- Adherence: no dropouts reported

\begin{tabular}{|c|c|c|}
\hline Outcomes & \multicolumn{2}{|c|}{$\begin{array}{l}\text { Outcomes: total number of anaerobic bacteria on the tongue surface, tongue coating index, moisture } \\
\text { level of the tongue surface } \\
\text { Data collection: baseline, week } 1 \text { and } 2\end{array}$} \\
\hline Funding & \multicolumn{2}{|c|}{$\begin{array}{l}\text { Study authors declared no conflicts of interest. Study funded by Research Funding for Longesvity } \\
\text { Sciences (25-7) from the National Center for Geriatrics and Gerontology, Japan }\end{array}$} \\
\hline Notes & \multicolumn{2}{|c|}{$\begin{array}{l}\text { Dropouts are detailed in Table } 6 \\
\text { Suitable statistical data permitting inclusion within the review meta-analyses unavailable }\end{array}$} \\
\hline \multicolumn{3}{|l|}{ Risk of bias } \\
\hline Bias & Authors' judgement & Support for judgement \\
\hline $\begin{array}{l}\text { Random sequence genera- } \\
\text { tion (selection bias) }\end{array}$ & Unclear risk & $\begin{array}{l}\text { Quote: "... randomly divided into four groups according to the methods used } \\
\text { to clean the teeth and tongue." }\end{array}$ \\
\hline $\begin{array}{l}\text { Allocation concealment } \\
\text { (selection bias) }\end{array}$ & Unclear risk & Comment: not reported. \\
\hline $\begin{array}{l}\text { Blinding of participants } \\
\text { and personnel (perfor- } \\
\text { mance bias) } \\
\text { All outcomes }\end{array}$ & Unclear risk & Comment: not reported. \\
\hline
\end{tabular}

\begin{tabular}{|c|c|c|}
\hline $\begin{array}{l}\text { Blinding of outcome as- } \\
\text { sessment (detection bias) }\end{array}$ & Unclear risk & $\begin{array}{l}\text { Quote: "measurements were carried out by one dentist who was excluded } \\
\text { from carrying out the oral cleaning." }\end{array}$ \\
\hline
\end{tabular}

All outcomes

Comment: insufficient information.

Incomplete outcome data Low risk Comment: no CONSORT diagram, no dropouts reported.

(attrition bias)

All outcomes

\begin{tabular}{lll}
\hline $\begin{array}{l}\text { Selective reporting (re- } \\
\text { porting bias) }\end{array}$ & High risk & $\begin{array}{l}\text { Comment: sample size for each group not reported and limited statistical in- } \\
\text { formation presented for each outcome measure. }\end{array}$
\end{tabular}

\begin{tabular}{lll}
\hline $\begin{array}{l}\text { Baseline data compara- } \\
\text { ble? }\end{array}$ & Unclear risk & $\begin{array}{l}\text { Comment: study authors reported no significant difference between groups on } \\
\text { outcome measures at baseline; however, no baseline demographics reported } \\
\text { so unable to judge whether the groups were comparable. }\end{array}$ \\
\hline A priori power calculation & Unclear risk & Comment: not reported. \\
\hline Other bias & Unclear risk & Comment: limited data reported in the study. \\
\hline
\end{tabular}

\section{Study characteristics}

Interventions for improving oral health in people after stroke (Review) 
Kobayashi 2017iii (Continued)

Methods RCT randomised at individual level, Japan

Study recruitment and setting details: see Table 1

Participants Inclusion criteria: not reported

Exclusion criteria: receiving antibiotic or steroid therapy within 1 month before start of study

Sample size: not reported for each group (quote: "60 participants randomly divided")

Details of participants are shown in Table 2

Interventions

\section{Multi-component OHC intervention}

- Intervention: mouthwash and gel

- Materials: toothbrush (Dent EX; Lion Dental Products Company, Tokyo, Japan), mouthwash (ConCool Mouth Rinse; Weltec, Osaka, Japan), tongue brush (TongueMate Kamemizu Chem, Osaka, Japan), mouth gel (1 g containing glycerine, lactoferrin and whey protein: ConCool Mouth Gel; Weltec, Osaka, Japan), tongue scraper (Tongood; Molten, Hiroshima, Japan)

- Agent: mouthwash contained cetylpyridinium chloride (ConCool Mouth Rinse; Weltec, Osaka, Japan), mouth gel (1 g containing glycerine, lactoferrin and whey protein: ConCool Mouth Gel; Weltec, Osaka, Japan)

- Procedures: tooth and tongue cleaning once each day while participant was in a lying position. Teeth were cleaned for 3 minutes using a toothbrush immersed in mouthwash. Toothpaste was not applied. To clean the tongue, a tongue brush that was immersed in mouthwash was applied in 1 direction from the back to the tip of the tongue with a cleaning pressure of $100 \mathrm{gf}$ applied 5 times on each side. After wiping intraoral residues, the moisturising gel was applied to the surface of the tongue using an elastomeric tongue scraper

- Provided by: a dentist or 1 of 5 nurses

- Training: instructed on the method of $\mathrm{OHC}$ by the dentist

- Delivery: face-to-face; 1-to-1

- Location: hospital

- Regimen: specified oral cleaning (3 minutes) once each day for 2 weeks

- Tailoring: none

- Modification: none

- Adherence: no dropouts reported

\section{Multi-component OHC intervention}

- Intervention: water alone

- Materials: toothbrush (Dent EX; Lion Dental Products Company, Tokyo, Japan), tongue brush (TongueMate Kamemizu Chem, Osaka, Japan)

- Agent: none

- Procedures: tooth and tongue cleaning once each day while participant was in a lying position. Teeth were cleaned for 3 minutes using a toothbrush immersed in water. Toothpaste was not applied. To clean the tongue, a tongue brush that was immersed in water was applied in 1 direction from the back to the tip of the tongue with a cleaning pressure of $100 \mathrm{gf}$ applied 5 times on each side

- Provided by: a dentist or 1 of 5 nurses

- Training: instructed on the method of $\mathrm{OHC}$ by the dentist

- Delivery: face-to-face; 1-to-1

- Location: hospital

- Regimen: specified oral cleaning (3 minutes) once each day for 2 weeks

- Tailoring: none

- Modification: none

- Adherence: no dropouts reported 
Kobayashi 2017iii (Continued)

Outcomes

Outcomes: total number of anaerobic bacteria on the tongue surface, tongue coating index, moisture level of the tongue surface

Data collection: baseline, week 1 and 2

Funding

Study authors declared no conflicts of interest. Study funded by Research Funding for Longesvity Sciences (25-7) from the National Center for Geriatrics and Gerontology, Japan

Notes

Dropouts are detailed in Table 6

Suitable statistical data permitting inclusion within the review meta-analyses unavailable

\section{Risk of bias}

\begin{tabular}{|c|c|c|}
\hline Bias & Authors' judgement & Support for judgement \\
\hline $\begin{array}{l}\text { Random sequence genera- } \\
\text { tion (selection bias) }\end{array}$ & Unclear risk & $\begin{array}{l}\text { Quote: "randomly divided into four groups according to the methods used to } \\
\text { clean the teeth and tongue." }\end{array}$ \\
\hline $\begin{array}{l}\text { Allocation concealment } \\
\text { (selection bias) }\end{array}$ & Unclear risk & Comment: not reported. \\
\hline $\begin{array}{l}\text { Blinding of participants } \\
\text { and personnel (perfor- } \\
\text { mance bias) } \\
\text { All outcomes }\end{array}$ & Unclear risk & Comment: not reported. \\
\hline $\begin{array}{l}\text { Blinding of outcome as- } \\
\text { sessment (detection bias) } \\
\text { All outcomes }\end{array}$ & Unclear risk & $\begin{array}{l}\text { Quote: "measurements were carried out by one dentist who was excluded } \\
\text { from carrying out the oral cleaning." } \\
\text { Comment: insufficient information. }\end{array}$ \\
\hline $\begin{array}{l}\text { Incomplete outcome data } \\
\text { (attrition bias) } \\
\text { All outcomes }\end{array}$ & Low risk & Comment: no CONSORT diagram, no dropouts reported. \\
\hline $\begin{array}{l}\text { Selective reporting (re- } \\
\text { porting bias) }\end{array}$ & High risk & $\begin{array}{l}\text { Comment: sample size for each group not reported and limited statistical in- } \\
\text { formation presented for each outcome measure. }\end{array}$ \\
\hline $\begin{array}{l}\text { Baseline data compara- } \\
\text { ble? }\end{array}$ & Unclear risk & $\begin{array}{l}\text { Comment: study authors reported no significant difference between groups on } \\
\text { outcome measures at baseline; however, no baseline demographics reported } \\
\text { so unable to judge whether the groups were comparable. }\end{array}$ \\
\hline A priori power calculation & Unclear risk & Comment: not reported. \\
\hline Other bias & Unclear risk & Comment: limited data reported in the study. \\
\hline
\end{tabular}

Kobayashi 2017 iii

\section{Study characteristics}

\begin{tabular}{ll}
\hline Methods & RCT randomised at individual level, Japan \\
& Study recruitment and setting details: see Table 1 \\
\hline Participants & Inclusion criteria: not reported
\end{tabular}


Sample size: not reported for each group (quote: "60 participants randomly divided")

Details of participants are shown in Table 2

- Intervention: mouthwash and gel

- Materials: toothbrush (Dent EX; Lion Dental Products Company, Tokyo, Japan), mouthwash (ConCool Mouth Rinse; Weltec, Osaka, Japan), tongue brush (TongueMate Kamemizu Chem, Osaka, Japan), mouth gel (1 g containing glycerine, lactoferrin and whey protein: ConCool Mouth Gel; Weltec, Osaka, Japan), tongue scraper (Tongood; Molten, Hiroshima, Japan)

- Agent: mouthwash contained cetylpyridinium chloride (ConCool Mouth Rinse; Weltec, Osaka, Japan), mouth gel (1 g containing glycerine, lactoferrin and whey protein: ConCool Mouth Gel; Weltec, Osaka, Japan)

- Procedures: tooth and tongue cleaning once each day while participant was in a lying position. Teeth were cleaned for 3 minutes using a toothbrush immersed in mouthwash. Toothpaste was not applied. To clean the tongue, a tongue brush that was immersed in mouthwash was applied in 1 direction from the back to the tip of the tongue with a cleaning pressure of $100 \mathrm{gf}$ applied 5 times on each side. After wiping intraoral residues, the moisturising gel was applied to the surface of the tongue using an elastomeric tongue scraper

- Provided by: a dentist or 1 of 5 nurses

- Training: instructed on the method of $\mathrm{OHC}$ by the dentist

- Delivery: face-to-face; 1-to-1

- Location: hospital

- Regimen: specified oral cleaning (3 minutes) once each day for 2 weeks

- Tailoring: none

- Modification: none

- Adherence: no dropouts reported

\section{Multi-component OHC intervention}

- Intervention: water alone

- Materials: toothbrush (Dent EX; Lion Dental Products Company, Tokyo, Japan), tongue brush (TongueMate Kamemizu Chem, Osaka, Japan)

- Agent: none

- Procedures: tooth and tongue cleaning once each day while participant was in a lying position. Teeth were cleaned for 3 minutes using a toothbrush immersed in water. Toothpaste was not applied. To clean the tongue, a tongue brush that was immersed in water was applied in 1 direction from the back to the tip of the tongue with a cleaning pressure of $100 \mathrm{gf}$ applied 5 times on each side

- Provided by: a dentist or 1 of 5 nurses

- Training: instructed on the method of $\mathrm{OHC}$ by the dentist

- Delivery: face-to-face; 1 -to-1

- Location: hospital

- Regimen: specified oral cleaning (3 minutes) once each day for 2 weeks

- Tailoring: none

- Modification: none

- Adherence: no dropouts reported

Outcomes

Outcomes: total number of anaerobic bacteria on the tongue surface, tongue coating index, moisture level of the tongue surface

Data collection: baseline, week 1 and 2 
Kobayashi 2017iii (Continued)
Notes
Dropouts are detailed in Table 6
Suitable statistical data permitting inclusion within the review meta-analyses unavailable

\section{Risk of bias}

\begin{tabular}{|c|c|c|}
\hline Bias & Authors' judgement & Support for judgement \\
\hline $\begin{array}{l}\text { Random sequence genera- } \\
\text { tion (selection bias) }\end{array}$ & Unclear risk & $\begin{array}{l}\text { Quote: "randomly divided into four groups according to the methods used to } \\
\text { clean the teeth and tongue." }\end{array}$ \\
\hline $\begin{array}{l}\text { Allocation concealment } \\
\text { (selection bias) }\end{array}$ & Unclear risk & Comment: not reported. \\
\hline $\begin{array}{l}\text { Blinding of participants } \\
\text { and personnel (perfor- } \\
\text { mance bias) } \\
\text { All outcomes }\end{array}$ & Unclear risk & Comment: not reported. \\
\hline $\begin{array}{l}\text { Blinding of outcome as- } \\
\text { sessment (detection bias) } \\
\text { All outcomes }\end{array}$ & Unclear risk & $\begin{array}{l}\text { Quote: "measurements were carried out by one dentist who was excluded } \\
\text { from carrying out the oral cleaning." } \\
\text { Comment: insufficient information. }\end{array}$ \\
\hline $\begin{array}{l}\text { Incomplete outcome data } \\
\text { (attrition bias) } \\
\text { All outcomes }\end{array}$ & Low risk & Comment: no CONSORT diagram, no dropouts reported. \\
\hline $\begin{array}{l}\text { Selective reporting (re- } \\
\text { porting bias) }\end{array}$ & High risk & $\begin{array}{l}\text { Comment: sample size for each group not reported and limited statistical in- } \\
\text { formation presented for each outcome measure. }\end{array}$ \\
\hline $\begin{array}{l}\text { Baseline data compara- } \\
\text { ble? }\end{array}$ & Unclear risk & $\begin{array}{l}\text { Comment: study authors reported no significant difference between groups on } \\
\text { outcome measures at baseline; however, no baseline demographics reported } \\
\text { so unable to judge whether the groups were comparable. }\end{array}$ \\
\hline A priori power calculation & Unclear risk & Comment: not reported. \\
\hline Other bias & Unclear risk & Comment: limited data reported in the study. \\
\hline
\end{tabular}

Kobayashi 2017iv

\section{Study characteristics}

\begin{tabular}{ll}
\hline Methods & RCT randomised at individual level, Japan \\
& Study recruitment and setting details: see Table 1 \\
\hline Participants & Inclusion criteria: not reported \\
& Exclusion criteria: receiving antibiotic or steroid therapy within 1 month before start of study \\
& Sample size: quote: "60 participants randomly divided." \\
& Details of participants are shown in Table 2
\end{tabular}

\section{Multi-component OHC intervention}


- Intervention: mouthwash

- Materials: toothbrush (Dent EX; Lion Dental Products Company, Tokyo, Japan), mouthwash (ConCool Mouth Rinse; Weltec, Osaka, Japan), tongue brush (TongueMate Kamemizu Chem, Osaka, Japan)

- Agent: mouthwash contained cetylpyridinium chloride (ConCool Mouth Rinse; Weltec, Osaka, Japan)

- Procedures: tooth and tongue cleaning once each day while participant was in a lying position. Teeth were cleaned for 3 minutes using a toothbrush immersed in mouthwash. Toothpaste was not applied. To clean the tongue, a tongue brush that was immersed in mouthwash was applied in 1 direction from the back to the tip of the tongue with a cleaning pressure of $100 \mathrm{gf}$ applied 5 times on each side

- Provided by: a dentist or 1 of 5 nurses

- Training: instructed on the method of oral cleaning by the dentist

- Delivery: face-to-face; 1-to-1

- Location: hospital

- Regimen: specified oral cleaning (3 minutes) once each day for 2 weeks

- Tailoring: none

- Modification: none

- Adherence: no dropouts reported

\section{Multi-component OHC Intervention}

- Intervention: water and moisturising gel

- Materials: toothbrush (Dent EX; Lion Dental Products Company, Tokyo, Japan), mouth gel (1 g containing glycerine, lactoferrin and whey protein: ConCool Mouth Gel; Weltec, Osaka, Japan), tongue scraper (Tongood; Molten, Hiroshima, Japan)

- Agent: mouth gel (1 g containing glycerine, lactoferrin and whey protein: ConCool Mouth Gel; Weltec, Osaka, Japan)

- Procedures: tooth and tongue cleaning once each day while participant was in a lying position. Teeth were cleaned for 3 minutes using a toothbrush immersed in mouthwash. Toothpaste was not applied. To clean the tongue, a tongue brush that was immersed in mouthwash was applied in 1 direction from the back to the tip of the tongue with a cleaning pressure of $100 \mathrm{gf}$ applied 5 times on each side. After wiping intraoral residues, the moisturising gel was applied to the surface of the tongue using an elastomeric tongue scraper

- Provided by: a dentist or 1 of 5 nurses

- Training: instructed on the method of oral cleaning by the dentist

- Delivery: face-to-face; 1 -to-1

- Location: hospital

- Regimen: specified oral cleaning (3 minutes) once each day for 2 weeks

- Tailoring: none

- Modification: none

- Adherence: no dropouts reported

Outcomes

Outcomes: total number of anaerobic bacteria on the tongue surface, tongue coating index, moisture level of the tongue surface

Data collection: baseline, week 1 and 2

Funding

Study authors declared no conflicts of interest. Study funded by Research Funding for Longesvity Sciences (25-7) from the National Center for Geriatrics and Gerontology, Japan

Notes Dropouts are detailed in Table 6

Suitable statistical data permitting inclusion within the review meta-analyses unavailable

\section{Risk of bias}


Kobayashi 2017iv (Continued)

Random sequence genera- Unclear risk Quote: "randomly divided into four groups according to the methods used to tion (selection bias) clean the teeth and tongue."

\begin{tabular}{lll}
$\begin{array}{l}\text { Allocation concealment } \\
\text { (selection bias) }\end{array}$ & Unclear risk & Comment: not reported. \\
\hline $\begin{array}{l}\text { Blinding of participants } \\
\text { and personnel (perfor- }\end{array}$ & Unclear risk & Comment: not reported. \\
mance bias) & & \\
All outcomes & &
\end{tabular}

\begin{tabular}{|c|c|c|}
\hline $\begin{array}{l}\text { Blinding of outcome as- } \\
\text { sessment (detection bias) }\end{array}$ & Unclear risk & $\begin{array}{l}\text { Quote: "measurements were carried out by one dentist who was excluded } \\
\text { from carrying out the oral cleaning." }\end{array}$ \\
\hline
\end{tabular}

All outcomes

Comment: insufficient information.

Incomplete outcome data Low risk Comment: no CONSORT diagram, no dropouts reported.

(attrition bias)

All outcomes

\begin{tabular}{lll}
\hline $\begin{array}{l}\text { Selective reporting (re- } \\
\text { porting bias) }\end{array}$ & High risk & $\begin{array}{l}\text { Comment: sample size for each group not reported and limited statistical in- } \\
\text { formation presented for each outcome measure. }\end{array}$
\end{tabular}

Baseline data compara- Unclear risk Comment: study authors reported no significant difference between groups on ble? outcome measures at baseline; however, no baseline demographics reported so unable to judge whether the groups were comparable.

\begin{tabular}{lll}
\hline A priori power calculation & Unclear risk & Comment: not reported. \\
\hline Other bias & Unclear risk & Comment: limited data reported in the study. \\
\hline
\end{tabular}

Kobayashi 2017iv

\section{Study characteristics}

\begin{tabular}{ll}
\hline Methods & RCT randomised at individual level, Japan \\
& Study recruitment and setting details: see Table 1 \\
\hline Participants & Inclusion criteria: not reported \\
& Exclusion criteria: receiving antibiotic or steroid therapy within 1 month before start of study \\
& Sample size: quote: "60 participants randomly divided." \\
& Details of participants are shown in Table 2 \\
\hline
\end{tabular}

Interventions

Multi-component OHC intervention

- Intervention: mouthwash

- Materials: toothbrush (Dent EX; Lion Dental Products Company, Tokyo, Japan), mouthwash (ConCool Mouth Rinse; Weltec, Osaka, Japan), tongue brush (TongueMate Kamemizu Chem, Osaka, Japan)

- Agent: mouthwash contained cetylpyridinium chloride (ConCool Mouth Rinse; Weltec, Osaka, Japan)

- Procedures: tooth and tongue cleaning once each day while participant was in a lying position. Teeth were cleaned for 3 minutes using a toothbrush immersed in mouthwash. Toothpaste was not applied. To clean the tongue, a tongue brush that was immersed in mouthwash was applied in 1 direction from the back to the tip of the tongue with a cleaning pressure of $100 \mathrm{gf}$ applied 5 times on each side 
- Provided by: a dentist or 1 of 5 nurses

- Training: instructed on the method of oral cleaning by the dentist

- Delivery: face-to-face; 1 -to-1

- Location: hospital

- Regimen: specified oral cleaning (3 minutes) once each day for 2 weeks

- Tailoring: none

- Modification: none

- Adherence: no dropouts reported

\section{Multi-component OHC Intervention}

- Intervention: water and moisturising gel

- Materials: toothbrush (Dent EX; Lion Dental Products Company, Tokyo, Japan), mouth gel (1 g containing glycerine, lactoferrin and whey protein: ConCool Mouth Gel; Weltec, Osaka, Japan), tongue scraper (Tongood; Molten, Hiroshima, Japan)

- Agent: mouth gel (1 g containing glycerine, lactoferrin and whey protein: ConCool Mouth Gel; Weltec, Osaka, Japan)

- Procedures: tooth and tongue cleaning once each day while participant was in a lying position. Teeth were cleaned for 3 minutes using a toothbrush immersed in mouthwash. Toothpaste was not applied. To clean the tongue, a tongue brush that was immersed in mouthwash was applied in 1 direction from the back to the tip of the tongue with a cleaning pressure of 100 gf applied 5 times on each side. After wiping intraoral residues, the moisturising gel was applied to the surface of the tongue using an elastomeric tongue scraper

- Provided by: a dentist or 1 of 5 nurses

- Training: instructed on the method of oral cleaning by the dentist

- Delivery: face-to-face; 1 -to-1

- Location: hospital

- Regimen: specified oral cleaning (3 minutes) once each day for 2 weeks

- Tailoring: none

- Modification: none

- Adherence: no dropouts reported

Outcomes Outcomes: total number of anaerobic bacteria on the tongue surface, tongue coating index, moisture level of the tongue surface

Data collection: baseline, week 1 and 2

Funding Study authors declared no conflicts of interest. Study funded by Research Funding for Longesvity
Sciences (25-7) from the National Center for Geriatrics and Gerontology, Japan

Notes Dropouts are detailed in Table 6

Suitable statistical data permitting inclusion within the review meta-analyses unavailable

\section{Risk of bias}

\begin{tabular}{lll}
\hline Bias & Authors' judgement & Support for judgement \\
\hline $\begin{array}{l}\text { Random sequence genera- } \\
\text { tion (selection bias) }\end{array}$ & Unclear risk & $\begin{array}{l}\text { Quote: "randomly divided into four groups according to the methods used to } \\
\text { clean the teeth and tongue." }\end{array}$ \\
\hline $\begin{array}{l}\text { Allocation concealment } \\
\text { (selection bias) }\end{array}$ & Unclear risk & Comment: not reported. \\
\hline $\begin{array}{l}\text { Blinding of participants } \\
\begin{array}{l}\text { and personnel (perfor- } \\
\text { mance bias) }\end{array}\end{array}$ & Unclear risk & Comment: not reported.
\end{tabular}


Kobayashi 2017iv (Continued)

All outcomes

\begin{tabular}{|c|c|c|}
\hline $\begin{array}{l}\text { Blinding of outcome as- } \\
\text { sessment (detection bias) }\end{array}$ & Unclear risk & $\begin{array}{l}\text { Quote: "measurements were carried out by one dentist who was excluded } \\
\text { from carrying out the oral cleaning." }\end{array}$ \\
\hline
\end{tabular}

All outcomes

Comment: insufficient information.

Incomplete outcome data Low risk Comment: no CONSORT diagram, no dropouts reported.

(attrition bias)

All outcomes

\begin{tabular}{lll}
\hline $\begin{array}{l}\text { Selective reporting (re- } \\
\text { porting bias) }\end{array}$ & High risk & $\begin{array}{l}\text { Comment: sample size for each group not reported and limited statistical in- } \\
\text { formation presented for each outcome measure. }\end{array}$
\end{tabular}

\begin{tabular}{lll}
\hline $\begin{array}{l}\text { Baseline data compara- } \\
\text { ble? }\end{array}$ & Unclear risk & $\begin{array}{l}\text { Comment: study authors reported no significant difference between groups on } \\
\text { outcome measures at baseline; however, no baseline demographics reported } \\
\text { so unable to judge whether the groups were comparable. }\end{array}$ \\
\hline A priori power calculation & Unclear risk & Comment: not reported. \\
\hline Other bias & Unclear risk & Comment: limited data reported in the study. \\
\hline
\end{tabular}

Kobayashi 2017v

\section{Study characteristics}

\begin{tabular}{ll}
\hline Methods & RCT randomised at individual level, Japan \\
& Study recruitment and setting details: see Table 1 \\
\hline Participants & Inclusion criteria: not reported \\
& Exclusion criteria: receiving antibiotic or steroid therapy within 1 month before start of study \\
& Sample size: quote: "60 participants randomly divided." \\
& Details of participants are shown in Table 2 \\
\hline
\end{tabular}

Interventions Multi-component OHC intervention

- Intervention: mouthwash

- Materials: toothbrush (Dent EX; Lion Dental Products Company, Tokyo, Japan), mouthwash (ConCool Mouth Rinse; Weltec, Osaka, Japan), tongue brush (TongueMate Kamemizu Chem, Osaka, Japan)

- Agent: mouthwash contained cetylpyridinium chloride (ConCool Mouth Rinse; Weltec, Osaka, Japan)

- Procedures: tooth and tongue cleaning once each day while participant was in a lying position. Teeth were cleaned for 3 minutes using a toothbrush immersed in mouthwash. Toothpaste was not applied. To clean the tongue, a tongue brush that was immersed in mouthwash was applied in 1 direction from the back to the tip of the tongue with a cleaning pressure of $100 \mathrm{gf}$ applied 5 times on each side

- Provided by: a dentist or 1 of 5 nurses

- Training: instructed on the method of oral cleaning by the dentist

- Delivery: face-to-face; 1-to-1

- Location: hospital

- Regimen: specified oral cleaning (3 minutes) once each day for 2 weeks

- Tailoring: none

- Modification: none

- Adherence: not reported 
Kobayashi 2017v (Continued)

\section{Multi-component OHC intervention}

- Intervention: water alone

- Materials: toothbrush (Dent EX; Lion Dental Products Company, Tokyo, Japan), tongue brush (TongueMate Kamemizu Chem, Osaka, Japan)

- Agent: none

- Procedures: tooth and tongue cleaning once each day while participant was in a lying position. Teeth were cleaned for 3 minutes using a toothbrush immersed in water. Toothpaste was not applied. To clean the tongue, a tongue brush that was immersed in water was applied in 1 direction from the back to the tip of the tongue with a cleaning pressure of $100 \mathrm{gf}$ applied 5 times on each side

- Provided by: a dentist or 1 of 5 nurses

- Training: instructed on the method of oral cleaning by the dentist

- Delivery: face-to-face; 1 -to-1

- Location: hospital

- Regimen: specified oral cleaning (3 minutes) once each day for 2 weeks

- Tailoring: none

- Modification: none

- Adherence: not reported

Outcomes

Outcomes: total number of anaerobic bacteria on the tongue surface, tongue coating index, moisture level of the tongue surface

Data collection: baseline, week 1 , and week 2

Funding Study authors declared no conflicts of interest. Study funded by Research Funding for Longesvity Sciences (25-7) from the National Center for Geriatrics and Gerontology, Japan

Notes Dropouts are detailed in Table 6

Suitable statistical data permitting inclusion within the review meta-analyses unavailable

\section{Risk of bias}

Bias Authors' judgement Support for judgement

\begin{tabular}{|c|c|c|}
\hline $\begin{array}{l}\text { Random sequence genera- } \\
\text { tion (selection bias) }\end{array}$ & Unclear risk & $\begin{array}{l}\text { Quote: "randomly divided into four groups according to the methods used to } \\
\text { clean the teeth and tongue." }\end{array}$ \\
\hline
\end{tabular}

\begin{tabular}{lll}
\hline $\begin{array}{l}\text { Allocation concealment } \\
\text { (selection bias) }\end{array}$ & Unclear risk & Comment: not reported. \\
\hline $\begin{array}{l}\text { Blinding of participants } \\
\text { and personnel (perfor- }\end{array}$ & Unclear risk & Comment: not reported. \\
mance bias) & & \\
All outcomes & &
\end{tabular}

\begin{tabular}{lll}
\hline $\begin{array}{l}\text { Blinding of outcome as- } \\
\text { sessment (detection bias) } \\
\text { All outcomes }\end{array}$ & Unclear risk & $\begin{array}{l}\text { Quote: "measurements were carried out by one dentist who was excluded } \\
\text { from carrying out the oral cleaning." }\end{array}$ \\
\hline $\begin{array}{l}\text { Incomplete outcome data } \\
\text { (attrition bias) } \\
\begin{array}{l}\text { All outcomes } \\
\text { Comment: insufficient information. }\end{array}\end{array}$ & Low risk \\
\hline $\begin{array}{l}\text { Selective reporting (re- } \\
\text { porting bias) }\end{array}$ & High risk & $\begin{array}{l}\text { Comment: no CONSORT diagram, no dropouts reported. } \\
\text { formation presented for each outcome measure. }\end{array}$ \\
\hline
\end{tabular}


Kobayashi 2017v (Continued)

Baseline data compara- Unclear risk Comment: authors reported no significant difference between groups on outble? come measures at baseline; however, no baseline demographics reported so unable to judge whether the groups were comparable.

\begin{tabular}{lll}
\hline A priori power calculation & Unclear risk & Comment: not reported. \\
\hline Other bias & Unclear risk & Comment: limited data reported in the study.
\end{tabular}

Kobayashi 2017v

\section{Study characteristics}

$\begin{array}{ll}\text { Methods } & \text { RCT randomised at individual level, Japan } \\ & \text { Study recruitment and setting details: see Table } 1\end{array}$

Participants Inclusion criteria: not reported

Exclusion criteria: receiving antibiotic or steroid therapy within 1 month before start of study

Sample size: quote: "60 participants randomly divided."

Details of participants are shown in Table 2

Interventions

\section{Multi-component OHC intervention}

- Intervention: mouthwash

- Materials: toothbrush (Dent EX; Lion Dental Products Company, Tokyo, Japan), mouthwash (ConCool Mouth Rinse; Weltec, Osaka, Japan), tongue brush (TongueMate Kamemizu Chem, Osaka, Japan)

- Agent: mouthwash contained cetylpyridinium chloride (ConCool Mouth Rinse; Weltec, Osaka, Japan)

- Procedures: tooth and tongue cleaning once each day while participant was in a lying position. Teeth were cleaned for 3 minutes using a toothbrush immersed in mouthwash. Toothpaste was not applied. To clean the tongue, a tongue brush that was immersed in mouthwash was applied in 1 direction from the back to the tip of the tongue with a cleaning pressure of $100 \mathrm{gf}$ applied 5 times on each side

- Provided by: a dentist or 1 of 5 nurses

- Training: instructed on the method of oral cleaning by the dentist

- Delivery: face-to-face; 1-to-1

- Location: hospital

- Regimen: specified oral cleaning (3 minutes) once each day for 2 weeks

- Tailoring: none

- Modification: none

- Adherence: not reported

\section{Multi-component OHC intervention}

- Intervention: water alone

- Materials: toothbrush (Dent EX; Lion Dental Products Company, Tokyo, Japan), tongue brush (TongueMate Kamemizu Chem, Osaka, Japan)

- Agent: none

- Procedures: tooth and tongue cleaning once each day while participant was in a lying position. Teeth were cleaned for 3 minutes using a toothbrush immersed in water. Toothpaste was not applied. To clean the tongue, a tongue brush that was immersed in water was applied in 1 direction from the back to the tip of the tongue with a cleaning pressure of $100 \mathrm{gf}$ applied 5 times on each side

- Provided by: a dentist or 1 of 5 nurses

- Training: instructed on the method of oral cleaning by the dentist 
Kobayashi 2017v (Continued)

- Delivery: face-to-face; 1 -to-1

- Location: hospital

- Regimen: specified oral cleaning (3 minutes) once each day for 2 weeks

- Tailoring: none

- Modification: none

- Adherence: not reported

\begin{tabular}{ll}
\hline Outcomes & $\begin{array}{l}\text { Outcomes: total number of anaerobic bacteria on the tongue surface, tongue coating index, moisture } \\
\text { level of the tongue surface } \\
\text { Data collection: baseline, week 1, and week } 2\end{array}$ \\
\hline Funding & $\begin{array}{l}\text { Study authors declared no conflicts of interest. Study funded by Research Funding for Longesvity } \\
\text { Sciences (25-7) from the National Center for Geriatrics and Gerontology, Japan }\end{array}$ \\
\hline Notes & Dropouts are detailed in Table 6 \\
Suitable statistical data permitting inclusion within the review meta-analyses unavailable
\end{tabular}

\section{Risk of bias}

\begin{tabular}{|c|c|c|}
\hline Bias & Authors' judgement & Support for judgement \\
\hline $\begin{array}{l}\text { Random sequence genera- } \\
\text { tion (selection bias) }\end{array}$ & Unclear risk & $\begin{array}{l}\text { Quote: "randomly divided into four groups according to the methods used to } \\
\text { clean the teeth and tongue." }\end{array}$ \\
\hline $\begin{array}{l}\text { Allocation concealment } \\
\text { (selection bias) }\end{array}$ & Unclear risk & Comment: not reported. \\
\hline $\begin{array}{l}\text { Blinding of participants } \\
\text { and personnel (perfor- } \\
\text { mance bias) } \\
\text { All outcomes }\end{array}$ & Unclear risk & Comment: not reported. \\
\hline $\begin{array}{l}\text { Blinding of outcome as- } \\
\text { sessment (detection bias) } \\
\text { All outcomes }\end{array}$ & Unclear risk & $\begin{array}{l}\text { Quote: "measurements were carried out by one dentist who was excluded } \\
\text { from carrying out the oral cleaning." } \\
\text { Comment: insufficient information. }\end{array}$ \\
\hline $\begin{array}{l}\text { Incomplete outcome data } \\
\text { (attrition bias) } \\
\text { All outcomes }\end{array}$ & Low risk & Comment: no CONSORT diagram, no dropouts reported. \\
\hline $\begin{array}{l}\text { Selective reporting (re- } \\
\text { porting bias) }\end{array}$ & High risk & $\begin{array}{l}\text { Comment: sample size for each group not reported and limited statistical in- } \\
\text { formation presented for each outcome measure. }\end{array}$ \\
\hline $\begin{array}{l}\text { Baseline data compara- } \\
\text { ble? }\end{array}$ & Unclear risk & $\begin{array}{l}\text { Comment: authors reported no significant difference between groups on out- } \\
\text { come measures at baseline; however, no baseline demographics reported so } \\
\text { unable to judge whether the groups were comparable. }\end{array}$ \\
\hline A priori power calculation & Unclear risk & Comment: not reported. \\
\hline Other bias & Unclear risk & Comment: limited data reported in the study. \\
\hline
\end{tabular}


Kobayashi 2017vi

\section{Study characteristics}

$\begin{array}{ll}\text { Methods } & \text { RCT randomised at individual level, Japan } \\ \text { Study recruitment and setting details: see Table } 1\end{array}$

Participants Inclusion criteria: not reported

Exclusion criteria: receiving antibiotic or steroid therapy within 1 month before start of study

Sample size: quote: "60 participants randomly divided."

Details of participants are shown in Table 2

\section{Multi-component OHC intervention}

- Intervention: water and moisturising gel

- Materials: toothbrush (Dent EX; Lion Dental Products Company, Tokyo, Japan), mouth gel (1 g containing glycerine, lactoferrin and whey protein: ConCool Mouth Gel; Weltec, Osaka, Japan), tongue scraper (Tongood; Molten, Hiroshima, Japan)

- Agent: mouth gel (1 g containing glycerine, lactoferrin and whey protein (ConCool Mouth Gel; Weltec, Osaka, Japan)

- Procedures: tooth and tongue cleaning once each day while the participant was in a lying position. Teeth were cleaned for 3 minutes using a toothbrush immersed in water. Toothpaste was not applied. To clean the tongue, a tongue brush that was immersed in water was applied in applied in 1 direction from the back to the tip of the tongue with a cleaning pressure of $100 \mathrm{gf}$ applied 5 times on each side. After wiping intraoral residues, the moisturising gel was applied to the surface of the tongue using an elastomeric tongue scraper

- Provided by: a dentist or 1 of 5 nurses

- Training: instructed on the method of oral cleaning by the dentist

- Delivery: face-to-face; 1-to-1

- Location: hospital

- Regimen: specified oral cleaning (3 minutes) once each day for 2 weeks

- Tailoring: none

- Modification: none

- Adherence: no dropouts reported

\section{Multi-component OHC intervention}

- Intervention: water alone

- Materials: toothbrush (Dent EX; Lion Dental Products Company, Tokyo, Japan), tongue brush (TongueMate Kamemizu Chem, Osaka, Japan)

- Agent: none

- Procedures: tooth and tongue cleaning once each day while participant was in a lying position. Teeth were cleaned for 3 minutes using a toothbrush immersed in water. Toothpaste was not applied. To clean the tongue, a tongue brush that was immersed in water was applied in 1 direction from the back to the tip of the tongue with a cleaning pressure of $100 \mathrm{gf}$ applied 5 times on each side

- Provided by: a dentist or 1 of 5 nurses

- Training: instructed on the method of oral cleaning by the dentist

- Delivery: face-to-face; 1-to-1

- Location: hospital

- Regimen: specified oral cleaning (3 minutes) once each day for 2 weeks

- Tailoring: none

- Modification: none

- Adherence: no dropouts reported 
Kobayashi 2017vi (Continued)

Outcomes

Outcomes: total number of anaerobic bacteria on the tongue surface, tongue coating index, moisture level of the tongue surface

Data collection: baseline, week 1 and 2

Funding

Study authors declared no conflicts of interest. Study funded by Research Funding for Longesvity Sciences (25-7) from the National Center for Geriatrics and Gerontology, Japan

Notes

Dropouts are detailed in Table 6

Suitable statistical data permitting inclusion within the review meta-analyses unavailable

\section{Risk of bias}

\begin{tabular}{|c|c|c|}
\hline Bias & Authors' judgement & Support for judgement \\
\hline $\begin{array}{l}\text { Random sequence genera- } \\
\text { tion (selection bias) }\end{array}$ & Unclear risk & $\begin{array}{l}\text { Quote: "randomly divided into four groups according to the methods used to } \\
\text { clean the teeth and tongue." }\end{array}$ \\
\hline $\begin{array}{l}\text { Allocation concealment } \\
\text { (selection bias) }\end{array}$ & Unclear risk & Comment: not reported. \\
\hline $\begin{array}{l}\text { Blinding of participants } \\
\text { and personnel (perfor- } \\
\text { mance bias) } \\
\text { All outcomes }\end{array}$ & Unclear risk & Comment: not reported. \\
\hline $\begin{array}{l}\text { Blinding of outcome as- } \\
\text { sessment (detection bias) } \\
\text { All outcomes }\end{array}$ & Unclear risk & $\begin{array}{l}\text { Quote: "measurements were carried out by one dentist who was excluded } \\
\text { from carrying out the oral cleaning." } \\
\text { Comment: insufficient information. }\end{array}$ \\
\hline $\begin{array}{l}\text { Incomplete outcome data } \\
\text { (attrition bias) } \\
\text { All outcomes }\end{array}$ & Low risk & Comment: no CONSORT diagram, no dropouts reported. \\
\hline $\begin{array}{l}\text { Selective reporting (re- } \\
\text { porting bias) }\end{array}$ & High risk & $\begin{array}{l}\text { Comment: sample size for each group not reported and limited statistical in- } \\
\text { formation presented for each outcome measure. }\end{array}$ \\
\hline $\begin{array}{l}\text { Baseline data compara- } \\
\text { ble? }\end{array}$ & Unclear risk & $\begin{array}{l}\text { Comment: study authors reported no significant difference between groups on } \\
\text { outcome measures at baseline; however, no baseline demographics reported } \\
\text { so unable to judge whether the groups were comparable. }\end{array}$ \\
\hline A priori power calculation & Unclear risk & Comment: not reported. \\
\hline Other bias & Unclear risk & Comment: limited data reported in the study. \\
\hline
\end{tabular}

Kobayashi $2017 \mathrm{vi}$

\section{Study characteristics}

\begin{tabular}{ll}
\hline Methods & RCT randomised at individual level, Japan \\
& Study recruitment and setting details: see Table 1 \\
\hline Participants & Inclusion criteria: not reported
\end{tabular}


Kobayashi 2017vi (Continued)

Exclusion criteria: receiving antibiotic or steroid therapy within 1 month before start of study

Sample size: quote: "60 participants randomly divided."

Details of participants are shown in Table 2

- Intervention: water and moisturising gel

- Materials: toothbrush (Dent EX; Lion Dental Products Company, Tokyo, Japan), mouth gel (1 g containing glycerine, lactoferrin and whey protein: ConCool Mouth Gel; Weltec, Osaka, Japan), tongue scraper (Tongood; Molten, Hiroshima, Japan)

- Agent: mouth gel (1 g containing glycerine, lactoferrin and whey protein (ConCool Mouth Gel; Weltec, Osaka, Japan)

- Procedures: tooth and tongue cleaning once each day while the participant was in a lying position. Teeth were cleaned for 3 minutes using a toothbrush immersed in water. Toothpaste was not applied. To clean the tongue, a tongue brush that was immersed in water was applied in applied in 1 direction from the back to the tip of the tongue with a cleaning pressure of $100 \mathrm{gf}$ applied 5 times on each side. After wiping intraoral residues, the moisturising gel was applied to the surface of the tongue using an elastomeric tongue scraper

- Provided by: a dentist or 1 of 5 nurses

- Training: instructed on the method of oral cleaning by the dentist

- Delivery: face-to-face; 1-to-1

- Location: hospital

- Regimen: specified oral cleaning (3 minutes) once each day for 2 weeks

- Tailoring: none

- Modification: none

- Adherence: no dropouts reported

\section{Multi-component OHC intervention}

- Intervention: water alone

- Materials: toothbrush (Dent EX; Lion Dental Products Company, Tokyo, Japan), tongue brush (TongueMate Kamemizu Chem, Osaka, Japan)

- Agent: none

- Procedures: tooth and tongue cleaning once each day while participant was in a lying position. Teeth were cleaned for 3 minutes using a toothbrush immersed in water. Toothpaste was not applied. To clean the tongue, a tongue brush that was immersed in water was applied in 1 direction from the back to the tip of the tongue with a cleaning pressure of $100 \mathrm{gf}$ applied 5 times on each side

- Provided by: a dentist or 1 of 5 nurses

- Training: instructed on the method of oral cleaning by the dentist

- Delivery: face-to-face; 1-to-1

- Location: hospital

- Regimen: specified oral cleaning (3 minutes) once each day for 2 weeks

- Tailoring: none

- Modification: none

- Adherence: no dropouts reported

Outcomes

Outcomes: total number of anaerobic bacteria on the tongue surface, tongue coating index, moisture level of the tongue surface

Data collection: baseline, week 1 and 2 
Kobayashi 2017vi (Continued)

Suitable statistical data permitting inclusion within the review meta-analyses unavailable

\section{Risk of bias}

\begin{tabular}{|c|c|c|}
\hline Bias & Authors' judgement & Support for judgement \\
\hline $\begin{array}{l}\text { Random sequence genera- } \\
\text { tion (selection bias) }\end{array}$ & Unclear risk & $\begin{array}{l}\text { Quote: "randomly divided into four groups according to the methods used to } \\
\text { clean the teeth and tongue." }\end{array}$ \\
\hline $\begin{array}{l}\text { Allocation concealment } \\
\text { (selection bias) }\end{array}$ & Unclear risk & Comment: not reported. \\
\hline $\begin{array}{l}\text { Blinding of participants } \\
\text { and personnel (perfor- } \\
\text { mance bias) } \\
\text { All outcomes }\end{array}$ & Unclear risk & Comment: not reported. \\
\hline $\begin{array}{l}\text { Blinding of outcome as- } \\
\text { sessment (detection bias) } \\
\text { All outcomes }\end{array}$ & Unclear risk & $\begin{array}{l}\text { Quote: "measurements were carried out by one dentist who was excluded } \\
\text { from carrying out the oral cleaning." } \\
\text { Comment: insufficient information. }\end{array}$ \\
\hline $\begin{array}{l}\text { Incomplete outcome data } \\
\text { (attrition bias) } \\
\text { All outcomes }\end{array}$ & Low risk & Comment: no CONSORT diagram, no dropouts reported. \\
\hline $\begin{array}{l}\text { Selective reporting (re- } \\
\text { porting bias) }\end{array}$ & High risk & $\begin{array}{l}\text { Comment: sample size for each group not reported and limited statistical in- } \\
\text { formation presented for each outcome measure. }\end{array}$ \\
\hline $\begin{array}{l}\text { Baseline data compara- } \\
\text { ble? }\end{array}$ & Unclear risk & $\begin{array}{l}\text { Comment: study authors reported no significant difference between groups on } \\
\text { outcome measures at baseline; however, no baseline demographics reported } \\
\text { so unable to judge whether the groups were comparable. }\end{array}$ \\
\hline A priori power calculation & Unclear risk & Comment: not reported. \\
\hline Other bias & Unclear risk & Comment: limited data reported in the study. \\
\hline
\end{tabular}

Kuo 2016

\section{Study characteristics}

$\begin{array}{ll}\text { Methods } & \text { RCT randomised at individual level, Taiwan } \\ & \text { Study recruitment and setting details: see Table } 1\end{array}$

Participants

Inclusion criteria: carers were eligible if their family member had experienced a stroke (ICD-9 430-438), $\mathrm{BI}<60$, not able to 'intake oral,' actively caring for their stroke survivor (for $\geq 8$ hours per day), able to communicate in Mandarin or Taiwanese

Exclusion criteria: carers were excluded if their family member who had experienced stroke also had a confirmed diagnosis of pulmonary infection or a diagnosis of oral or tongue pathology, or if they were unable to open their mouth

OHC group: 50 participants

Usual care group: 50 participants 
Kuo 2016 (Continued)

Details of participants are shown in Table 2

Interventions

\section{Multi-component OHC Intervention}

- Intervention: homebased OHC training. Theoretically guided by the PRECEDE-PROCEED model

- Materials: educational pamphlets, daily reminder sheets, dual action tongue cleaner (Sunstar American, Inc.), finger toothbrush

- Procedures: oral care overview (educational pamphlets), 20-minute verbal presentation discussing basic oral care procedures and risks, oral care products were provided (tongue cleaner and finger tooth brush), training, demonstrations, daily reminder (record) sheets, telephone follow-up at 1 month. Multiple teaching strategies including 1. brushing twice (after breakfast and before sleep) a day; 2. 2 minutes per time; 3. learning brushing sequence (from teeth to tongue); 4. learning tongue cleaning (distinguishing 6 regions, from left-middle-right of the anterior tongue to left-middle-right of the posterior tongue); 5. learning how to use the equipment (tongue cleaner and finger toothbrush); 6. checking the dental cavities; 7. confirming the method of toothbrush; 8 . using the technique of bass brushing and oral mucosa cleaning. Programme detailed in Table 1.

- Provided by: the researchers

- Intervention and delivery of the training were conducted by a trained home healthcare nurse

- Training: qualified home healthcare nurse with 10 years of experience who had received training from a dental specialist

- Delivery: face-to-face; 1 -to-1

- Location: home

- Regimen: protocolised; oral cleaning (2 minutes twice daily for 2 months)

- Tailoring: none

- Modification: none

- Adherence: not reported

\section{Usual care}

- Intervention: standard care

- Materials: not reported

- Procedures: encouraged to maintain routine OHC practices (including oral cleaning with cotton swabs)

- Provided by: not reported

- Delivery: not reported

- Regimen: not reported

- Tailoring: not reported

- Modification: not reported

- Adherence: no dropouts reported
Outcomes: Knowledge of Oral Care questionnaire, Attitudes towards oral care questionnaire, Family caregiver self-efficacy of Oral care questionnaire, Behaviour of Oral Care questionnaire

Data collection: baseline, month 1 and 2 of the intervention period

$$
\text { Funding Study authors declared no conflicts of interest. There was no external funding for this study }
$$

Notes Dropouts are detailed in Table 6

Statistical data included within the review meta-analyses

Family carers in the control group were given the home-based $\mathrm{OHC}$ protocol after the 2-month intervention period

\section{Risk of bias}


Kuo 2016 (Continued)

Random sequence genera- Unclear risk Comment: computer-generated random number table. tion (selection bias)

Allocation concealment Unclear risk Comment: not reported.
(selection bias)

\begin{tabular}{|c|c|c|}
\hline $\begin{array}{l}\text { Blinding of participants } \\
\text { and personnel (perfor- }\end{array}$ & Unclear risk & $\begin{array}{l}\text { Comment: not reported although outcomes were self-reported question- } \\
\text { naires. }\end{array}$ \\
\hline
\end{tabular}

mance bias)

All outcomes

Blinding of outcome as- $\quad$ Unclear risk $\quad$ Comment: not reported.
sessment (detection bias)

\begin{tabular}{|c|c|c|}
\hline $\begin{array}{l}\text { Incomplete outcome data } \\
\text { (attrition bias) } \\
\text { All outcomes }\end{array}$ & Low risk & Comment: dropouts accounted for; ITT not employed. \\
\hline $\begin{array}{l}\text { Selective reporting (re- } \\
\text { porting bias) }\end{array}$ & Low risk & Comment: all prespecified outcomes reported. \\
\hline $\begin{array}{l}\text { Baseline data compara- } \\
\text { ble? }\end{array}$ & Low risk & $\begin{array}{l}\text { Quote: "Baseline characteristics (gender, education, family relationship, daily } \\
\text { care time and age) were similar between the two groups." }\end{array}$ \\
\hline \multirow[t]{2}{*}{ A priori power calculation } & Low risk & Yes. \\
\hline & & $\begin{array}{l}\text { Quote: "Sample estimates were based on Cohen's ( } 31 \text { ) suggested criteria for } \\
\text { comparing the means of two groups. With a power of } 0.8 \text { and a }=0.05 \text {, a sam- } \\
\text { ple size of } 26 \text { family caregivers was required. Applying an estimated dropout } \\
\text { rate of } 25 \% \text {, each group required } 33 \text { family caregivers. Further, the mortality } \\
\text { rate for severe stroke survivors with home health care was also considered. Fi- } \\
\text { nally, the sample size was estimated based on three data collection times, and } \\
\text { thus, we estimated the sample size as } 50 . "\end{array}$ \\
\hline Other bias & Low risk & Comment: none identified. \\
\hline
\end{tabular}

Kuo 2016

\section{Study characteristics}

Methods $\quad$ RCT randomised at individual level, Taiwan
Study recruitment and setting details: see Table 1

Participants

Inclusion criteria: carers were eligible if their family member had experienced a stroke (ICD-9 430-438), $\mathrm{BI}<60$, not able to 'intake oral,' actively caring for their stroke survivor (for $\geq 8$ hours per day), able to communicate in Mandarin or Taiwanese

Exclusion criteria: carers were excluded if their family member who had experienced stroke also had a confirmed diagnosis of pulmonary infection or a diagnosis of oral or tongue pathology, or if they were unable to open their mouth

OHC group: 50 participants

Usual care group: 50 participants 
Kuo 2016 (Continued)

Details of participants are shown in Table 2

Interventions

\section{Multi-component OHC Intervention}

- Intervention: homebased OHC training. Theoretically guided by the PRECEDE-PROCEED model

- Materials: educational pamphlets, daily reminder sheets, dual action tongue cleaner (Sunstar American, Inc.), finger toothbrush

- Procedures: oral care overview (educational pamphlets), 20-minute verbal presentation discussing basic oral care procedures and risks, oral care products were provided (tongue cleaner and finger tooth brush), training, demonstrations, daily reminder (record) sheets, telephone follow-up at 1 month. Multiple teaching strategies including 1. brushing twice (after breakfast and before sleep) a day; 2. 2 minutes per time; 3. learning brushing sequence (from teeth to tongue); 4. learning tongue cleaning (distinguishing 6 regions, from left-middle-right of the anterior tongue to left-middle-right of the posterior tongue); 5. learning how to use the equipment (tongue cleaner and finger toothbrush); 6. checking the dental cavities; 7. confirming the method of toothbrush; 8 . using the technique of bass brushing and oral mucosa cleaning. Programme detailed in Table 1.

- Provided by: the researchers

- Intervention and delivery of the training were conducted by a trained home healthcare nurse

- Training: qualified home healthcare nurse with 10 years of experience who had received training from a dental specialist

- Delivery: face-to-face; 1 -to-1

- Location: home

- Regimen: protocolised; oral cleaning (2 minutes twice daily for 2 months)

- Tailoring: none

- Modification: none

- Adherence: not reported

\section{Usual care}

- Intervention: standard care

- Materials: not reported

- Procedures: encouraged to maintain routine OHC practices (including oral cleaning with cotton swabs)

- Provided by: not reported

- Delivery: not reported

- Regimen: not reported

- Tailoring: not reported

- Modification: not reported

- Adherence: no dropouts reported
Outcomes: Knowledge of Oral Care questionnaire, Attitudes towards oral care questionnaire, Family caregiver self-efficacy of Oral care questionnaire, Behaviour of Oral Care questionnaire

Data collection: baseline, month 1 and 2 of the intervention period

$$
\text { Funding Study authors declared no conflicts of interest. There was no external funding for this study }
$$

Notes Dropouts are detailed in Table 6

Statistical data included within the review meta-analyses

Family carers in the control group were given the home-based $\mathrm{OHC}$ protocol after the 2-month intervention period

\section{Risk of bias}


Kuo 2016 (Continued)

Random sequence genera- Unclear risk Comment: computer-generated random number table. tion (selection bias)

Allocation concealment $\quad$ Unclear risk Comment: not reported.
(selection bias)

\begin{tabular}{|c|c|c|}
\hline $\begin{array}{l}\text { Blinding of participants } \\
\text { and personnel (perfor- }\end{array}$ & Unclear risk & $\begin{array}{l}\text { Comment: not reported although outcomes were self-reported question- } \\
\text { naires. }\end{array}$ \\
\hline
\end{tabular}

mance bias)

All outcomes

Blinding of outcome as- Unclear risk Comment: not reported.

sessment (detection bias)

All outcomes

Incomplete outcome data Low risk Comment: dropouts accounted for; ITT not employed.
(attrition bias)

All outcomes

\begin{tabular}{lll}
\hline $\begin{array}{l}\text { Selective reporting (re- } \\
\text { porting bias) }\end{array}$ & Low risk & Comment: all prespecified outcomes reported. \\
\hline $\begin{array}{l}\text { Baseline data compara- } \\
\text { ble? }\end{array}$ & Low risk & $\begin{array}{l}\text { Quote: "Baseline characteristics (gender, education, family relationship, daily } \\
\text { care time and age) were similar between the two groups." }\end{array}$ \\
\hline $\begin{array}{l}\text { A priori power calculation } \\
\text { Low risk }\end{array}$ & $\begin{array}{l}\text { Yes. } \\
\text { Quote: "Sample estimates were based on Cohen's (31) suggested criteria for } \\
\text { comparing the means of two groups. With a power of } 0.8 \text { and a }=0.05, \text { a sam- } \\
\text { ple size of } 26 \text { family caregivers was required. Applying an estimated dropout } \\
\text { rate of } 25 \%, \text { each group required } 33 \text { family caregivers. Further, the mortality } \\
\text { rate for severe stroke survivors with home health care was also considered. Fi- } \\
\text { nally, the sample size was estimated based on three data collection times, and } \\
\text { thus, we estimated the sample size as } 50 . "\end{array}$
\end{tabular}

Other bias Low risk Comment: none identified.

Lam 2013i

\section{Study characteristics}

\begin{tabular}{|c|c|}
\hline Methods & $\begin{array}{l}\text { RCT randomised at individual level, Hong Kong, People's Republic of China } \\
\text { Study recruitment and setting details: see Table } 1\end{array}$ \\
\hline Participants & $\begin{array}{l}\text { Inclusion criteria: aged } \geq 50 \text { years, stroke, } \mathrm{Bl}<70 \text {, and admitted to rehabilitation unit within } 7 \text { days } \\
\text { Exclusion criteria: edentulous, presented with communication difficulties (unable to follow a 1-step } \\
\text { command) or severe cognitive impairment (Mini Mental Status Examination } \leq 9 \text { ) or indwelling nasogas- } \\
\text { tric feeding tube } \\
\text { Oral hygiene instruction, mouthrinse and assisted brushing group: } 25 \text { participants } \\
\text { Oral hygiene instruction and chlorhexidine mouthrinse group: } 26 \text { participants } \\
\text { Details of participants are shown in Table } 2\end{array}$ \\
\hline
\end{tabular}

Interventions

Multi-component OHC intervention

Interventions for improving oral health in people after stroke (Review) 
- Intervention: oral hygiene instruction, mouthrinse and assisted brushing

- Materials: electric toothbrush, a standard sodium fluoride toothpaste, chlorhexidine (Corsodyl) mouthrinse $(0.2 \%, 10 \mathrm{~mL})$

- Agent: chlorhexidine (Corsodyl) mouthrinse $(0.2 \%, 10 \mathrm{~mL})$

- Procedures: dentures were cleaned with a manual toothbrush. All participants were provided with an electric toothbrush and a standard sodium fluoride toothpaste. Professional oral hygiene instruction provided by a dentist; quote: "nursing care aides administered mouthrinses and performed intermittent assisted brushing. Nursing care aides monitored participants for toothbrushing difficulties and ensured that tooth surfaces (buccal, occlusal, lingual) were cleaned in a systematic manner. Handover-hand guiding was provided if participants had difficulty handling and placing the toothbrush."

- Provided by: registered dentist, dental hygienists (certified), nurse aides

- Training: nursing care aides were provided with an oral health training session consisting of a 30minute lecture comprising basic concepts of oral health and disease, as well as a demonstration and practical exercise on the administration of mouthrinse and assisted brushing. Training sessions were carried out by certified dental hygienists

- Delivery: face-to-face, $1: 1$, rehabilitation ward

- Regimen: mouthrinse (spaced $\geq 2$ hours apart from toothbrushing) and assistance with toothbrushing twice a day, delivered daily over a 3-week period

- Tailoring: none

- Modification: none

- Adherence: not reported

\section{Multi-component OHC intervention}

- Intervention: oral hygiene instruction and chlorhexidine mouthrinse

- Materials: electric toothbrush, a standard sodium fluoride toothpaste, chlorhexidine (Corsodyl) mouthrinse $(0.2 \%, 10 \mathrm{~mL})$

- Agent: chlorhexidine (Corsodyl) mouthrinse $(0.2 \%, 10 \mathrm{~mL})$

- Procedures: dentures were cleaned with a manual toothbrush. All participants were provided with an electric toothbrush and a standard sodium fluoride toothpaste. OHC training provided by a dentist; nursing care aides administered mouthrinses

- Provided by: registered dentist, dental hygienists (certified), nurse aides

- Training: quote: "Nursing care aides were provided with an oral health training session consisting of a lecture (30 minutes) comprising basic concepts of oral health and disease, as well as a demonstration and practical exercise on the administration of mouthrinse and assisted brushing. Oral health training sessions were carried out by certified dental hygienists."

- Delivery: face-to-face, 1:1, rehabilitation ward

- Regimen: mouthrinse twice daily, delivered daily over a 3-week period

- Tailoring: none

- Modification: none

- Adherence: reported 1 dropout because of non-compliance with mouthrinse

Outcomes

Outcomes: Dental Plaque Index, Gingival Bleeding Index, BI, swallowing disability (Royal Brisbane Hospital Outcome Measure for Swallowing), treatment satisfaction

Data collection: baseline and 3 weeks (before hospital discharge)

Funding

Study authors declared no conflicts of interest. Study funded by the Committee of Research and Conference Grants of the University of Hong Kong

Notes

Dropouts are detailed in Table 6

Suitable statistical data permitting inclusion within the review meta-analyses unavailable

\section{Risk of bias}


Lam 2013i (Continued) $\begin{array}{ll}\begin{array}{l}\text { Random sequence genera- } \\ \text { tion (selection bias) }\end{array} & \text { Low risk } \\ \end{array}$

Allocation concealment $\quad$ Unclear risk
(selection bias)

Blinding of participants Unclear risk Comment: not reported.

and personnel (perfor-

mance bias)

All outcomes

\begin{tabular}{|c|c|c|}
\hline $\begin{array}{l}\text { Blinding of outcome as- } \\
\text { sessment (detection bias) }\end{array}$ & Unclear risk & $\begin{array}{l}\text { Comment: described as 'single-blind' but insufficient information available to } \\
\text { make a judgement. }\end{array}$ \\
\hline
\end{tabular}

All outcomes

\begin{tabular}{lll}
\hline $\begin{array}{l}\text { Incomplete outcome data } \\
\text { (attrition bias) }\end{array}$ & High risk & $\begin{array}{l}\text { Comment; high attrition rate (20.5\%) but dropouts accounted for and bal- } \\
\text { anced across groups. ITT not employed and unclear how missing data were } \\
\text { dealt with in the analysis. }\end{array}$
\end{tabular}

All outcomes

Unclear risk

Selective reporting (re- Unclear risk
porting bias)

Comment: although prespecified outcomes were reported, data were reported porting bias) in Table 4 of the publication but it was unclear whether the data were mean/ median (and IQR). Clarification required.

\begin{tabular}{|c|c|c|}
\hline $\begin{array}{l}\text { Baseline data compara- } \\
\text { ble? }\end{array}$ & Low risk & $\begin{array}{l}\text { Quote: "No significant differences between groups }(\mathrm{P}>.05) \text { were noted at } \\
\text { baseline with regards to demographic, oral health-related behaviours, or med- } \\
\text { ications taken." }\end{array}$ \\
\hline
\end{tabular}

A priori power calculation Low risk Yes.

Quote: "initial sample size was based on a Plaque index change score SD of $0.21 \pm 0.40$, documented in a previous observational study and set at $40 \mathrm{pa}$ tients per group in order to detect a difference of 0.3 in plaque change scores within and between groups, and account for (1) a 5\% statistical significance level, (2) a power of $80 \%$, and (3) an anticipated $10 \%$ dropout rate."

\begin{tabular}{|c|c|c|}
\hline \multirow[t]{2}{*}{ Other bias } & High risk & $\begin{array}{l}\text { Quote: "At the time of baseline assessment, over two-thirds ( } 67.9 \%) \text { of the pa- } \\
\text { tients reported not to have a regular daily brushing habit (i.e. at least once a } \\
\text { day)." }\end{array}$ \\
\hline & & Comment: insufficient power - minimum sample size was not achieved. \\
\hline
\end{tabular}

Lam 2013i

\section{Study characteristics}

\begin{tabular}{ll}
\hline Methods & RCT randomised at individual level, Hong Kong, People's Republic of China \\
& Study recruitment and setting details: see Table 1 \\
\hline Participants & $\begin{array}{l}\text { Inclusion criteria: aged } \geq 50 \text { years, stroke, } \mathrm{BI}<70 \text {, and admitted to rehabilitation unit within } 7 \text { days } \\
\text { Exclusion criteria: edentulous, presented with communication difficulties (unable to follow a 1-step } \\
\text { command) or severe cognitive impairment (Mini Mental Status Examination } \leq 9 \text { ) or indwelling nasogas- } \\
\text { tric feeding tube }\end{array}$ \\
Oral hygiene instruction, mouthrinse and assisted brushing group: 25 participants \\
Oral hygiene instruction and chlorhexidine mouthrinse group: 26 participants
\end{tabular}


Lam 2013i (Continued)

Details of participants are shown in Table 2

Interventions

\section{Multi-component OHC intervention}

- Intervention: oral hygiene instruction, mouthrinse and assisted brushing

- Materials: electric toothbrush, a standard sodium fluoride toothpaste, chlorhexidine (Corsodyl) mouthrinse $(0.2 \%, 10 \mathrm{~mL})$

- Agent: chlorhexidine (Corsodyl) mouthrinse $(0.2 \%, 10 \mathrm{~mL})$

- Procedures: dentures were cleaned with a manual toothbrush. All participants were provided with an electric toothbrush and a standard sodium fluoride toothpaste. Professional oral hygiene instruction provided by a dentist; quote: "nursing care aides administered mouthrinses and performed intermittent assisted brushing. Nursing care aides monitored participants for toothbrushing difficulties and ensured that tooth surfaces (buccal, occlusal, lingual) were cleaned in a systematic manner. Handover-hand guiding was provided if participants had difficulty handling and placing the toothbrush."

- Provided by: registered dentist, dental hygienists (certified), nurse aides

- Training: nursing care aides were provided with an oral health training session consisting of a 30minute lecture comprising basic concepts of oral health and disease, as well as a demonstration and practical exercise on the administration of mouthrinse and assisted brushing. Training sessions were carried out by certified dental hygienists

- Delivery: face-to-face, $1: 1$, rehabilitation ward

- Regimen: mouthrinse (spaced $\geq 2$ hours apart from toothbrushing) and assistance with toothbrushing twice a day, delivered daily over a 3-week period

- Tailoring: none

- Modification: none

- Adherence: not reported

\section{Multi-component OHC intervention}

- Intervention: oral hygiene instruction and chlorhexidine mouthrinse

- Materials: electric toothbrush, a standard sodium fluoride toothpaste, chlorhexidine (Corsodyl) mouthrinse $(0.2 \%, 10 \mathrm{~mL})$

- Agent: chlorhexidine (Corsodyl) mouthrinse $(0.2 \%, 10 \mathrm{~mL})$

- Procedures: dentures were cleaned with a manual toothbrush. All participants were provided with an electric toothbrush and a standard sodium fluoride toothpaste. $\mathrm{OHC}$ training provided by a dentist; nursing care aides administered mouthrinses

- Provided by: registered dentist, dental hygienists (certified), nurse aides

- Training: quote: "Nursing care aides were provided with an oral health training session consisting of a lecture (30 minutes) comprising basic concepts of oral health and disease, as well as a demonstration and practical exercise on the administration of mouthrinse and assisted brushing. Oral health training sessions were carried out by certified dental hygienists."

- Delivery: face-to-face, 1:1, rehabilitation ward

- Regimen: mouthrinse twice daily, delivered daily over a 3-week period

- Tailoring: none

- Modification: none

- Adherence: reported 1 dropout because of non-compliance with mouthrinse

Outcomes

Outcomes: Dental Plaque Index, Gingival Bleeding Index, BI, swallowing disability (Royal Brisbane Hospital Outcome Measure for Swallowing), treatment satisfaction

Data collection: baseline and 3 weeks (before hospital discharge)

Funding

Study authors declared no conflicts of interest. Study funded by the Committee of Research and Conference Grants of the University of Hong Kong

\section{Notes}

Dropouts are detailed in Table 6

Suitable statistical data permitting inclusion within the review meta-analyses unavailable 
Lam 2013i (Continued)

Risk of bias

\begin{tabular}{lll}
\hline Bias & Authors' judgement & Support for judgement \\
\hline $\begin{array}{l}\text { Random sequence genera- } \\
\text { tion (selection bias) }\end{array}$ & Low risk & $\begin{array}{l}\text { Comment: allocated randomly using block randomisation by a research assis- } \\
\text { tant. }\end{array}$ \\
\hline $\begin{array}{l}\text { Allocation concealment } \\
\text { (selection bias) }\end{array}$ & Unclear risk & Comment: not reported. \\
\hline $\begin{array}{l}\text { Blinding of participants } \\
\begin{array}{l}\text { and personnel (perfor- } \\
\text { mance bias) } \\
\text { All outcomes }\end{array}\end{array}$ & Unclear risk & Comment: not reported. \\
\hline
\end{tabular}

\begin{tabular}{|c|c|c|}
\hline $\begin{array}{l}\text { Blinding of outcome as- } \\
\text { sessment (detection bias) }\end{array}$ & Unclear risk & $\begin{array}{l}\text { Comment: described as 'single-blind' but insufficient information available to } \\
\text { make a judgement. }\end{array}$ \\
\hline
\end{tabular}

All outcomes

\begin{tabular}{lll}
\hline $\begin{array}{l}\text { Incomplete outcome data } \\
\text { (attrition bias) }\end{array}$ & High risk & $\begin{array}{l}\text { Comment; high attrition rate (20.5\%) but dropouts accounted for and bal- } \\
\text { anced across groups. ITT not employed and unclear how missing data were } \\
\text { deall with in the analysis. }\end{array}$
\end{tabular}

\begin{tabular}{|c|c|c|}
\hline $\begin{array}{l}\text { Selective reporting (re- } \\
\text { porting bias) }\end{array}$ & Unclear risk & $\begin{array}{l}\text { Comment: although prespecified outcomes were reported, data were reported } \\
\text { in Table } 4 \text { of the publication but it was unclear whether the data were mean/ } \\
\text { median (and IQR). Clarification required. }\end{array}$ \\
\hline $\begin{array}{l}\text { Baseline data compara- } \\
\text { ble? }\end{array}$ & Low risk & $\begin{array}{l}\text { Quote: "No significant differences between groups }(P>.05) \text { were noted at } \\
\text { baseline with regards to demographic, oral health-related behaviours, or med- } \\
\text { ications taken." }\end{array}$ \\
\hline \multirow[t]{2}{*}{ A priori power calculation } & Low risk & Yes. \\
\hline & & $\begin{array}{l}\text { Quote: "initial sample size was based on a Plaque index change score SD of } \\
0.21 \pm 0.40 \text {, documented in a previous observational study and set at } 40 \text { pa- } \\
\text { tients per group in order to detect a difference of } 0.3 \text { in plaque change scores } \\
\text { within and between groups, and account for ( } 1 \text { ) a } 5 \% \text { statistical significance } \\
\text { level, (2) a power of } 80 \% \text {, and (3) an anticipated } 10 \% \text { dropout rate." }\end{array}$ \\
\hline \multirow[t]{2}{*}{ Other bias } & High risk & $\begin{array}{l}\text { Quote: "At the time of baseline assessment, over two-thirds ( } 67.9 \%) \text { of the pa- } \\
\text { tients reported not to have a regular daily brushing habit (i.e. at least once a } \\
\text { day)." }\end{array}$ \\
\hline & & Comment: insufficient power - minimum sample size was not achieved. \\
\hline
\end{tabular}

Lam 2013ii

\section{Study characteristics}

\begin{tabular}{ll}
\hline Methods & RCT randomised at individual level, Hong Kong, People's Republic of China \\
& Study recruitment and setting details: see Table 1 \\
\hline Participants & Inclusion criteria: aged $\geq 50$ years, stroke, $\mathrm{BI}<70$, and admitted to rehabilitation unit within 7 days \\
& $\begin{array}{l}\text { Exclusion criteria: edentulous, presented with communication difficulties (unable to follow a } 1 \text {-step } \\
\text { command) or severe cognitive impairment (MMSE } \leq 9 \text { ) or indwelling nasogastric feeding tube }\end{array}$
\end{tabular}


Lam 2013ii (Continued)

Oral hygiene instruction, mouthrinse and assisted brushing group: 25 participants

Oral hygiene instruction group: 30 participants

Details of participants are shown in Table 2

Interventions

\section{Multi-component OHC intervention}

- Intervention: oral hygiene instruction, mouthrinse and assisted brushing

- Materials: electric toothbrush, a standard sodium fluoride toothpaste, chlorhexidine (Corsodyl) mouthrinse $(0.2 \%, 10 \mathrm{~mL})$

- Agent: chlorhexidine (Corsodyl) mouthrinse $(0.2 \%, 10 \mathrm{~mL})$

- Procedures: dentures were cleaned with a manual toothbrush. All participants were provided with an electric toothbrush and a standard sodium fluoride toothpaste. Professional oral hygiene instruction provided by a dentist; quote: "nursing care aides administered mouthrinses and performed intermittent assisted brushing. Nursing care aides monitored participants for toothbrushing difficulties and ensured that tooth surfaces (buccal, occlusal, lingual) were cleaned in a systematic manner. Handover-hand guiding was provided if participants had difficulty handling and placing the toothbrush."

- Provided by: registered dentist, dental hygienists (certified), nurse aides

- Training: nursing care aides were provided with an oral health training session consisting of a 30minute lecture comprising basic concepts of oral health and disease, as well as a demonstration and practical exercise on the administration of mouthrinse and assisted brushing. Oral health training sessions were carried out by certified dental hygienists

- Delivery: face-to-face, 1:1, rehabilitation ward

- Regimen: mouthrinse (spaced $\geq 2$ hours apart from toothbrushing) and assistance with toothbrushing twice per day delivered over a 3-week period

- Tailoring: none

- Modification: none

- Adherence: not reported

\section{Multi-component OHC intervention}

- Intervention: oral hygiene instruction

- Materials: electric toothbrush, a standard sodium fluoride toothpaste

- Agent: standard sodium fluoride toothpaste

- Procedures: all participants were provided with an electric toothbrush and toothpaste. Nurse care aides provided with oral care instruction

- Provided by: dental hygienists (certified), nurse aides

- Training: quote: "Nursing care aides were provided with an oral health training session consisting of a lecture (30 minutes) comprising basic concepts of oral health and disease, as well as a demonstration and practical exercise on the administration of mouthrinse and assisted brushing. Oral health training sessions were carried out by certified dental hygienists."

- Delivery: face-to-face, 1:1, rehabilitation ward

- Regimen: none

- Tailoring: none

- Modification: none

- Adherence: not reported

Outcomes

Outcomes: Dental Plaque Index, Gingival Bleeding Index, BI, swallowing disability (Royal Brisbane Hospital Outcome Measure for Swallowing), treatment satisfaction

Data collection: baseline and 3 weeks (before hospital discharge)

Funding

Study authors declared no conflicts of interest. Study funded by the Committee of Research and Conference Grants of the University of Hong Kong 


\section{Risk of bias}

\begin{tabular}{lll}
\hline Bias & Authors' judgement & Support for judgement \\
\hline $\begin{array}{l}\text { Random sequence genera- } \\
\text { tion (selection bias) }\end{array}$ & Low risk & $\begin{array}{l}\text { Comment: allocated randomly using block randomisation by a research assis- } \\
\text { tant. }\end{array}$ \\
\hline $\begin{array}{l}\text { Allocation concealment } \\
\text { (selection bias) }\end{array}$ & Unclear risk & Comment: not reported. \\
\hline
\end{tabular}

\begin{tabular}{lll}
\hline $\begin{array}{l}\text { Blinding of participants } \\
\text { and personnel (perfor- } \\
\text { mance bias) }\end{array}$ & Unclear risk & \\
$\begin{array}{l}\text { All outcomes } \\
\text { Blinding of outcome as- } \\
\begin{array}{l}\text { sessment (detection bias) } \\
\text { All outcomes }\end{array}\end{array} \quad$ Unclear risk & $\begin{array}{l}\text { Comment: described as 'single-blind' but insufficient information available to } \\
\text { make a judgement. }\end{array}$ \\
\hline
\end{tabular}

\begin{tabular}{|c|c|c|}
\hline $\begin{array}{l}\text { Incomplete outcome data } \\
\text { (attrition bias) } \\
\text { All outcomes }\end{array}$ & High risk & $\begin{array}{l}\text { Comment: high attrition rate }(20.5 \%) \text { but dropouts accounted for and bal- } \\
\text { anced across groups. ITT not employed and unclear how missing data were } \\
\text { dealt with in the analysis. }\end{array}$ \\
\hline
\end{tabular}

\begin{tabular}{|c|c|c|}
\hline $\begin{array}{l}\text { Selective reporting (re- } \\
\text { porting bias) }\end{array}$ & Unclear risk & $\begin{array}{l}\text { Comment: although prespecified outcomes were reported, data were reported } \\
\text { in Table } 4 \text { of the publication but it was unclear whether the data were mean/ } \\
\text { median (and IQR). Clarification required. }\end{array}$ \\
\hline
\end{tabular}

\begin{tabular}{|c|c|c|}
\hline $\begin{array}{l}\text { Baseline data compara- } \\
\text { ble? }\end{array}$ & Low risk & $\begin{array}{l}\text { Quote: "No significant differences between groups }(P>.05) \text { were noted at } \\
\text { baseline with regards to demographic, oral health-related behaviours, or med- } \\
\text { ications taken." }\end{array}$ \\
\hline
\end{tabular}

A priori power calculation Low risk Yes.

Quote: "initial sample size was based on a Plaque index change score SD of $0.21 \pm 0.40$, documented in a previous observational study and set at $40 \mathrm{pa}$ tients per group in order to detect a difference of 0.3 in plaque change scores within and between groups, and account for (1) a 5\% statistical significance level, (2) a power of $80 \%$, and (3) an anticipated $10 \%$ dropout rate."

\begin{tabular}{ll}
\hline Other bias & Comment: insufficient power - minimum sample size was not achieved. \\
& $\begin{array}{l}\text { Quote: "At the time of baseline assessment, over two thirds ( } 67.9 \%) \text { of the pa- } \\
\text { tients reported not to have a regular daily brushing habit (i.e., at least once a } \\
\text { day)." }\end{array}$
\end{tabular}

Lam 2013ii

\section{Study characteristics}

\begin{tabular}{ll}
\hline Methods & RCT randomised at individual level, Hong Kong, People's Republic of China \\
& Study recruitment and setting details: see Table 1 \\
\hline Participants & Inclusion criteria: aged $\geq 50$ years, stroke, $\mathrm{Bl}<70$, and admitted to rehabilitation unit within 7 days \\
\hline
\end{tabular}


Exclusion criteria: edentulous, presented with communication difficulties (unable to follow a 1-step command) or severe cognitive impairment (MMSE $\leq 9)$ or indwelling nasogastric feeding tube

Oral hygiene instruction, mouthrinse and assisted brushing group: 25 participants

Oral hygiene instruction group: 30 participants

Details of participants are shown in Table 2
Interventions

\section{Multi-component OHC intervention}

- Intervention: oral hygiene instruction, mouthrinse and assisted brushing

- Materials: electric toothbrush, a standard sodium fluoride toothpaste, chlorhexidine (Corsodyl) mouthrinse $(0.2 \%, 10 \mathrm{~mL})$

- Agent: chlorhexidine (Corsodyl) mouthrinse $(0.2 \%, 10 \mathrm{~mL})$

- Procedures: dentures were cleaned with a manual toothbrush. All participants were provided with an electric toothbrush and a standard sodium fluoride toothpaste. Professional oral hygiene instruction provided by a dentist; quote: "nursing care aides administered mouthrinses and performed intermittent assisted brushing. Nursing care aides monitored participants for toothbrushing difficulties and ensured that tooth surfaces (buccal, occlusal, lingual) were cleaned in a systematic manner. Handover-hand guiding was provided if participants had difficulty handling and placing the toothbrush."

- Provided by: registered dentist, dental hygienists (certified), nurse aides

- Training: nursing care aides were provided with an oral health training session consisting of a 30minute lecture comprising basic concepts of oral health and disease, as well as a demonstration and practical exercise on the administration of mouthrinse and assisted brushing. Oral health training sessions were carried out by certified dental hygienists

- Delivery: face-to-face, 1:1, rehabilitation ward

- Regimen: mouthrinse (spaced $\geq 2$ hours apart from toothbrushing) and assistance with toothbrushing twice per day delivered over a 3-week period

- Tailoring: none

- Modification: none

- Adherence: not reported

\section{Multi-component OHC intervention}

- Intervention: oral hygiene instruction

- Materials: electric toothbrush, a standard sodium fluoride toothpaste

- Agent: standard sodium fluoride toothpaste

- Procedures: all participants were provided with an electric toothbrush and toothpaste. Nurse care aides provided with oral care instruction

- Provided by: dental hygienists (certified), nurse aides

- Training: quote: "Nursing care aides were provided with an oral health training session consisting of a lecture (30 minutes) comprising basic concepts of oral health and disease, as well as a demonstration and practical exercise on the administration of mouthrinse and assisted brushing. Oral health training sessions were carried out by certified dental hygienists."

- Delivery: face-to-face, 1:1, rehabilitation ward

- Regimen: none

- Tailoring: none

- Modification: none

- Adherence: not reported

Outcomes Outcomes: Dental Plaque Index, Gingival Bleeding Index, BI, swallowing disability (Royal Brisbane Hospital Outcome Measure for Swallowing), treatment satisfaction

Data collection: baseline and 3 weeks (before hospital discharge) 
Lam 2013ii (Continued)

Notes Dropouts are detailed in Table 6

Suitable statistical data permitting inclusion within the review meta-analyses unavailable

\section{Risk of bias}

\begin{tabular}{lll}
\hline Bias & Authors' judgement & Support for judgement \\
\hline $\begin{array}{l}\text { Random sequence genera- } \\
\text { tion (selection bias) }\end{array}$ & Low risk & $\begin{array}{l}\text { Comment: allocated randomly using block randomisation by a research assis- } \\
\text { tant. }\end{array}$ \\
\hline $\begin{array}{l}\text { Allocation concealment } \\
\text { (selection bias) }\end{array}$ & Unclear risk & Comment: not reported. \\
\hline
\end{tabular}

\begin{tabular}{|c|c|c|}
\hline $\begin{array}{l}\text { Blinding of participants } \\
\text { and personnel (perfor- } \\
\text { mance bias) } \\
\text { All outcomes }\end{array}$ & Unclear risk & Comment: not reported. \\
\hline $\begin{array}{l}\text { Blinding of outcome as- } \\
\text { sessment (detection bias) } \\
\text { All outcomes }\end{array}$ & Unclear risk & $\begin{array}{l}\text { Comment: described as 'single-blind' but insufficient information available to } \\
\text { make a judgement. }\end{array}$ \\
\hline
\end{tabular}

\begin{tabular}{ll}
\hline $\begin{array}{l}\text { Incomplete outcome data } \\
\text { (attrition bias) }\end{array}$ & High risk \\
All outcomes & $\begin{array}{l}\text { Comment: high attrition rate (20.5\%) but dropouts accounted for and bal- } \\
\text { anced across groups. ITT not employed and unclear how missing data were } \\
\text { dealt with in the analysis. }\end{array}$ \\
\hline
\end{tabular}

\begin{tabular}{|c|c|c|}
\hline $\begin{array}{l}\text { Selective reporting (re- } \\
\text { porting bias) }\end{array}$ & Unclear risk & $\begin{array}{l}\text { Comment: although prespecified outcomes were reported, data were reported } \\
\text { in Table } 4 \text { of the publication but it was unclear whether the data were mean/ } \\
\text { median (and IQR). Clarification required. }\end{array}$ \\
\hline
\end{tabular}

\begin{tabular}{ll}
\hline $\begin{array}{l}\text { Baseline data compara- } \\
\text { ble? }\end{array}$ & Low risk \\
& $\begin{array}{l}\text { Quote: "No significant differences between groups }(P>.05) \text { were noted at } \\
\text { baseline with regards to demographic, oral health-related behaviours, or med- } \\
\text { ications taken." }\end{array}$ \\
\hline
\end{tabular}

A priori power calculation Low risk Yes.

Quote: "initial sample size was based on a Plaque index change score SD of $0.21 \pm 0.40$, documented in a previous observational study and set at 40 patients per group in order to detect a difference of 0.3 in plaque change scores within and between groups, and account for (1) a 5\% statistical significance level, (2) a power of $80 \%$, and (3) an anticipated $10 \%$ dropout rate."

Other bias High risk Comment: insufficient power - minimum sample size was not achieved.

Quote: "At the time of baseline assessment, over two thirds (67.9\%) of the patients reported not to have a regular daily brushing habit (i.e., at least once a day)."

\section{Study characteristics}

Methods RCT randomised at individual level, Hong Kong, People's Republic of China

Study recruitment and setting details: see Table 1 
Lam 2013iii (Continued)

Participants
Inclusion criteria: aged $\geq 50$ years, stroke, $\mathrm{BI}<70$, and admitted to rehabilitation unit with 7 days

Exclusion criteria: edentulous, presented with communication difficulties (unable to follow a 1-step command) or severe cognitive impairment (MMSE $\leq 9)$ or indwelling nasogastric feeding tube

Oral hygiene instruction and chlorhexidine mouthrinse group: 26 participants

Oral hygiene instruction group: 30 participants

Details of participants are shown in Table 2
Interventions

\section{Multi-component OHC intervention}

- Intervention: oral hygiene instruction and chlorhexidine mouthrinse

- Materials: electric toothbrush, a standard sodium fluoride toothpaste, chlorhexidine (Corsodyl) mouthrinse $(0.2 \%, 10 \mathrm{~mL})$

- Agent: chlorhexidine (Corsodyl) mouthrinse $(0.2 \%, 10 \mathrm{~mL})$

- Procedures: dentures were cleaned with a manual toothbrush. All participants were provided with an electric toothbrush and a standard sodium fluoride toothpaste. Professional oral hygiene instruction provided by a dentist; nursing care aides administered mouthrinses

- Provided by: registered dentist, dental hygienists (certified), nurse aides

- Training: quote: "Nursing care aides were provided with an oral health training session consisting of a lecture (30 minutes) comprising basic concepts of oral health and disease, as well as a demonstration and practical exercise on the administration of mouthrinse and assisted brushing. Oral health training sessions were carried out by certified dental hygienists."

- Delivery: face-to-face, 1:1, rehabilitation ward

- Regimen: mouthrinse twice per day delivered over a 3-week period

- Tailoring: none

- Modification: none

- Adherence: reported 1 dropout because of non-compliance with mouthrinse

\section{Multi-component OHC intervention}

- Intervention: oral hygiene instruction

- Materials: electric toothbrush, a standard sodium fluoride toothpaste

- Agent: standard sodium fluoride toothpaste

- Procedures: all participants were provided with an electric toothbrush and toothpaste. Nurse care aides provided with oral care instruction

- Provided by: dental hygienists (certified), nurse aides

- Training: quote: "Nursing care aides were provided with an oral health training session consisting of a lecture (30 minutes) comprising basic concepts of oral health and disease, as well as a demonstration and practical exercise on the administration of mouthrinse and assisted brushing. Oral health training sessions were carried out by certified dental hygienists."

- Delivery: face-to-face, 1:1, rehabilitation ward

- Regimen: none

- Tailoring: none

- Modification: none

- Adherence: not reported
Outcomes: Dental Plaque Index, Gingival Bleeding Index, BI, swallowing disability (Royal Brisbane Hospital Outcome Measure for Swallowing), treatment satisfaction

Data collection: baseline and 3 weeks (before hospital discharge) 
Lam 2013iii (Continued)

Suitable statistical data permitting inclusion within the review meta-analyses unavailable

\section{Risk of bias}

\begin{tabular}{lll}
\hline Bias & Authors' judgement & Support for judgement \\
\hline $\begin{array}{l}\text { Random sequence genera- } \\
\text { tion (selection bias) }\end{array}$ & Low risk & $\begin{array}{l}\text { Comment: allocated randomly using block randomisation by a research assis } \\
\text { tant. }\end{array}$
\end{tabular}

Allocation concealment $\quad$ Unclear risk $\quad$ Comment: not reported.
(selection bias)

Blinding of participants Unclear risk $\quad$ Comment: not reported.
and personnel (perfor-
mance bias)
All outcomes

\begin{tabular}{|c|c|c|}
\hline $\begin{array}{l}\text { Blinding of outcome as- } \\
\text { sessment (detection bias) } \\
\text { All outcomes }\end{array}$ & Unclear risk & $\begin{array}{l}\text { Comment: described as 'single-blind' but insufficient information available to } \\
\text { make a judgement. }\end{array}$ \\
\hline
\end{tabular}

\begin{tabular}{|c|c|c|}
\hline $\begin{array}{l}\text { Incomplete outcome data } \\
\text { (attrition bias) } \\
\text { All outcomes }\end{array}$ & High risk & $\begin{array}{l}\text { Comment: high attrition rate ( } 20.5 \%) \text { but dropouts accounted for and bal- } \\
\text { anced across groups. ITT not employed and not clear how missing data were } \\
\text { dealt with in the analysis. }\end{array}$ \\
\hline
\end{tabular}

\begin{tabular}{ll}
\hline $\begin{array}{l}\text { Selective reporting (re- } \\
\text { porting bias) }\end{array}$ & $\begin{array}{l}\text { Comment: although prespecified outcomes were reported, data were reported } \\
\text { in Table } 4 \text { of the publication but it was unclear whether the data were mean/ } \\
\text { median (and IQR). Clarification required. }\end{array}$ \\
\hline
\end{tabular}

\begin{tabular}{|c|c|c|}
\hline $\begin{array}{l}\text { Baseline data compara- } \\
\text { ble? }\end{array}$ & Low risk & $\begin{array}{l}\text { Quote: "No significant differences between groups }(P>.05) \text { were noted at } \\
\text { baseline with regards to demographic, oral health-related behaviours, or med- } \\
\text { ications taken." }\end{array}$ \\
\hline
\end{tabular}

A priori power calculation Low risk Yes.

Quote: "initial sample size was based on a Plaque index change score SD of $0.21 \pm 0.40$, documented in a previous observational study and set at 40 patients per group in order to detect a difference of 0.3 in plaque change scores within and between groups, and account for (1) a 5\% statistical significance level, (2) a power of $80 \%$, and (3) an anticipated $10 \%$ dropout rate."

\begin{tabular}{ll}
\hline Other bias & Comment: insufficient power - minimum sample size was not achieved. \\
& $\begin{array}{l}\text { Quote: "At the time of baseline assessment, over two thirds (67.9\%) of the pa- } \\
\text { tients reported not to have a regular daily brushing habit (i.e., at least once a } \\
\text { day)." }\end{array}$
\end{tabular}

Lam 2013iii

\section{Study characteristics}

\begin{tabular}{ll}
\hline Methods & RCT randomised at individual level, Hong Kong, People's Republic of China \\
& Study recruitment and setting details: see Table 1 \\
\hline Participants & Inclusion criteria: aged $\geq 50$ years, stroke, $\mathrm{BI}<70$, and admitted to rehabilitation unit with 7 days \\
\hline
\end{tabular}


Lam 2013iii (Continued)

Exclusion criteria: edentulous, presented with communication difficulties (unable to follow a 1-step command) or severe cognitive impairment (MMSE $\leq 9)$ or indwelling nasogastric feeding tube

Oral hygiene instruction and chlorhexidine mouthrinse group: 26 participants

Oral hygiene instruction group: 30 participants

Details of participants are shown in Table 2

Interventions

\section{Multi-component OHC intervention}

- Intervention: oral hygiene instruction and chlorhexidine mouthrinse

- Materials: electric toothbrush, a standard sodium fluoride toothpaste, chlorhexidine (Corsodyl) mouthrinse $(0.2 \%, 10 \mathrm{~mL})$

- Agent: chlorhexidine (Corsodyl) mouthrinse $(0.2 \%, 10 \mathrm{~mL})$

- Procedures: dentures were cleaned with a manual toothbrush. All participants were provided with an electric toothbrush and a standard sodium fluoride toothpaste. Professional oral hygiene instruction provided by a dentist; nursing care aides administered mouthrinses

- Provided by: registered dentist, dental hygienists (certified), nurse aides

- Training: quote: "Nursing care aides were provided with an oral health training session consisting of a lecture (30 minutes) comprising basic concepts of oral health and disease, as well as a demonstration and practical exercise on the administration of mouthrinse and assisted brushing. Oral health training sessions were carried out by certified dental hygienists."

- Delivery: face-to-face, 1:1, rehabilitation ward

- Regimen: mouthrinse twice per day delivered over a 3-week period

- Tailoring: none

- Modification: none

- Adherence: reported 1 dropout because of non-compliance with mouthrinse

\section{Multi-component OHC intervention}

- Intervention: oral hygiene instruction

- Materials: electric toothbrush, a standard sodium fluoride toothpaste

- Agent: standard sodium fluoride toothpaste

- Procedures: all participants were provided with an electric toothbrush and toothpaste. Nurse care aides provided with oral care instruction

- Provided by: dental hygienists (certified), nurse aides

- Training: quote: "Nursing care aides were provided with an oral health training session consisting of a lecture (30 minutes) comprising basic concepts of oral health and disease, as well as a demonstration and practical exercise on the administration of mouthrinse and assisted brushing. Oral health training sessions were carried out by certified dental hygienists."

- Delivery: face-to-face, $1: 1$, rehabilitation ward

- Regimen: none

- Tailoring: none

- Modification: none

- Adherence: not reported

Outcomes

Outcomes: Dental Plaque Index, Gingival Bleeding Index, BI, swallowing disability (Royal Brisbane Hospital Outcome Measure for Swallowing), treatment satisfaction

Data collection: baseline and 3 weeks (before hospital discharge)

Funding

Study authors declared no conflicts of interest. Study funded by the Committee of Research and Conference Grants of the University of Hong Kong

Notes

Dropouts are detailed in Table 6

Suitable statistical data permitting inclusion within the review meta-analyses unavailable 
Lam 2013iii (Continued)

Risk of bias

\begin{tabular}{|c|c|c|}
\hline Bias & Authors' judgement & Support for judgement \\
\hline $\begin{array}{l}\text { Random sequence genera- } \\
\text { tion (selection bias) }\end{array}$ & Low risk & $\begin{array}{l}\text { Comment: allocated randomly using block randomisation by a research assis- } \\
\text { tant. }\end{array}$ \\
\hline $\begin{array}{l}\text { Allocation concealment } \\
\text { (selection bias) }\end{array}$ & Unclear risk & Comment: not reported. \\
\hline $\begin{array}{l}\text { Blinding of participants } \\
\text { and personnel (perfor- } \\
\text { mance bias) } \\
\text { All outcomes }\end{array}$ & Unclear risk & Comment: not reported. \\
\hline $\begin{array}{l}\text { Blinding of outcome as- } \\
\text { sessment (detection bias) } \\
\text { All outcomes }\end{array}$ & Unclear risk & $\begin{array}{l}\text { Comment: described as 'single-blind' but insufficient information available to } \\
\text { make a judgement. }\end{array}$ \\
\hline $\begin{array}{l}\text { Incomplete outcome data } \\
\text { (attrition bias) } \\
\text { All outcomes }\end{array}$ & High risk & $\begin{array}{l}\text { Comment: high attrition rate }(20.5 \%) \text { but dropouts accounted for and bal- } \\
\text { anced across groups. ITT not employed and not clear how missing data were } \\
\text { dealt with in the analysis. }\end{array}$ \\
\hline $\begin{array}{l}\text { Selective reporting (re- } \\
\text { porting bias) }\end{array}$ & Unclear risk & $\begin{array}{l}\text { Comment: although prespecified outcomes were reported, data were reported } \\
\text { in Table } 4 \text { of the publication but it was unclear whether the data were mean/ } \\
\text { median (and IQR). Clarification required. }\end{array}$ \\
\hline $\begin{array}{l}\text { Baseline data compara- } \\
\text { ble? }\end{array}$ & Low risk & $\begin{array}{l}\text { Quote: "No significant differences between groups }(P>.05) \text { were noted at } \\
\text { baseline with regards to demographic, oral health-related behaviours, or med- } \\
\text { ications taken." }\end{array}$ \\
\hline \multirow[t]{2}{*}{ A priori power calculation } & Low risk & Yes. \\
\hline & & $\begin{array}{l}\text { Quote: "initial sample size was based on a Plaque index change score SD of } \\
0.21 \pm 0.40 \text {, documented in a previous observational study and set at } 40 \text { pa- } \\
\text { tients per group in order to detect a difference of } 0.3 \text { in plaque change scores } \\
\text { within and between groups, and account for ( } 1 \text { ) a } 5 \% \text { statistical significance } \\
\text { level, (2) a power of } 80 \% \text {, and (3) an anticipated } 10 \% \text { dropout rate." }\end{array}$ \\
\hline Other bias & High risk & Comment: insufficient power - minimum sample size was not achieved. \\
\hline & & $\begin{array}{l}\text { Quote: "At the time of baseline assessment, over two thirds ( } 67.9 \%) \text { of the pa- } \\
\text { tients reported not to have a regular daily brushing habit (i.e., at least once a } \\
\text { day)." }\end{array}$ \\
\hline
\end{tabular}

Lee 2011

\section{Study characteristics}

\begin{tabular}{ll}
\hline Methods & RCT randomised at individual level, South Korea \\
& Study recruitment and setting details: see Table 1 \\
\hline Participants & Inclusion criteria: unclear \\
& Exclusion criteria: unclear
\end{tabular}


Lee 2011 (Continued)

\section{Saengmaeg-san extract group: 12 participants}

Placebo group: 12 participants

Details of participants are shown in Table 2

Saengmaeg-san extract
- Interventions
- Materials: not reported
- Agent: saengmaeg-san extract
- Procedures: capsules
- Provided by: not reported
- Training: not reported
- Delivery: face-to-face; 1 -to-1
- Location: not reported
- Regimen: capsules given 3 times per day for 7 days
- Tailoring: not reported
- Modification: not reported
- Adherence: 1 dropout because of poor medication compliance

Placebo

- Intervention: opaque capsules

- Materials: not reported

- Agent: not reported

- Procedures: capsules

- Provided by: not reported

- Training: not reported

- Delivery: face-to-face; 1 -to-1

- Location: not reported

- Regimen: capsules given 3 times per day for 7 days

- Tailoring: not reported

- Modification: not reported

- Adherence: not reported

Outcomes

Outcomes: visual analogue scale to evaluate subjective oral dryness (dry in night/morning, dry in daytime, dry while eating a meal, hard to swallow food, lack of saliva, general discomfort)

Data collection: baseline and follow-up (1 week later)

Paper in Korean - translation unavailable so we were unable to determine whether there were any potential conflicts of interest or how the study was funded

Notes Dropouts are detailed in Table 6

Statistical data included within the review meta-analyses

\section{Risk of bias}

\section{Bias \\ Authors' judgement Support for judgement}

Random sequence genera- Unclear risk tion (selection bias)
Comment: no details available at present ("randomised") - translation unavailable. 
Lee 2011 (Continued)

Allocation concealment $\quad$ Unclear risk $\quad$ Comment: no details available at present - translation unavailable.
(selection bias)

\begin{tabular}{|c|c|c|}
\hline $\begin{array}{l}\text { Blinding of participants } \\
\text { and personnel (perfor- } \\
\text { mance bias) } \\
\text { All outcomes }\end{array}$ & Low risk & $\begin{array}{l}\text { Comment: reported as 'double-blind' but no other details available at present } \\
\text { - translation unavailable. }\end{array}$ \\
\hline $\begin{array}{l}\text { Blinding of outcome as- } \\
\text { sessment (detection bias) }\end{array}$ & Low risk & $\begin{array}{l}\text { Comment: reported as 'double-blind' but no other details available - transla- } \\
\text { tion unavailable. }\end{array}$ \\
\hline
\end{tabular}

All outcomes

\begin{tabular}{lll}
\hline $\begin{array}{l}\text { Incomplete outcome data } \\
\text { (attrition bias) } \\
\text { All outcomes }\end{array}$ & Unclear risk & Comment: dropouts accounted for, ITT not employed. \\
\hline $\begin{array}{l}\text { Selective reporting (re- } \\
\text { porting bias) }\end{array}$ & Unclear risk & Comment: all prespecified outcomes reported. \\
\hline $\begin{array}{l}\text { Baseline data compara- } \\
\text { ble? }\end{array}$ & Unclear risk & Comment: no details available at present - translation unavailable. \\
\hline A priori power calculation & Unclear risk & Comment: no details available at present - translation unavailable. \\
\hline Other bias & Unclear risk & Comment: no details available at present - translation unavailable. \\
\hline
\end{tabular}

Lee 2011

\section{Study characteristics}

\begin{tabular}{ll}
\hline Methods & RCT randomised at individual level, South Korea \\
& Study recruitment and setting details: see Table 1 \\
\hline Participants & Inclusion criteria: unclear \\
Exclusion criteria: unclear & Saengmaeg-san extract group: 12 participants \\
Placebo group: 12 participants \\
Details of participants are shown in Table 2
\end{tabular}

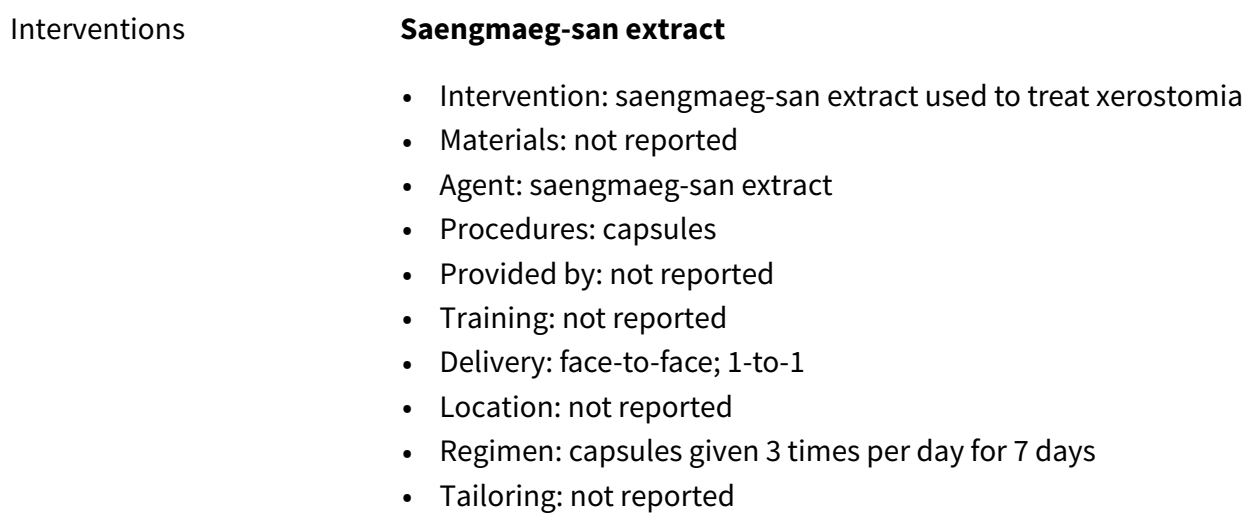

- Intervention: saengmaeg-san extract used to treat xerostomia

- Materials: not reported

- Agent: saengmaeg-san extract

- Procedures: capsules

- Provided by: not reported

- Training: not reported

- Delivery: face-to-face; 1 -to-1

- Location: not reported

- Regimen: capsules given 3 times per day for 7 days

- Tailoring: not reported 
Lee 2011 (Continued)

- Modification: not reported

- Adherence: 1 dropout because of poor medication compliance

\section{Placebo}

- Intervention: opaque capsules

- Materials: not reported

- Agent: not reported

- Procedures: capsules

- Provided by: not reported

- Training: not reported

- Delivery: face-to-face; 1 -to-1

- Location: not reported

- Regimen: capsules given 3 times per day for 7 days

- Tailoring: not reported

- Modification: not reported

- Adherence: not reported

Outcomes Outcomes: visual analogue scale to evaluate subjective oral dryness (dry in night/morning, dry in daytime, dry while eating a meal, hard to swallow food, lack of saliva, general discomfort)

Data collection: baseline and follow-up (1 week later)

Funding Paper in Korean - translation unavailable so we were unable to determine whether there were any potential conflicts of interest or how the study was funded

Notes Dropouts are detailed in Table 6

Statistical data included within the review meta-analyses

\section{Risk of bias}

\begin{tabular}{|c|c|c|}
\hline Bias & Authors' judgement & Support for judgement \\
\hline $\begin{array}{l}\text { Random sequence genera- } \\
\text { tion (selection bias) }\end{array}$ & Unclear risk & $\begin{array}{l}\text { Comment: no details available at present ("randomised") - translation un- } \\
\text { available. }\end{array}$ \\
\hline $\begin{array}{l}\text { Allocation concealment } \\
\text { (selection bias) }\end{array}$ & Unclear risk & Comment: no details available at present - translation unavailable. \\
\hline $\begin{array}{l}\text { Blinding of participants } \\
\text { and personnel (perfor- } \\
\text { mance bias) } \\
\text { All outcomes }\end{array}$ & Low risk & $\begin{array}{l}\text { Comment: reported as 'double-blind' but no other details available at present } \\
\text { - translation unavailable. }\end{array}$ \\
\hline $\begin{array}{l}\text { Blinding of outcome as- } \\
\text { sessment (detection bias) } \\
\text { All outcomes }\end{array}$ & Low risk & $\begin{array}{l}\text { Comment: reported as 'double-blind' but no other details available - transla- } \\
\text { tion unavailable. }\end{array}$ \\
\hline $\begin{array}{l}\text { Incomplete outcome data } \\
\text { (attrition bias) } \\
\text { All outcomes }\end{array}$ & Unclear risk & Comment: dropouts accounted for, ITT not employed. \\
\hline $\begin{array}{l}\text { Selective reporting (re- } \\
\text { porting bias) }\end{array}$ & Unclear risk & Comment: all prespecified outcomes reported. \\
\hline
\end{tabular}


Lee 2011 (Continued)

Baseline data compara- Unclear risk Comment: no details available at present - translation unavailable. ble?

\begin{tabular}{lll}
\hline A priori power calculation & Unclear risk & Comment: no details available at present - translation unavailable. \\
\hline Other bias & Unclear risk & Comment: no details available at present - translation unavailable.
\end{tabular}

\section{Study characteristics}

\begin{tabular}{|c|c|}
\hline Methods & $\begin{array}{l}\text { RCT randomised at individual level, France } \\
\text { Study recruitment and setting details: see Table } 1\end{array}$ \\
\hline Participants & $\begin{array}{l}\text { Inclusion criteria: aged } \geq 18 \text { years with closed traumatic brain injury (with Glasgow Coma Scale } \leq 8 \text { ), } \\
\text { mechanically ventilated } \geq 48 \text { hours. People with cerebral haemorrhage were included } 4 \text { months after } \\
\text { recruitment started } \\
\text { Exclusion criteria: people in whom oral care procedure could not be performed within the } 12 \text { hours af- } \\
\text { ter endotracheal intubation or had tetraplegia (or both), facial trauma, pulmonary contusion involving } \\
>1 \text { lobe, aspiration pneumonia, current curative antimicrobial therapy, known allergy to povidone-io- } \\
\text { dine and pregnancy } \\
\text { Povidone-iodine group: } 91 \text { participants } \\
\text { Placebo group: } 88 \text { participants } \\
\text { Details of participants are shown in Table } 2\end{array}$ \\
\hline
\end{tabular}

- Intervention: povidone-iodine

- Materials: povidone-iodine (Betadine $10 \%$ oral antiseptic solution; Meda Pharma, Paris, France) portioned in vials containing $125 \mathrm{~mL}$ of product and dispensed by the Pharmacy of Rennes to the pharmacies of the participating centres

- Procedures: participants received nasopharynx and oropharynx rinsing with $20 \mathrm{~mL}$ of povidone-iodine $10 \%$ using a $60 \mathrm{~mL}$ syringe (final concentration 3.3\%). The solution was progressively injected in the buccal and pharyngeal cavities and regularly suctioned over 2 minutes, every 4 hours. The intervention was continued until extubation or until day 30

- Provided by: all nurses were trained in the oral procedure. Film describing in detail the oral care procedure was made available to all investigators

- Delivery: face-to-face; 1-to-1

- Location: intensive care unit

- Regimen: nasopharynx and oropharynx rinsing with $20 \mathrm{~mL}$ of povidone-iodine $10 \%$ or placebo diluted in $40 \mathrm{~mL}$ of sterile water using a $60 \mathrm{~mL}$ syringe (final concentration 3.3\%). The solution was progressively injected in the buccal and pharyngeal cavities and regularly suctioned for 2 minutes, every 4 hours (i.e. 6 times daily). Intervention was continued until extubation or until day 30

- Tailoring: none

- Modification: none

- Adherence: tolerance of the oral procedure was monitored

\section{Oropharyngeal care with placebo}

- Intervention: placebo

- Materials: placebo were portioned in vials containing $125 \mathrm{~mL}$ of product and dispensed by the Pharmacy of Rennes to the pharmacies of the participating centres 
Seguin 2014 (Continued)

- Procedures: participants received nasopharynx and oropharynx rinsing with placebo diluted in $40 \mathrm{~mL}$ of sterile water using a $60 \mathrm{~mL}$ syringe (final concentration 3.3\%). The solution was progressively injected in the buccal and pharyngeal cavities and regularly suctioned over 2 minutes, every 4 hours. The intervention was continued until extubation or until day 30

- Provided by: all nurses were trained in the oral procedure. Film describing in detail the oral care procedure was made available to all investigators

- Delivery: face-to-face; 1 -to-1

- Location: intensive care unit

- Regimen: the solution was progressively injected in the buccal and pharyngeal cavities and regularly suctioned for 2 minutes, every 4 hours (i.e. 6 times daily). Intervention was continued until extubation or until day 30

- Tailoring: none

- Modification: none

- Adherence: tolerance of the oral procedure was also monitored
Primary outcomes: rate of VAP

Secondary outcomes: delay of first VAP occurrence (between admission and diagnosis), rate of early ( $\leq$ 7 days) and late (> 7 days) VAP, micro-organisms involved, rates of ventilator ventilator-associated tracheobronchitis and acute respiratory distress syndrome, and the number of ventilation-free days, other nosocomial infections in intensive care unit, hospital and intensive care unit, length of stay, and 90-day mortality were reported, tolerance of the oral procedure was also monitored

Data collection: detailed above
3 study authors declared a potential conflict of interest (Dr Veber is a board member for Lily and lectured for Baxter, and has received support for travel from Pfizer. Dr Asehnoune lectured for B-Braun, Fresenius and Baxter. Dr Mimoz has received lecture and consultant fees from CareFusion, 3M Company and Ethicon)

The remaining authors reported no conflicts of interest

Study funded in part by a grant from the French Ministry of Health (2006, Programme Hospitalier de Recherche Clinique)
Dropouts are detailed in Table 6

4 months after the beginning of recruitment, the protocol was amended to include participants with cerebral haemorrhage, fulfilling the same eligibility criteria

Stroke-specific trial data was sent by the study authors

Statistical data included within the review meta-analyses

\section{Risk of bias}

\begin{tabular}{lll}
\hline Bias & Authors' judgement & Support for judgement \\
\hline $\begin{array}{l}\text { Random sequence genera- } \\
\text { tion (selection bias) }\end{array}$ & Low risk & $\begin{array}{l}\text { Comment: centralised and performed by the pharmacy of the co-ordinating } \\
\text { centre, stratified by centre and by type of participants (trauma or cerebral } \\
\text { haemorrhage), and equilibrated by blocks of } 4 .\end{array}$ \\
\hline $\begin{array}{l}\text { Allocation concealment } \\
\text { (selection bias) }\end{array}$ & Unclear risk & Comment: not reported. \\
\hline $\begin{array}{l}\text { Blinding of participants } \\
\text { and personnel (perfor- } \\
\text { mance bias) }\end{array}$ & Low risk & Comment: placebo control and study reported as "double-blind." \\
\begin{tabular}{l} 
All outcomes \\
\hline
\end{tabular}
\end{tabular}


Seguin 2014 (Continued)

Blinding of outcome as- Low risk Comment: 3 experienced physicians "blindly classified each patient as positive sessment (detection bias) or negative for VAP or ventilator-associated tracheobronchitis."

All outcomes

\begin{tabular}{|c|c|c|}
\hline $\begin{array}{l}\text { Incomplete outcome data } \\
\text { (attrition bias) }\end{array}$ & Low risk & $\begin{array}{l}\text { Comment: dropouts accounted for; ITT analysis not employed but missing } \\
\text { outcome data balanced across groups. }\end{array}$ \\
\hline
\end{tabular}

All outcomes outcome data balanced across groups.

Selective reporting (re- Low risk Comment: all prespecified outcomes reported.
porting bias)

\begin{tabular}{|c|c|c|}
\hline $\begin{array}{l}\text { Baseline data compara- } \\
\text { ble? }\end{array}$ & Low risk & $\begin{array}{l}\text { Comment: groups were comparable for demographic and disease characteris- } \\
\text { tics. }\end{array}$ \\
\hline
\end{tabular}

A priori power calculation Low risk Yes.

Quote: " ... calculated that a sample size of 146 patients (73 in each group) would be necessary to detect an absolute reduction of $25 \%$ with povidone-iodine, with a type I error of $5 \%$ and a power of $95 \%$ in a one-sided test. The protocol planned to enrol $10 \%$ more patients in order to take into account patients that could not be assessable because of death or mechanical ventilation withdrawal within 48 hours following inclusion."

\begin{tabular}{ll}
\hline Other bias & Unclear risk \\
& $\begin{array}{l}\text { Comment: protocol was amended } 4 \text { months after start of study to include peo- } \\
\text { ple with cerebral haemorhage (fulfilling the same eligibility criteria) - no in- } \\
\text { formation given about why the protocol was amended. }\end{array}$
\end{tabular}

Seguin 2014

\section{Study characteristics}

\begin{tabular}{|c|c|}
\hline Methods & $\begin{array}{l}\text { RCT randomised at individual level, France } \\
\text { Study recruitment and setting details: see Table } 1\end{array}$ \\
\hline \multirow[t]{5}{*}{ Participants } & $\begin{array}{l}\text { Inclusion criteria: aged } \geq 18 \text { years with closed traumatic brain injury (with Glasgow Coma Scale } \leq 8 \text { ), } \\
\text { mechanically ventilated } \geq 48 \text { hours. People with cerebral haemorrhage were included } 4 \text { months after } \\
\text { recruitment started }\end{array}$ \\
\hline & $\begin{array}{l}\text { Exclusion criteria: people in whom oral care procedure could not be performed within the } 12 \text { hours af- } \\
\text { ter endotracheal intubation or had tetraplegia (or both), facial trauma, pulmonary contusion involving } \\
>1 \text { lobe, aspiration pneumonia, current curative antimicrobial therapy, known allergy to povidone-io- } \\
\text { dine and pregnancy }\end{array}$ \\
\hline & Povidone-iodine group: 91 participants \\
\hline & Placebo group: 88 participants \\
\hline & Details of participants are shown in Table 2 \\
\hline
\end{tabular}

Interventions Oropharyngeal care with povidone-iodine

- Intervention: povidone-iodine

- Materials: povidone-iodine (Betadine $10 \%$ oral antiseptic solution; Meda Pharma, Paris, France) portioned in vials containing $125 \mathrm{~mL}$ of product and dispensed by the Pharmacy of Rennes to the pharmacies of the participating centres

- Procedures: participants received nasopharynx and oropharynx rinsing with $20 \mathrm{~mL}$ of povidone-iodine $10 \%$ using a $60 \mathrm{~mL}$ syringe (final concentration 3.3\%). The solution was progressively injected in 
the buccal and pharyngeal cavities and regularly suctioned over 2 minutes, every 4 hours. The intervention was continued until extubation or until day 30

- Provided by: all nurses were trained in the oral procedure. Film describing in detail the oral care procedure was made available to all investigators

- Delivery: face-to-face; 1 -to-1

- Location: intensive care unit

- Regimen: nasopharynx and oropharynx rinsing with $20 \mathrm{~mL}$ of povidone-iodine $10 \%$ or placebo diluted in $40 \mathrm{~mL}$ of sterile water using a $60 \mathrm{~mL}$ syringe (final concentration 3.3\%). The solution was progressively injected in the buccal and pharyngeal cavities and regularly suctioned for 2 minutes, every 4 hours (i.e. 6 times daily). Intervention was continued until extubation or until day 30

- Tailoring: none

- Modification: none

- Adherence: tolerance of the oral procedure was monitored

\section{Oropharyngeal care with placebo}

- Intervention: placebo

- Materials: placebo were portioned in vials containing $125 \mathrm{~mL}$ of product and dispensed by the Pharmacy of Rennes to the pharmacies of the participating centres

- Procedures: participants received nasopharynx and oropharynx rinsing with placebo diluted in $40 \mathrm{~mL}$ of sterile water using a $60 \mathrm{~mL}$ syringe (final concentration 3.3\%). The solution was progressively injected in the buccal and pharyngeal cavities and regularly suctioned over 2 minutes, every 4 hours. The intervention was continued until extubation or until day 30

- Provided by: all nurses were trained in the oral procedure. Film describing in detail the oral care procedure was made available to all investigators

- Delivery: face-to-face; 1 -to-1

- Location: intensive care unit

- Regimen: the solution was progressively injected in the buccal and pharyngeal cavities and regularly suctioned for 2 minutes, every 4 hours (i.e. 6 times daily). Intervention was continued until extubation or until day 30

- Tailoring: none

- Modification: none

- Adherence: tolerance of the oral procedure was also monitored

Secondary outcomes: delay of first VAP occurrence (between admission and diagnosis), rate of early ( $\leq$ 7 days) and late ( $>7$ days) VAP, micro-organisms involved, rates of ventilator ventilator-associated tracheobronchitis and acute respiratory distress syndrome, and the number of ventilation-free days, other nosocomial infections in intensive care unit, hospital and intensive care unit, length of stay, and 90-day mortality were reported, tolerance of the oral procedure was also monitored

Data collection: detailed above tured for Baxter, and has received support for travel from Pfizer. Dr Asehnoune lectured for B-Braun, Fresenius and Baxter. Dr Mimoz has received lecture and consultant fees from CareFusion, 3M Company and Ethicon)

The remaining authors reported no conflicts of interest

Study funded in part by a grant from the French Ministry of Health (2006, Programme Hospitalier de Recherche Clinique)

4 months after the beginning of recruitment, the protocol was amended to include participants with cerebral haemorrhage, fulfilling the same eligibility criteria 
Seguin 2014 (Continued)

Stroke-specific trial data was sent by the study authors

Statistical data included within the review meta-analyses

\section{Risk of bias}

\begin{tabular}{lll}
\hline Bias & Authors' judgement & Support for judgement \\
\hline $\begin{array}{l}\text { Random sequence genera- } \\
\text { tion (selection bias) }\end{array}$ & Low risk & $\begin{array}{l}\text { Comment: centralised and performed by the pharmacy of the co-ordinating } \\
\text { centre, stratified by centre and by type of participants (trauma or cerebral } \\
\text { haemorrhage), and equilibrated by blocks of } 4 .\end{array}$ \\
\hline
\end{tabular}

\begin{tabular}{lll}
\hline $\begin{array}{l}\text { Allocation concealment } \\
\text { (selection bias) }\end{array}$ & Unclear risk & Comment: not reported. \\
\hline $\begin{array}{l}\text { Blinding of participants } \\
\text { and personnel (perfor- } \\
\text { mance bias) }\end{array}$ & Low risk & Comment: placebo control and study reported as "double-blind." \\
All outcomes & & \\
\hline
\end{tabular}

\begin{tabular}{lll}
\hline $\begin{array}{l}\text { Blinding of outcome as- } \\
\text { sessment (detection bias) }\end{array}$ & Low risk & $\begin{array}{l}\text { Comment: } 3 \text { experienced physicians "blindly classified each patient as positive } \\
\text { oll outcomes }\end{array}$
\end{tabular}

\begin{tabular}{ll}
\hline $\begin{array}{l}\text { Incomplete outcome data } \\
\text { (attrition bias) }\end{array}$ & Low risk
\end{tabular}

All outcomes

Comment: dropouts accounted for; ITT analysis not employed but missing

\begin{tabular}{lll}
\hline $\begin{array}{l}\text { Selective reporting (re- } \\
\text { porting bias) }\end{array}$ & Low risk & Comment: all prespecified outcomes reported. \\
\hline $\begin{array}{l}\text { Baseline data compara- } \\
\text { ble? }\end{array}$ & Low risk & $\begin{array}{l}\text { Comment: groups were comparable for demographic and disease characteris- } \\
\text { tics. }\end{array}$ \\
\hline $\begin{array}{l}\text { A priori power calculation } \\
\text { Low risk }\end{array}$ & Yes. \\
& $\begin{array}{l}\text { Quote: " ... calculated that a sample size of } 146 \text { patients (73 in each group) } \\
\text { would be necessary to detect an absolute reduction of } 25 \% \text { with povidone-io- } \\
\text { dine, with a type l error of } 5 \% \text { and a power of } 95 \% \text { in a one-sided test. The pro- } \\
\text { tocol planned to enrol } 10 \% \text { more patients in order to take into account pa- } \\
\text { tients that could not be assessable because of death or mechanical ventilation } \\
\text { withdrawal within } 48 \text { hours following inclusion." }\end{array}$ \\
\hline Other bias & Unclear risk & $\begin{array}{l}\text { Comment: protocol was amended } 4 \text { months after start of study to include peo- } \\
\text { ple with cerebral haemorrhage (fulfilling the same eligibility criteria) - no in- } \\
\text { formation given about why the protocol was amended. }\end{array}$ \\
\hline
\end{tabular}

\section{SOCLE II}

\section{Study characteristics}

\begin{tabular}{ll}
\hline Methods & Stepped-wedge clustered pilot RCT randomised at hospital level, UK \\
& Study recruitment and setting details: see Table 1 \\
\hline Participants & $\begin{array}{l}\text { Inclusion criteria: wards with a specific remit for stroke rehabilitation care, all ward admissions includ- } \\
\text { ing all ages, dentition profiles, reason for admission (including non-stroke), cognitive and communica- }\end{array}$
\end{tabular}


SOCLE II (Continued)

tion impairment status. Similarly, all nursing staff (registered nurses, nursing assistants and student nurses) were eligible for inclusion

Exclusion criteria: acute stroke wards

OHC group: 135 patients; 108 staff

Usual care group: 147 patients; 84 staff

Details of participants are shown in Table 2

Interventions

Multi-component OHC intervention

- Intervention: complex multi-component OHC intervention

- Materials: toothbrushes, Internet-based training module, computer

- Agent: toothpaste, oral balance gel, denture marking kit

- Procedures: patient-level intervention involved treatment from specialist trained staff, individualised assessment, individualised care plan, oral health promotion. Staff-level intervention involved online training ( $\mathrm{OHC}$ assessment, $\mathrm{OHC}$ protocol), access to a co-produced best-practice SOCLE assessment and protocol of care were shared with the nursing staff ward range of $\mathrm{OHC}$ equipment and products. Service-level intervention included specialist dental support (dentist denture repair laboratory) and availability of $\mathrm{OHC}$ equipment and products

- Provided by: registered nurses, nursing assistants, nursing students

- Training: specialised 90-minute online training session to improve staff knowledge and attitudes toward $\mathrm{OHC}$ and provide practical information on how best to care for patients' oral health

- Delivery: patients: face-to-face, 1:1, stroke rehabilitation ward; staff: remote, online training, self-led use of assessments and protocol and equipment

- Regimen: encouraged twice daily cleaning of natural teeth. Cleaning of dentures after every meal

- Tailoring: intervention individualised to patient's oral health, needs and abilities to independently care for their mouth and teeth

- Modification: no modifications to the protocol

- Adherence: documentation of the $\mathrm{OHC}$ assessment and care plan was monitored

\section{Usual care}

- Intervention: usual OHC

- Materials: not reported

- Agent: not reported

- Procedures: usual care was the care in place at the time of the study start

- Provided by: nursing staff

- Training: none

- Delivery: patients: face-to-face, 1:1, stroke ward; staff: N/A

- Regimen: individualised

- Tailoring: yes to individual patient needs

- Modification: none

- Adherence: $\mathrm{OHC}$ assessment and care plan documentation was monitored

Outcomes

Outcome data were collected at patient, staff and service level

\section{Patient level}

Primary outcome: pneumonia as per Mann Chest Criteria

Secondary outcomes: Oral Health Impact Profile, plaque (dental and denture), use of antibiotics, adverse events (e.g. broken or missing dentures)

Secondary outcomes (measured at cluster level): length of hospital stay, death

\section{Staff level}


Primary outcome (measured at individual level): knowledge and attitudes questionnaire

Secondary outcome (measured at cluster level): $\mathrm{OHC}$ equipment and product use, documented $\mathrm{OHC}$ assessment, documented $\mathrm{OHC}$ plan

Feasibility and implementation: focus groups

Service level (measured at cluster level)

Primary outcomes: referrals to dental support (urgent and non-urgent)

Secondary outcomes: use of $\mathrm{OHC}$ equipment and products

\section{Economic outcomes}

Quote: "... potential net impact on healthcare costs combined with data gathered on health outcomes to determine whether outcomes are improved and (1) (clinical and patient) costs saved, constituting an unambiguous improvement in efficiency, or (2) the magnitude of cost increases incurred in achieving any established health improvement. Relevant outcomes include oral health-related QoL. Costs will reflect resources used in the intervention itself and post-intervention impacts (relative to standard care) on service use and staff time, including expected reductions in incidence of major events, such as pneumonia and in length of stay."

\section{Data collection}

\section{Patient level}

Primary outcome assessed weekly

Secondary outcomes (measured at individual level) assessed weekly

Secondary outcomes measured at cluster level were linked to routinely collected national health data

\section{Staff level}

Primary outcome collected at baseline, pretraining, post-training and at study end

Secondary outcomes assessed weekly

Focus group data collected at study end

\section{Service level}

Primary outcome assessed weekly

Secondary outcomes collected monthly

Funding Study authors declared no conflicts of interest. Study funded by Stroke Association, UK

Notes Dropouts are detailed in Table 6

Unpublished statistical data (supplied by the authors) is included within the meta-analyses

\section{Risk of bias}

\begin{tabular}{lll}
\hline Bias & Authors' judgement & Support for judgement \\
\hline $\begin{array}{l}\text { Random sequence genera- } \\
\text { tion (selection bias) }\end{array}$ & Low risk & $\begin{array}{l}\text { Quote: "Edinburgh Clinical Trials Unit randomised the order of site start date } \\
\text { using a computer-generated algorithm." }\end{array}$ \\
\hline $\begin{array}{l}\text { Allocation concealment } \\
\text { (selection bias) }\end{array}$ & Low risk & $\begin{array}{l}\text { Quote: "Each site was randomly allocated, at a series of fixed time-points, to } \\
\text { commence conversion to the enhanced OHC intervention." }\end{array}$
\end{tabular}


Comment: authors confirmed that the Edinburgh Clinical Trials Unit dealt with allocation.

\begin{tabular}{lll}
\hline $\begin{array}{l}\text { Blinding of participants } \\
\text { and personnel (perfor- }\end{array}$ & High risk & $\begin{array}{l}\text { Comment: not possible to blind staff participants to the start of the interven- } \\
\text { tion but patient participants were masked to the allocation and study phase. }\end{array}$
\end{tabular}

mance bias)

All outcomes

\begin{tabular}{|c|c|c|}
\hline $\begin{array}{l}\text { Blinding of outcome as- } \\
\text { sessment (detection bias) }\end{array}$ & Low risk & Comment: site allocation was concealed from the blinded assessor. \\
\hline All outcomes & & $\begin{array}{l}\text { Quote: "Site allocation and phase conversion points were concealed as much } \\
\text { as possible from SOCLE data collectors given the inherent limitations to blind- } \\
\text { ing within a trial design where all sites provide usual care at study start and } \\
\text { end delivering enhanced care." }\end{array}$ \\
\hline
\end{tabular}

Incomplete outcome data Low risk

(attrition bias)

Comment: dropouts accounted for. Staff withdrawals differed across each site,

All outcomes with greater attrition from sites 2 and 3 compared to sites 1 and 4 and were usually due to staff retirement, sickness or change of jobs. Study authors reported that they "experienced no patient withdrawals or dropouts in the usual sense as there was no formal follow-up beyond the ward admission." ITT analysis employed.

Selective reporting (re- Low risk Comment: all prespecified outcomes reported.
porting bias)

\begin{tabular}{|c|c|c|}
\hline $\begin{array}{l}\text { Baseline data compara- } \\
\text { ble? }\end{array}$ & Low risk & $\begin{array}{l}\text { Quote: "Patients' alertness, stroke diagnosis, capacity, modified Rankin Scale, } \\
\text { dentition, dysphagia and nutritional status were similar across sites } 1 \text { to } 3 . \\
\text { Fifty-one (15/7\%) were incapacitated. A greater proportion of patient partici- } \\
\text { pants at site } 4 \text { were female, alert, more disabled, incapacitated and had non- } \\
\text { stroke diagnoses and dentures than patients at other sites (Table } 2-3 \text { ) [of the } \\
\text { publication]. Sites } 1-3 \text { recruited more stroke survivors ( } 76 \%-81 \% \text { of site re- } \\
\text { cruits) typically admitted within } 2 \text { days of stroke onset compared to partici- } \\
\text { pants from Site 4." }\end{array}$ \\
\hline
\end{tabular}

A priori power calculation Low risk No.

Comment: pilot RCT aimed at collecting these data.

Other bias Low risk Comment: none identified.

AGNB: aerobic Gram-negative bacilli; BI: Barthel Index; FOIS: Functional Oral Intake Scale; ICD-9: International Classification of Diseases 9th edition; ITT: intention-to-treat; MASA: Mann assessment of swallowing ability; mBI: modified Barthel Index; MMSE: Mini-Mental State Examination; MRSA: Methicillin-resistant Staphylococcus aureus; N/A: not applicable; OHC: oral health care; RCT: randomised controlled trial; R-THROAT: revised THROAT oral assessment tool; SD: standard deviation; VAP: ventilator-associated pneumonia.

SOCLE II

\section{Study characteristics}

\begin{tabular}{ll}
\hline Methods & Stepped-wedge clustered pilot RCT randomised at hospital level, UK \\
& Study recruitment and setting details: see Table 1 \\
\hline Participants & $\begin{array}{l}\text { Inclusion criteria: wards with a specific remit for stroke rehabilitation care, all ward admissions includ- } \\
\text { ing all ages, dentition profiles, reason for admission (including non-stroke), cognitive and communica- } \\
\text { tion impairment status. Similarly, all nursing staff (registered nurses, nursing assistants and student } \\
\text { nurses) were eligible for inclusion } \\
\text { Exclusion criteria: acute stroke wards }\end{array}$ \\
\hline
\end{tabular}


SOCLE II (Continued)

OHC group: 135 patients; 108 staff

Usual care group: 147 patients; 84 staff

Details of participants are shown in Table 2

- Intervention: complex multi-component $\mathrm{OHC}$ intervention

- Materials: toothbrushes, Internet-based training module, computer

- Agent: toothpaste, oral balance gel, denture marking kit

- Procedures: patient-level intervention involved treatment from specialist trained staff, individualised assessment, individualised care plan, oral health promotion. Staff-level intervention involved online training ( $\mathrm{OHC}$ assessment, $\mathrm{OHC}$ protocol), access to a co-produced best-practice SOCLE assessment and protocol of care were shared with the nursing staff ward range of OHC equipment and products. Service-level intervention included specialist dental support (dentist denture repair laboratory) and availability of $\mathrm{OHC}$ equipment and products

- Provided by: registered nurses, nursing assistants, nursing students

- Training: specialised 90-minute online training session to improve staff knowledge and attitudes toward $\mathrm{OHC}$ and provide practical information on how best to care for patients' oral health

- Delivery: patients: face-to-face, 1:1, stroke rehabilitation ward; staff: remote, online training, self-led use of assessments and protocol and equipment

- Regimen: encouraged twice daily cleaning of natural teeth. Cleaning of dentures after every meal

- Tailoring: intervention individualised to patient's oral health, needs and abilities to independently care for their mouth and teeth

- Modification: no modifications to the protocol

- Adherence: documentation of the $\mathrm{OHC}$ assessment and care plan was monitored

\section{Usual care}

- Intervention: usual OHC

- Materials: not reported

- Agent: not reported

- Procedures: usual care was the care in place at the time of the study start

- Provided by: nursing staff

- Training: none

- Delivery: patients: face-to-face, 1:1, stroke ward; staff: N/A

- Regimen: individualised

- Tailoring: yes to individual patient needs

- Modification: none

- Adherence: OHC assessment and care plan documentation was monitored

Outcome data were collected at patient, staff and service level

\section{Patient level}

Primary outcome: pneumonia as per Mann Chest Criteria

Secondary outcomes: Oral Health Impact Profile, plaque (dental and denture), use of antibiotics, adverse events (e.g. broken or missing dentures)

Secondary outcomes (measured at cluster level): length of hospital stay, death

\section{Staff level}

Primary outcome (measured at individual level): knowledge and attitudes questionnaire

Secondary outcome (measured at cluster level): $\mathrm{OHC}$ equipment and product use, documented $\mathrm{OHC}$ assessment, documented $\mathrm{OHC}$ plan 
Feasibility and implementation: focus groups

Service level (measured at cluster level)

Primary outcomes: referrals to dental support (urgent and non-urgent)

Secondary outcomes: use of $\mathrm{OHC}$ equipment and products

\section{Economic outcomes}

Quote: "... potential net impact on healthcare costs combined with data gathered on health outcomes to determine whether outcomes are improved and (1) (clinical and patient) costs saved, constituting an unambiguous improvement in efficiency, or (2) the magnitude of cost increases incurred in achieving any established health improvement. Relevant outcomes include oral health-related QoL. Costs will reflect resources used in the intervention itself and post-intervention impacts (relative to standard care) on service use and staff time, including expected reductions in incidence of major events, such as pneumonia and in length of stay."

\section{Data collection}

\section{Patient level}

Primary outcome assessed weekly

Secondary outcomes (measured at individual level) assessed weekly

Secondary outcomes measured at cluster level were linked to routinely collected national health data

\section{Staff level}

Primary outcome collected at baseline, pretraining, post-training and at study end

Secondary outcomes assessed weekly

Focus group data collected at study end

\section{Service level}

Primary outcome assessed weekly

Secondary outcomes collected monthly

\begin{tabular}{ll}
\hline Funding & Study authors declared no conflicts of interest. Study funded by Stroke Association, UK \\
\hline Notes & Dropouts are detailed in Table 6 \\
& Unpublished statistical data (supplied by the authors) is included within the meta-analyses
\end{tabular}

\section{Risk of bias}

\begin{tabular}{lll}
\hline Bias & Authors' judgement & Support for judgement \\
\hline $\begin{array}{l}\text { Random sequence genera- } \\
\text { tion (selection bias) }\end{array}$ & Low risk & $\begin{array}{l}\text { Quote: "Edinburgh Clinical Trials Unit randomised the order of site start date } \\
\text { using a computer-generated algorithm." }\end{array}$ \\
\hline $\begin{array}{l}\text { Allocation concealment } \\
\text { (selection bias) }\end{array}$ & Low risk & $\begin{array}{l}\text { Quote: "Each site was randomly allocated, at a series of fixed time-points, to } \\
\text { commence conversion to the enhanced OHC intervention." }\end{array}$ \\
& $\begin{array}{l}\text { Comment: authors confirmed that the Edinburgh Clinical Trials Unit dealt with } \\
\text { allocation. }\end{array}$
\end{tabular}

Blinding of participants and personnel (performance bias)
High risk

Comment: not possible to blind staff participants to the start of the intervention but patient participants were masked to the allocation and study phase. 
SOCLE II (Continued)

All outcomes

$\begin{array}{ll}\begin{array}{l}\text { Blinding of outcome as- } \\ \text { sessment (detection bias) }\end{array} & \text { Low risk } \\ \text { All outcomes } & \text { Comment: site allocation was concealed from the blinded assessor. } \\ & \begin{array}{l}\text { Quote: "Site allocation and phase conversion points were concealed as much } \\ \text { as possible from SOCLE data collectors given the inherent limitations to blind- } \\ \text { ing within a trial design where all sites provide usual care at study start and } \\ \text { end delivering enhanced care." }\end{array}\end{array}$

Incomplete outcome data Low risk

(attrition bias)

Comment: dropouts accounted for. Staff withdrawals differed across each site,

All outcomes with greater attrition from sites 2 and 3 compared to sites 1 and 4 and were usually due to staff retirement, sickness or change of jobs. Study authors reported that they "experienced no patient withdrawals or dropouts in the usual sense as there was no formal follow-up beyond the ward admission." ITT analysis employed.

Selective reporting (re- Low risk Comment: all prespecified outcomes reported.
porting bias)

Baseline data compara- Low risk ble?

\begin{abstract}
Quote: "Patients' alertness, stroke diagnosis, capacity, modified Rankin Scale, dentition, dysphagia and nutritional status were similar across sites 1 to 3 . Fifty-one $(15 / 7 \%)$ were incapacitated. A greater proportion of patient participants at site 4 were female, alert, more disabled, incapacitated and had nonstroke diagnoses and dentures than patients at other sites (Table 2-3) [of the publication]. Sites $1-3$ recruited more stroke survivors $(76 \%-81 \%$ of site recruits) typically admitted within 2 days of stroke onset compared to participants from Site 4."
\end{abstract}

A priori power calculation Low risk No.

Comment: pilot RCT aimed at collecting these data.

Other bias Low risk Comment: none identified.

AGNB: aerobic Gram-negative bacilli; BI: Barthel Index; FOIS: Functional Oral Intake Scale; ICD-9: International Classification of Diseases 9th edition; ITT: intention-to-treat; MASA: Mann assessment of swallowing ability; mBI: modified Barthel Index; MMSE: Mini-Mental State Examination; MRSA: Methicillin-resistant Staphylococcus aureus; N/A: not applicable; OHC: oral health care; RCT: randomised controlled trial; R-THROAT: revised THROAT oral assessment tool; SD: standard deviation; VAP: ventilator-associated pneumonia.

\title{
Characteristics of excluded studies [ordered by study ID]
}

\begin{tabular}{ll}
\hline Study & Reason for exclusion \\
\hline Boden-Albala 2016 & RCT \\
& Secondary stroke prevention and no relevant outcome measures \\
\hline Brailsford 2002 & RCT \\
& $\begin{array}{l}\text { Fluoride-containing varnish + antimicrobial varnish (Cervitec) vs fluoride-containing varnish + } \\
\text { placebo varnish. Stroke-specific data unavailable }\end{array}$ \\
\hline Duck-Won 2013 & RCT \\
Intervention focused on treatment for limited oral mouth opening and not focused on improving \\
OHC
\end{tabular}




\begin{tabular}{ll}
\hline Study & Reason for exclusion \\
\hline & Intervention not focused on improving OHC \\
\hline Hägglund 2017 & RCT \\
& Swallowing intervention only - not OHC intervention
\end{tabular}

\begin{tabular}{ll}
\hline Hajizamani 2006 & RCT \\
& Stroke-specific data unavailable. Carer knowledge data only reported for intervention group before \\
& and after the intervention
\end{tabular}

RCT
Jones 2007
$\begin{aligned} & \text { Periodontal therapy vs usual care. Periodontal therapy typically requires specialist dental care and } \\ & \text { takes place in the presence of periodontal disease and so the intervention was not within the inclu- } \\ & \text { sion criteria of 'routine assisted oral health care.' }\end{aligned}$

RCT
Kikutani $2006 \quad \begin{aligned} & \text { Nutritional supplementation plus oral functional training vs nutritional supplementation. Oral } \\ & \text { functional training does not relate to OHC but instead movement of the oral articulators (lips, } \\ & \text { cheeks, tongue, soft palate) }\end{aligned}$

\begin{tabular}{ll}
\hline Kim 2014b & RCT \\
& Intervention focused on treatment for xerostomia \\
\hline Lee 2017 & RCT \\
& $\begin{array}{l}\text { No patient data. Intervention focused on whether staff could identify oral health conditions after } \\
\text { watching a videorecording but not the impact of that training on patient health }\end{array}$ \\
\hline
\end{tabular}

Mojon $1998 \quad$ Cluster RCT

Oral health programme vs usual care. Stroke-specific data unavailable

\begin{tabular}{ll}
\hline Murray 2016 & RCT \\
& $\begin{array}{l}\text { Swallowing intervention evaluation. Although there is an OHC component in the intervention, } \\
\text { there are no relevant oral hygiene outcomes measured }\end{array}$ \\
\hline RCT01777672 & SCT \\
\hline NCT02379182 & RCT \\
& $\begin{array}{l}\text { Swallowing intervention evaluation. Although there was an oral hygiene component in the inter- } \\
\text { vention, there did not appear to be a difference in OHC provided to the groups }\end{array}$ \\
\hline RCT02541032 & $\begin{array}{l}\text { RCT } \\
\text { Intensive dental treatment vs standard dental treatment. Secondary stroke prevention and no rel- } \\
\text { evant outcome measures. In addition, periodontal therapy typically requires specialist dental care } \\
\text { and general anaesthetic, so the intervention was not within our inclusion criteria of 'routine assist- } \\
\text { ed oral health care' }\end{array}$ \\
\hline $\begin{array}{l}\text { RCT } \\
6 \text { different OHC intervention programmes (3 specifically for people with dysphagia). Stroke-specific } \\
\text { data unavailable }\end{array}$ \\
\hline \hline
\end{tabular}




\begin{tabular}{|c|c|}
\hline Study & Reason for exclusion \\
\hline \multirow[t]{2}{*}{ Redwood 2001} & Cluster RCT \\
\hline & Oral health programme vs oral healthcare worker. Stroke-specific data unavailable \\
\hline \multirow[t]{2}{*}{ Schou 1989} & Cluster RCT \\
\hline & $\begin{array}{l}\text { OHC programme for staff only vs OHC programme for residents only vs OHC programme for staff } \\
\text { and residents vs usual care Stroke-specific data unavailable }\end{array}$ \\
\hline \multirow[t]{2}{*}{ Simons 1997} & $\mathrm{RCT}$ \\
\hline & Chlorhexidine acetate or xylitol gum vs xylitol gum. Stroke-specific data unavailable \\
\hline Simons 2002 & $\begin{array}{l}\text { Chlorhexidine acetate or xylitol gum vs xylitol gum vs usual care (no gum). Stroke-specific data un- } \\
\text { available }\end{array}$ \\
\hline
\end{tabular}

OHC: oral health care; RCT: randomised controlled trial.

Characteristics of studies awaiting classification [ordered by study ID]

Cabov 2010

\begin{tabular}{ll}
\hline Methods & Prospective double-blind, placebo-RCT \\
\hline Participants & $\begin{array}{l}60 \text { non-edentulous patients consecutively admitted to the surgical ICU and requiring minimum } \\
\text { stay of } 3 \text { days } \\
\text { Inclusion criteria: aged }>18 \text { years, medical condition suggesting hospitalisation in the ICU for } \geq 3 \\
\text { days, and an eventual requirement for mechanical ventilation by oro- or nasotracheal intubation } \\
\text { Exclusion criteria: not reported }\end{array}$
\end{tabular}
Interventions
- Chlorohexidine: antiseptic decontamination of dental plaque and the oral mucosa with chlorhex- idine gel
- Placebo: placebo gel

\begin{tabular}{ll} 
Outcomes & $\begin{array}{l}\text { Outcomes: dental status assessed using a caries-absent-occluded score, and the amount of plaque } \\
\text { assessed using a semi-quantitative score }\end{array}$ \\
& $\begin{array}{l}\text { Samples of dental plaque, oral mucosa, and nasal and tracheal aspirates were collected for bacter } \\
\text { ial culture, and nosocomial infections were assessed }\end{array}$ \\
\hline Notes & $\begin{array}{l}\text { Unclear whether any stroke-specific data are available - e-mail sent to study authors requesting } \\
\text { further information }\end{array}$
\end{tabular}

\begin{tabular}{ll}
\hline Methods & Single-blind parallel RCT \\
\hline Participants & Intubated patients in ICU \\
& $\begin{array}{l}\text { Inclusion criteria: patient has an endotracheal tube through the mouth, aged 15-85 years, } 8 \text { hours } \\
\text { of intubation in the ICU; no history of allergy is to plant compounds Savory (carvacrol); lack of any } \\
\text { damage characterised by endotracheal intubation or planes in the mouth, lesion is unknown }\end{array}$ \\
\hline
\end{tabular}


IRCT2017012232101N1 (Continued)

Exclusion criteria: transmission or discharge or death of the patient from the ICU before the study was completed; creating profit any damage characterised by endotracheal intubation or planes or other physical harm; lack of desire to continue to study the patient's legal guardian; and immune system dysfunction, radiotherapy and chemotherapy, and having any malignant disease

$\begin{array}{ll}\text { Interventions } & \text { Mouthrinse (ortodentol) } \\ \text { - } & \text { Chlorhexidine mouth rinse. } 15 \mathrm{~mL} \text { each time with a soft toothbrush can be rinsed, and the suction } \\ & \text { within } 30 \text { seconds. Before rinsing the mouth at the interval ( } 8,48,72 \text { hours) from different areas } \\ \text { of the mouth sample and agar cultured and assessment of oral hygiene by standard scale-back } \\ \text { and plaque oral mucous measured and the questionnaire recorded }\end{array}$

Outcomes Primary outcomes: oral health, studied groups, endotracheal tube intubation time, the oral microbial

Notes

Unclear whether the trial is completed and if stroke-specific data are available. E-mail sent to study authors seeking further information

IRCT registration number: IRCT2017012232101N1

\section{IRCT2017091636194N1}

\begin{tabular}{ll}
\hline Methods & Single-blinded parallel RCT \\
\hline Participants & 80 participants \\
& Inclusion criteria: aged $18-70$ years; no clear maxillofacial trauma; having tracheal tube, locating \\
the patient under the mechanical ventilator; no pneumonia or previous respiratory infections; $\geq 48$ \\
hours had passed since the onset of intubation; no ban and having no allergy on using mouthwash \\
Exclusion criteria: death before the end of intervention; extubation before the end of intervention; \\
transfer the patient to other wards or hospital among the intervention; other diagnostic or thera- \\
peutic procedure on mouth and pharyn or trachea
\end{tabular}

Interventions

- Intervention group: during a 5-day period, using $10 \mathrm{~mL}$ of Nanosil mouthwash, oral care and decontamination every 8 hours

- Control group: $10 \mathrm{~mL}$ chlorohexidine mouthwash, oral care and decontamination every 8 hours

Outcomes

Primary outcome: occurrence of ventilator-associated pneumonia measured using standard modified clinical pulmonary infection score

Secondary outcomes: degree of dysfunction of organs and prediction of mortality measured using standard sepsis related organ failure assessment tool, Glasgow Coma Scale

Data collection: days 1 and 5

Notes IRCT2017091636194N1

Unclear if there are stroke-specific data available. E-mail sent to study authors requesting further information

\begin{tabular}{ll}
\hline Methods & Parallel RCT \\
\hline Participants & 104 participants
\end{tabular}


Jin 2018 (Continued)

Inclusion criteria: people with stroke and bad breath

Exclusion criteria: not reported

\begin{tabular}{ll}
\hline Interventions & $\begin{array}{l}\text { Ageratum liquid combined with long cotton swab for oral care for } 7 \text { days } \\
\text { C Conventional saline cotton ball for oral care for } 7 \text { days }\end{array}$ \\
\hline Outcomes & Improvement of bad breath, condition of tongue coating and clearance of oral pathogens \\
\hline Notes & Translation unavailable \\
\hline
\end{tabular}

\section{Marchini 2018}

\begin{tabular}{|c|c|}
\hline Methods & Pilot RCT \\
\hline \multirow[t]{3}{*}{ Participants } & 81 residents \\
\hline & $\begin{array}{l}\text { Inclusion criteria: aged } \geq 20 \text { years, resident or primary care worker in } 1 \text { of the following nursing } \\
\text { homes: Linn Manor Care Center Simpson Memorial Home, Inc., Wilton Retirement Community, All- } \\
\text { American Care of Muscatine, Pioneer Park of Lone Tree, Colonial Manor of the Columbus Communi- } \\
\text { ty, Sunrise Terrace Nursing and Rehabilitation Center Parkview Home-Wayland }\end{array}$ \\
\hline & $\begin{array}{l}\text { Exclusion criteria: aged } \leq 21 \text { years or }>110 \text { years; not a resident or primary care worker in } 1 \text { of the } \\
\text { retirement homes listed in the inclusion criteria }\end{array}$ \\
\hline \multirow[t]{3}{*}{ Interventions } & - Control (current oral hygiene practice) \\
\hline & - Educational programme only \\
\hline & - Educational programme plus $1 \%$ chlorhexidine varnish monthly application \\
\hline \multirow[t]{2}{*}{ Outcomes } & $\begin{array}{l}\text { Outcomes: demographics, pneumonia, number of febrile days in last } 6 \text { months, existing medical } \\
\text { conditions and medications taken, mini-cog test (Mini-Cog), mini nutritional assessment short form } \\
\text { (Mini-Nutri), Rand 36-item Short Form health survey instrument version } 1.0 \text { (SF-36), Oral Health Im- } \\
\text { pact Profile 14-question (OHIP-14), Geriatric Oral Health Assessment Index (GOHAI), and subjects } \\
\text { oral health (self-reported dry mouth, oral lesions, denture status, number of teeth, dental plaque } \\
\text { index, denture plaque index, bleeding on brushing, gingival bleeding index, coronal DMFS, root } \\
\text { DMFS }\end{array}$ \\
\hline & $\begin{array}{l}\text { Data collection: baseline and } 6 \text { months; microbiological samples were collected at baseline, 2, } 4 \\
\text { and } 6 \text { months }\end{array}$ \\
\hline Notes & $\begin{array}{l}\text { Stroke-specific data not reported separately. Study authors contacted by e-mail to see if these data } \\
\text { are available }\end{array}$ \\
\hline
\end{tabular}

\section{Mori 2012}

\begin{tabular}{ll}
\hline Methods & Parallel RCT \\
\hline Participants & 40 participants with acute cerebrovascular disorders or neurotrauma \\
& Inclusion criteria: none reported \\
& Exclusion criteria: none reported \\
\hline Interventions & Professional oral health care: delivered by dental hygienists \\
& - Usual care
\end{tabular}


Mori 2012 (Continued)

Both groups received the same daily oral care performed by the neurosurgical ward nurses

Outcomes

Outcomes: periodontal pocket depth, gingival bleeding on probing, modified Oral Health Index (debris index), maximal interincisal opening, volatile sulphur compounds such as hydrogen sulphide $(\mathrm{H} 2 \mathrm{~S})$ and methyl mercaptan $(\mathrm{CH} 3 \mathrm{SH})$ in the mouth air were measured using gas chromatograph

Data collection: baseline and 4 weeks after the baseline examination (or immediately before hospital discharge, whichever came first)

Notes

Stroke-specific data not reported separately in the paper. Study authors contacted by e-mail to see if these data are available

\section{NCT00610324}

\begin{tabular}{ll}
\hline Methods & Parallel RCT \\
\hline Participants & 512 participants \\
& Inclusion criteria: aged $>13$ years, admitted to medical ICU and expected to stay in ICU for $>48$ \\
hours & Exclusion criteria: pregnant women, people with nosocomial pneumonia at time of ICU admission, \\
people with community-acquired pneumonia at time of ICU admission, people in whom oropha- \\
ryngeal cleansing is contraindicated
\end{tabular}

NCT03219346

\begin{tabular}{ll}
\hline Methods & Parallel RCT \\
\hline Participants & 100 participants \\
Inclusion criteria: clinical diagnosis of first stroke with nasal tube retention, language therapist pro- \\
viding swallowing treatment, caregiver providing oral care to patients \\
Exclusion criteria: oral cancer and head and neck cancer \\
\hline Interventions & $\begin{array}{l}\text { OHC programme: oral care (sputum and special needs of people cleaning teeth) } 3 \text { days per week } \\
\text { (with swallowing treatment time before) once a day. } 10 \text { minutes of oral care programme }\end{array}$ \\
\hline & Control group: no details reported
\end{tabular}


NCT03219346 (Continued)

Secondary outcome measures: functional oral intake scale

Notes

Study start date: July 2017

Estimated completion date: February 2018

Outcomes reported in the trial register differ from our criteria but data not published yet. Study authors contacted for further information

Yakiwchuk 2013

\begin{tabular}{|c|c|}
\hline Methods & Parallel RCT \\
\hline \multirow[t]{3}{*}{ Participants } & 22 adults with dysphagia resident in a long-term care facility \\
\hline & $\begin{array}{l}\text { Inclusion criteria: medical diagnosis of oropharyngeal dysphagia, and who were residing in chronic } \\
\text { care programme units with access to wall suction }\end{array}$ \\
\hline & $\begin{array}{l}\text { Exclusion criteria: }<3 \text { scoreable sextants of natural teeth, required sedation or antibiotic premed- } \\
\text { ication for dental care, or who were under a DNR order }\end{array}$ \\
\hline \multirow[t]{3}{*}{ Interventions } & $\begin{array}{l}\text { - Carers were trained in mouth care using a suction toothbrush. Carer training included: viewing a } \\
\text { video on the reusable suction toothbrush; attending a 30-minute oral health education session or } \\
\text { viewing a video focused on mouth care, the study protocol, and wall unit suction operation, and } \\
\text { participating in a hands-on mouth care skill development and coaching session for co-operative } \\
\text { and care resistant residents }\end{array}$ \\
\hline & - Carers trained in mouth care using a manual soft toothbrush \\
\hline & Both groups received mouth care twice daily for 12 -month period \\
\hline \multirow[t]{2}{*}{ Outcomes } & Outcomes: Plaque Index, Calculus Index, Pocket Bleeding Index, Gingival Index and probing depth \\
\hline & $\begin{array}{l}\text { Data collection: oral health examination conducted at baseline, } 1 \text { month and pneumonia rates } \\
\text { monitored over } 12 \text { months }\end{array}$ \\
\hline Notes & $\begin{array}{l}\text { Unclear if there are stroke-specific data available. E-mail sent to study authors requesting further } \\
\text { information }\end{array}$ \\
\hline
\end{tabular}

DMFS: decayed, missing and filled permanent surface; DNR: do not resuscitate; ICU: intensive care unit; RCT: randomised controlled trial.

Characteristics of ongoing studies [ordered by study ID]

ChicTR-IPR-17013403

\begin{tabular}{ll}
\hline Study name & $\begin{array}{l}\text { Effect of oral care on the incidence of pneumonia in acute stroke patients with different degrees of } \\
\text { dysphagia }\end{array}$ \\
\hline Methods & Parallel RCT \\
\hline Participants & 80 participants \\
& $\begin{array}{l}\text { Inclusion criteria: people with acute stroke aged 18-99 years; able to tolerate an oral examination } \\
\text { and sample collection; able to provide informed consent }\end{array}$ \\
& $\begin{array}{l}\text { Exclusion criteria: pneumonia at admission; requiring mechanical ventilation; removable dentures; } \\
\text { allergic to chlorhexidine; oral tumour or acute oral infection, who received periodontal treatment }\end{array}$
\end{tabular}


ChicTR-IPR-17013403 (Continued)

in the past 3 months; severe liver, kidney and heart dysfunction; use of antibiotics, hormones or other immunosuppressive agents; people with tumours and autoimmune diseases

\begin{tabular}{ll}
\hline Interventions & - Intensive oral care \\
& Standard oral care \\
\hline Outcomes & Primary outcome: incidence of pneumonia \\
& Secondary outcome: pathogenic bacteria of pneumonia \\
\hline Starting date & 1 April 2016; anticipated completion 30 September 2018 \\
\hline Contact information & Professor Yue Wang, Beijing Stomatological Hospital, Capital Medical Hospital, Beijing, China \\
\hline Notes & ChiCTR-IPR-17013403 \\
\hline
\end{tabular}

Hollaar 2015

\begin{tabular}{ll} 
Study name & $\begin{array}{l}\text { Effect of daily application of a } 0.05 \% \text { chlorhexidine solution on the incidence of (aspiration) pneu- } \\
\text { monia in care home residents: design of a multicentre cluster randomised controlled clinical trial }\end{array}$ \\
\hline Methods & Multi-centre cRCT with care homes as units of randomisation \\
\hline Participants & 500 physically disabled care home residents with dysphagia \\
& $\begin{array}{l}\text { Inclusion criteria: aged } \geq 65 \text { years, physically disabled and diagnosed with dysphagia } \\
\text { Exclusion criteria: cognitively impaired (mainly with dementia), in a coma or vegetative state, ter- } \\
\text { minally ill, dependent on mechanical ventilation, in day care, in short-term care or already using an } \\
\text { oral hygiene care solution }\end{array}$
\end{tabular}

Interventions

- $0.05 \%$ chlorhexidine containing solution and usual daily oral hygiene care

- Usual daily oral hygiene care

Outcomes Primary outcomes: incidence of pneumonia (diagnosed by a physician)

Secondary outcomes: correlations between age, gender, diagnosed diseases, dysphagia severity, care dependency, actually used medication, number of teeth and implants present, and presence of removable dentures and the incidence of pneumonia in physically disabled care home residents with dysphagia who did or did not apply a $0.05 \%$ chlorhexidine-containing solution to their usual oral hygiene care

Data collection: Dysphagia Outcome and Severity Scale (DOSS): baseline and endpoint; Care Dependency Scale (CDS): baseline and endpoint; patient record: gender, age (baseline), diagnoses and medication use (baseline and endpoint); oral examination: number of teeth, implants and the presence of removable dentures (baseline); pneumonia: pneumonia will be diagnosed by a set of strictly described criteria: when symptoms occur during study

\begin{tabular}{ll}
\hline Starting date & 14 February 2013 \\
\hline Contact information & $\begin{array}{l}\text { Dr Vanessa Hollaar, Department of Neurohabilitation, University of Applied Sciences Nijmegen, } \\
\text { Postbus 6960, Nijmegen, The Netherlands }\end{array}$ \\
\hline Notes & NTR3515 \\
\hline
\end{tabular}


MAPS-2

\begin{tabular}{ll}
\hline Study name & The Metoclopramide and selective oral decontamination for Avoiding Pneumonia after Stroke trial \\
(MAPS-2)
\end{tabular}

\begin{tabular}{ll}
\hline Methods & $2 \times 2$ factorial double-blinded RCT \\
\hline Participants & 1160 participants
\end{tabular}

Inclusion criteria: adults with clinical diagnosis of acute stroke; within 9 hours of stroke onset; moderate-to-severe neurological impairment with NIHSS score $\geq 10$; unable to take a normal oral diet of fluids

Exclusion criteria: evidence of vomiting since stroke onset; pre-existing swallowing problem; known oesophageal pathology that might interfere with placement of an NGT, probable or definite pneumonia, contraindications to metoclopramide, epilepsy, gastrointestinal obstruction, perforation, or haemorrhage, gastrointestinal surgery within the last week, Parkinson's disease, treatment with levodopa or dopaminergic agonists, phaeochromocytoma or neuroleptic malignant syndrome or tardive dyskinesia or methaemoglobinaemia or NADH cytochrome; people with severe liver disease or kidney disease; known allergy to colistin; pregnant or breastfeeding; other comorbid conditions with a life expectancy $<3$ months at the discretion of the clinical treating team; inability to gain consent from the patient or a legal representative or refusal of consent

Recruited from 50 UK emergency department and acute stroke wards

\begin{tabular}{ll}
\hline Interventions & Metoclopramide and selective oral decontamination paste \\
- & Metoclopramide and placebo selective oral decontamination paste \\
- Placebo metoclopramide and placebo selective oral decontamination paste & Participants will receive metoclopramide or placebo for 21 days or until the NGT is removed, and \\
& selective oral decontamination paste for 21 days or until the NGT is removed \\
\hline Outcomes & Primary outcomes: mortality rates up to the end of study \\
& $\begin{array}{l}\text { Secondary outcomes: pneumonia within } 14 \text { days; number of days of antibiotic treatment for pneu- } \\
\text { monia within the first } 30 \text { days; neurological recovery measured using the NIHSS at } 30 \text { days; disabili- } \\
\text { ty measured using the modified Rankin Scale at 90 days; quality of life measured using the EuroQol } \\
\text { Five Dimensions questionnaire at } 90 \text { days } \\
\text { Data collection: daily clinical logs (14 days). Follow-up at } 30 \text { days (or day of discharge if sooner) and } \\
\text { follow-up at } 90 \text { days for secondary outcomes }\end{array}$ \\
\hline Starting date & 1 December 2017 ; anticipated completion September 2019 \\
\hline Contact information & $\begin{array}{l}\text { Professor Christine Roffe, Institute for Applied Clinical Sciences (IACS) Keele University Guy Hilton } \\
\text { Research Centre, Thornburrow Drive, Hartshill, Stoke-on-Trent, ST4 7QB, UK }\end{array}$ \\
\hline ISRCTN14124645
\end{tabular}

CRCT: cluster randomised controlled trial; ED: emergency department; NADH: nicotinamide adenine dinucleotide; NGT: nasogastric tube; NIHSS: National Institutes of Health Stroke Scale; RCT: randomised controlled trial.

\section{DATA AND ANALYSES}


Comparison 1. Oral health care $(\mathrm{OHC})$ interventions versus usual care

\begin{tabular}{|c|c|c|c|c|}
\hline Outcome or subgroup title & $\begin{array}{l}\text { No. of } \\
\text { studies }\end{array}$ & $\begin{array}{l}\text { No. of } \\
\text { partici- } \\
\text { pants }\end{array}$ & Statistical method & Effect size \\
\hline 1.1 Dental plaque (up to 1 month) & 2 & & $\begin{array}{l}\text { Diff in mean score (IV, Random, } \\
95 \% \mathrm{CI})\end{array}$ & $-0.66[-1.40,0.09]$ \\
\hline 1.1.1 Multi-component $\mathrm{OHC}$ intervention & 2 & & $\begin{array}{l}\text { Diff in mean score (IV, Random, } \\
95 \% \mathrm{Cl})\end{array}$ & $-0.66[-1.40,0.09]$ \\
\hline 1.2 Dental plaque (6 months) & 1 & & $\begin{array}{l}\text { Diff in mean score (IV, Fixed, 95\% } \\
\mathrm{Cl})\end{array}$ & Subtotals only \\
\hline 1.2.1 Multi-component OHC intervention & 1 & & $\begin{array}{l}\text { Diff in mean score (IV, Fixed, 95\% } \\
\mathrm{CI})\end{array}$ & $-0.43[-0.98,0.13]$ \\
\hline 1.3 Denture plaque & 1 & & $\begin{array}{l}\text { Diff in mean score (IV, Fixed, 95\% } \\
\mathrm{CI})\end{array}$ & Subtotals only \\
\hline $\begin{array}{l}\text { 1.3.1 Multi-component OHC intervention (1 } \\
\text { month) }\end{array}$ & 1 & & $\begin{array}{l}\text { Diff in mean score (IV, Fixed, 95\% } \\
\mathrm{CI})\end{array}$ & $-1.31[-1.96,-0.66]$ \\
\hline $\begin{array}{l}\text { 1.3.2 Multi-component } \mathrm{OHC} \text { intervention ( } 6 \\
\text { months) }\end{array}$ & 1 & & $\begin{array}{l}\text { Diff in mean score (IV, Fixed, 95\% } \\
\mathrm{CI})\end{array}$ & $-1.57[-2.23,-0.92]$ \\
\hline $\begin{array}{l}\text { 1.4 Presence of oral disease: gingivitis (up to } \\
1 \text { month) }\end{array}$ & 2 & & $\begin{array}{l}\text { Diff in mean score (IV, Random, } \\
95 \% \mathrm{CI})\end{array}$ & $-0.60[-1.66,0.45]$ \\
\hline 1.4.1 Multi-component $\mathrm{OHC}$ intervention & 2 & & $\begin{array}{l}\text { Diff in mean score (IV, Random, } \\
95 \% \mathrm{CI})\end{array}$ & $-0.60[-1.66,0.45]$ \\
\hline $\begin{array}{l}\text { 1.5 Presence of oral disease: gingivitis ( } 6 \\
\text { months) }\end{array}$ & 1 & & $\begin{array}{l}\text { Diff in mean score (IV, Fixed, 95\% } \\
\mathrm{CI})\end{array}$ & Subtotals only \\
\hline 1.5.1 Multi-component $\mathrm{OHC}$ intervention & 1 & & $\begin{array}{l}\text { Diff in mean score (IV, Fixed, 95\% } \\
\mathrm{CI})\end{array}$ & $-0.25[-0.61,0.10]$ \\
\hline 1.6 Denture-induced stomatitis & 1 & & $\begin{array}{l}\text { Diff in mean score (IV, Fixed, 95\% } \\
\mathrm{CI})\end{array}$ & Subtotals only \\
\hline $\begin{array}{l}\text { 1.6.1 Multi-component OHC intervention (1 } \\
\text { month) }\end{array}$ & 1 & & $\begin{array}{l}\text { Diff in mean score (IV, Fixed, 95\% } \\
\mathrm{CI})\end{array}$ & $-0.33[-0.92,0.26]$ \\
\hline $\begin{array}{l}\text { 1.6.2 Multi-component } \mathrm{OHC} \text { intervention ( } 6 \\
\text { month) }\end{array}$ & 1 & & $\begin{array}{l}\text { Diff in mean score (IV, Fixed, 95\% } \\
\mathrm{CI})\end{array}$ & $-0.10[-0.61,0.40]$ \\
\hline 1.7 Pneumonia & 1 & 204 & $\begin{array}{l}\text { Peto Odds Ratio (Peto, Fixed, 95\% } \\
\mathrm{Cl} \text { ) }\end{array}$ & $4.17[0.82,21.11]$ \\
\hline $1.8 \mathrm{OHC}$ knowledge (1 month) & 3 & 728 & $\begin{array}{l}\text { Std. Mean Difference (IV, Random, } \\
95 \% \mathrm{Cl} \text { ) }\end{array}$ & $0.70[0.06,1.35]$ \\
\hline 1.8.1 Educational intervention & 1 & 373 & $\begin{array}{l}\text { Std. Mean Difference (IV, Random, } \\
95 \% \mathrm{CI} \text { ) }\end{array}$ & $0.19[-0.01,0.39]$ \\
\hline 1.8.2 Multi-component $\mathrm{OHC}$ intervention & 2 & 355 & $\begin{array}{l}\text { Std. Mean Difference (IV, Random, } \\
95 \% \mathrm{CI} \text { ) }\end{array}$ & $1.00[-0.26,2.27]$ \\
\hline
\end{tabular}




\begin{tabular}{|c|c|c|c|c|}
\hline Outcome or subgroup title & $\begin{array}{l}\text { No. of } \\
\text { studies }\end{array}$ & $\begin{array}{l}\text { No. of } \\
\text { partici- } \\
\text { pants }\end{array}$ & Statistical method & Effect size \\
\hline $1.9 \mathrm{OHC}$ knowledge (2 months) & 1 & 94 & Mean Difference (IV, Fixed, 95\% CI) & $11.30[8.78,13.82]$ \\
\hline 1.9.1 Multi-component $\mathrm{OHC}$ intervention & 1 & 94 & Mean Difference (IV, Fixed, 95\% CI) & $11.30[8.78,13.82]$ \\
\hline $1.10 \mathrm{OHC}$ knowledge (6 months) & 2 & 596 & $\begin{array}{l}\text { Std. Mean Difference (IV, Fixed, } \\
95 \% \mathrm{Cl})\end{array}$ & $0.34[0.18,0.50]$ \\
\hline 1.10.1 Educational intervention & 1 & 373 & $\begin{array}{l}\text { Std. Mean Difference (IV, Fixed, } \\
95 \% \mathrm{Cl} \text { ) }\end{array}$ & $0.27[0.07,0.48]$ \\
\hline 1.10.2 Multi-component $\mathrm{OHC}$ intervention & 1 & 223 & $\begin{array}{l}\text { Std. Mean Difference (IV, Fixed, } \\
95 \% \mathrm{CI} \text { ) }\end{array}$ & $0.45[0.18,0.72]$ \\
\hline 1.11 Attitudes to oral care (1 month) & 3 & 728 & $\begin{array}{l}\text { Std. Mean Difference (IV, Random, } \\
95 \% \mathrm{CI})\end{array}$ & $0.28[0.01,0.54]$ \\
\hline 1.11.1 Educational intervention & 1 & 373 & $\begin{array}{l}\text { Std. Mean Difference (IV, Random, } \\
95 \% \mathrm{CI} \text { ) }\end{array}$ & $0.06[-0.14,0.26]$ \\
\hline 1.11.2 Multi-component $\mathrm{OHC}$ intervention & 2 & 355 & $\begin{array}{l}\text { Std. Mean Difference (IV, Random, } \\
95 \% \mathrm{CI} \text { ) }\end{array}$ & $0.42[0.21,0.63]$ \\
\hline 1.12 Attitudes to oral care (2 months) & 1 & & Mean Difference (IV, Fixed, 95\% CI) & Subtotals only \\
\hline 1.12.1 Multi-component OHC intervention & 1 & 94 & Mean Difference (IV, Fixed, 95\% CI) & $2.00[-0.12,4.12]$ \\
\hline 1.13 Attitudes to oral care (6 months) & 2 & 596 & $\begin{array}{l}\text { Std. Mean Difference (IV, Random, } \\
95 \% \mathrm{CI} \text { ) }\end{array}$ & $0.36[-0.01,0.74]$ \\
\hline 1.13.1 Educational intervention & 1 & 373 & $\begin{array}{l}\text { Std. Mean Difference (IV, Random, } \\
95 \% \mathrm{CI} \text { ) }\end{array}$ & $0.18[-0.02,0.39]$ \\
\hline 1.13.2 Multi-component OHC intervention & 1 & 223 & $\begin{array}{l}\text { Std. Mean Difference (IV, Random, } \\
95 \% \mathrm{CI} \text { ) }\end{array}$ & $0.57[0.30,0.83]$ \\
\hline
\end{tabular}




\section{Analysis 1.1. Comparison 1: Oral health care (OHC) interventions versus usual care, Outcome 1: Dental plaque (up to 1 month)}

\begin{tabular}{|c|c|c|c|c|c|}
\hline Studv or Subgroup & Diff in mean score & SE & Weight & $\begin{array}{c}\text { Diff in mean score } \\
\text { IV, Random, 95\% CI }\end{array}$ & $\begin{array}{l}\text { Diff in mean score } \\
\text { IV, Random. 95\% CI }\end{array}$ \\
\hline
\end{tabular}

1.1.1 Multi-component OHC intervention

$\begin{array}{lrrrr}\text { Kim 2014a } & -1.01 & 0.1615 & 53.9 \% & -1.01[-1.33,-0.69] \\ \text { Frenkel 2001 } & -0.2454 & 0.2681 & 46.1 \% & -0.25[-0.77,0.28] \\ \text { Subtotal (95\% CI) } & & & \mathbf{1 0 0 . 0 \%} & \mathbf{- 0 . 6 6}[-\mathbf{1 . 4 0 , 0 . 0 9}]\end{array}$

Heterogeneity: $\mathrm{Tau}^{2}=0.24 ; \mathrm{Chi}^{2}=5.97, \mathrm{df}=1(\mathrm{P}=0.01) ; \mathrm{I}^{2}=83 \%$

Test for overall effect: $\mathrm{Z}=1.73(\mathrm{P}=0.08)$

Total $(95 \%$ CI)

$100.0 \%$

Heterogeneity: $\mathrm{Tau}^{2}=0.24 ; \mathrm{Chi}^{2}=5.97, \mathrm{df}=1(\mathrm{P}=0.01) ; \mathrm{I}^{2}=83 \%$

Test for overall effect: $Z=1.73(P=0.08)$

Test for subgroup differences: Not applicable

$-0.66[-1.40,0.09]$

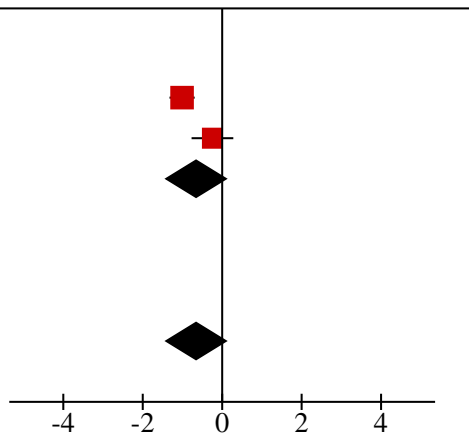

Favours $\mathrm{OHC}$ intervention

\section{Analysis 1.2. Comparison 1: Oral health care (OHC) interventions versus usual care, Outcome 2: Dental plaque (6 months)}

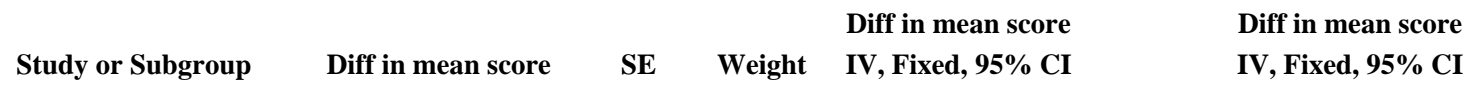

1.2.1 Multi-component $\mathrm{OHC}$ intervention

$\begin{array}{lrrrr}\text { Frenkel } 2001 & -0.4278 & 0.2823 & 100.0 \% & -0.43[-0.98,0.13] \\ \text { Subtotal }(\mathbf{9 5 \%} \text { CI) } & & & \mathbf{1 0 0 . 0 \%} & \mathbf{- 0 . 4 3}[-\mathbf{0 . 9 8}, \mathbf{0 . 1 3}]\end{array}$

Heterogeneity: Not applicable

Test for overall effect: $\mathrm{Z}=1.52(\mathrm{P}=0.13)$

Analysis 1.3. Comparison 1: Oral health care $(\mathrm{OHC})$ interventions versus usual care, Outcome 3: Denture plaque

$\begin{array}{llllll}\text { Study or Subgroup } & \text { Diff in mean score } & \text { SE } & \text { Weight } & \text { Diff in mean score } & \text { Diff in mean score } \\ \text { IV, Fixed, 95\% CI } & \text { IV, Fixed, 95\% CI }\end{array}$

1.3.1 Multi-component OHC intervention (1 month)

$\begin{array}{lrrrr}\text { Frenkel } 2001 & -1.3117 & 0.3318 & 100.0 \% & -1.31[-1.96,-0.66] \\ \text { Subtotal }(\mathbf{9 5 \%} \text { CI) } & & & \mathbf{1 0 0 . 0 \%} & \mathbf{- 1 . 3 1}[\mathbf{- 1 . 9 6 , - 0 . 6 6}]\end{array}$

Heterogeneity: Not applicable

Test for overall effect: $\mathrm{Z}=3.95(\mathrm{P}<0.0001)$

1.3.2 Multi-component OHC intervention (6 months)

$\begin{array}{lllll}\text { Frenkel } 2001 & -1.5748 & 0.3341 & 100.0 \% & -1.57[-2.23,-0.92] \\ \text { Subtotal }(\mathbf{9 5 \%} \text { CI) } & & & \mathbf{1 0 0 . 0 \%} & \mathbf{- 1 . 5 7}[-\mathbf{2 . 2 3}, \mathbf{- 0 . 9 2}]\end{array}$

Heterogeneity: Not applicable

$-1.57[-2.23,-0.92]$

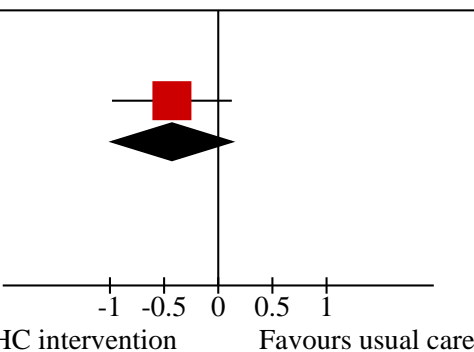

Test for overall effect: $\mathrm{Z}=4.71(\mathrm{P}<0.00001)$ 


\section{Analysis 1.4. Comparison 1: Oral health care (OHC) interventions versus usual care, Outcome 4: Presence of oral disease: gingivitis (up to 1 month)}

$\begin{array}{lccccc} & & & \text { Diff in mean score } & \text { Diff in mean score } \\ \text { Study or Subgroup } & \text { Diff in mean score } & \text { SE } & \text { Weight } & \text { IV, Random, 95\% CI } & \text { IV, Random, 95\% CI }\end{array}$

\subsubsection{Multi-component OHC intervention}

$\begin{array}{lrrrr}\text { Frenkel 2001 } & -0.0539 & 0.2285 & 48.9 \% & -0.05[-0.50,0.39] \\ \text { Kim 2014a } & -1.13 & 0.167 & 51.1 \% & -1.13[-1.46,-0.80] \\ \text { Subtotal (95\% CI) } & & & \mathbf{1 0 0 . 0 \%} & \mathbf{- 0 . 6 0}[-\mathbf{1 . 6 6 , 0 . 4 5}]\end{array}$

Heterogeneity: $\mathrm{Tau}^{2}=0.54 ; \mathrm{Chi}^{2}=14.46, \mathrm{df}=1(\mathrm{P}=0.0001) ; \mathrm{I}^{2}=93 \%$

Test for overall effect: $\mathrm{Z}=1.12(\mathrm{P}=0.26)$

Total $(95 \%$ CI)

$\mathbf{1 0 0 . 0 \%}$

Heterogeneity: $\mathrm{Tau}^{2}=0.54 ; \mathrm{Chi}^{2}=14.46, \mathrm{df}=1(\mathrm{P}=0.0001) ; \mathrm{I}^{2}=93 \%$

Test for overall effect: $\mathrm{Z}=1.12(\mathrm{P}=0.26)$

Test for subgroup differences: Not applicable

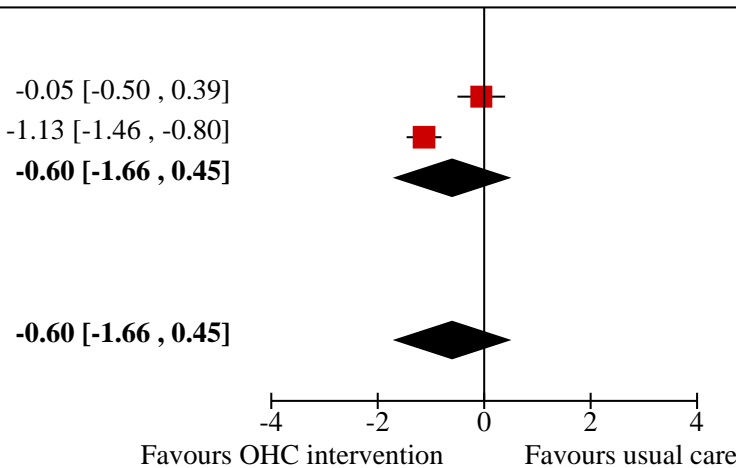

\section{Analysis 1.5. Comparison 1: Oral health care $(\mathrm{OHC})$ interventions versus usual care, Outcome 5: Presence of oral disease: gingivitis (6 months)}

$\begin{array}{lccccc} & & & \text { Diff in mean score } & \text { Diff in mean score } \\ \text { Study or Subgroup } & \text { Diff in mean score } & \text { SE } & \text { Weight } & \text { IV, Fixed, 95\% CI } & \text { IV, Fixed, 95\% CI }\end{array}$

1.5.1 Multi-component OHC intervention

Frenkel 2001

$-0.2547$

0.1821

$100.0 \%$

$-0.25[-0.61,0.10]$

Subtotal $(95 \%$ CI)

$100.0 \%$

$-0.25[-0.61,0.10]$

Heterogeneity: Not applicable

Test for overall effect: $\mathrm{Z}=1.40(\mathrm{P}=0.16)$

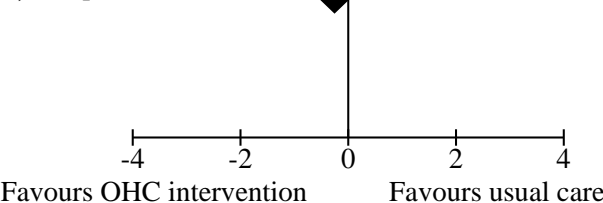




\section{Analysis 1.6. Comparison 1: Oral health care (OHC) interventions versus usual care, Outcome 6: Denture-induced stomatitis}

$\begin{array}{llllll} & & & \text { Diff in mean score } & \text { Diff in mean score } \\ \text { Study or Subgroup } & \text { Diff in mean score } & \text { SE } & \text { Weight } & \text { IV, Fixed, 95\% CI } & \text { IV, Fixed, 95\% CI }\end{array}$

1.6.1 Multi-component OHC intervention (1 month)
Frenkel 2001

$-0.3262$

0.3012

Subtotal (95\% CI)

$100.0 \%$

$-0.33[-0.92,0.26]$

Heterogeneity: Not applicable

$100.0 \%$

$-0.33[-0.92,0.26]$

Test for overall effect: $\mathrm{Z}=1.08(\mathrm{P}=0.28)$

1.6.2 Multi-component $\mathrm{OHC}$ intervention (6 month)
Frenkel 2001
$-0.103 \quad 0.2583$
Subtotal (95\% CI)
$100.0 \%$
$-0.10[-0.61,0.40]$
$100.0 \%$
$-0.10[-0.61,0.40]$

Heterogeneity: Not applicable

Test for overall effect: $\mathrm{Z}=0.40(\mathrm{P}=0.69)$

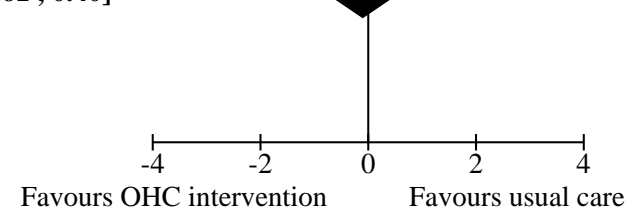

\section{Analysis 1.7. Comparison 1: Oral health care $(\mathrm{OHC})$ interventions versus usual care, Outcome 7: Pneumonia}

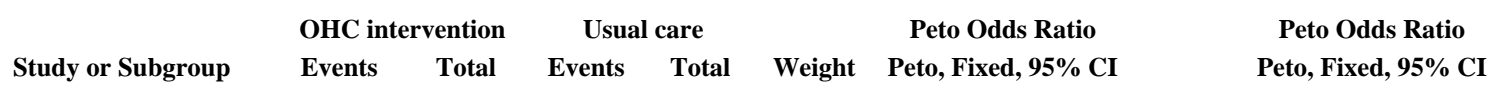

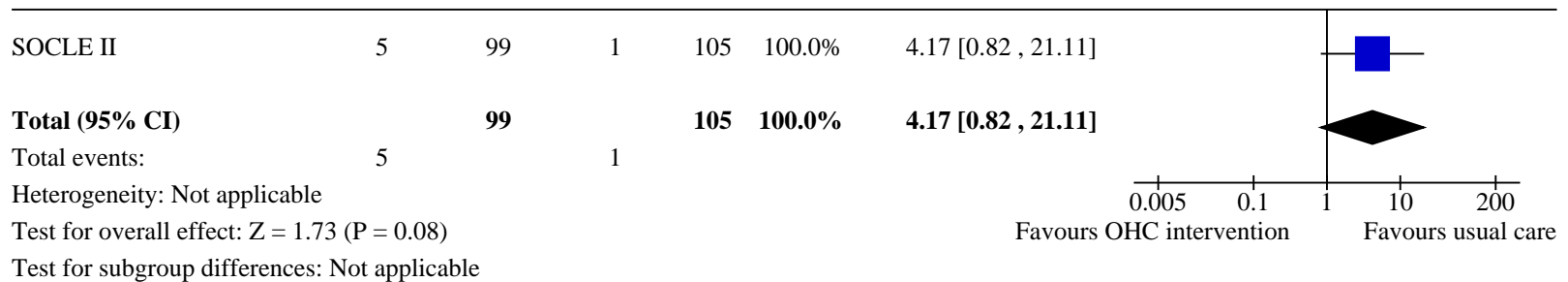

\section{Analysis 1.8. Comparison 1: Oral health care (OHC) interventions versus usual care, Outcome 8: OHC knowledge (1 month)}

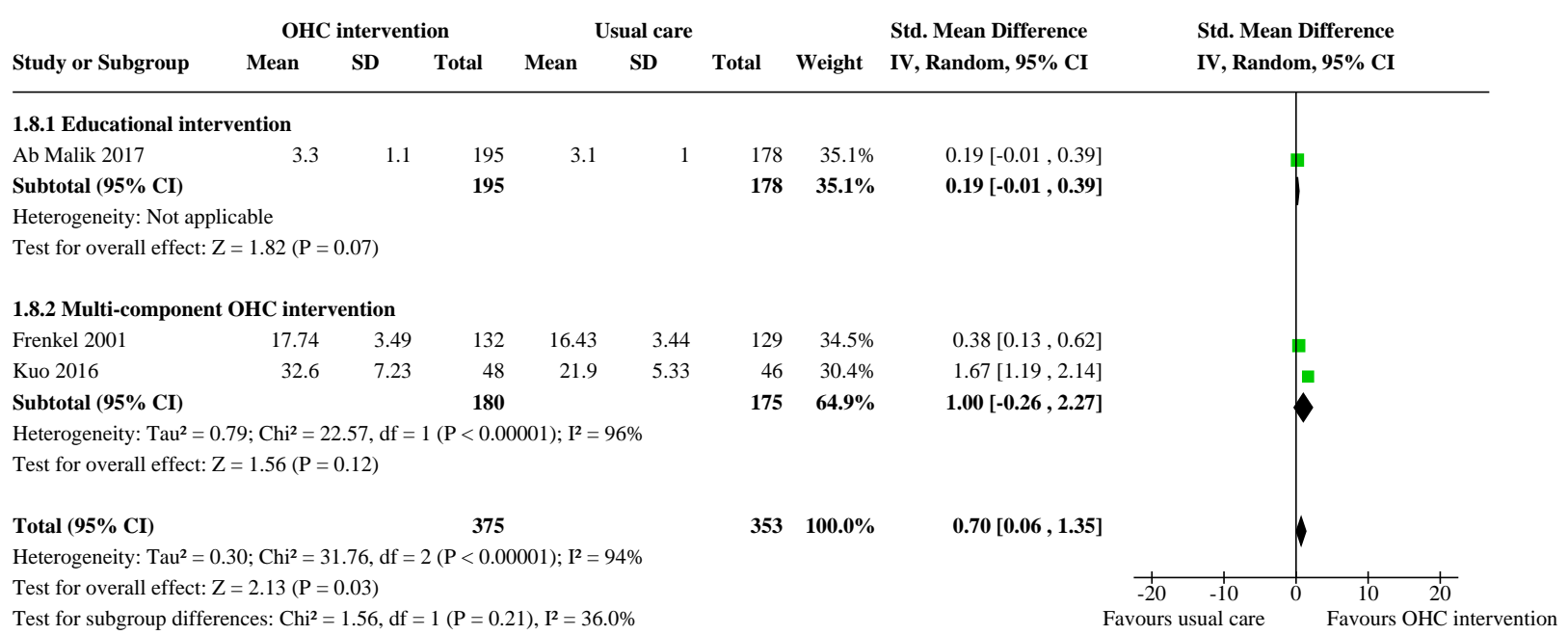




\section{Analysis 1.9. Comparison 1: Oral health care (OHC) interventions versus usual care, Outcome 9: OHC knowledge (2 months)}

\begin{tabular}{|c|c|c|c|c|c|c|c|c|c|}
\hline Study or Subgroup & \multicolumn{2}{|c|}{ OHC intervention } & Total & Mean & Usual care & Total & Weight & $\begin{array}{c}\text { Mean Difference } \\
\text { IV, Fixed, 95\% CI }\end{array}$ & $\begin{array}{c}\text { Mean Difference } \\
\text { IV, Fixed, } 95 \% \text { CI }\end{array}$ \\
\hline \multicolumn{10}{|c|}{ 1.9.1 Multi-component $\mathrm{OHC}$ intervention } \\
\hline Kuo 2016 & 31.8 & 7.29 & 48 & 20.5 & 5.03 & 46 & $100.0 \%$ & $11.30[8.78,13.82]$ & \\
\hline Subtotal $(95 \%$ CI $)$ & & & 48 & & & 46 & $100.0 \%$ & $11.30[8.78,13.82]$ & \\
\hline \multicolumn{10}{|c|}{ Heterogeneity: Not applicable } \\
\hline \multicolumn{10}{|c|}{ Test for overall effect: $Z=8.78(\mathrm{P}<0.00001)$} \\
\hline Total $(95 \% \mathrm{CI})$ & & & 48 & & & 46 & $100.0 \%$ & $11.30[8.78,13.82]$ & 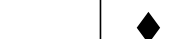 \\
\hline \multicolumn{10}{|c|}{ Heterogeneity: Not applicable } \\
\hline \multirow{2}{*}{\multicolumn{9}{|c|}{ Test for overall effect: $\mathrm{Z}=8.78(\mathrm{P}<0.00001)$}} & $\begin{array}{ccccc} & 1 & 1 & 1 & 1 \\
-20 & -10 & 0 & 10 & 20\end{array}$ \\
\hline & & & & & & & & & ual care \\
\hline
\end{tabular}

\section{Analysis 1.10. Comparison 1: Oral health care (OHC) interventions versus usual care, Outcome 10: OHC knowledge (6 months)}

\begin{tabular}{|c|c|c|c|c|c|c|c|c|c|}
\hline & \multicolumn{3}{|c|}{$\mathrm{OHC}$ intervention } & \multicolumn{3}{|c|}{ Usual care } & \multirow{2}{*}{\multicolumn{2}{|c|}{$\begin{array}{l}\text { Std. Mean Difference } \\
\text { IV, Fixed, 95\% CI }\end{array}$}} & \multirow{2}{*}{$\begin{array}{l}\text { Std. Mean Differenc } \\
\text { IV, Fixed, 95\% CI }\end{array}$} \\
\hline Study or Subgroup & Mean & SD & Total & Mean & SD & Total & & & \\
\hline
\end{tabular}

1.10.1 Educational intervention

$\begin{array}{lrlllllll}\text { Ab Malik } 2017 & 3.3 & 1.1 & 195 & 3 & 1.1 & 178 & 63.0 \% & 0.27[0.07,0.48]\end{array}$

$\begin{array}{lllll}\text { Subtotal }(95 \% \text { CI }) & 195 & 178 & 63.0 \% & 0.27[0.07,0.48]\end{array}$

Heterogeneity: Not applicable

Test for overall effect: $\mathrm{Z}=2.61(\mathrm{P}=0.009)$

1.10.2 Multi-component OHC intervention

$\begin{array}{lcccccccc}\text { Frenkel } 2001 & 18.54 & 3.06 & 117 & 17.16 & 3.06 & 106 & 37.0 \% & 0.45[0.18,0.72] \\ \text { Subtotal (95\% CI) } & & & \mathbf{1 1 7} & & & \mathbf{1 0 6} & \mathbf{3 7 . 0 \%} & \mathbf{0 . 4 5}[\mathbf{0 . 1 8 , 0 . 7 2}]\end{array}$

Heterogeneity: Not applicable

Test for overall effect: $\mathrm{Z}=3.31(\mathrm{P}=0.0009)$

Total $(95 \%$ CI $)$

312

Heterogeneity: $\mathrm{Chi}^{2}=1.07, \mathrm{df}=1(\mathrm{P}=0.30) ; \mathrm{I}^{2}=7 \%$

Test for overall effect: $\mathrm{Z}=4.09(\mathrm{P}<0.0001)$

Test for subgroup differences: $\mathrm{Chi}^{2}=1.07, \mathrm{df}=1(\mathrm{P}=0.30), \mathrm{I}^{2}=6.8 \%$

$284 \quad 100.0 \%$

$0.34[0.18,0.50]$

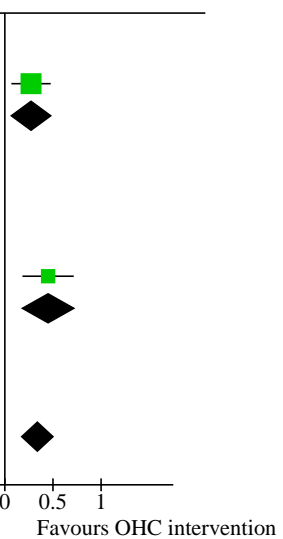

\section{Analysis 1.11. Comparison 1: Oral health care $(\mathrm{OHC})$ interventions versus usual care, Outcome 11: Attitudes to oral care (1 month)}

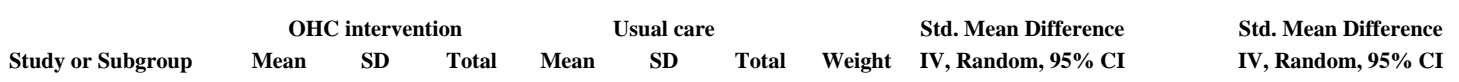

1.11.1 Educational intervention

$\begin{array}{lllllllll}\text { Ab Malik } 2017 & 12.9 & 1.8 & 195 & 12.8 & 1.5 & 178 & 40.2 \% & 0.06[-0.14,0.26] \\ \text { Subtotal (95\% CI) } & & & \mathbf{1 9 5} & & & \mathbf{1 7 8} & \mathbf{4 0 . 2 \%} & \mathbf{0 . 0 6}[-\mathbf{0 . 1 4}, \mathbf{0 . 2 6}]\end{array}$

Heterogeneity: Not applicable

Test for overall effect: $\mathrm{Z}=0.58(\mathrm{P}=0.56)$

1.11.2 Multi-component $\mathrm{OHC}$ intervention

$\begin{array}{llllllll}\text { Frenkel 2001 } & 19.6 & 10.46 & 132 & 15.15 & 11.46 & 129 & 36.3 \%\end{array}$

$353 \quad 100.0 \%$

$0.28[0.01,0.54]$

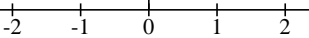

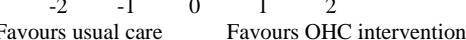




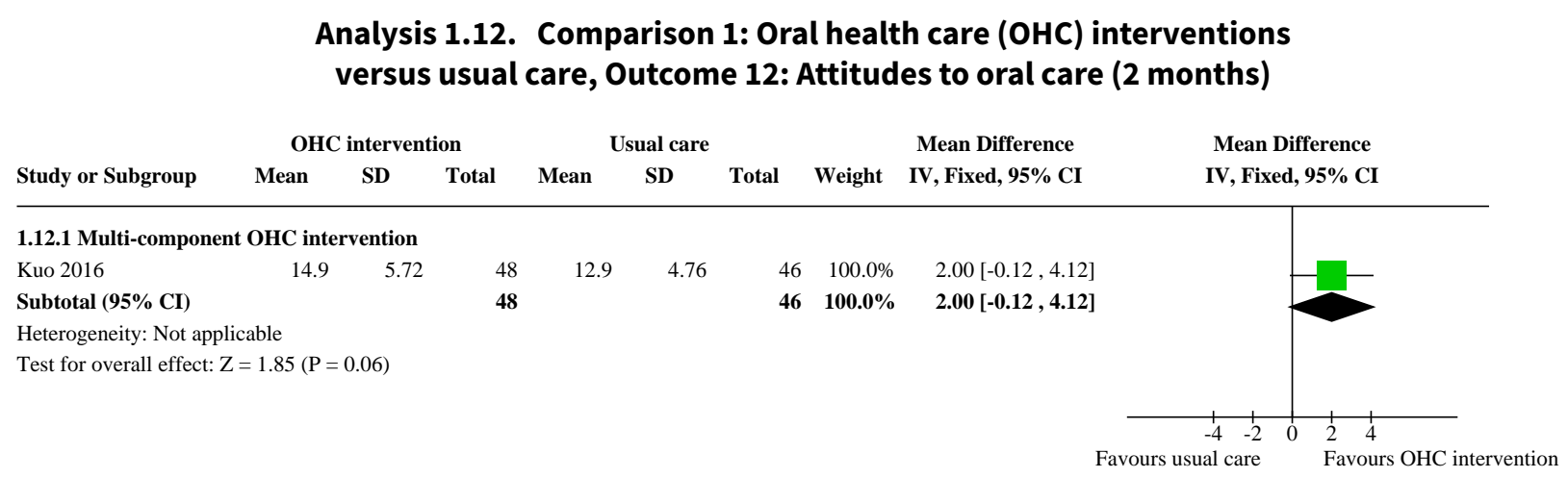

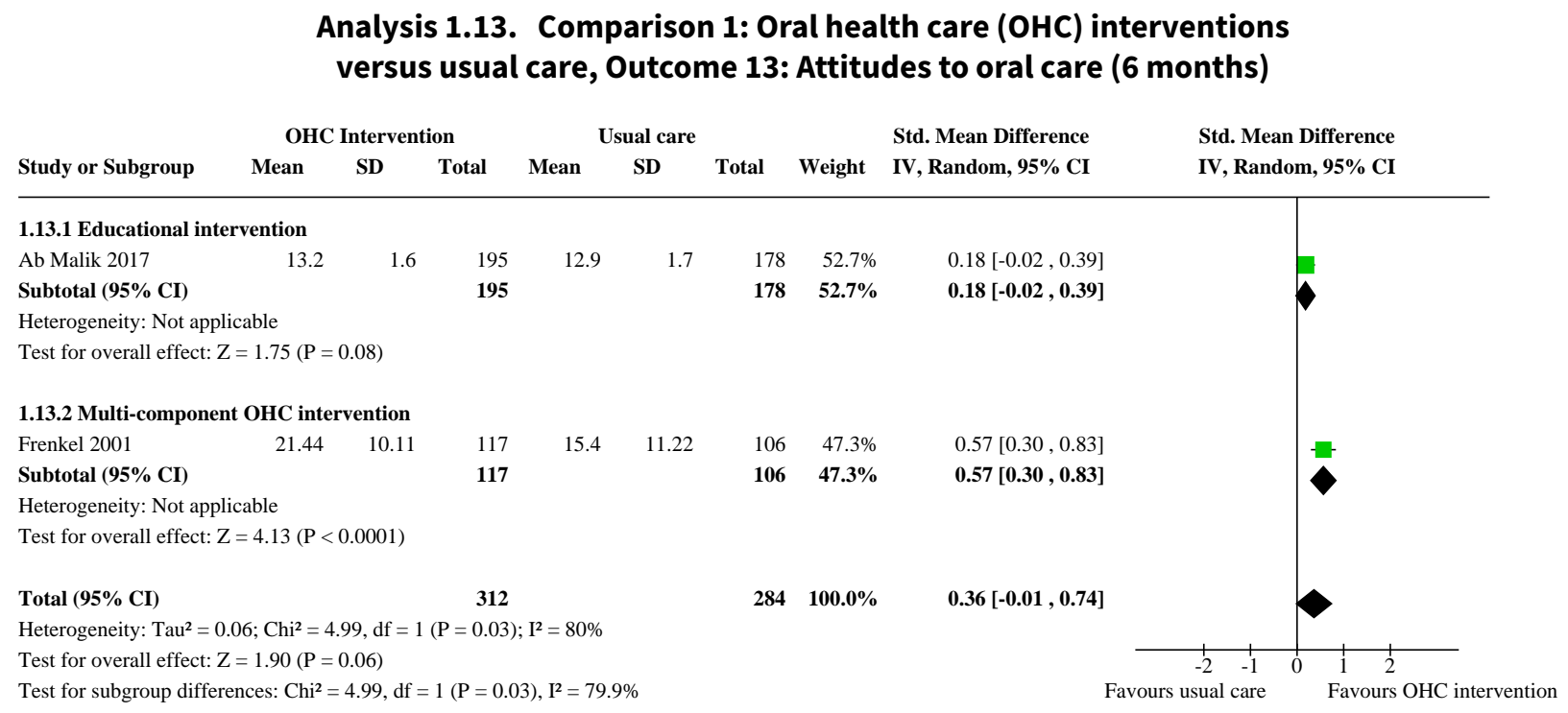

Comparison 2. Oral health care $(\mathrm{OHC})$ interventions versus placebo

\begin{tabular}{lllll}
\hline Outcome or subgroup title & $\begin{array}{l}\text { No. of } \\
\text { studies }\end{array}$ & $\begin{array}{l}\text { No. of } \\
\text { partici- } \\
\text { pants }\end{array}$ & Statistical method & Effect size \\
\hline $\begin{array}{l}2.1 \text { Presence of oral disease: pneu- } \\
\text { monia }\end{array}$ & 2 & 242 & Peto Odds Ratio (Peto, Fixed, 95\% Cl) & $0.39[0.14,1.09]$ \\
\hline $\begin{array}{l}2.2 \text { Presence of oral disease: ac- } \\
\text { quired Aerobic Gram-negative } \\
\text { bacilli (AGNB) }\end{array}$ & 2 & 242 & Risk Ratio (M-H, Fixed, 95\% Cl) & $0.56[0.32,1.01]$ \\
\hline $\begin{array}{l}2.3 \text { Presence of oral disease: car- } \\
\text { riage of AGNB }\end{array}$ & 1 & 203 & Risk Ratio (M-H, Fixed, 95\% Cl) & $0.91[0.48,1.74]$ \\
\hline $\begin{array}{l}2.4 \text { Self-reported oral dryness } \\
\text { 2.4.1 Oral dryness over 24-hour pe- }\end{array}$ & 1 & & Mean Difference (IV, Fixed, 95\% Cl) & Subtotals only \\
\hline \begin{tabular}{l} 
riod \\
\hline
\end{tabular} & 21 & Mean Difference (IV, Fixed, 95\% Cl) & $-0.13[-1.81,1.55]$ \\
\hline
\end{tabular}




\begin{tabular}{llllll}
\hline Outcome or subgroup title & $\begin{array}{l}\text { No. of } \\
\text { studies }\end{array}$ & $\begin{array}{l}\text { No. of } \\
\text { partici- } \\
\text { pants }\end{array}$ & Statistical method & Effect size \\
\hline 2.4.2 Oral dryness during the day & 1 & 21 & Mean Difference (IV, Fixed, 95\% CI) & $-0.64[-2.43,1.15]$ \\
\hline 2.4.3 Oral dryness during a meal & 1 & 21 & Mean Difference (IV, Fixed, 95\% Cl) & $0.66[-1.61,2.93]$ \\
\hline 2.4.4 Difficulty swallowing food & 1 & 21 & Mean Difference (IV, Fixed, 95\% Cl) & $-0.62[-2.53,1.29]$ \\
\hline 2.4.5 Lack of saliva & 1 & 21 & Mean Difference (IV, Fixed, 95\% CI) & $1.12[-0.28,2.52]$ \\
\hline 2.4.6 General discomfort & 1 & 21 & Mean Difference (IV, Fixed, 95\% CI) & $0.45[-0.91,1.81]$ \\
\hline
\end{tabular}

\section{Analysis 2.1. Comparison 2: Oral health care (OHC) interventions versus placebo, Outcome 1: Presence of oral disease: pneumonia}

\begin{tabular}{|c|c|c|c|c|c|c|c|}
\hline & OHC Ir & yention & Pla & & & Peto Odds Ratio & Peto Odds Ratio \\
\hline Study or Subgroup & Events & Total & Events & Total & Weight & Peto, Fixed, 95\% CI & Peto, Fixed, 95\% CI \\
\hline
\end{tabular}

\begin{tabular}{lrrrrrr}
\hline Gosney 2006 (1) & 1 & 103 & 7 & 100 & $52.1 \%$ & $0.20[0.05,0.84]$ \\
Seguin 2014 (2) & 4 & 19 & 5 & 20 & $47.9 \%$ & $0.81[0.18,3.51]$ \\
& & & & & & \\
Total (95\% CI) & 5 & $\mathbf{1 2 2}$ & & $\mathbf{1 2 0}$ & $\mathbf{1 0 0 . 0 \%}$ & $\mathbf{0 . 3 9}[\mathbf{0 . 1 4}, \mathbf{1 . 0 9}]$ \\
Total events: & & 12 & & &
\end{tabular}

Total events: $\quad 5 \quad 12$

Heterogeneity: $\mathrm{Chi}^{2}=1.73, \mathrm{df}=1(\mathrm{P}=0.19) ; \mathrm{I}^{2}=42 \%$

Test for overall effect: $\mathrm{Z}=1.79(\mathrm{P}=0.07)$

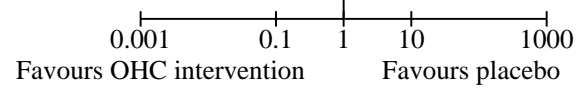

Test for subgroup differences: Not applicable

Footnotes

(1) Intervention: Selective decontamination gel

(2) Intervention: Povidine-iodine

Analysis 2.2. Comparison 2: Oral health care (OHC) interventions versus placebo, Outcome 2: Presence of oral disease: acquired Aerobic Gram-negative bacilli (AGNB)

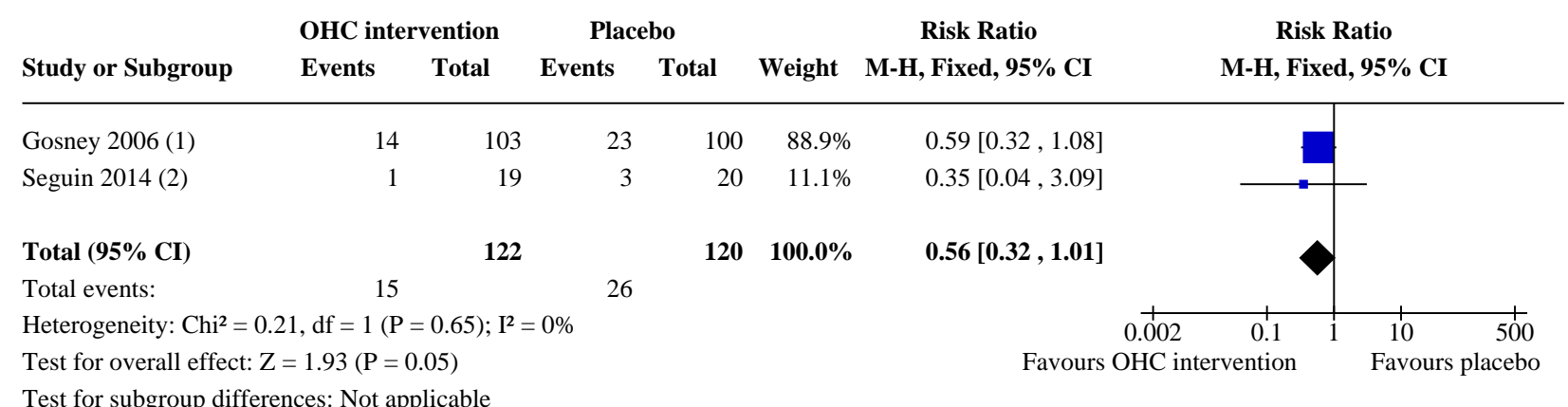

Footnotes

(1) Intervention: Selective decontamination gel

(2) Intervention: Povidine-iodine 
Analysis 2.3. Comparison 2: Oral health care $(\mathrm{OHC})$ interventions versus placebo, Outcome 3: Presence of oral disease: carriage of AGNB

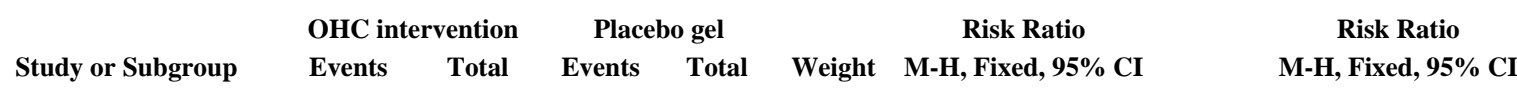

\begin{tabular}{lcccccc}
\hline Gosney 2006(1) & 15 & 103 & 16 & 100 & $100.0 \%$ & $0.91[0.48,1.74]$ \\
$\begin{array}{l}\text { Total (95\% CI) } \\
\text { Total events: }\end{array}$ & 15 & $\mathbf{1 0 3}$ & & $\mathbf{1 0 0}$ & $\mathbf{1 0 0 . 0 \%}$ & $\mathbf{0 . 9 1}[\mathbf{0 . 4 8 , \mathbf { 1 . 7 4 } ]}$ \\
& & & 16 & & &
\end{tabular}

Heterogeneity: Not applicable

Test for overall effect: $\mathrm{Z}=0.28(\mathrm{P}=0.78)$

Test for subgroup differences: Not applicable

\section{Footnotes}

(1) Intervention: Selective decontamination gel

\section{Analysis 2.4. Comparison 2: Oral health care (OHC) interventions versus placebo, Outcome 4: Self-reported oral dryness}

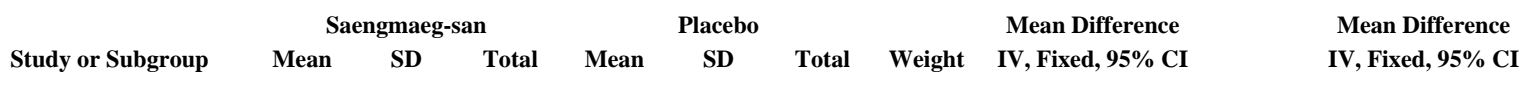

2.4.1 Oral dryness over
24-hour period
Lee 2011

Heterogeneity: Not applicable

Test for overall effect: $\mathrm{Z}=0.15(\mathrm{P}=0.88)$

2.4.2 Oral dryness during the day

$\begin{array}{lllllllll}\text { Lee } 2011 & 4.8 & 1.75 & 11 & 5.44 & 2.35 & 10 & 100.0 \% & -0.64[-2.43,1.15] \\ \text { Subtotal (95\% CI) } & & & \mathbf{1 1} & & & \mathbf{1 0} & \mathbf{1 0 0 . 0 \%} & \mathbf{- 0 . 6 4}[\mathbf{- 2 . 4 3}, \mathbf{1 . 1 5}]\end{array}$

Heterogeneity: Not applicable

Test for overall effect: $\mathrm{Z}=0.70(\mathrm{P}=0.48)$

2.4.3 Oral dryness during a meal

\begin{tabular}{|c|c|c|c|c|c|c|c|}
\hline Lee 2011 & 4.33 & 3.44 & 11 & 3.67 & 1.63 & 10 & $0.66[-1.61,2.93]$ \\
\hline CI) & & & 11 & & & 10 & $0.66[-1.61,2.93]$ \\
\hline
\end{tabular}

Heterogeneity: Not applicable

Test for overall effect: $\mathrm{Z}=0.57(\mathrm{P}=0.57)$

2.4.4 Difficulty swallowing food

$\begin{array}{lllllllll}\text { Lee } 2011 & 4.63 & 2.56 & 11 & 5.25 & 1.89 & 10 & 100.0 \% & -0.62[-2.53,1.29] \\ \text { Subtotal (95\% CI) } & & & \mathbf{1 1} & & & \mathbf{1 0} & \mathbf{1 0 0 . 0 \%} & \mathbf{- 0 . 6 2}[-\mathbf{2 . 5 3}, \mathbf{1 . 2 9}]\end{array}$

Heterogeneity: Not applicable

Test for overall effect: $\mathrm{Z}=0.64(\mathrm{P}=0.53)$

2.4.5 Lack of saliva

$\begin{array}{lllllllll}\text { Lee } 2011 & 5.5 & 1.77 & 11 & 4.38 & 1.5 & 10 & 100.0 \% & 1.12[-0.28,2.52] \\ \text { Subtotal (95\% CI) } & & & \mathbf{1 1} & & & \mathbf{1 0} & \mathbf{1 0 0 . 0 \%} & \mathbf{1 . 1 2}[-\mathbf{- 0 . 2 8}, \mathbf{2 . 5 2}]\end{array}$

Heterogeneity: Not applicable

Test for overall effect: $\mathrm{Z}=1.57(\mathrm{P}=0.12)$

2.4.6 General discomfort

Lee 201

Heterogeneity: Not applicable

Test for overall effect: $\mathrm{Z}=0.65(\mathrm{P}=0.52)$

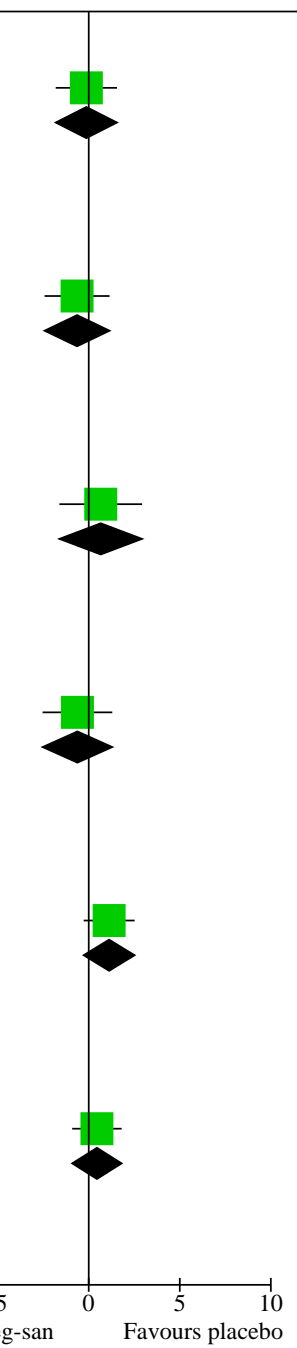


Comparison 3. Oral health care $(\mathrm{OHC})$ interventions versus another $\mathrm{OHC}$ intervention

\begin{tabular}{|c|c|c|c|c|}
\hline Outcome or subgroup title & $\begin{array}{l}\text { No. of } \\
\text { studies }\end{array}$ & $\begin{array}{l}\text { No. of } \\
\text { partici- } \\
\text { pants }\end{array}$ & Statistical method & Effect size \\
\hline 3.1 Dental plaque (3 months) & 1 & 61 & Mean Difference (IV, Fixed, 95\% CI) & $-0.04[-0.33,0.25]$ \\
\hline 3.2 Dental plaque (6 months) & 1 & 54 & Mean Difference (IV, Fixed, 95\% CI) & $-0.15[-0.46,0.16]$ \\
\hline $\begin{array}{l}\text { 3.3 Presence of oral disease: aero- } \\
\text { bic Gram-negative bacilli (AGNB) ( } 3 \\
\text { months) }\end{array}$ & 2 & 126 & Risk Ratio (M-H, Fixed, 95\% Cl) & $1.00[0.71,1.42]$ \\
\hline $\begin{array}{l}\text { 3.4 Presence of oral disease: AGNB } \\
\text { ( } 6 \text { months) }\end{array}$ & 1 & 52 & Risk Ratio (M-H, Fixed, 95\% Cl) & $0.80[0.47,1.38]$ \\
\hline 3.5 Candida (3 months) & 1 & 52 & Risk Ratio (M-H, Fixed, 95\% Cl) & $1.08[0.61,1.89]$ \\
\hline 3.6 Candida (6 months) & 1 & 52 & Risk Ratio (M-H, Fixed, 95\% Cl) & $1.17[0.62,2.20]$ \\
\hline 3.7 Staphylococcus aureus & 2 & 119 & Risk Ratio (M-H, Fixed, 95\% Cl) & $1.29[0.57,2.91]$ \\
\hline
\end{tabular}

Analysis 3.1. Comparison 3: Oral health care (OHC) interventions versus another OHC intervention, Outcome 1: Dental plaque (3 months)

\begin{tabular}{|c|c|c|c|c|c|c|c|c|c|}
\hline \multirow[b]{2}{*}{ Study or Subgroup } & \multicolumn{3}{|c|}{ Enhanced OHC protocol } & \multicolumn{3}{|c|}{ Routine OHC protocol } & \multirow[b]{2}{*}{ Weight } & \multirow{2}{*}{$\begin{array}{l}\text { Mean Difference } \\
\text { IV, Fixed, 95\% CI }\end{array}$} & \multirow{2}{*}{$\begin{array}{l}\text { Mean Difference } \\
\text { IV, Fixed, 95\% CI }\end{array}$} \\
\hline & Mean & SD & Total & Mean & SD & Total & & & \\
\hline Ab Malik 2018 & 1.27 & 0.61 & 27 & 1.31 & 0.51 & 34 & $100.0 \%$ & $-0.04[-0.33,0.25]$ & \\
\hline Total $(95 \%$ CI) & & & 27 & & & 34 & $100.0 \%$ & $-0.04[-0.33,0.25]$ & \\
\hline \multicolumn{10}{|c|}{ Heterogeneity: Not applicable } \\
\hline \multirow{2}{*}{\multicolumn{4}{|c|}{$\begin{array}{l}\text { Test for overall effect: } \mathrm{Z}=0.27(\mathrm{P}=0.78) \\
\text { Test for subgroup differences: Not applicable }\end{array}$}} & & & & & & 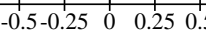 \\
\hline & & & & & & & & Fave & ed OHC Favour \\
\hline
\end{tabular}

Analysis 3.2. Comparison 3: Oral health care $(\mathrm{OHC})$ interventions versus another $\mathrm{OHC}$ intervention, Outcome 2: Dental plaque (6 months)

\begin{tabular}{|c|c|c|c|c|c|c|c|c|c|}
\hline \multirow[b]{2}{*}{ Study or Subgroup } & \multicolumn{3}{|c|}{ Enhanced OHC protocol } & \multicolumn{3}{|c|}{ Routine OHC protocol } & \multirow[b]{2}{*}{ Weight } & \multirow{2}{*}{$\begin{array}{c}\text { Mean Difference } \\
\text { IV, Fixed, 95\% CI }\end{array}$} & \multirow{2}{*}{$\begin{array}{l}\text { Mean Difference } \\
\text { IV, Fixed, 95\% CI }\end{array}$} \\
\hline & Mean & SD & Total & Mean & SD & Total & & & \\
\hline Ab Malik 2018 & 0.92 & 0.59 & 25 & 1.07 & 0.57 & 29 & $100.0 \%$ & $-0.15[-0.46,0.16]$ & \\
\hline Total $(95 \%$ CI $)$ & & & 25 & & & 29 & $100.0 \%$ & $-0.15[-0.46,0.16]$ & \\
\hline \multicolumn{10}{|c|}{ Heterogeneity: Not applicable } \\
\hline \multirow{2}{*}{\multicolumn{4}{|c|}{ Test for overall effect: $\mathrm{Z}=0.95(\mathrm{P}=0.34)$}} & & & & & & $\begin{array}{ccccc} & 1 & 1 & 1 & 1 \\
-1 & -0.5 & 0 & 0.5 & 1\end{array}$ \\
\hline & & & & & & & & Favou & ed OHC Favou \\
\hline
\end{tabular}


Analysis 3.3. Comparison 3: Oral health care $(\mathrm{OHC})$ interventions versus another $\mathrm{OHC}$ intervention, Outcome 3: Presence of oral disease: aerobic Gram-negative bacilli (AGNB) (3 months)

\begin{tabular}{|c|c|c|c|c|c|c|c|}
\hline \multirow[b]{2}{*}{ Study or Subgroup } & \multicolumn{2}{|c|}{ Enhanced OHC protocol } & \multicolumn{2}{|c|}{ Routine OHC protocol } & \multirow[b]{2}{*}{ Weight } & \multirow{2}{*}{$\begin{array}{c}\text { Risk Ratio } \\
\text { M-H, Fixed, 95\% CI }\end{array}$} & \multirow{2}{*}{$\begin{array}{c}\text { Risk Ratio } \\
\text { M-H, Fixed, 95\% CI }\end{array}$} \\
\hline & Events & Total & Events & Total & & & \\
\hline Ab Malik 2018 & 15 & 24 & 17 & 28 & $50.9 \%$ & $1.03[0.67,1.58]$ & \\
\hline Dai 2017 & 16 & 40 & 14 & 34 & $49.1 \%$ & $0.97[0.56,1.69]$ & \\
\hline Total $(95 \%$ CI $)$ & & 64 & & 62 & $100.0 \%$ & $1.00[0.71,1.42]$ & \\
\hline Total events: & 31 & & 31 & & & & \\
\hline \multicolumn{3}{|c|}{ Heterogeneity: $\mathrm{Chi}^{2}=0.03, \mathrm{df}=1(\mathrm{P}=0.87) ; \mathrm{I}^{2}=0 \%$} & & & & & 0.01 \\
\hline Test for overall effect & $0.01(\mathrm{P}=1.00)$ & & & & & $\mathrm{Fa}$ & Irs enhanced $\mathrm{OHC}$ \\
\hline
\end{tabular}

Test for subgroup differences: Not applicable

Analysis 3.4. Comparison 3: Oral health care $(\mathrm{OHC})$ interventions versus another OHC intervention, Outcome 4: Presence of oral disease: AGNB (6 months)

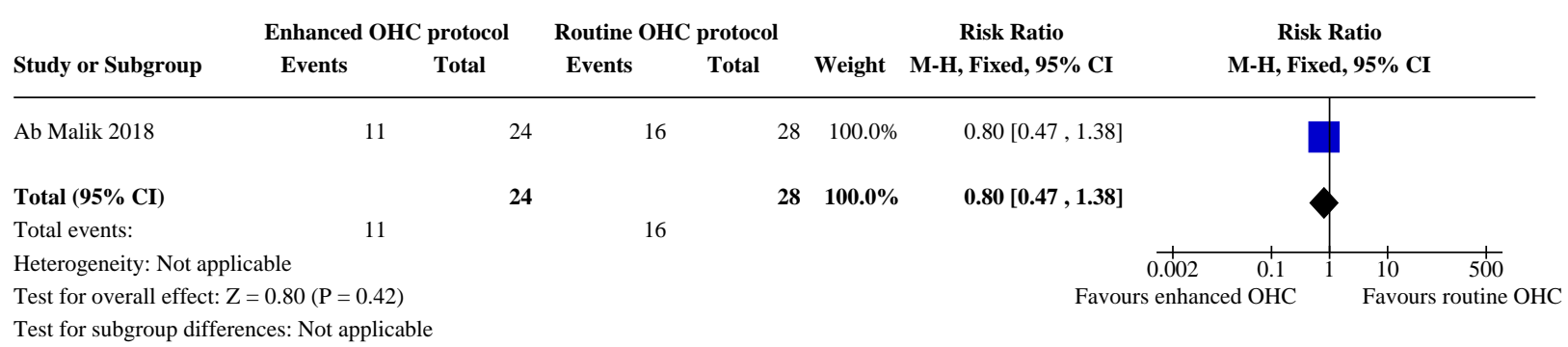

Analysis 3.5. Comparison 3: Oral health care (OHC) interventions versus another $\mathrm{OHC}$ intervention, Outcome 5: Candida (3 months)

\begin{tabular}{|c|c|c|c|c|c|c|c|}
\hline \multirow[b]{2}{*}{ Study or Subgroup } & \multicolumn{2}{|c|}{ Enhanced OHC protocol } & \multicolumn{2}{|c|}{ Routine OHC protocol } & \multicolumn{2}{|r|}{ Risk Ratio } & \multirow{2}{*}{$\begin{array}{c}\text { Risk Ratio } \\
\text { M-H, Fixed, 95\% CI }\end{array}$} \\
\hline & Events & Total & Events & Total & Weight & M-H, Fixed, 95\% CI & \\
\hline
\end{tabular}

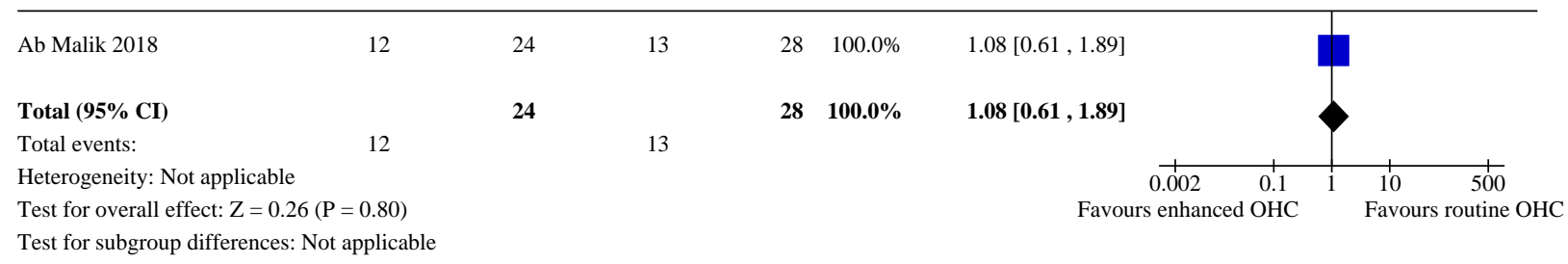

Test for subgroup differences: Not applicable

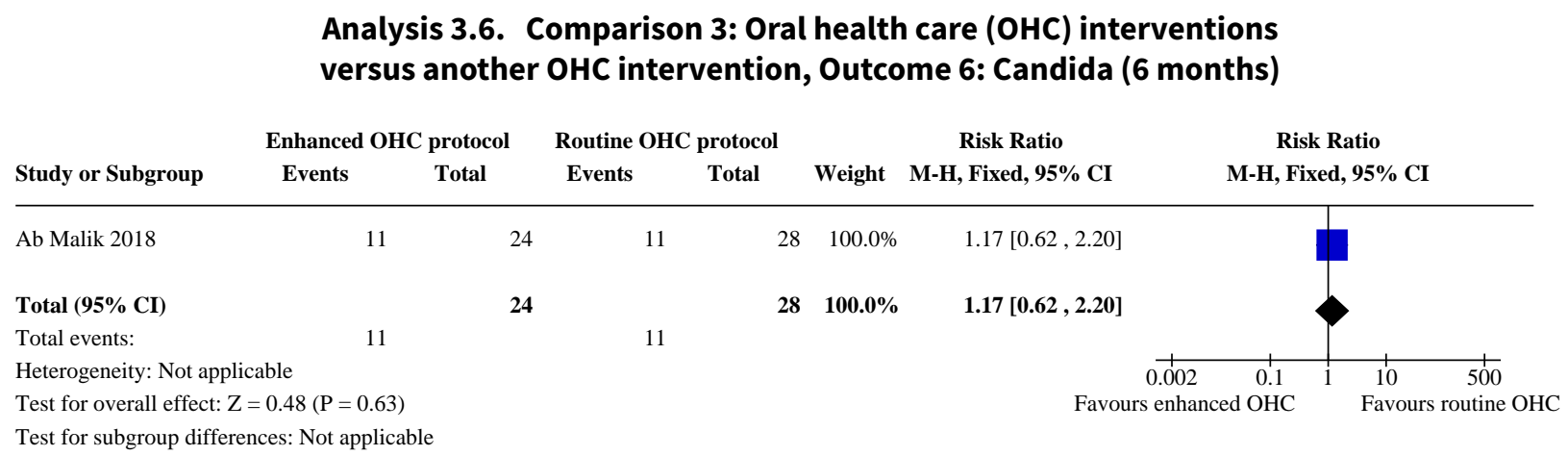


Analysis 3.7. Comparison 3: Oral health care (OHC) interventions versus another OHC intervention, Outcome 7: Staphylococcus aureus

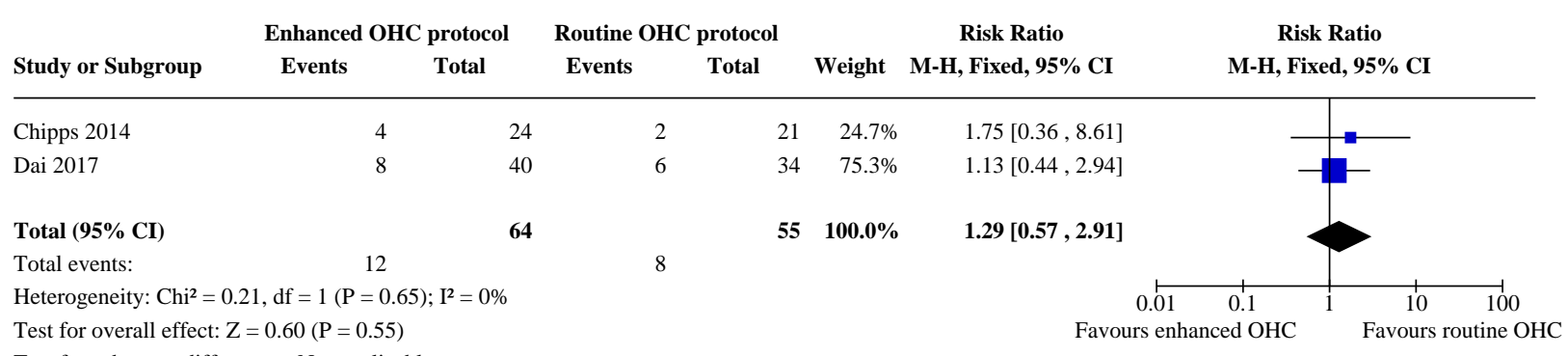

\section{ADDITIONAL TABLES}

Table 1. Summary of study recruitment and setting

\begin{tabular}{ll}
\hline Study ID & Recruitment details \\
& \\
\hline Ab Malik & $\begin{array}{l}\text { Study populations were RNs caring for people with stroke, } \\
\text { mainly from rehabilitation and general medical wards. All } \\
\text { RNs from identified wards were invited to take part. RNs giv- } \\
\text { en written information sheet and informed consent forms dis- } \\
\text { tributed by ward managers or chief nurses. Participation was } \\
\text { voluntary and no contact was made with the nurses to ensure } \\
\text { confidentiality and reduce the potential for 'social bias.' }\end{array}$
\end{tabular}

$\begin{array}{ll}\text { Number } & \begin{array}{l}\text { Type of centre } \\ \text { of cen- }\end{array} \\ \text { and location }\end{array}$

Geo- Trial graphi- registratres cal location tails

Mul-

ti-centre

(10) in a survey of oral

Malaysia

NMhygiene practice for people with stroke. Hospitals selected because they provide rehabilitation services that are led by rehabilitation medicine specialists.

$\begin{array}{llll}\text { Mul- } & \text { Public hospitals } & \text { Malaysia } & \text { NM- } \\ \text { ti-centre } & & & \text { RR-13-1664-17247 }\end{array}$

(5)

(IIR)

$\begin{array}{ll}\text { Chipps } & \text { People admitted following a stroke who met inclusion criteria } \\ 2014 & \text { were invited to take part in the study. No other details report- } \\ & \text { ed. }\end{array}$

Single

Free standing 60-

USA bed acute rehabilitation unit

RR-13-1540-18833

(IIR)

\section{Dai 2017 Following hospital discharge, people with stroke who had} sustained functional impairment were referred to outpatient centre for further rehabilitation with MDT. Patients who ful-

Single

Outpatients 'day'
centre hospital

$\begin{array}{ll}\text { Hong } & \text { HK Clini- } \\ \text { Kong, } & \text { cal Trial } \\ \text { PRC } & \text { Register } \\ & 003900\end{array}$

tial benefits and adverse effects of interventions, procedures and anticipated outcomes of the study. At next follow-up appointment, patients who agreed to participate gave written informed consent

\begin{tabular}{llll}
\hline $\begin{array}{l}\text { Fields } \\
2008\end{array}$ & $\begin{array}{l}\text { Enrolment and data collection began in October 2005. No oth- } \\
\text { er details reported. }\end{array}$ & $\begin{array}{l}\text { Single } \\
\text { Critical care unit, }\end{array}$ & $\begin{array}{l}\text { USA } \\
\text { large teaching } \\
\text { hospital }\end{array}$
\end{tabular}


Table 1. Summary of study recruitment and setting (Continued)

Frenkel Directors of the nursing homes were contacted and agreed to 2001 participation. Carers were encouraged, but not compelled, to take part. Individual carers therefore implicitly consented by completing the questionnaire and attending the training, or refused by failing to participate.
Mul- Nursing homes UK Not re-

ti-centre (20-40 beds) reg- ported

istered with Avon

Health Authority

$\begin{array}{ll}\text { Gosney } & \text { Recruited from acute stroke assessment from } 3 \text { hospitals. Par- } \\ 2006 & \text { ticipants were recruited within } 24 \text { hours from admission fol- } \\ & \text { lowing first acute stroke. }\end{array}$

\begin{tabular}{ll}
\hline Juthani- & $\begin{array}{l}\text { Administrative leadership at all nursing homes approved the } \\
\text { study and signed letters of agreement to participate, and par- }\end{array}$ \\
2015 & $\begin{array}{l}\text { ticipants or their surrogates provided written consent. } \\
\text { tichta }\end{array}$
\end{tabular}

Mul-

Stroke unit UK $\quad \begin{aligned} & \text { Not re- } \\ & \text { ported }\end{aligned}$

(3)

\begin{tabular}{ll}
\hline Kim & $\begin{array}{l}\text { Consecutive people with stroke admitted to ICU were ap- } \\
\text { proached. No other details reported. }\end{array}$
\end{tabular}

$\begin{array}{ll}\begin{array}{l}\text { Mul- } \\ \text { ti-centre }\end{array} & \begin{array}{l}\text { Nursing home fa- } \\ \text { cilities (housed } \geq \\ 90 \text { residents) }\end{array} \\ \text { (36) } & \text { USA NCTC }\end{array}$

\begin{tabular}{|c|c|c|}
\hline Single & $\begin{array}{l}\text { ICU, Neurosurgery } \\
\text { Department }\end{array}$ & Korea \\
\hline
\end{tabular}

of University Hos-

pital

\begin{tabular}{|c|c|c|c|c|c|}
\hline $\begin{array}{l}\text { Kobayashi } \\
\text { 2017i; } \\
\text { Kobayashi } \\
\text { 2017ii; } \\
\text { Kobayashi } \\
\text { 2017iii; } \\
\text { Kobayashi } \\
\text { 2017iv; } \\
\text { Kobayashi } \\
\text { 2017v; } \\
\text { Kobayashi } \\
\text { 2017vi }\end{array}$ & $\begin{array}{l}\text { Written informed consent was obtained from participants or } \\
\text { from family members. }\end{array}$ & Single & Hospital & Japan & $\begin{array}{l}\text { Not re- } \\
\text { ported }\end{array}$ \\
\hline Kuo 2016 & $\begin{array}{l}\text { Study conducted between September } 2012 \text { and February } \\
\text { 2013. Nursing directors of } 3 \text { hospital-based home care institu- } \\
\text { tions serving > } 100 \text { patients were contacted for screening of } \\
\text { family carers. }\end{array}$ & $\begin{array}{l}\text { Mul- } \\
\text { ti-centre } \\
(3)\end{array}$ & $\begin{array}{l}\text { Hospital and } \\
\text { home }\end{array}$ & Taiwan & $\begin{array}{l}\text { Not re- } \\
\text { ported }\end{array}$ \\
\hline $\begin{array}{l}\text { Lam } \\
\text { 2013i; } \\
\text { Lam } \\
\text { 2013ii; } \\
\text { Lam } \\
\text { 2013iii }\end{array}$ & $\begin{array}{l}\text { Patients meeting selection criteria were recruited. No other } \\
\text { details reported. }\end{array}$ & Single & $\begin{array}{l}\text { Stroke rehabilita- } \\
\text { tion ward }\end{array}$ & $\begin{array}{l}\text { Hong } \\
\text { Kong, } \\
\text { PRC }\end{array}$ & Unclear \\
\hline Lee 2011 & Unclear (translation unavailable at present) & Single & $\begin{array}{l}\text { Unclear } \\
\text { (translation un- } \\
\text { available at } \\
\text { present) }\end{array}$ & Korea & $\begin{array}{l}\text { Not re- } \\
\text { ported }\end{array}$ \\
\hline $\begin{array}{l}\text { Seguin } \\
2014\end{array}$ & $\begin{array}{l}\text { Study conducted between May } 2008 \text { and May } 2011 \text {. Written in- } \\
\text { formed consent obtained from personal or professional legal } \\
\text { representative and participants themselves at discharge when } \\
\text { possible. }\end{array}$ & $\begin{array}{l}\text { Mul- } \\
\text { ti-centre } \\
\text { (6) }\end{array}$ & ICU & France & NCT00950027 \\
\hline
\end{tabular}


Table 1. Summary of study recruitment and setting (Continued)
SOCLE II Sites were local to the investigators. All ward admissions were approached to participate by research assistant or research nurse. Information sheets and consent forms were adapted to make them as accessible as possible for people with aphasia
Mul- ti-centre
(4) or other language problems
Stroke rehabilita- tion wards. Acute stroke wards were
Scot- land, UK excluded

ICU: intensive care unit; MDT: multi-disciplinary team; PRC: People's Republic of China; RN: registered nurse.

Table 2. Characteristics of participants in included studies

\begin{tabular}{|c|c|c|c|c|c|c|}
\hline $\begin{array}{l}\text { Study } \\
\text { ID }\end{array}$ & Group & $\begin{array}{l}\text { No of par- } \\
\text { ticipants }\end{array}$ & $\begin{array}{l}\text { Men/ } \\
\text { women }\end{array}$ & $\begin{array}{l}\text { Age in } \\
\text { years } \\
\text { Mean (SD) } \\
\text { [range] }\end{array}$ & Types of stroke & $\begin{array}{l}\text { Time } \\
\text { post } \\
\text { onset }\end{array}$ \\
\hline \multirow{2}{*}{$\begin{array}{l}\text { Ab Ma- } \\
\text { lik } 2017\end{array}$} & $\mathrm{OHC}$ training (Internet-based CPD programme) & \multirow{2}{*}{$\begin{array}{l}\text { Whole } \\
\text { group: } \\
547 \mathrm{RNs} \\
\text { but final } \\
\text { response } \\
\text { rate was } \\
373 \mathrm{RNs}^{a}\end{array}$} & \multirow{2}{*}{$\begin{array}{l}\text { Whole } \\
\text { group: } \\
16 / 357\end{array}$} & \multirow[t]{2}{*}{ NR } & \multirow[t]{2}{*}{ NA } & \multirow[t]{2}{*}{ NA } \\
\hline & $\begin{array}{l}\text { General stroke care training (Internet-based CPDP } \\
\text { programme not specific to oral hygiene) }\end{array}$ & & & & & \\
\hline \multirow[t]{2}{*}{$\begin{array}{l}\text { Ab Ma- } \\
\text { lik } 2018\end{array}$} & $\begin{array}{l}\text { Multi-component } \mathrm{OHC} \text { intervention (intense method } \\
\text { for plaque control) }\end{array}$ & 38 & $24 / 14$ & $\begin{array}{l}20-39 \text { years } \\
(n=6) \\
\geq 40 \text { years } \\
(n=32)\end{array}$ & $\begin{array}{l}\text { Ischaemic } 35 \\
\text { Haemorrhage: } 3\end{array}$ & $\begin{array}{l}33 / 38 \\
\text { first } \\
\text { stroke; } \\
\text { time } \\
\text { post- } \\
\text { stroke: } \\
\text { NR }\end{array}$ \\
\hline & $\begin{array}{l}\text { Multi-component } \mathrm{OHC} \text { intervention (conventional } \\
\text { method for plaque control) }\end{array}$ & 48 & $28 / 20$ & $\begin{array}{l}20-39 \text { years } \\
(n=7) \\
\geq 40 \text { years } \\
(n=41)\end{array}$ & $\begin{array}{l}\text { Ischaemic } 42 \\
\text { Haemorrhage: } 6\end{array}$ & $\begin{array}{l}42 / 48 \\
\text { first } \\
\text { stroke; } \\
\text { time } \\
\text { post- } \\
\text { stroke: } \\
\text { NR }\end{array}$ \\
\hline \multirow[t]{2}{*}{$\begin{array}{l}\text { Chipps } \\
2014\end{array}$} & $\begin{array}{l}\text { Multi-component } \mathrm{OHC} \text { intervention (enhanced oral } \\
\text { care protocol) }\end{array}$ & 29 & $15 / 14$ & $62.54(13.5)$ & NR & NR \\
\hline & Multi-component $\mathrm{OHC}$ intervention (routine oral care) & 22 & $14 / 8$ & $63.74(15.6)$ & NR & NR \\
\hline \multirow[t]{2}{*}{$\begin{array}{l}\text { Dai } \\
2017\end{array}$} & $\begin{array}{l}\text { Multi-component } \mathrm{OHC} \text { intervention (advanced oral } \\
\text { hygiene care programme) }\end{array}$ & 47 & $29 / 18$ & $66.3(11.2)$ & $\begin{array}{l}\text { Ischaemic } 31 \\
\text { Haemorrhage: } 16\end{array}$ & NR \\
\hline & $\begin{array}{l}\text { Multi-component } \mathrm{OHC} \text { intervention (conventional oral } \\
\text { hygiene programme) }\end{array}$ & 47 & $28 / 19$ & $66.9(10.6)$ & $\begin{array}{l}\text { Ischaemic } 35 \\
\text { Haemorrhage: } 12\end{array}$ & NR \\
\hline $\begin{array}{l}\text { Fields } \\
2008\end{array}$ & $\begin{array}{l}\text { Multi-component } \mathrm{OHC} \text { intervention ( } \mathrm{OHC} \text { and timed } \\
\text { toothbrushing in care bundle) }\end{array}$ & $\begin{array}{l}345 \text { (but } \\
\text { complet- }\end{array}$ & NR & NR & NR & NR \\
\hline
\end{tabular}


Table 2. Characteristics of participants in included studies

\begin{tabular}{|c|c|c|c|c|c|c|}
\hline & Usual care & $\begin{array}{l}\text { ed data } \\
\text { only avail- } \\
\text { able on } \\
\text { 200) }\end{array}$ & NR & NR & NR & NR \\
\hline \multirow[t]{3}{*}{$\begin{array}{l}\text { Frenkel } \\
2001\end{array}$} & $\begin{array}{l}\text { Multi-component } \mathrm{OHC} \text { intervention (workplace } \mathrm{OHC} \\
\text { training session) }\end{array}$ & $\begin{array}{l}\text { Whole } \\
\text { group: } \\
369 \text { care } \\
\text { assistants } \\
\text { at base- } \\
\text { line; }\end{array}$ & $4 / 147$ & {$[16-55+]$} & NR & NR \\
\hline & & $\begin{array}{l}151 \text { resi- } \\
\text { dents }^{*}\end{array}$ & & & & \\
\hline & Usual care & $\begin{array}{l}144 \text { resi- } \\
\text { dents }\end{array}$ & $8 / 136$ & {$[16-55+]$} & NR & NR \\
\hline \multirow[t]{2}{*}{$\begin{array}{l}\text { Gosney } \\
2006\end{array}$} & $\begin{array}{l}\text { OHC gel (selective decontamination of digestive tract } \\
\text { oral gel) }\end{array}$ & 103 & $54 / 49$ & {$[16-96]$} & NR & \multirow{2}{*}{$\begin{array}{l}\text { First } \\
\text { acute } \\
\text { stroke; } \\
\text { time } \\
\text { post- } \\
\text { stroke: } \\
\text { NR }\end{array}$} \\
\hline & Placebo gel & 100 & $48 / 52$ & [45-92] & NR & \\
\hline \multirow{2}{*}{$\begin{array}{l}\text { Juthani- } \\
\text { Mehta } \\
2015\end{array}$} & Multi-component $\mathrm{OHC}$ intervention & 434 & $105 / 329$ & $86.5(8.0)$ & $\begin{array}{l}100 \text { participants } \\
\text { with stroke }\end{array}$ & NR \\
\hline & Usual care & 400 & $93 / 307$ & $86.1(8.3)$ & $\begin{array}{l}92 \text { participants } \\
\text { with stroke }\end{array}$ & NR \\
\hline \multirow[t]{2}{*}{$\begin{array}{l}\text { Kim } \\
2014 a\end{array}$} & Multi-component $\mathrm{OHC}$ intervention (OHCP) & 29 & $13 / 16$ & $\begin{array}{l}57.38 \\
(14.22)\end{array}$ & $\begin{array}{l}\text { Infarct: } 3 \\
\text { Haemorrhage: } 26\end{array}$ & NR \\
\hline & Usual care & 27 & $14 / 13$ & $\begin{array}{l}56.15 \\
(14.55)\end{array}$ & $\begin{array}{l}\text { Infarct: } 3 \\
\text { Haemorrhage: } 24\end{array}$ & NR \\
\hline $\begin{array}{l}\text { Kobayashi } \\
2017 \text {; } \\
\text { Kobayashi- } \\
\text { 2017ii; } \\
\text { Kobayashi } \\
\text { 2017iii; } \\
\text { Kobayashi } \\
\text { 2017iv; } \\
\text { Kobayashi } \\
\text { 2017v; } \\
\text { Kobayashi } \\
\text { 2017vi }\end{array}$ & $\begin{array}{l}\text { i Multi-component OHC intervention (mouthwash and } \\
\text { moisturising gel) }\end{array}$ & $\begin{array}{l}\text { Whole } \\
\text { group: } \\
60 \text { partici- } \\
\text { pants }\end{array}$ & $\begin{array}{l}\text { Whole } \\
\text { group: } \\
29 / 31\end{array}$ & $\begin{array}{l}\text { Whole } \\
\text { group: } 83.5 \\
\text { (5) }\end{array}$ & $\begin{array}{l}\text { Quote: "Treat- } \\
\text { ed for cerebral } \\
\text { stroke" - no oth- } \\
\text { er details report- } \\
\text { ed }\end{array}$ & NR \\
\hline \multirow[t]{2}{*}{$\begin{array}{l}\text { Kuo } \\
2016\end{array}$} & $\begin{array}{l}\text { Multi-component } \mathrm{OHC} \text { intervention (home-based } \\
\mathrm{OHC} \text { programme) }\end{array}$ & $\begin{array}{l}48 \text { family } \\
\text { carers }\end{array}$ & $16 / 32$ & $52.7(11.29)$ & NR & NR \\
\hline & Usual care & $\begin{array}{l}46 \text { family } \\
\text { carers }\end{array}$ & $19 / 27$ & $53.9(16.74)$ & NR & NR \\
\hline
\end{tabular}


Table 2. Characteristics of participants in included studies (Continued)

\begin{tabular}{|c|c|c|c|c|c|c|}
\hline \multirow{3}{*}{$\begin{array}{l}\text { Lam } \\
\text { 2013i; } \\
\text { Lam } \\
\text { 2013ii; } \\
\text { Lam } \\
\text { 2013iii }\end{array}$} & $\begin{array}{l}\text { Multi-component } \mathrm{OHC} \text { intervention (oral hygiene } \\
\text { instruction }+ \text { chlorhexidine mouthrinse }+ \text { assisted } \\
\text { brushing) }\end{array}$ & 30 & $19 / 11$ & $71(11.7)$ & $\begin{array}{l}\text { Ischaemic } 27 \\
\text { Haemorrhage: } 3\end{array}$ & NR \\
\hline & $\begin{array}{l}\text { Multi-component OHC intervention (oral hygiene in- } \\
\text { struction + chlorhexidine mouthrinse) }\end{array}$ & 26 & $16 / 10$ & $69.4(9.6)$ & $\begin{array}{l}\text { Ischaemic } 22 \\
\text { Haemorrhage: } 4\end{array}$ & NR \\
\hline & $\begin{array}{l}\text { Multi-component } \mathrm{OHC} \text { intervention (oral hygiene in- } \\
\text { struction) }\end{array}$ & 25 & $16 / 9$ & $68.9(11.4)$ & $\begin{array}{l}\text { Ischaemic } 19 \\
\text { Haemorrhage: } 6\end{array}$ & NR \\
\hline \multirow{3}{*}{$\begin{array}{l}\text { Lee } \\
2011\end{array}$} & Saengmaeg-san extract & 12 & NR & NR & NR & NR \\
\hline & Placebo & 12 & $\begin{array}{l}\text { (trans- } \\
\text { lation } \\
\text { un- } \\
\text { avail- } \\
\text { able } \\
\text { at }\end{array}$ & $\begin{array}{l}\text { (translation } \\
\text { unavailable } \\
\text { at } \\
\text { present) }\end{array}$ & $\begin{array}{l}\text { (translation un- } \\
\text { available at } \\
\text { present) }\end{array}$ & $\begin{array}{l}\text { (trans- } \\
\text { lation } \\
\text { un- } \\
\text { avail- } \\
\text { able } \\
\text { at }\end{array}$ \\
\hline & & & present) & & & present) \\
\hline \multirow{4}{*}{$\begin{array}{l}\text { Seguin } \\
2014\end{array}$} & Oropharyngeal care with povidone-iodine & 85 & $60 / 25$ & $48(19)$ & TBI: 62 & NR \\
\hline & & & & & $\begin{array}{l}\text { Cerebral haem- } \\
\text { orrhage: } 23\end{array}$ & \\
\hline & Oropharyngeal care with placebo & 82 & $64 / 18$ & $48(18)$ & TBI: 61 & NR \\
\hline & & & & & $\begin{array}{l}\text { Cerebral haem- } \\
\text { orrhage: } 21\end{array}$ & \\
\hline \multirow{4}{*}{$\begin{array}{l}\text { SOCLE } \\
\text { II }\end{array}$} & Multi-component $\mathrm{OHC}$ intervention (enhanced $\mathrm{OHC}$ ) & $\begin{array}{l}\text { Whole } \\
\text { group: }\end{array}$ & \multirow[t]{4}{*}{$165 / 160$} & \multirow{4}{*}{$\begin{array}{l}\text { Median } \\
\text { age: } 76 \\
\text { [IQR 63-83] }\end{array}$} & \multirow[t]{4}{*}{$243 / 325$ stroke } & \multirow[t]{4}{*}{ NR } \\
\hline & Usual care & $\begin{array}{l}325(243 \\
\text { stroke) } \\
\text { patients }\end{array}$ & & & & \\
\hline & & $\begin{array}{l}112 \text { nurs- } \\
\text { ing }\end{array}$ & & & & \\
\hline & & staff & & & & \\
\hline
\end{tabular}

apopulation demographics only reported for the 373 RNs who completed the trial; group labels that trialists reported in their original publication(s) are shown in brackets.

CPD: continuing professional development; IQR: interquartile range; $n$ : number of participants; NA: not applicable; NR: not reported; OHC: oral health care; OHCP: oral hygiene care programme; RN: registered nurse; SD: standard deviation; TBI: traumatic brain injury. 


\begin{tabular}{|c|c|c|c|c|c|c|c|c|}
\hline Study ID & Intervention & Training & $\begin{array}{l}\text { Tooth- } \\
\text { brush }\end{array}$ & Toothpaste & Mouth gel & Mouthwash & Protocol & Other \\
\hline \multicolumn{9}{|c|}{ Comparison group 1: oral healthcare interventions vs no treatment or usual care } \\
\hline \multirow[t]{2}{*}{$\begin{array}{l}\text { Ab Malik } \\
2017\end{array}$} & Internet-based CPD programme & $\begin{array}{l}\text { Staff train- } \\
\text { ing (special- } \\
\text { ist) com- } \\
\text { puter-aided } \\
\text { learning }\end{array}$ & - & - & - & - & - & - \\
\hline & $\begin{array}{l}\text { Internet-based CPD programme (not spe- } \\
\text { cific to oral hygiene) }\end{array}$ & $\begin{array}{l}\text { Brief com- } \\
\text { puter-aided } \\
\text { learning }\end{array}$ & - & - & - & - & - & - \\
\hline \multirow[t]{2}{*}{ Fields 2008} & $\begin{array}{l}\text { Multi-component } \mathrm{OHC} \text { intervention (OHC } \\
\text { and timed toothbrushing in care bundle) }\end{array}$ & $\begin{array}{l}\text { Staff train- } \\
\text { ing }\end{array}$ & $\begin{array}{l}\text { Manu- } \\
\text { al (new } \\
\text { tooth- } \\
\text { brush for } \\
\text { each ses- } \\
\text { sion) }\end{array}$ & Yes & - & - & $\begin{array}{l}\text { Laminated } \\
\text { care with } \\
\text { basic in- } \\
\text { structions }\end{array}$ & $\begin{array}{l}\text { Toothette (foam } \\
\text { swab), lip mois- } \\
\text { turiser }\end{array}$ \\
\hline & Usual care & - & $\begin{array}{l}\text { Manual } \\
\text { (kit had } \\
2 \text { tooth- } \\
\text { brushes) }\end{array}$ & - & - & - & - & $\begin{array}{l}\text { Toothette (foam } \\
\text { swab), lip mois- } \\
\text { turiser as re- } \\
\text { quired }\end{array}$ \\
\hline \multirow[t]{2}{*}{ Frenkel 2001} & $\begin{array}{l}\text { Multi-component } \mathrm{OHC} \text { intervention (work- } \\
\text { place } \mathrm{OHC} \text { training session) }\end{array}$ & $\begin{array}{l}\text { Staff train- } \\
\text { ing }\end{array}$ & Manual & - & - & - & - & $\begin{array}{l}\text { Booklet, teach- } \\
\text { ing aids and mod- } \\
\text { els, course atten- } \\
\text { dance certificate }\end{array}$ \\
\hline & Usual care & $\begin{array}{l}\text { Health edu- } \\
\text { cation pro- } \\
\text { gramme de- } \\
\text { livered after } \\
\text { completion } \\
\text { of data col- } \\
\text { lection }\end{array}$ & - & - & - & - & - & - \\
\hline $\begin{array}{l}\text { Juthani- } \\
\text { Mehta } 2015\end{array}$ & Multi-component $\mathrm{OHC}$ intervention & $\begin{array}{l}\text { Staff train- } \\
\text { ing }\end{array}$ & Manual & - & - & $\begin{array}{l}0.12 \% \\
\text { chlorhexi- }\end{array}$ & - & $\begin{array}{l}\text { Upright position- } \\
\text { ing during feed- } \\
\text { ing }\end{array}$ \\
\hline
\end{tabular}


Table 3. Summary of intervention components across comparison groups (Continued)

dene oral

rinse

\begin{tabular}{|c|c|c|c|c|c|c|c|c|}
\hline & Usual care & - & - & - & - & - & - & - \\
\hline \multirow[t]{2}{*}{ Kim 2014a } & $\begin{array}{l}\text { Multi-component } \mathrm{OHC} \text { intervention (oral } \\
\text { hygienic care programme) }\end{array}$ & - & $\begin{array}{l}\text { Children's } \\
\text { manu- } \\
\text { al tooth- } \\
\text { brush and } \\
\text { interden- } \\
\text { tal tooth- } \\
\text { brush }\end{array}$ & & & $\begin{array}{l}0.5 \% \\
\text { chlorhexi- } \\
\text { dine }\end{array}$ & - & $\begin{array}{l}\text { Tongue cleaner, } \\
\text { mouth gag, suc- } \\
\text { tion }\end{array}$ \\
\hline & Usual care & - & - & - & - & - & - & - \\
\hline \multirow[t]{2}{*}{ Kuo 2016} & $\begin{array}{l}\text { Multi-component } \mathrm{OHC} \text { intervention } \\
\text { (home-based oral care programme) }\end{array}$ & $\begin{array}{l}\text { Staff train- } \\
\text { ing }\end{array}$ & $\begin{array}{l}\text { Finger } \\
\text { tooth- } \\
\text { brush }\end{array}$ & - & - & - & - & $\begin{array}{l}\text { Tongue cleaner, } \\
\text { educational pam- } \\
\text { phlets, daily re- } \\
\text { minder sheets }\end{array}$ \\
\hline & Usual care & $\begin{array}{l}\text { Encouraged } \\
\text { to main- } \\
\text { tain routine } \\
\text { practices }\end{array}$ & - & - & - & - & - & $\begin{array}{l}\text { OHC could in- } \\
\text { clude oral clean- } \\
\text { ing with oral } \\
\text { swabs }\end{array}$ \\
\hline \multirow[t]{2}{*}{ SOCLE II } & $\begin{array}{l}\text { Multi-component } \mathrm{OHC} \text { intervention (en- } \\
\text { hanced } \mathrm{OHC} \text { ) }\end{array}$ & $\begin{array}{l}\text { Staff train- } \\
\text { ing }\end{array}$ & Manual & Yes & $\begin{array}{l}\text { Oral balance } \\
\text { gel }\end{array}$ & Yes & Yes & $\begin{array}{l}\text { Stroke-specific } \\
\text { assessment tool, } \\
\text { foam swab, in- } \\
\text { formation sheet, } \\
\text { suction, denture } \\
\text { making kit }\end{array}$ \\
\hline & Usual care & No training & Varied & Varied & Varied & Varied & - & Foam swab \\
\hline
\end{tabular}

Comparison group 2: oral healthcare interventions vs placebo interventions

Gosney 2006 OHC gel (selective decontamination of digestive tract oral gel)

Orabase 500

mg gel (con-

taining $2 \%$

(w/v) col-

istin, $2 \%(w /$

v) polymyx-

in $\mathrm{E}, 2 \%(\mathrm{w} /$ 


\begin{tabular}{|c|c|c|c|c|c|c|c|c|}
\hline & & & & & $\begin{array}{l}\text { v) ampho- } \\
\text { tericin B }\end{array}$ & & & \\
\hline & Placebo gel & - & - & - & $\begin{array}{l}\text { Placebo gel } \\
500 \mathrm{mg}\end{array}$ & - & - & - \\
\hline \multirow[t]{2}{*}{ Lee 2011} & Saengmaeg-san extract & - & - & - & - & - & - & $\begin{array}{l}\text { Saengmaeg-san } \\
\text { extract given in } \\
\text { opaque capsules }\end{array}$ \\
\hline & Placebo & - & - & - & - & - & - & $\begin{array}{l}\text { Placebo given in } \\
\text { opaque capsules }\end{array}$ \\
\hline \multirow[t]{2}{*}{ Seguin 2014} & $\begin{array}{l}\text { Povidone-iodine (oropharyngeal care with } \\
\text { povidone-iodine) }\end{array}$ & $\begin{array}{l}\text { All nurses } \\
\text { were trained } \\
\text { in the oral } \\
\text { procedure. } \\
\text { Film de- } \\
\text { scribing in } \\
\text { detail the } \\
\text { oral care } \\
\text { procedure } \\
\text { was made } \\
\text { available to } \\
\text { all investi- } \\
\text { gators }\end{array}$ & - & - & $\begin{array}{l}\text { Povi- } \\
\text { done-iodine } \\
\text { (betadine } \\
10 \% \text { oral } \\
\text { antiseptic } \\
\text { solution; } \\
\text { Meda Phar- } \\
\text { ma, Paris, } \\
\text { France) por- } \\
\text { tioned in } \\
\text { vials con- } \\
\text { taining } 125 \\
\text { mL of prod- } \\
\text { uct and dis- } \\
\text { pensed by } \\
\text { the Pharma- } \\
\text { cy of Rennes } \\
\text { to the phar- } \\
\text { macies of } \\
\text { the partici- } \\
\text { pating cen- } \\
\text { tres }\end{array}$ & - & $\begin{array}{l}\text { Nasophar- } \\
\text { ynx and } \\
\text { oropharynx } \\
\text { rinsing, reg- } \\
\text { ular suction, } \\
\text { cuffed tra- } \\
\text { cheal tube } \\
\text { pressure } \\
\text { checked and } \\
\text { adjusted as } \\
\text { required }\end{array}$ & - \\
\hline & $\begin{array}{l}\text { Placebo (oropharyngeal care with place- } \\
\text { bo) }\end{array}$ & As above & - & - & $\begin{array}{l}\text { Placebo } \\
\text { were por- } \\
\text { tioned in } \\
\text { vials con- } \\
\text { taining } 125 \\
\mathrm{~mL} \text { of prod- } \\
\text { uct and dis- } \\
\text { pensed by } \\
\text { the Pharma- }\end{array}$ & - & As above & - \\
\hline
\end{tabular}




\begin{tabular}{|c|c|c|c|c|c|c|c|c|}
\hline & & & & & $\begin{array}{l}\text { cy of Renne } \\
\text { to the phar } \\
\text { macies of } \\
\text { the partici- } \\
\text { pating cen- } \\
\text { tres }\end{array}$ & & & \\
\hline \multicolumn{9}{|c|}{ Comparison group 3: oral healthcare interventions vs another oral healthcare intervention } \\
\hline \multirow[t]{2}{*}{$\begin{array}{l}\text { Ab Malik } \\
2018\end{array}$} & $\begin{array}{l}\text { Multi-component } \mathrm{OHC} \text { intervention (in- } \\
\text { tense method for plaque control) }\end{array}$ & $\begin{array}{l}\text { Patient (in- } \\
\text { dividual) } \\
\text { training }\end{array}$ & $\begin{array}{l}\text { Powered } \\
\text { (Oral B } \\
\text { Pro-Health } \\
\text { DB4010) }\end{array}$ & - & $\begin{array}{l}1 \% \\
\text { chlorhex- } \\
\text { idine glu- } \\
\text { conate gel }\end{array}$ & - & - & $\begin{array}{l}\text { Plastic tooth } \\
\text { model, a pam- } \\
\text { phlet on tooth } \\
\text { brushing tech- } \\
\text { niques }\end{array}$ \\
\hline & $\begin{array}{l}\text { Multi-component } \mathrm{OHC} \text { intervention (con- } \\
\text { ventional method for plaque control) }\end{array}$ & As above & $\begin{array}{l}\text { Manual } \\
\text { (Oral-B su- } \\
\text { per thin } \\
\text { and extra } \\
\text { soft bris- } \\
\text { tles tooth- } \\
\text { brush) }\end{array}$ & Commercial & - & - & - & - \\
\hline \multirow[t]{3}{*}{ Chipps 2014} & $\begin{array}{l}\text { Multi-component } \mathrm{OHC} \text { intervention (en- } \\
\text { hanced oral care protocol) }\end{array}$ & $\begin{array}{l}\text { Staff train- } \\
\text { ing }\end{array}$ & Powered & $\begin{array}{l}\text { Crest-Pro- } \\
\text { Health } \\
\text { toothpaste }\end{array}$ & - & Listerine & - & $\begin{array}{l}\text { Glide disposable } \\
\text { floss picks, Sun- } \\
\text { star dual action } \\
\text { tongue cleaner, } \\
\text { Carmex lip balm }\end{array}$ \\
\hline & $\begin{array}{l}\text { Multi-component } \mathrm{OHC} \text { intervention (rou- } \\
\text { tine oral care protocol) }\end{array}$ & As above & Manual & $\begin{array}{l}\text { Sage Oral } \\
\text { Care Sodi- } \\
\text { um }\end{array}$ & - & $\begin{array}{l}\text { Careline al- } \\
\text { cohol-free } \\
\text { mouthwash }\end{array}$ & - & $\begin{array}{l}\text { Regular Chaplet } \\
\text { lip balm }\end{array}$ \\
\hline & & & & $\begin{array}{l}\text { Bicarbonate } \\
\text { Mouthpaste }\end{array}$ & & & & \\
\hline Dai 2017 & $\begin{array}{l}\text { Multi-component } \mathrm{OHC} \text { intervention (ad- } \\
\text { vanced oral hygiene care programme) }\end{array}$ & $\begin{array}{l}\text { Patients: } \\
\text { oral hygiene } \\
\text { training }\end{array}$ & $\begin{array}{l}\text { Powered } \\
\text { (Oral-B } \\
\text { Advance- } \\
\text { PowerTM } \\
400 \text { series) }\end{array}$ & $\begin{array}{l}\text { Standard- } \\
\text { ised tooth- } \\
\text { paste (Col- } \\
\text { gate Maxi- } \\
\text { mum Cavity } \\
\text { Protection) }\end{array}$ & - & $\begin{array}{l}0.2 \% \\
\text { chlorhex- } \\
\text { idine glu- } \\
\text { conate } \\
\text { mouth rinse } \\
\text { Corsodyl }\end{array}$ & - & $\begin{array}{l}\text { Information } \\
\text { sheet: oral hy- } \\
\text { giene pamphlet }\end{array}$ \\
\hline
\end{tabular}




\begin{tabular}{|c|c|c|c|c|c|c|c|c|}
\hline & $\begin{array}{l}\text { Multi-component } \mathrm{OHC} \text { intervention (con- } \\
\text { ventional oral hygiene programme) }\end{array}$ & As above & $\begin{array}{l}\text { Manual } \\
\text { (Oral-B } \\
\text { Pro-Health } \\
\text { All-In-One) }\end{array}$ & As above & - & - & - & - \\
\hline \multirow[t]{2}{*}{$\begin{array}{l}\text { Kobayashi } \\
2017 i\end{array}$} & $\begin{array}{l}\text { Multi-component } \mathrm{OHC} \text { intervention } \\
\text { (mouthwash and moisturising gel) }\end{array}$ & - & $\begin{array}{l}\text { Manual } \\
\text { (Dent Ex) }\end{array}$ & - & $\begin{array}{l}\text { Mouth gel (1 } \\
\text { g containing } \\
\text { glycerine, } \\
\text { lactoferrin } \\
\text { and whey } \\
\text { protein) }\end{array}$ & $\begin{array}{l}\text { Mouth wash } \\
\text { (contained } \\
\text { cetylpyri- } \\
\text { dinium chlo- } \\
\text { ride) }\end{array}$ & - & $\begin{array}{l}\text { Tongue brush, } \\
\text { water, Elastomer- } \\
\text { ic tongue scraper }\end{array}$ \\
\hline & $\begin{array}{l}\text { Multi-component OHC intervention } \\
\text { (mouthwash) }\end{array}$ & - & $\begin{array}{l}\text { Manual } \\
\text { (Dent Ex) }\end{array}$ & - & - & $\begin{array}{l}\text { Mouth wash } \\
\text { (contained } \\
\text { cetylpyri- } \\
\text { dinium chlo- } \\
\text { ride) }\end{array}$ & - & Tongue brush \\
\hline \multirow[t]{2}{*}{$\begin{array}{l}\text { Kobayashi } \\
\text { 2017ii }\end{array}$} & $\begin{array}{l}\text { Multi-component } \mathrm{OHC} \text { intervention } \\
\text { (mouthwash and gel) }\end{array}$ & - & $\begin{array}{l}\text { Manual } \\
\text { (Dent Ex) }\end{array}$ & - & $\begin{array}{l}\text { Mouth gel (1 } \\
\text { g containing } \\
\text { glycerine, } \\
\text { lactoferrin } \\
\text { and whey } \\
\text { protein) }\end{array}$ & $\begin{array}{l}\text { Mouth wash } \\
\text { (contained } \\
\text { cetylpyri- } \\
\text { dinium chlo- } \\
\text { ride) }\end{array}$ & - & $\begin{array}{l}\text { Tongue brush, } \\
\text { water, Elastomer- } \\
\text { ic tongue scraper }\end{array}$ \\
\hline & $\begin{array}{l}\text { Multi-component } \mathrm{OHC} \text { intervention (water } \\
\text { and moisturising gel) }\end{array}$ & - & $\begin{array}{l}\text { Manual } \\
\text { (Dent Ex }\end{array}$ & - & $\begin{array}{l}\text { Mouth gel (1 } \\
\text { g containing } \\
\text { glycerine, } \\
\text { lactoferrin } \\
\text { and whey } \\
\text { protein) }\end{array}$ & - & - & $\begin{array}{l}\text { Tongue brush, } \\
\text { water, Elastomer- } \\
\text { ic tongue scraper }\end{array}$ \\
\hline \multirow[t]{2}{*}{$\begin{array}{l}\text { Kobayashi } \\
\text { 2017iii }\end{array}$} & $\begin{array}{l}\text { Multi-component } \mathrm{OHC} \text { intervention } \\
\text { (mouthwash and gel) }\end{array}$ & - & $\begin{array}{l}\text { Manual } \\
\text { (Dent Ex) }\end{array}$ & - & $\begin{array}{l}\text { Mouth gel (1 } \\
\text { g containing } \\
\text { glycerine, } \\
\text { lactoferrin } \\
\text { and whey } \\
\text { protein) }\end{array}$ & $\begin{array}{l}\text { Mouthwash } \\
\text { (contained } \\
\text { cetylpyri- } \\
\text { dinium chlo- } \\
\text { ride) }\end{array}$ & - & $\begin{array}{l}\text { Tongue brush, } \\
\text { water, Elastomer- } \\
\text { ic tongue scraper }\end{array}$ \\
\hline & $\begin{array}{l}\text { Multi-component } \mathrm{OHC} \text { intervention (water } \\
\text { alone) }\end{array}$ & - & $\begin{array}{l}\text { Manual } \\
\text { (Dent Ex) }\end{array}$ & - & - & - & - & $\begin{array}{l}\text { Tongue brush, } \\
\text { water }\end{array}$ \\
\hline
\end{tabular}




\begin{tabular}{|c|c|c|c|c|c|c|c|c|}
\hline $\begin{array}{l}\text { Kobayashi } \\
\text { 2017iv }\end{array}$ & $\begin{array}{l}\text { Multi-component } \mathrm{OHC} \text { intervention } \\
\text { (mouthwash) }\end{array}$ & - & $\begin{array}{l}\text { Manual } \\
\text { (Dent Ex) }\end{array}$ & - & - & $\begin{array}{l}\text { Mouthwash } \\
\text { (contained } \\
\text { cetylpyri- } \\
\text { dinium chlo- } \\
\text { ride) }\end{array}$ & - & Tongue brush \\
\hline & $\begin{array}{l}\text { Multi-component } \mathrm{OHC} \text { intervention (water } \\
\text { and moisturising gel) }\end{array}$ & - & $\begin{array}{l}\text { Manual } \\
\text { (Dent Ex }\end{array}$ & - & $\begin{array}{l}\text { Mouth gel (1 } \\
\text { g containing } \\
\text { glycerine, } \\
\text { lactoferrin } \\
\text { and whey } \\
\text { protein) }\end{array}$ & - & - & $\begin{array}{l}\text { Tongue brush, } \\
\text { water, Elastomer- } \\
\text { ic tongue scraper }\end{array}$ \\
\hline $\begin{array}{l}\text { Kobayashi } \\
2017 v\end{array}$ & $\begin{array}{l}\text { Multi-component OHC intervention } \\
\text { (mouthwash) }\end{array}$ & - & $\begin{array}{l}\text { Manual } \\
\text { (Dent Ex) }\end{array}$ & - & - & $\begin{array}{l}\text { Mouthwash } \\
\text { (contained } \\
\text { cetylpyri- } \\
\text { dinium chlo- } \\
\text { ride) }\end{array}$ & - & Tongue brush \\
\hline & $\begin{array}{l}\text { Multi-component } \mathrm{OHC} \text { intervention (water } \\
\text { alone) }\end{array}$ & - & $\begin{array}{l}\text { Manual } \\
\text { (Dent Ex) }\end{array}$ & - & - & - & - & $\begin{array}{l}\text { Tongue brush, } \\
\text { water }\end{array}$ \\
\hline $\begin{array}{l}\text { Kobayashi } \\
\text { 2017vi }\end{array}$ & $\begin{array}{l}\text { Multi-component } \mathrm{OHC} \text { intervention (water } \\
\text { and moisturising gel) }\end{array}$ & - & $\begin{array}{l}\text { Manual } \\
\text { (Dent Ex) }\end{array}$ & - & $\begin{array}{l}\text { Mouth gel (1 } \\
\text { g containing } \\
\text { glycerine, } \\
\text { lactoferrin } \\
\text { and whey } \\
\text { protein) }\end{array}$ & - & - & $\begin{array}{l}\text { Tongue brush, } \\
\text { water, Elastomer- } \\
\text { ic tongue scraper }\end{array}$ \\
\hline & $\begin{array}{l}\text { Multi-component } \mathrm{OHC} \text { intervention (water } \\
\text { alone) }\end{array}$ & - & $\begin{array}{l}\text { Manual } \\
\text { (Dent Ex) }\end{array}$ & - & - & - & - & $\begin{array}{l}\text { Tongue brush, } \\
\text { water }\end{array}$ \\
\hline Lam 2013i & $\begin{array}{l}\text { Multi-component } \mathrm{OHC} \text { intervention (oral } \\
\text { hygiene instruction, mouthrinse, and as- } \\
\text { sisted brushing) }\end{array}$ & $\begin{array}{l}\text { Staff train- } \\
\text { ing }\end{array}$ & $\begin{array}{l}\text { Powered } \\
\text { (dentures } \\
\text { cleaned } \\
\text { with man- } \\
\text { ual tooth- } \\
\text { brush) }\end{array}$ & $\begin{array}{l}\text { Standard } \\
\text { (sodium flu- } \\
\text { oride) }\end{array}$ & - & $\begin{array}{l}\text { Chlorhexi- } \\
\text { dine (Cor- } \\
\text { sodyl) } \\
\text { mouthrinse } \\
(0.2 \%, 10 \\
\mathrm{mL})\end{array}$ & - & $\begin{array}{l}\text { Assisted brushing } \\
\text { (hand-over-hand) }\end{array}$ \\
\hline & $\begin{array}{l}\text { Multi-component } \mathrm{OHC} \text { intervention (oral } \\
\text { hygiene instruction, mouthrinse) }\end{array}$ & As above & $\begin{array}{l}\text { Powered } \\
\text { (dentures } \\
\text { cleaned } \\
\text { with man- }\end{array}$ & $\begin{array}{l}\text { Standard } \\
\text { (sodium flu- } \\
\text { oride) }\end{array}$ & - & $\begin{array}{l}\text { Chlorhexi- } \\
\text { dine (Cor- } \\
\text { sodyl) } \\
\text { mouthrinse }\end{array}$ & - & - \\
\hline
\end{tabular}




\begin{tabular}{|c|c|c|c|c|c|c|c|c|}
\hline & & & $\begin{array}{l}\text { ual tooth- } \\
\text { brush) }\end{array}$ & & & $\begin{array}{l}(0.2 \%, 10 \\
\mathrm{mL})\end{array}$ & & \\
\hline \multirow[t]{2}{*}{ Lam 2013ii } & $\begin{array}{l}\text { Multi-component } \mathrm{OHC} \text { intervention (oral } \\
\text { hygiene instruction, mouthrinse, and as- } \\
\text { sisted brushing) }\end{array}$ & $\begin{array}{l}\text { Staff train- } \\
\text { ing }\end{array}$ & $\begin{array}{l}\text { Powered } \\
\text { (dentures } \\
\text { cleaned } \\
\text { with man- } \\
\text { ual tooth- } \\
\text { brush) }\end{array}$ & $\begin{array}{l}\text { Standard } \\
\text { (sodium flu- } \\
\text { oride) }\end{array}$ & - & $\begin{array}{l}\text { Chlorhexi- } \\
\text { dine (Cor- } \\
\text { sodyl) } \\
\text { mouthrinse } \\
(0.2 \%, 10 \\
\mathrm{mL})\end{array}$ & - & $\begin{array}{l}\text { Assisted brushing } \\
\text { (hand-over-hand) }\end{array}$ \\
\hline & $\begin{array}{l}\text { Multi-component } \mathrm{OHC} \text { intervention (oral } \\
\text { hygiene instruction) }\end{array}$ & As above & $\begin{array}{l}\text { Powered } \\
\text { (dentures } \\
\text { cleaned } \\
\text { with man- } \\
\text { ual tooth- } \\
\text { brush) }\end{array}$ & $\begin{array}{l}\text { Standard } \\
\text { (sodium flu- } \\
\text { oride) }\end{array}$ & - & - & - & - \\
\hline \multirow[t]{2}{*}{ Lam 2013iii } & $\begin{array}{l}\text { Multi-component } \mathrm{OHC} \text { intervention (oral } \\
\text { hygiene instruction, mouthrinse) }\end{array}$ & $\begin{array}{l}\text { Staff train- } \\
\text { ing }\end{array}$ & $\begin{array}{l}\text { Powered } \\
\text { (dentures } \\
\text { cleaned } \\
\text { with man- } \\
\text { ual tooth- } \\
\text { brush) }\end{array}$ & $\begin{array}{l}\text { Standard } \\
\text { (sodium flu- } \\
\text { oride) }\end{array}$ & - & $\begin{array}{l}\text { Chlorhexi- } \\
\text { dine (Cor- } \\
\text { sodyl) } \\
\text { mouthrinse } \\
(0.2 \%, 10 \\
\mathrm{mL})\end{array}$ & - & - \\
\hline & $\begin{array}{l}\text { Multi-component } \mathrm{OHC} \text { intervention (oral } \\
\text { hygiene instruction) }\end{array}$ & As above & $\begin{array}{l}\text { Powered } \\
\text { (dentures } \\
\text { cleaned } \\
\text { with man- } \\
\text { ual tooth- } \\
\text { brush) }\end{array}$ & $\begin{array}{l}\text { Standard } \\
\text { (sodium flu- } \\
\text { oride) }\end{array}$ & - & - & - & - \\
\hline
\end{tabular}

Note: group labels that trialists used are shown in brackets.

CPD: continuing professional development; $\mathrm{OHC}$ : oral health care; w/v: weight/volume.

\section{Table 4. Outcome measures within included studies}

Study ID Primary outcomes Secondary outcomes




\begin{tabular}{|c|c|c|c|c|c|c|c|c|}
\hline & $\begin{array}{l}\text { Dental } \\
\text { plaque }\end{array}$ & $\begin{array}{l}\text { Denture } \\
\text { plaque }\end{array}$ & $\begin{array}{l}\text { Patient sat- } \\
\text { isfaction }\end{array}$ & $\begin{array}{l}\text { Presence of } \\
\text { oral disease }\end{array}$ & $\begin{array}{l}\text { Presence of related infec- } \\
\text { tion and oral opportunistic } \\
\text { pathogens }\end{array}$ & $\begin{array}{l}\text { Staff } \\
\text { oral } \\
\text { health } \\
\text { knowl- } \\
\text { edge } \\
\text { and atti- } \\
\text { tudes }\end{array}$ & & \\
\hline $\begin{array}{l}\text { Ab Malik } \\
2017\end{array}$ & - & - & - & - & - & $\begin{array}{l}\text { Self-ad- } \\
\text { minis- } \\
\text { tered } \\
\text { ques- } \\
\text { tionnaire } \\
\text { based on } \\
\text { theory of } \\
\text { planned } \\
\text { behav- } \\
\text { iour. } \\
5 \text { do- } \\
\text { mains: } \\
\text { attitude, } \\
\text { sub- } \\
\text { jective } \\
\text { norm, } \\
\text { per- } \\
\text { ceived } \\
\text { behav- } \\
\text { iour con- } \\
\text { trol, } \\
\text { gener- } \\
\text { al inten- } \\
\text { tion and } \\
\text { knowl- } \\
\text { edge re- } \\
\text { lated to } \\
\text { provid- } \\
\text { ing OHC }\end{array}$ & - & - \\
\hline $\begin{array}{l}\text { Ab Malik } \\
2018\end{array}$ & $\begin{array}{l}\text { Dental } \\
\text { Plaque In- } \\
\text { dex (Silness } \\
\text { and Loe) }\end{array}$ & - & - & - & $\begin{array}{l}\text { Oral prevalence of Candida and } \\
\text { yeast, } S \text { aureus, AGNB }\end{array}$ & - & - & $\begin{array}{l}\text { Presence and type of dental } \\
\text { prosthesis; modified BI; MMSE }\end{array}$ \\
\hline Chipps 2014 & - & - & - & - & $\begin{array}{l}\text { Nasal and oral pharyngeal cul- } \\
\text { tures for S aureus }\end{array}$ & - & - & $\begin{array}{l}\text { R-THROAT assessment;Mann } \\
\text { Assessment of swallowing }\end{array}$ \\
\hline
\end{tabular}




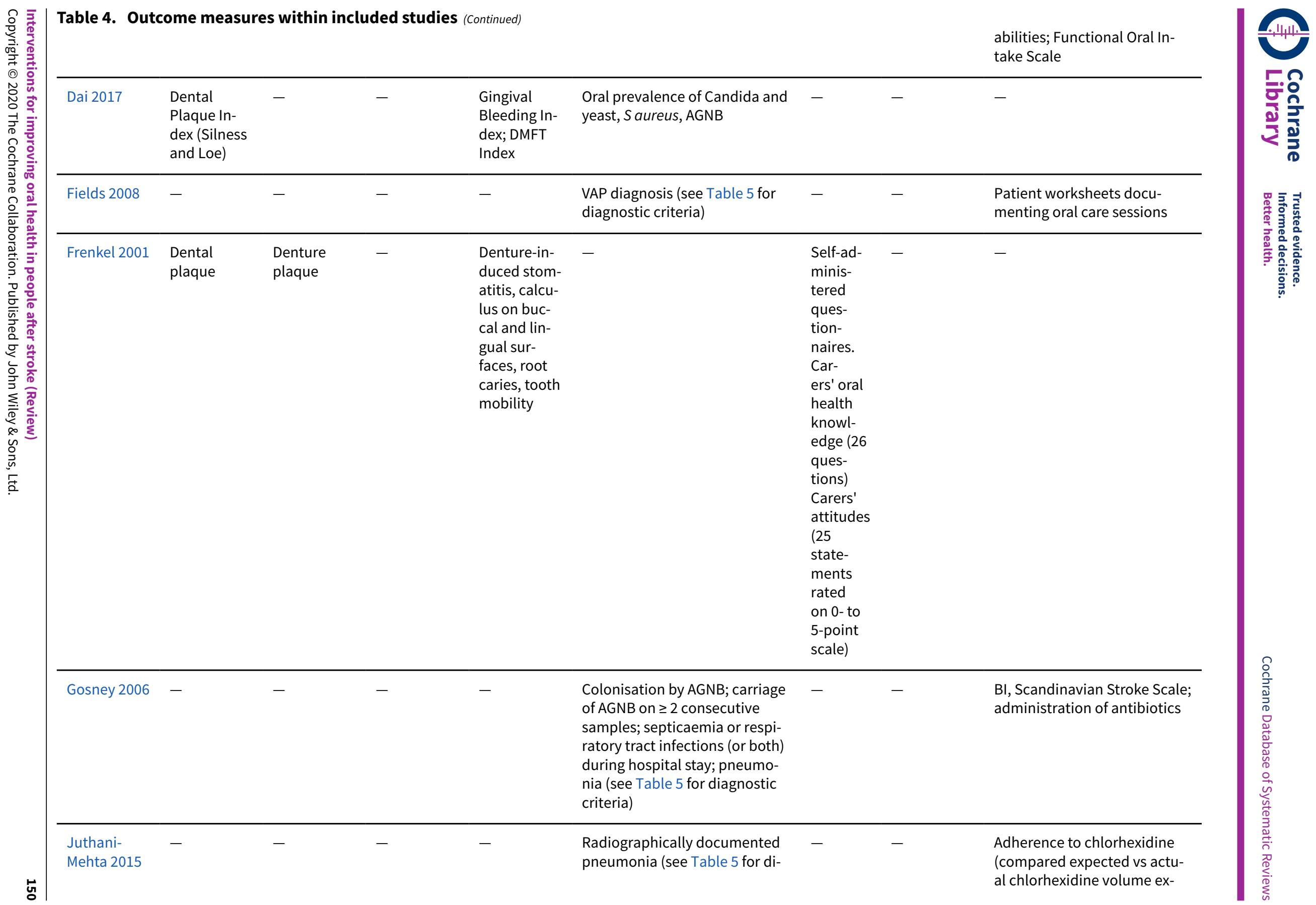




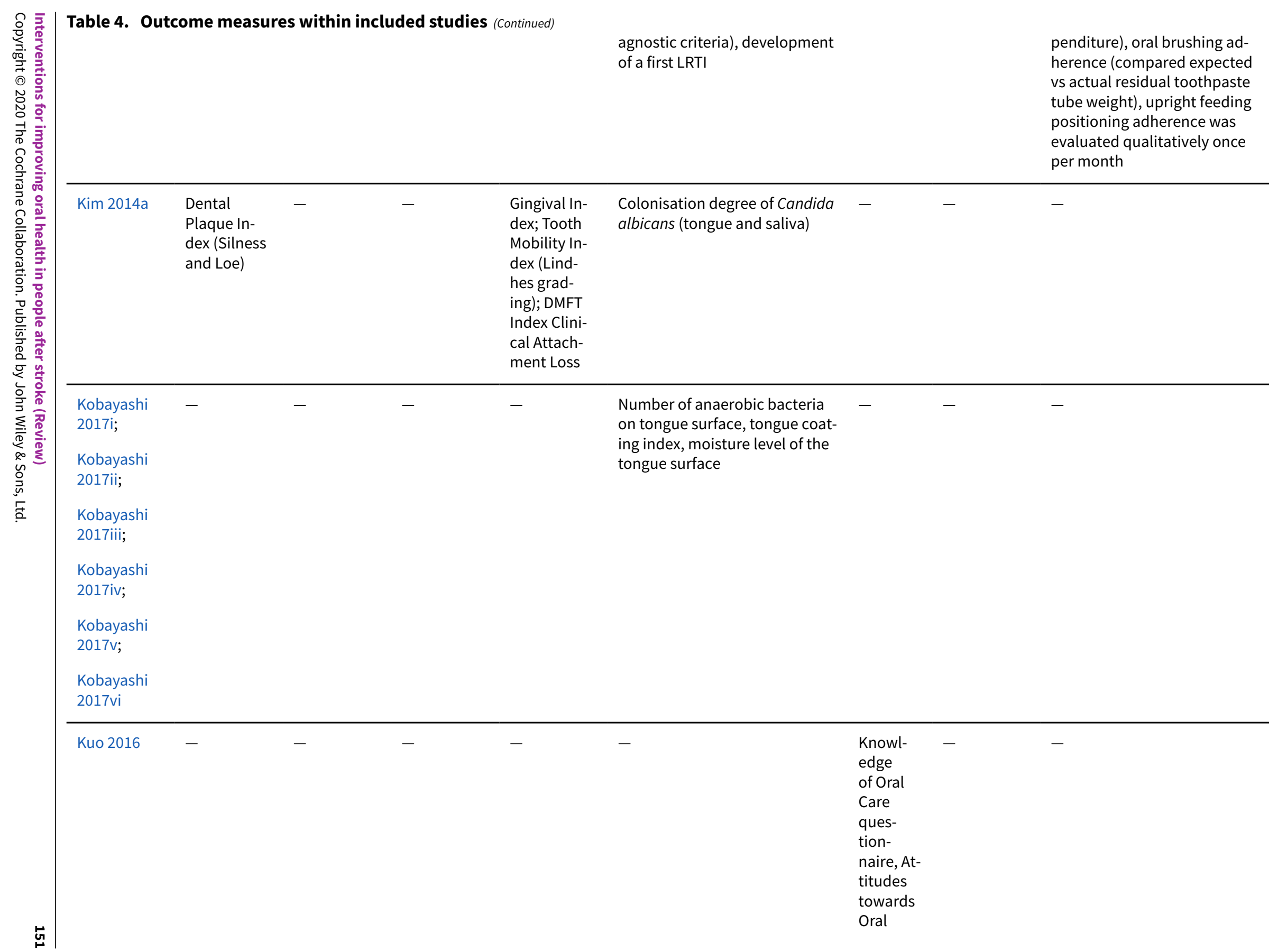




\begin{tabular}{|c|c|c|c|c|c|c|c|}
\hline & & & & 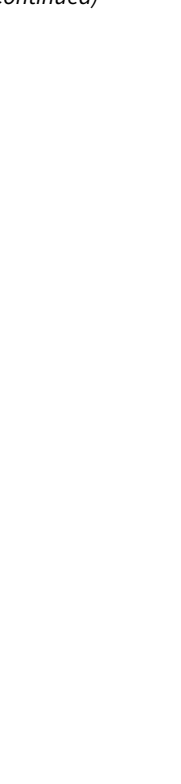 & & \multicolumn{2}{|l|}{$\begin{array}{l}\text { Care } \\
\text { Ques- } \\
\text { tion- } \\
\text { naire, } \\
\text { Family } \\
\text { Caregiv- } \\
\text { er Self- } \\
\text { efficacy } \\
\text { of Oral } \\
\text { Care } \\
\text { (Self-E) } \\
\text { Ques- } \\
\text { tion- } \\
\text { naire, } \\
\text { Behav- } \\
\text { iour of } \\
\text { Oral } \\
\text { Care } \\
\text { Ques- } \\
\text { tionnaire }\end{array}$} \\
\hline $\begin{array}{l}\text { Lam 2013i; } \\
\text { Lam 2013ii; } \\
\text { Lam 2013iii }\end{array}$ & $\begin{array}{l}\text { Dental } \\
\text { Plaque In- } \\
\text { dex (Silness } \\
\text { and Loe) }\end{array}$ & - & $\begin{array}{l}\text { Patient sat- } \\
\text { isfaction } \\
\text { with inter- } \\
\text { ventions } \\
\text { and condi- } \\
\text { tion of their } \\
\text { mouth using } \\
\text { a rated scale } \\
(1=\text { totally } \\
\text { satisfied to } \\
5=\text { not at all } \\
\text { satisfied) }\end{array}$ & $\begin{array}{l}\text { Gingival } \\
\text { Bleeding In- } \\
\text { dex }\end{array}$ & $\begin{array}{l}\text { Medical chart review at end of } \\
\text { trial for development of infec- } \\
\text { tious complications including } \\
\text { pneumonia (see Table } 5 \text { for di- } \\
\text { agnostic criteria), oral preva- } \\
\text { lence of Candida and yeast, } S \\
\text { aureus, AGNB }\end{array}$ & - & $\begin{array}{l}\text { BI, Royal Brisbane Hospital } \\
\text { Outcome measure for swal- } \\
\text { lowing, oral functional sta- } \\
\text { tus questions (ability to brush } \\
\text { teeth and insert/remove den- } \\
\text { tures) } \\
\text { Medical chart review at end of } \\
\text { clinical trial for medications } \\
\text { taken throughout the study }\end{array}$ \\
\hline Lee 2011 & - & - & $\begin{array}{l}\text { VAS to eval- } \\
\text { uate subjec- } \\
\text { tive oral dry- } \\
\text { ness (dry in } \\
\text { night/morn- } \\
\text { ing, dry in } \\
\text { daytime, dry } \\
\text { while eating } \\
\text { a meal, hard } \\
\text { to swallow } \\
\text { food, lack of }\end{array}$ & - & - & - & - \\
\hline
\end{tabular}




\begin{tabular}{|c|c|c|c|c|c|c|c|c|}
\hline & & & $\begin{array}{l}\text { saliva, gen- } \\
\text { eral discom- } \\
\text { fort) }\end{array}$ & & & & & \\
\hline Seguin 2014 & - & - & $\begin{array}{l}\text { Tolerance of } \\
\text { oral proce- } \\
\text { dure }\end{array}$ & - & $\begin{array}{l}\text { Rate of VAP (American Thoracic } \\
\text { Society } 2005 \text { guidelines) (see } \\
\text { Table } 5 \text { for diagnostic criteria), } \\
\text { delay of other VAP occurrence, } \\
\text { rate of VAP (early vs late), mi- } \\
\text { cro-organisms involved, rates } \\
\text { of ventilator-associated tra- } \\
\text { cheobronchitis, other nosoco- } \\
\text { mial infections }\end{array}$ & - & - & $\begin{array}{l}\text { Number of ventilation-free } \\
\text { days, length of stay (in ICU, in } \\
\text { hospital), mortality (in ICU, at } \\
\text { day 90), bacterial colonisation } \\
\text { follow-up (oropharyngeal and } \\
\text { tracheal swabs) in subgroup } \\
\text { of patients }\end{array}$ \\
\hline SOCLE II & $\begin{array}{l}\text { Dental } \\
\text { Plaque In- } \\
\text { dex (Silness } \\
\text { and Loe) }\end{array}$ & $\begin{array}{l}\text { Denture } \\
\text { plaque }\end{array}$ & $\begin{array}{l}\text { Oral Health } \\
\text { Impact Pro- } \\
\text { file }\end{array}$ & - & $\begin{array}{l}\text { Pneumonia (Mann Chest crite- } \\
\text { ria) (see Table } 5 \text { for diagnostic } \\
\text { criteria) }\end{array}$ & $\begin{array}{l}\text { Knowl- } \\
\text { edge } \\
\text { and at- } \\
\text { titudes } \\
\text { ques- } \\
\text { tionnaire }\end{array}$ & $\begin{array}{l}\text { Data relat- } \\
\text { ing to any } \\
\text { interven- } \\
\text { tion adverse } \\
\text { even report- } \\
\text { ed by pa- } \\
\text { tient/car- } \\
\text { er/health- } \\
\text { care staff/ } \\
\text { researcher } \\
\text { (e.g. bro- } \\
\text { ken or miss- } \\
\text { ing den- } \\
\text { tures) were } \\
\text { recorded }\end{array}$ & $\begin{array}{l}\text { Length of hospital stay, death, } \\
\text { use of antibiotics, OHC proto- } \\
\text { col adherence, documented } \\
\text { OHC assessment, document- } \\
\text { ed OHC plan, OHC equipment } \\
\text { and product use, referrals } \\
\text { to dental support (urgent } \\
\text { and non-urgent), use of OHC } \\
\text { equipment and procedures, } \\
\text { economic outcomes. } \\
\text { Feasibility and implementa- } \\
\text { tion: focus groups }\end{array}$ \\
\hline
\end{tabular}

AGNB: aerobic and facultative Gram-negative bacilli; BI: Barthel Index; DMFT Index: Decayed Missing and Filled Teeth Index; LRTI: lower respiratory tract infection; OHC: oral health care; MMSE: Mini-Mental State Examination; PI: Plaque Index; R-THROAT: revised THROAT oral assessment tool; S aureus: Staphylococcus aureus; VAP: ventilator-associated pneumonia; VAS: visual analogue scale. 
Table 5. Criteria used to diagnose pneumonia

\begin{tabular}{|c|c|c|}
\hline Studies & Description of criteria used to diagnose criteria & Diagnosed by? \\
\hline Fields 2008 & $\begin{array}{l}\text { Based on } \geq 1 \text { finding, such as a new or persistent infiltrate on chest x-ray, an organ- } \\
\text { ism isolated on sputum, or pleural fluid or a positive culture from a broncho-alve- } \\
\text { olar lavage. VAP diagnosis could also be made if } 2 \text { further symptoms, (e.g. fever }> \\
38.3^{\circ} \mathrm{C} \text {, leukocytosis }\left(25 \% \text { increase and value }>10,000 \mathrm{~mm}^{3}\right) \text {, leukopenia ( } 25 \% \text { de- } \\
\text { crease and value }<5000 \mathrm{~mm}^{3} \text { ) or purulent secretions are present. }\end{array}$ & $\begin{array}{l}\text { VAP episodes were } \\
\text { tracked by the infec- } \\
\text { tion-control nurse }\end{array}$ \\
\hline Gosney 2006 & $\begin{array}{l}\text { Clinical signs and symptoms of pneumonia in medical records were accepted as ev- } \\
\text { idence of probably pneumonia. This included comments about changes on x-rays, } \\
\text { diagnosis of pneumonia, chest infection or lower respiratory tract infection being } \\
\text { recorded in the notes as well as positive sputum culture reports. }\end{array}$ & $\begin{array}{l}\text { NR (as recorded in } \\
\text { case notes) }\end{array}$ \\
\hline Juthani-Mehta 2015 & $\begin{array}{l}\text { Pneumonia diagnosis required the presence of a compatible infiltration chest x-ray } \\
\text { and } \geq 2 \text { of the following clinical features within } 72 \text { hours of the chest x-ray: fever, } \\
\text { pleuritic chest pain, respiratory rate }>25 \text { breaths per minute, worsening functional } \\
\text { status (i.e. decline in the level of consciousness or activities of daily living), or new } \\
\text { or increased cough, sputum production, shortness of breath or chest examination } \\
\text { findings. }\end{array}$ & $\begin{array}{l}\text { Quote: "Two inves- } \\
\text { tigators adjudicat- } \\
\text { ed all outcomes ... a } \\
\text { third blinded inves- } \\
\text { tigator resolved dis- } \\
\text { agreement" }\end{array}$ \\
\hline $\begin{array}{l}\text { Lam 2013i; Lam } \\
\text { 2013ii; Lam 2013iii }\end{array}$ & $\begin{array}{l}\text { Medical records were reviewed at the end of the clinical trial for development of in- } \\
\text { fectious complications including pneumonia. }\end{array}$ & $\begin{array}{l}\text { NR (as recorded in } \\
\text { case notes) }\end{array}$ \\
\hline Seguin 2014 & $\begin{array}{l}\text { VAP defined as new and persistent pulmonary infiltrates on chest } x \text {-ray, occurring } \\
\text { after } 48 \text { hours of mechanical ventilation, combined with } \geq 2 \text { of the following crite- } \\
\text { ria: purulent tracheal secretions or body core temperature }>38^{\circ} \mathrm{C} \text { or leukocytosis } \\
>10,000 \mathrm{~mm}^{3} \text { (or a combination of these) and microbiological confirmation with } \\
\text { quantitative culture from bronchoalveolar lavage or endotracheal aspirate, growing } \\
\geq 10^{4} \mathrm{cfu} / \mathrm{mL} \text { or } 10^{6} \mathrm{cfu} / \mathrm{mL} \text { " (American Thoracic Society 2005). }\end{array}$ & $\begin{array}{l}\text { Quote: "An indepen- } \\
\text { dent diagnosis val- } \\
\text { idation committee } \\
\text { composed of three } \\
\text { experienced physi- } \\
\text { cians in intensive } \\
\text { care, pneumology } \\
\text { and microbiology, } \\
\text { blindly classified } \\
\text { each patient as posi- } \\
\text { tive or negative." }\end{array}$ \\
\hline SOCLE II & $\begin{array}{l}\text { Mann criteria: chest infection was diagnosed by the attending clinician and based } \\
\text { on the presence of } \geq 3 \text { of the following variables: fever }\left(>38^{\circ} \mathrm{C}\right) \text {, productive cough } \\
\text { with purulent sputum, abnormal respiratory examination (tachypnea ( }>22 / \text { minute), } \\
\text { tachycardia, inspiratory crackles, bronchial breathing), abnormal chest x-ray, arte- } \\
\text { rial hypoxaemia ( } \mathrm{PO}_{2}<70 \mathrm{mmHg} \text { ), and isolation of a relevant pathogen (positive } \\
\text { Gram's stain and culture) (Mann 1999). }\end{array}$ & Attending physician \\
\hline
\end{tabular}

cfu: colony-forming unit; NR: not reported; VAP: ventilator-associated pneumonia.

Table 6. Details of dropouts

\begin{tabular}{|c|c|c|c|c|}
\hline Study ID & Dropouts & Reasons & Follow-up & Reasons \\
\hline \multirow[t]{2}{*}{$\begin{array}{l}\text { Ab Malik } \\
2017\end{array}$} & $\begin{array}{l}\text { OHC training (Internet-based CPD pro- } \\
\text { gramme): } 82\end{array}$ & \multirow{2}{*}{$\begin{array}{l}\text { Mostly loss to follow-up was because } \\
\text { nurses were transferred to other wards } \\
\text { or hospitals }\end{array}$} & \multirow{2}{*}{$\begin{array}{l}\text { Unclear. Dropouts } \\
\text { were only reported } \\
\text { in the CONSORT as } \\
\text { 'loss to follow-up,' } \\
\text { so we could not de- } \\
\text { termine when (i.e. } \\
\text { at 1- or 6-month fol- } \\
\text { low-up) }\end{array}$} & \multirow[t]{2}{*}{ NR } \\
\hline & $\begin{array}{l}\text { General stroke care training (Inter- } \\
\text { net-based CPD programme not specific } \\
\text { to oral hygiene): } 92\end{array}$ & & & \\
\hline
\end{tabular}


Table 6. Details of dropouts (Continued)

\begin{tabular}{|c|c|c|c|}
\hline \multirow[t]{2}{*}{$\begin{array}{l}\text { Ab Malik } \\
2018\end{array}$} & $\begin{array}{l}\text { Multi-component } \mathrm{OHC} \text { intervention } \\
\text { (intense method for plaque control): } \\
11\end{array}$ & $\begin{array}{l}2 \text { refused to continue, } 2 \text { transfers, } 3 \\
\text { died, } 1 \text { lost contact, } 3 \text { other reason (not } \\
\text { specified) }\end{array}$ & $\begin{array}{l}\text { At 6-month fol- } \\
\text { low-up: } 2\end{array}$ \\
\hline & $\begin{array}{l}\text { Multi-component } \mathrm{OHC} \text { intervention } \\
\text { (conventional method for plaque con- } \\
\text { trol): } 14\end{array}$ & $\begin{array}{l}4 \text { refused to continue, } 4 \text { died, } 4 \text { lost con- } \\
\text { tact, } 2 \text { other reason (not specified) }\end{array}$ & $\begin{array}{l}\text { At 6-month fol- } \\
\text { low-up: } 5\end{array}$ \\
\hline \multirow[t]{2}{*}{$\begin{array}{l}\text { Chipps } \\
2014\end{array}$} & $\begin{array}{l}\text { Multi-component OHC intervention } \\
\text { (enhanced oral care protocol): } 8\end{array}$ & $\begin{array}{l}2 \text { transferred to acute care, } 3 \text { discharged } \\
\text { from rehabilitation, } 3 \text { voluntary with- } \\
\text { drawal }\end{array}$ & \multirow{2}{*}{$\begin{array}{l}\text { Numbers that did } \\
\text { not finish proto- } \\
\text { col are reported for } \\
\text { each group but no } \\
\text { details given about } \\
\text { when participants } \\
\text { withdrew }\end{array}$} \\
\hline & $\begin{array}{l}\text { Multi-component } \mathrm{OHC} \text { intervention } \\
\text { (routine oral care): } 1\end{array}$ & 1 transferred to acute care & \\
\hline
\end{tabular}

\begin{tabular}{|c|c|c|c|c|}
\hline Dai 2017 & $\begin{array}{l}\text { Multi-component OHC intervention } \\
\text { (advanced oral hygiene care pro- } \\
\text { gramme): } 3\end{array}$ & 2 recurrent stroke, 1 loss of contact & $\begin{array}{l}\text { At 6-month fol- } \\
\text { low-up: } 10\end{array}$ & $\begin{array}{l}4 \text { loss of } \\
\text { contact, } 6 \\
\text { not willing } \\
\text { to partici- } \\
\text { pate }\end{array}$ \\
\hline & $\begin{array}{l}\text { Multi-component } \mathrm{OHC} \text { intervention } \\
\text { (conventional oral hygiene care pro- } \\
\text { gramme): } 17\end{array}$ & $\begin{array}{l}1 \text { recurrent stroke, } 6 \text { loss of contact, } 10 \\
\text { not willing to participate }\end{array}$ & $\begin{array}{l}\text { At 6-month fol- } \\
\text { low-up: } 7\end{array}$ & $\begin{array}{l}3 \text { re- } \\
\text { current } \\
\text { stroke, } \\
4 \text { loss of } \\
\text { contact }\end{array}$ \\
\hline $\begin{array}{l}\text { Fields } \\
2008\end{array}$ & NR & NR & NR & - \\
\hline
\end{tabular}

Frenkel $\quad$ Availability of residents varied over the $\quad-\quad-$

2001 duration of the trial (baseline: 55 residents; 1 month after training: 57 residents; 6 months after training: 53 residents).

\begin{tabular}{|c|c|c|c|c|}
\hline \multirow[t]{2}{*}{$\begin{array}{l}\text { Gosney } \\
2006\end{array}$} & $\begin{array}{l}\text { OHC gel (selective decontamination of } \\
\text { digestive tract oral gel): } 9\end{array}$ & 9 died, no other details reported & \multirow{2}{*}{$\begin{array}{l}3 \text { died within } 3 \\
\text { months of dis- } \\
\text { charge from hospi- } \\
\text { tal. Unclear which } \\
\text { group these came } \\
\text { from. Authors re- } \\
\text { ported that an ad- } \\
\text { ditional } 19 \text { partici- } \\
\text { pants withdrew but } \\
\text { no reasons given } \\
\text { and unclear when } \\
\text { they withdrew }\end{array}$} & \multirow[t]{2}{*}{-} \\
\hline & Placebo gel: 11 & 11 died, no other details reported & & \\
\hline $\begin{array}{l}\text { Juthani- } \\
\text { Mehta } \\
2015\end{array}$ & Multi-component $\mathrm{OHC}$ intervention: 0 & No dropouts reported & $\begin{array}{l}2 \text { nursing homes; } \\
157 \text { participants }\end{array}$ & $\begin{array}{l}\text { Nursing } \\
\text { home } \\
\text { withdrew } \\
\text { due to } \\
\text { admin- } \\
\text { istrative } \\
\text { leader- }\end{array}$ \\
\hline
\end{tabular}


Table 6. Details of dropouts (Continued)

Usual care: 0

ship deci-

sion. Par-

ticipants

were lost

to fol-

low-up

because

dis-

charged

from facil-

ity, or fa-

cility with-

drew from

study and

death

\begin{tabular}{|c|c|c|c|c|}
\hline & Usual care: 0 & & $\begin{array}{l}1 \text { nursing home; } \\
102 \text { participants }\end{array}$ & $\begin{array}{l}\text { Nursing } \\
\text { home } \\
\text { withdrew } \\
\text { due to } \\
\text { foreclo- } \\
\text { sure. Par- } \\
\text { ticipants } \\
\text { were lost } \\
\text { to fol- } \\
\text { low-up } \\
\text { because } \\
\text { dis- } \\
\text { charged } \\
\text { from facil- } \\
\text { ity, or fa- } \\
\text { cility with- } \\
\text { drew from } \\
\text { study and } \\
\text { death }\end{array}$ \\
\hline \multirow[t]{2}{*}{ Kim 2014a } & $\begin{array}{l}\text { Multi-component OHC intervention } \\
\text { (oral hygienic care programme): } 16\end{array}$ & $\begin{array}{l}6 \text { withdrew; } 2 \text { died; } 3 \text { "aggravation" of } \\
\text { systemic condition; } 2 \text { discharged; } 3 \text { "un- } \\
\text { cooperation" }\end{array}$ & $\begin{array}{l}\text { No dropouts at fol- } \\
\text { low-up }\end{array}$ & NA \\
\hline & Usual care: 18 & $\begin{array}{l}8 \text { withdrew; } 3 \text { died; } 2 \text { "aggravation" of } \\
\text { systemic condition; } 3 \text { discharged; } 2 \text { "un- } \\
\text { cooperation" }\end{array}$ & $\begin{array}{l}\text { No dropouts at fol- } \\
\text { low-up }\end{array}$ & NA \\
\hline $\begin{array}{l}\text { Kobayashi } \\
\text { 2017i; } \\
\text { Kobayashi } \\
\text { 2017ii; } \\
\text { Kobayashi } \\
\text { 2017iii; } \\
\text { Kobayashi } \\
\text { 2017iv; } \\
\text { Kobayashi } \\
\text { 2017v; } \\
\text { Kobayashi } \\
\text { 2017vi }\end{array}$ & No dropouts reported for any group & - & - & - \\
\hline Kuo 2016 & $\begin{array}{l}\text { Multi-component } \mathrm{OHC} \text { intervention } \\
\text { (homebased } \mathrm{OHC} \text { training): } 2\end{array}$ & 1 refused to participate; 1 died & $\begin{array}{l}\text { Follow-up at } 2 \\
\text { months: } 0\end{array}$ & - \\
\hline
\end{tabular}


Table 6. Details of dropouts (Continued)

Usual care: $0 \quad$ No dropouts
8 lost to early discharge
Follow-up at 2 months: 4
4 partic-

ipants

died

$$
\begin{array}{ll}
\text { 2013i; } & \text { (oral hygiene instruction + chlorhexi- } \\
\text { Lam } & \text { dine mouthrinse + assisted brushing): } \\
\text { 2013ii; } & 8
\end{array}
$$

Lam

2013iii
Multi-component $\mathrm{OHC}$ intervention (oral hygiene instruction + chlorhexidine mouthrinse): 8
4 lost to early discharge; 2 transferred to another hospital for further assessment; 1 non-compliance with mouthrinse; 1 self-discharge from hospital

\begin{tabular}{|c|c|c|c|c|}
\hline Lee 2011 & Saengmaeg-san extract: 1 & $\begin{array}{l}\text { Reported that all participants were al- } \\
\text { located and received intervention; } 1 \\
\text { dropout at day } 7 \text { because of poor med- } \\
\text { ication compliance }\end{array}$ & $\begin{array}{l}\text { No dropouts at fol- } \\
\text { low-up }\end{array}$ & NA \\
\hline & Placebo: 2 & $\begin{array}{l}\text { Reported that all participants were al- } \\
\text { located and received intervention; } 2 \\
\text { dropouts at day } 7 \text { (no reason given) }\end{array}$ & $\begin{array}{l}\text { No dropouts at fol- } \\
\text { low-up }\end{array}$ & NA \\
\hline \multirow[t]{2}{*}{$\begin{array}{l}\text { Seguin } \\
2014\end{array}$} & $\begin{array}{l}\text { Oropharyngeal care with povidone-io- } \\
\text { dine: } 18\end{array}$ & $\begin{array}{l}6 \text { withdrew consent, } 12 \text { discontinued in- } \\
\text { tervention ( } 8 \text { adverse event, } 3 \text { patient or } \\
\text { family decision, } 1 \text { other) }\end{array}$ & NA & NA \\
\hline & Oropharyngeal care with placebo: 14 & $\begin{array}{l}6 \text { withdrew consent, } 8 \text { discontinued in- } \\
\text { tervention ( } 6 \text { adverse events, } 2 \text { patient } \\
\text { or family decision) }\end{array}$ & NA & NA \\
\hline \multirow[t]{2}{*}{ SOCLE II } & $\begin{array}{l}\text { Multi-component OHC intervention } \\
\text { (enhanced } \mathrm{OHC} \text { ): } 0\end{array}$ & \multirow{2}{*}{$\begin{array}{l}\text { Study authors reported no patient with- } \\
\text { drawals or dropouts in the usual sense } \\
\text { as there was no formal follow-up be- } \\
\text { yond the ward admission }\end{array}$} & NA & NA \\
\hline & Usual care: 0 & & NA & NA \\
\hline
\end{tabular}

No dropouts at fol- NA

low-up
No dropouts at fol- NA low-up

$\begin{array}{lll}\begin{array}{l}\text { Multi-component } \mathrm{OHC} \text { intervention } \\ \text { (oral hygiene instruction): } 5\end{array} & 5 \text { lost to early discharge } & \begin{array}{l}\text { No dropouts at fol- } \\ \text { low-up }\end{array}\end{array}$

Note: group labels that trialists reported in their original publication(s) are shown in brackets.

NA: not applicable; NR: not reported; OHC: oral health care.

\section{APPEN DICES}

\section{Appendix 1. Cochrane Oral Health Register search strategy}

1 "cerebrovascular disorder*" AND INREGISTER

2 (stroke* OR cva* OR cerebrovasc* OR "cerebral vascular*" OR poststroke or post-stroke):ti,ab AND INREGISTER

3 ((Cerebral OR cerebellar OR brain* OR vertebrobasilar) AND (infarct* OR ischaemi* OR ischemi* OR thrombo* OR emboli* OR apople*)):ti,ab AND INREGISTER

4 ((cerebral OR intracerebral OR intracranial OR brain* OR subarachnoid) AND (haemorrhag* OR hemorrhag* OR bleed*)):ti,ab AND INREGISTER

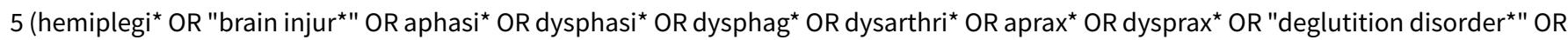
hemipleg* OR hemipar*):ti,ab AND INREGISTER

6 (swallow* AND (impair* OR disorder* OR problem* OR difficult*)):ti,ab AND INREGISTER

7 ("unilateral neglect*" OR "neglect syndrome*" OR "visual neglect" OR hemianop*):ti,ab AND INREGISTER

8 \#1 or \#2 or \#3 or \#4 or \#5 or \#6 or \#7 


\section{Appendix 2. CENTRAL search strategy}

\#1 MeSH descriptor: [Stomatognathic Diseases] explode all trees

\#2 MeSH descriptor: [Dentistry] explode all trees

\#3 MeSH descriptor: [Oral Health] this term only

\#4 MeSH descriptor: [Oral Hygiene] explode all trees

\#5 MeSH descriptor: [Dental Auxiliaries] explode all trees

\#6 MeSH descriptor: [Mouth] explode all trees

\#7 MeSH descriptor: [Halitosis] this term only

\#8 MeSH descriptor: [Facial Pain] this term only

\#9 ((dental or oral or periodontal) and disease $\left.{ }^{\star}\right): \mathrm{ti}, \mathrm{ab}, \mathrm{kw}$ (Word variations have been searched)

\#10 ((dental or tooth or teeth) and (caries or decay $\left.{ }^{\star}\right)$ ):ti,ab,kw (Word variations have been searched)

\#11 gingivitis:ti,ab,kw (Word variations have been searched)

\#12 xerostomia or "dry mouth":ti,ab,kw (Word variations have been searched)

\#13 (oral and (stomatitis or candidiasis)):ti,ab,kw (Word variations have been searched)

\#14 ((mouth near/6 ulcer*) or (mouth near/6 aphthous) or (mouth near/6 aphthae) or (oral near/6 ulcer*) or (oral near/6 aphthous) or (oral near/6 aphthae)):ti,ab,kw (Word variations have been searched)

\#15 ((mouth or dental or oral) and hygiene):ti,ab,kw (Word variations have been searched)

\#16 ((mouth near/4 odor) or (mouth near/4 odour)):ti,ab,kw (Word variations have been searched)

\#17 halitosis:ti,ab,kw (Word variations have been searched)

\#18 (dentist* or "dental nurse*" or dental therapist* or "dental hygienist*"):ti,ab,kw (Word variations have been searched)

\#19 "dental health educat*":ti,ab,kw (Word variations have been searched)

\#20 (dental and (disabled or handicap*)):ti,ab,kw (Word variations have been searched)

\#21 ((dental near/3 scaling) or (oral near/3 scaling) or (teeth near/3 scaling) or (dental near/3 prophylaxis) or (oral near/3 prophylaxis) or (teeth near/3 prophylaxis)):ti,ab,kw (Word variations have been searched)

\#22 (mouth and ulcer $\left.{ }^{\star}\right): t i, a b, k w$ (Word variations have been searched)

\#23 (mouthwash* or mouthrinse*):ti,ab,kw (Word variations have been searched)

\#24 (dental and (treatment ${ }^{\star}$ or care*)):ti,ab,kw (Word variations have been searched)

\#25 toothbrush*:ti,ab,kw (Word variations have been searched)

\#26 ((plaque next index) or (plaque next indices) or ("oral hygiene" next index) or ("oral hygiene" next indices) or (periodontal next index) or (periodontal next indices) or (DMF next index) or (DMF next indices)):ti,ab,kw (Word variations have been searched)

$\# 27$ or \#1-\#26\}

\#28 MeSH descriptor: [Cerebrovascular Disorders] explode all trees

\#29 (stroke* or cva* or cerebrovasc* or "cerebral vascular" or poststroke or post-stroke):ti,ab,kw (Word variations have been searched)

\#30 (cerebral or cerebellar or brain* or vertebrobasilar):ti,ab,kw (Word variations have been searched)

\#31 (infarct ${ }^{\star}$ or ischemi ${ }^{\star}$ or ischaemi ${ }^{\star}$ or thrombo* or emboli* or apople*):ti,ab,kw (Word variations have been searched)

\#32 (\#30 and \#31)

\#33 (cerebral or intracerebral or intracranial or brain* or subarachnoid):ti,ab,kw (Word variations have been searched)

\#34 (haemorrhage or hemorrhage or bleed*):ti,ab,kw (Word variations have been searched)

\#35 (\#33 and \#34)

\#36 MeSH descriptor: [Hemiplegia] this term only

\#37 MeSH descriptor: [Brain Injuries] this term only

\#38 MeSH descriptor: [Aphasia] explode all trees

\#39 MeSH descriptor: [Dysarthria] this term only

\#40 MeSH descriptor: [Apraxias] this term only

\#41 MeSH descriptor: [Deglutition Disorders] this term only

\#42 (hemipleg* or hemipar $\left.{ }^{\star}\right): t i, a b, k w$ (Word variations have been searched)

\#43 (aphasi ${ }^{\star}$ or dysphasi ${ }^{\star}$ or dysarthri* or dysphag* or aprax ${ }^{\star}$ or dysprax ${ }^{\star}$ ):ti,ab,kw (Word variations have been searched)

\#44 (swallow* and (impair ${ }^{\star}$ or disorder ${ }^{\star}$ or problem* or difficult*)):ti,ab,kw (Word variations have been searched)

\#45 ("unilateral neglect" or "neglect syndrome*" or "visual neglect" or hemianop*):ti,ab,kw (Word variations have been searched)

$\# 46$ (\#28 or \#29 or \#32 or \#35 or \#36 or \#37 or \#38 or \#39 or \#40 or \#41 or \#42 or \#43 or \#44 or \#45)

\#47 (\#27 and \#46)

\section{Appendix 3. MEDLINE search strategy}

\section{MEDLINE via OVID search strategy}

1. exp Stomatognathic diseases/

2. exp Dentistry/

3. oral health/

4. exp oral hygiene/

5. exp Dental Auxiliaries/

6. halitosis/ 
7. exp Mouth/ph [Physiology]

8. exp digestive system/ph

9. Facial Pain/

10. ((dental or oral or periodontal) and disease\$).tw.

11. ((dental or tooth or teeth) and (caries or decay\$)).tw.

12. gingivitis.tw.

13. (xerostomia or "dry mouth").tw.

14. (oral and (stomatitis or candidiasis)).tw.

15. ((mouth or oral) adj6 (ulcer\$ or aphthous or aphthae)).tw.

16. ((mouth or dental or oral) and hygiene).tw.

17. (mouth adj4 (odor or odour)).tw.

18. halitosis.tw.

19. (dentist\$ or "dental nurse\$" or "dental therapist\$" or "dental hygienist\$").tw.

20. "dental health educat\$".tw.

21. (dental and (disabled or handicap\$)).tw.

22. ((dental or oral or teeth) adj3 (scaling or prophylaxis)).tw.

23. (mouth and ulcer\$).tw.

24. (mouthwash\$ or mouthrinse\$).tw.

25. (dental and (treatment\$ or care\$)).tw.

26. toothbrush\$.tw.

27. ((plaque or "oral hygiene" or periodontal or DMF) adj (index or indices)).tw.

28. or/1-27

29. exp cerebrovascular disorders/

30. (stroke\$ or cva\$ or cerebrovasc\$ or "cerebral vascular\$" or poststroke or post-stroke).tw.

31. (cerebral or cerebellar or brain $\$$ or vertebrobasilar).tw.

32. (infarct\$ or isch?emi\$ or thrombo $\$$ or emboli\$ or apople\$).tw.

33. 31 and 32

34. (cerebral or intracerebral or intracranial or brain\$ or subarachnoid).tw.

35. (haemorrhage or hemorrhage or bleed\$).tw.

36.34 and 35

37. Brain Injuries/

38. hemiplegia/

39. exp aphasia/ or dysarthria/ or apraxia/ or deglutition disorders/

40. (hemipleg\$ or hemipar\$).tw.

41. (aphasi\$ or dysphasi\$ or dysarthri\$ or dysphag\$ or aprax\$ or dysprax\$).tw.

42. (swallow\$ and (impair $\$$ or disorder\$ or problem\$ or difficult\$)).tw.

43. ("unilateral neglect" or "neglect syndrome\$" or "visual neglect\$" or hemianop\$).tw.

44. 29 or 30 or 33 or (or/36-43)

45.28 and 44

\section{Cochrane Search filter for MEDLINE via OVID}

Cochrane Highly Sensitive Search Strategy (CHSSS) for identifying randomised trials in MEDLINE: sensitivity maximising version (2009 revision) as referenced in Chapter 6.4.11.1 and detailed in box 6.4.c of the Cochrane Handbook for Systematic Reviews of Interventions (Lefebvre 2011).

1. randomized controlled trial.pt.

2. controlled clinical trial.pt.

3. randomized.ab.

4. placebo.ab.

5. drug therapy.fs.

6. randomly.ab.

7. trial.ab.

8. groups.ab.

9. or/1-8

10. exp animals/ not humans.sh.

11.9 not 10

\section{Appendix 4. Embase Ovid search strategy}

1. exp mouth disease/

2. exp dentistry/

3. oral health/ 
4. exp mouth hygiene/

5. dental assistant/

6. exp mouth/

7. digestive system/

8. face pain/

9. ((dental or oral or periodontal) and disease\$).tw.

10. ((dental or tooth or teeth) and (caries or decay\$)).tw.

11. gingivitis.tw.

12. (xerostomia or "dry mouth").tw.

13. (oral and (stomatitis or candidiasis)).tw.

14. ((mouth or oral) adj6 (ulcer\$ or aphthous or aphthae)).tw.

15. ((mouth or dental or oral) and hygiene).tw.

16. (mouth adj4 (odor or odour)).tw.

17. halitosis.tw.

18. (dentist\$ or "dental nurse\$" or "dental therapist\$" or "dental hygienist\$").tw.

19. "dental health educat\$".tw.

20. (dental and (disabled or handicap\$)).tw.

21. ((dental or oral or teeth) adj3 (scaling or prophylaxis)).tw.

22. (mouth and ulcer\$).tw.

23. (mouthwash\$ or mouthrinse\$).tw.

24. (dental and (treatment\$ or care\$)).tw.

25. toothbrush\$.tw.

26. ((plaque or "oral hygiene" or periodontal or DMF) adj (index or indices)).tw.

27. or/1-26

28. exp cerebrovascular disease/

29. (stroke\$ or cva\$ or cerebrovasc\$ or "cerebral vascular\$" or poststroke or post-stroke).tw.

30. (cerebral or cerebellar or brain\$ or vertebrobasilar).tw.

31. (infarct\$ or isch?emi\$ or thrombo\$ or emboli\$ or apople\$).tw.

32. 30 and 31

33. (cerebral or intracerebral or intracranial or brain $\$$ or subarachnoid).tw.

34. (haemorrhage or hemorrhage or bleed\$).tw.

35.33 and 34

36. brain injury/

37. hemiplegia/

38. exp aphasia/

39. dysarthria/

40. apraxia/ or "apraxia of speech"/

41. dysphagia/

42. (hemipleg\$ or hemipar\$).tw.

43. (aphasi $\$$ or dysphasi\$ or dysarthri\$ or dysphag\$ or aprax\$ or dysprax\$).tw.

44. (swallow\$ and (impair\$ or disorder\$ or problem\$ or difficult\$)).tw.

45. ("unilateral neglect" or "neglect syndrome\$" or "visual neglect\$" or hemianop\$).tw.

46.28 or 29 or 32 or (or/35-45)

47. Randomized Controlled Trial/ or "randomized controlled trial (topic)"/

48. Randomization/

49. Controlled clinical trial/ or "controlled clinical trial (topic)"/

50. control group/ or controlled study/

51. clinical trial/ or "clinical trial (topic)"/ or phase 1 clinical trial/ or phase 2 clinical trial/or phase $3 \mathrm{clinical}$ trial/ or phase $4 \mathrm{clinical}$ trial/

52. Crossover Procedure/

53. Double Blind Procedure/

54. Single Blind Procedure/ or triple blind procedure/

55. placebo/ or placebo effect/

56. (random\$ or RCT or RCTs).tw.

57. (controlled adj5 (trial\$ or stud\$)).tw.

58. (clinical\$ adj5 trial\$).tw.

59. ((control or treatment or experiment\$ or intervention) adj5 (group\$ or subject\$ or patient\$)).tw.

60. (quasi-random $\$$ or quasi random\$ or pseudo-random $\$$ or pseudo random $\$$ ).tw.

61. ((control or experiment\$ or conservative) adj5 (treatment or therapy or procedure or manage\$)).tw.

62. ((singl\$ or doubl\$ or tripl\$ or trebl\$) adj5 (blind\$ or mask\$)).tw.

63. (cross-over or cross over or crossover).tw.

64. (placebo\$ or sham).tw.

65. trial.ti. 
66. (assign\$ or allocat\$).tw.

67. controls.tw.

68. or/47-67

69. 27 and 46 and 68

\section{Appendix 5. CINAHL search strategy}

1. exp stomatognathic diseases/

2. exp dentistry/

3. oral health/

4. exp oral hygiene/

5. mouth care/

6. exp dental auxiliaries/

7. halitosis/

8. exp mouth physiology/

9. exp digestive system physiology/

10. dental hygiene assessment/

11. facial pain/

12. ((dental or oral or periodontal) and disease\$).tw

13. ((dental or tooth or teeth) and (caries or decay\$)).tw

14. gingivitis.tw

15. (xerostomia or dry mouth).tw

16. (oral and (stomatitis or candidiasis)).tw

17. ((mouth or oral) adj6 (ulcer\$ or aphthous or aphthae)).tw

18. ((mouth or dental or oral) and hygiene).tw

19. (mouth adj4 (odor or odour)).tw

20. halitosis.tw

21. (dentist\$ or dental nurse $\$$ or dental therapist $\$$ or dental hygienist\$).tw

22. dental health educat\$.tw

23. (dental and (disabled or handicap\$)).tw

24. ((dental or oral or teeth) adj3 (scaling or prophylaxis)).tw

25. (mouth and ulcer\$).tw

26. (mouthwash\$ or mouthrinse\$).tw

27. (dental and (treatment\$ or care\$)).tw

28. toothbrush\$.tw

29. ((plaque or oral hygiene or periodontal or DMF) adj (index or indices)).tw

30. or/1-29

31. exp cerebrovascular disorders/

32. (stroke\$ or cva\$ or cerebrovasc $\$$ or cerebral vascular\$ or poststroke or post-stroke).tw

33. (cerebral or cerebellar or brain $\$$ or vertebrobasilar).tw

34. (infarct\$ or isch?emi\$ or thrombo $\$$ or emboli\$ or apople\$).tw

35. 33 and 34

36. (cerebral or intracerebral or intracranial or brain\$ or subarachnoid).tw

37. (haemorrhage or hemorrhage or bleed\$).tw

38. $36 \& 37$

39. hemiplegia/ or brain injury/

40. exp aphasia/ or dysarthria/ or apraxia/ or deglutition disorders/

41. (hemipleg\$ or hemipar\$).tw

42. (aphasi or dysphasi\$ or dysarthri\$ or dysphag $\$$ or aprax\$ or dysprax\$).tw

43. (swallow\$ and (impair\$ or disorder\$ or problem\$ or difficult\$)).tw

44. (unilateral neglect or neglect syndrome\$ or visual neglect or hemianop\$).tw

45.31 or 32 or 35 or (or/38-44)

46. 30 and 45

\section{Appendix 6. Clinical Trial Register search strategy}

- World Health Organization International Clinical Trials Registry Platform (apps.who.int/trialsearch)

* stroke AND "oral hygiene"

- US National Institutes of Health Ongoing Trials Register ClinicalTrials.gov (www.clinicaltrials.gov)

* oral hygiene AND Cerebrovascular Disorders [DISEASE] 


\section{Appendix 7. Previous searches from earlier reviews}

S1MH "Stomatognathic Diseases+"

S2MH "Dentistry+"

S3MH "Oral Health"

S4MH "Oral Hygiene+"

S5MH "Mouth care"

S6MH "Dental Auxiliaries+"

S7MH "Halitosis"

S8MH "Mouth physiology+"

S9MH "Digestive System Physiology+"

S10MH "Dental Hygiene Assessment"

S11MH "Facial Pain"

S12TI (((dental or oral or periodontal) and disease $\left.)^{\star}\right)$ OR AB ( ((dental or oral or periodontal) and disease $\left.\left.{ }^{\star}\right)\right)$

S13TI ( ((dental or tooth or teeth) and (caries or decay $\left.\left.{ }^{\star}\right)\right)$ ) OR AB ( ((dental or tooth or teeth) and (caries or decay $\left.\left.{ }^{\star}\right)\right)$ )

S14TI gingivitis OR AB gingivitis

S15TI (xerostomia or "dry mouth" ) OR AB (xerostomia or "dry mouth" )

S16TI ((oral and (stomatitis or candidiasis)) ) OR AB ( (oral and (stomatitis or candidiasis)) )

S17TI ( ((mouth N6 ulcer ${ }^{\star}$ ) or (mouth N6 aphthous) or (mouth N6 aphthae)) or ((oral N6 ulcer ${ }^{\star}$ ) or (oral N6 aphthous) or (oral N6 aphthae)) )

OR AB ( ((mouth N6 ulcer $\left.{ }^{\star}\right)$ or (mouth N6 aphthous) or (mouth N6 aphthae)) or ((oral N6 ulcer $\left.{ }^{\star}\right)$ or (oral N6 aphthous) or (oral N6 aphthae)) )

S18TI ( ((mouth or dental or oral) and hygiene) ) OR AB ( ((mouth or dental or oral) and hygiene) )

S19TI ( (mouth N4 odor) or (mouth N4 odour) ) OR AB ( (mouth N4 odor) or (mouth N4 odour))

S20TI halitosis OR AB halitosis

S21TI ( (dentist* or "dental nurse*" or "dental therapist*" or "dental hygienist*") ) OR AB ( (dentist* or "dental nurse*" or "dental therapist*" or "dental hygienist*"))

S22TI ("dental health educat*") OR AB ("dental health educat*")

S23TI ( (dental and (disabled or handicap*)) ) OR AB ( (dental and (disabled or handicap*)) )

S24TI ( ((dental N3 scaling) or (dental N3 prophylaxis)) or ((oral N3 scaling) or (oral N3 prophylaxis)) or ((teeth N3 scaling) or (teeth N3 prophylaxis)) ) OR AB ( ((dental N3 scaling) or (dental N3 prophylaxis)) or ((oral N3 scaling) or (oral N3 prophylaxis)) or ((teeth N3 scaling) or (teeth N3 prophylaxis)) )

S25TI ( ((mouth and ulcer $\left.{ }^{\star}\right)$ ) or ((oral N3 scaling) or (oral N3 prophylaxis)) or ((teeth N3 scaling) or (teeth N3 prophylaxis)) ) OR AB ( ((mouth and ulcer $\left.^{\star}\right)$ ) or ((oral N3 scaling) or (oral N3 prophylaxis)) or ((teeth N3 scaling) or (teeth N3 prophylaxis)) )

S26TI ( (mouthwash* or mouthrinse $\left.{ }^{\star}\right)$ ) OR AB ( (mouthwash* or mouthrinse $\left.{ }^{\star}\right)$ )

S27TI ( (dental and (treatment* or care $\left.\left.^{\star}\right)\right)$ ) OR AB ( (dental and (treatment* or care $\left.\left.{ }^{\star}\right)\right)$ )

S28TI toothbrush* OR AB toothbrush*

S29TI ( ((plaque N1 index) or (plaque N1 indices)) or (("oral hygiene" N1 index) or ("oral hygiene" N1 indices)) or ((periodontal N1 index) or (periodontal N1 indices)) or ((DMF N1 index) or (DMF N1 indices)) ) OR AB ( ((plaque N1 index) or (plaque N1 indices)) or (("oral hygiene" N1 index) or ("oral hygiene" N1 indices)) or ((periodontal N1 index) or (periodontal N1 indices)) or ((DMF N1 index) or (DMF N1 indices)) )

$\mathrm{S} 30 \mathrm{~S} 1$ or S2 or S3 or S4 or S5 or S6 or S7 or S8 or S9 or S10 or S11 or S12 or S13 or S14 or S15 or S16 or S17 or S18 or S19 or S20 or S21

or $\mathrm{S} 22$ or $\mathrm{S} 23$ or $\mathrm{S} 24$ or $\mathrm{S} 25$ or $\mathrm{S} 26$ or $\mathrm{S} 27$ or $\mathrm{S} 28$ or $\mathrm{S} 29$

S31MH "Cerebrovascular disorders+"

S32TI ( (stroke* or cva* or cerebrovasc* or "cerebral vascular" ${ }^{\star}$ or poststroke or post-stroke) ) OR AB ( (stroke* or cva* or cerebrovasc* or "cerebral vascular*" or poststroke or post-stroke))

S33TI ( (cerebral or cerebellar or brain* or vertebrobasilar) ) OR AB ( (cerebral or cerebellar or brain* or vertebrobasilar) )

S34TI ( (infarct* or isch?emi* or thrombo* or emboli* or apople*) ) OR AB ( (infarct* or isch?emi* or thrombo* or emboli* or apople*) )

S35 S33 AND S34

S36TI ( (cerebral or intracerebral or intracranial or brain* or subarachnoid) ) OR AB ( (cerebral or intracerebral or intracranial or brain* or subarachnoid))

S37TI ( (haemorrhage or hemorrhage or bleed $\left.{ }^{\star}\right)$ ) OR AB ( (haemorrhage or hemorrhage or bleed*) )

S38 S36 and S37

S39MH "Hemiplegia" or MH "Brain Injury"

S40MH "Aphasia+" or MH "dysarthria" or MH "Apraxia" or MH "Deglutition Disorders"

S41 TI ( hemipleg* or hemipar*) OR AB ( hemipleg* or hemipar*)

S42 TI ( (aphasi* or dysphasi ${ }^{\star}$ or dysarthri ${ }^{\star}$ or dysphag* or aprax ${ }^{\star}$ or dysprax $\left.{ }^{\star}\right)$ ) OR AB ( (aphasi* or dysphasi ${ }^{\star}$ or dysarthri ${ }^{\star}$ or dysphag $^{\star}$ or aprax* or dysprax*))

S43 TI ( (swallow* and (impair* or disorder ${ }^{\star}$ or problem* or difficult $\left.{ }^{\star}\right)$ ) ) OR AB ( (swallow ${ }^{\star}$ and (impair* or disorder ${ }^{\star}$ or problem* or difficult*)) ) Interface - EBSCOhost Research Databases

S44 TI ( ("unilateral neglect" or "neglect syndrome*" or "visual neglect" or hemianop*)) OR AB ( ("unilateral neglect" or "neglect syndrome*" or "visual neglect" or hemianop*) )

$\mathrm{S} 45 \mathrm{~S} 31$ or $\mathrm{S} 32$ or $\mathrm{S} 35$ or $\mathrm{S} 38$ or $\mathrm{S} 39$ or $\mathrm{S} 40$ or $\mathrm{S} 41$ or $\mathrm{S} 42$ or $\mathrm{S} 43$ or $\mathrm{S} 44$

\section{The above subject search was linked to the following filter for CINAHL via EBSCO}


S1 MH Random Assignment or MH Single-blind Studies or MH Double-blind Studies or MH Triple-blind Studies or MH Crossover design or MH Factorial Design

S2 TI ("multicentre study" or "multicenter study" or "multi-centre study" or "multi-center study") or AB ("multicentre study" or "multicenter study" or "multi-centre study" or "multi-center study") or SU ("multicentre study" or "multicenter study" or "multi-centre study" or "multicenter study")

S3 TI random* or AB random*

S4 AB "latin square" or TI "latin square"

S5 TI (crossover or cross-over) or AB (crossover or cross-over) or SU (crossover or cross-over)

S6 MH Placebos

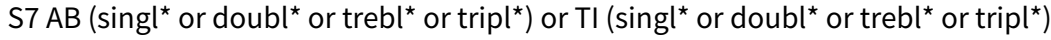

S8 TI blind ${ }^{\star}$ or $A B$ mask* or AB blind* or TI mask ${ }^{\star}$

S9 S7 and S8

S10 TI Placebo* or AB Placebo* or SU Placebo*

S11 MH Clinical Trials

S12 TI (Clinical AND Trial) or AB (Clinical AND Trial) or SU (Clinical AND Trial)

$\mathrm{S} 13 \mathrm{~S} 1$ or S2 or S3 or S4 or S5 or S6 or S9 or S10 or S11 or S12

Prepared by: Anne Littlewood, Cochrane Information Specialist, Cochrane Oral Health Group

\section{Appendix 8. Additional searches}

In an effort to identify further published, unpublished and ongoing studies we searched IWeb of Science Conference Proceedings Citation Index-Science (last searched 25 February 2019), Zetoc (last searched 25 February 2019) and Proquest Dissertations and Theses (last searched 25 February 2019) using the following key terms: stroke AND (oral hygiene OR oral health).

WHAT'S NEW

\begin{tabular}{lll}
\hline Date & Event & Description \\
\hline 18 February 2019 & $\begin{array}{l}\text { New citation required but conclusions } \\
\text { have not changed }\end{array}$ & Conclusions not changed. Changes to authorship. \\
\hline 18 February 2019 & New search has been performed & $\begin{array}{l}\text { The review was updated using a revised and updated search } \\
\text { strategy (including more databases) completed in February } \\
\text { 2019. The review now includes 15 studies (22 randomised paired } \\
\text { comparisons), 3631 participants of whom 1546 participants were } \\
\text { stroke survivors); the previous review only included three stud- } \\
\text { ies. }\end{array}$ \\
& $\begin{array}{l}\text { We extracted more information on the interventions used in each } \\
\text { of the trials using the TIDIER checklist and provided this addi- } \\
\text { tional information in the 'Characteristics of included studies' ta- } \\
\text { ble. }\end{array}$ \\
& We presented three new 'Summary of findings' tables. \\
\hline
\end{tabular}

\section{H I S T O R Y}

Protocol first published: Issue 4, 2002

Review first published: Issue 4, 2006

\begin{tabular}{lll}
\hline Date & Event & Description \\
\hline 7 June 2011 & Amended & $\begin{array}{l}\text { Page number added to Frenkel reference and risk of bias termi- } \\
\text { nology updated but no change to overall assessments }\end{array}$ \\
\hline 26 October 2010 & New search has been performed & $\begin{array}{l}\text { We updated the searches to May 2010. We have included two } \\
\text { new studies, bringing the total of included studies to three, in- }\end{array}$ \\
\hline
\end{tabular}




\begin{tabular}{lll}
\hline Date & Description & $\begin{array}{l}\text { volving } 470 \text { participants. The conclusions of the review have not } \\
\text { changed. }\end{array}$
\end{tabular}

Converted to new review format.

\section{CONTRIBUTIONS OF AUTHORS}

PC conducted the searches for 2019 update, screened retrieved references for inclusion or exclusion, extracted the data from included trials, evaluated methodological quality, entered data, conducted data analysis and drafted the review.

BB screened retrieved references for inclusion or exclusion, extracted data from included trials and commented on review drafts.

DF conducted the earlier searches, screened retrieved references for inclusion or exclusion, extracted the data from included trials, evaluated methodological quality, contacted trial authors, entered data, conducted data analysis and drafted the review.

MB updated the search, screened retrieved references for inclusion or exclusion, extracted the data from included trials, evaluated methodological quality, entered data, conducted data analysis and drafted the review.

\section{DECLARATIONS OF INTEREST}

PC: none.

BB: has been involved in one trial included in this review (see SOCLE II), but was not involved in the assessment or interpretation of this trial. DF: none.

MB: has been involved in one trial included in this review (see SOCLE II), but was not involved in the assessment or interpretation of this trial.

\section{SOURCES OF SUPPORT}

\section{Internal sources}

- Nursing, Midwifery and Allied Health Professions Research Unit, UK

\section{External sources}

- Chief Scientist Office, Scottish Government Health Directorate, UK

\section{DIFFERENCES BETWEEN PROTOCOLANDREVIEW}

\section{6 review}

- It was necessary to reduce the number of primary outcomes identified within the protocol to two because of the Cochrane Stroke Group guidelines. We originally listed gingivitis as a primary outcome, but on reflection it was more appropriate to include it as an oral disease outcome, together with denture-induced stomatitis and periodontal disease. We acknowledge that making this post-hoc change following publication of the protocol may lead to bias.

\section{9 review update}

- The review team decided to amend the title of the review from 'Staff-led interventions for improving oral hygiene in patients following stroke' to 'Interventions for improving oral health in people after stroke'. The decision was made to improve the accessibility of the review by employing more relevant international terms.

- We have included trials with secondary outcomes that present data for knowledge and attitudes for stroke survivors and providers, not only on staff oral health knowledge and attitudes. Increasing fiscal constraints in health care means that many family members and informal carers are now assuming responsibility for supporting people with their oral health. Furthermore, recent Royal College of Physicians guidelines specifically state that "People with stroke and their family/carers should receive information and training in mouth care and maintaining good oral hygiene before transfer of their care from hospital" (RCP 2016). 


\section{N DEX TERMS}

\section{Medical Subject Headings (MeSH)}

${ }^{\star}$ Caregivers; ${ }^{*}$ Health Education, Dental; Health Knowledge, Attitudes, Practice; Nursing Homes; Oral Hygiene [ ${ }^{\star}$ methods]; Randomized Controlled Trials as Topic; Stroke [ ${ }^{\star}$ nursing]

\section{MeSH check words}

Humans 